Illinois State University

ISU ReD: Research and eData

Theses and Dissertations

2-13-2019

\title{
Preservice Teachers Making Sense Of Fraction Concepts And Operations In A Mathematics Education Content Course
}

Deksiyos Demissie Desta

Illinois State University, deksiyos@sbcglobal.net

Follow this and additional works at: https://ir.library.illinoisstate.edu/etd

Part of the Science and Mathematics Education Commons

\section{Recommended Citation}

Desta, Deksiyos Demissie, "Preservice Teachers Making Sense Of Fraction Concepts And Operations In A Mathematics Education Content Course" (2019). Theses and Dissertations. 1104.

https://ir.library.illinoisstate.edu/etd/1104

This Dissertation is brought to you for free and open access by ISU ReD: Research and eData. It has been accepted for inclusion in Theses and Dissertations by an authorized administrator of ISU ReD: Research and eData. For more information, please contact ISUReD@ilstu.edu. 


\section{PRESERVICE TEACHERS MAKING SENSE OF FRACTION \\ CONCEPTS AND OPERATIONS IN A \\ MATHEMATICS EDUCATION}

CONTENT COURSE

\section{DEKSIYOS DEMISSIE DESTA}

\section{Pages}

Twenty-five first-year preservice teachers attending a university in the Midwest of the United States of America participated in a whole-class-setting study aimed at investigating their knowledge of how they made sense of fraction concepts and operations, and how the development of this knowledge was facilitated during a mathematics education content course. Classroom mathematical practices of the content course that became "taken-as-shared" overtime were documented using the three-phase data analysis framework of Stephan and Rasmussen $(2002,2008)$. In the first phase of the analysis, whole-class discussion of fraction concepts and operations were transcribed and noted each time preservice teachers drew conclusions. Toulmin's (2003) model (data, warrant, claim, and backing) was also used to code or draw up a claim or an argumentation scheme for each conclusion reached in each class period. The claims were identified from both video recordings and transcripts. An argumentation scheme was constructed for each claim so that each of the constituents of the argument can easily be identified. The data analysis generated a chronological argumentation log that documented each of the arguments which were made in whole discussions over the course of five weeks of time. The theoretical framework for this study derived from Cobb and Yackel's (1996) emergent 
perspective. The emergent or social constructivist perspective supports a psychological constructive viewpoint by making it possible to analyze individual students' constructive activities in social contexts (Cobb \& Yackel, 1996). Two research questions were identified and answered after all the data had been collected and analyzed. The results indicate that only the sociomathematical norm of what constituted an acceptable solution was reestablished, and 16 mathematical ideas became taken-as-shared as the class developed strategies for making sense of fraction concepts and operations. Implications are discussed for the ways in which preservice teachers may be taught fraction concepts and operations.

KEYWORDS: fraction concepts; fraction operations; preservice teachers; sense-making 
PRESERVICE TEACHERS MAKING SENSE OF FRACTION

CONCEPTS AND OPERATIONS IN A

MATHEMATICS EDUCATION

CONTENT COURSE

DEKSIYOS DEMISSIE DESTA

A Dissertation Submitted in Partial

Fulfillment of the Requirements

for the Degree of

DOCTOR OF PHILOSOPHY

Department of Mathematics

ILLINOIS STATE UNIVERSITY

2019 
Copyright 2019 Deksiyos Demissie Desta 


\title{
PRESERVICE TEACHERS MAKING SENSE OF FRACTION \\ CONCEPTS AND OPERATIONS IN A \\ MATHEMATICS EDUCATION \\ CONTENT COURSE
}

\author{
DEKSIYOS DEMISSIE DESTA
}

COMMITTEE MEMBERS:

Jennifer Tobias, Chair

McKenzie Clements

Nerida Ellerton

Beth Hatt

Cynthia Langrall 


\section{CONTENTS}

\section{Page}

TABLES

vii

FIGURES

viii

CHAPTER I: BACKGROUND AND RATIONALE

Research Focus on Content Knowledge of Preservice Teachers 1

The Mathematical Understanding of Preservice Teachers 1

Understanding Preservice Teachers' Knowledge of Fractions Concepts and Operations 3

Understanding the Role of the Content Course 6

Preservice Teachers' Lack of Sense-Making: Procedural and Conceptual Knowledge 7

Students' Difficulty in Learning and Using the Concept of Fractions 7

Research Focus and Limitation on One Aspect of Fractions Concepts and Operations $\quad 8$

Increased Attention on Preservice Elementary Teachers' Knowledge of Fractions $\quad 10$

Research Focus on Rational Numbers $\quad 11$

Preservice Teachers Learning as They Participate in Whole-Classroom Setting 12

Application of External Perspective in the Process of Data Collection and Analysis 14

$\begin{array}{ll}\text { Research Questions } & 14\end{array}$

CHAPTER II: RELATED LITERATURE 16

$\begin{array}{ll}\text { Introduction } & 16\end{array}$

Scheme Theory in the Construction of Fraction Multiplication 17

Different Meanings of Rational Numbers $\quad 19$

$\begin{array}{ll}\text { Part-whole } & 20\end{array}$

$\begin{array}{ll}\text { Quotient } & 20\end{array}$ 
Partitioning and Conceptualizing Quantitative Units in Fraction Multiplication 22

Children's' Thinking

Whole Number Intuitive Strategy in Discrete Sets

Intuitive Strategies for Understanding Fraction Order, Equivalence, and Part-

Whole

Equivalent Fractions

The Concept of Unit Fraction and Unitizing

Comparing and Ordering

Fraction Operations

Whole Number Thinking in Fraction Addition and Subtraction

Composing and Decomposing: Ways to Deepen Understanding of Fraction

Multiplication

Intuitive Reasoning: A Foundation for Developing Division and Multiplication

Algorithm

Preservice Teachers' Knowledge of Fraction Additions and Subtractions

Preservice Teachers' Knowledge of Fraction Multiplications and Divisions

Representing Symbolic Expression Using Words

Contextual support for subtracting fractions

Contextual support for multiplying fractions

Contextual support for dividing fractions

Models 
The Use of Models in Classroom $\quad 48$

Models for multiplication and division $\quad 51$

Models: Cross-Cultural Comparative Studies $\quad 54$

$\begin{array}{ll}\text { Summary } & 58\end{array}$

CHAPTER III: METHDOLOGY

$\begin{array}{ll}\text { Theoretical Framework } & 61\end{array}$

Emergent Perspective $\quad 61$

The social and psychological perspectives $\quad 61$

$\begin{array}{ll}\text { Classroom norms } & 62\end{array}$

Social norms $\quad 63$

Socio-mathematical norm 63

$\begin{array}{ll}\text { Classroom mathematical practices } & 64\end{array}$

Socio-Cultural Theoretical Perspectives $\quad 65$

The Theory of Conceptual Field 66

The Domain of Fraction Concepts and Operations 68

The Application of Emergent Perspective in My Research 69

$\begin{array}{ll}\text { Methods } & 72\end{array}$

$\begin{array}{ll}\text { The Content Course } & 72\end{array}$

Hypothetical Learning Trajectories $\quad 74$

An Overview of Research Methods 86

$\begin{array}{lr}\text { Participants and setting } & 87\end{array}$

$\begin{array}{ll}\text { Ethics and trustworthiness } & 88\end{array}$

$\begin{array}{ll}\text { Data collection } & 90\end{array}$ 
Analytic Process: Documenting Collective Activities

$\begin{array}{ll}\text { Interpretive research paradigm } & 94\end{array}$

$\begin{array}{ll}\text { Constant comparative method } & 94\end{array}$

CHAPTER IV: RESULTS 96

$\begin{array}{ll}\text { Social Norms } & 96\end{array}$

$\begin{array}{ll}\text { Explain and Justify } & 98\end{array}$

$\begin{array}{ll}\text { Making Sense of Others } & 101\end{array}$

$\begin{array}{ll}\text { Questioning } & 102\end{array}$

$\begin{array}{ll}\text { Sociomathematical Norms } & 104\end{array}$

$\begin{array}{ll}\text { Acceptable Solution } & 105\end{array}$

$\begin{array}{ll}\text { Different Solutions } & 109\end{array}$

$\begin{array}{ll}\text { Classroom Mathematical Practices } & 115\end{array}$

$\begin{array}{ll}\text { Partitioning: Equal-Sharing } & 116\end{array}$

$\begin{array}{ll}\text { Unitizing } & 120\end{array}$

$\begin{array}{lr}\text { Iterating a unit fraction } & 122\end{array}$

$\begin{array}{ll}\text { Iterating a unit fraction from composite fraction } & 124\end{array}$

$\begin{array}{ll}\text { Equivalent Fractions } & 128\end{array}$

Defining the Whole 132

Defining a whole: Labeling fractions 132

$\begin{array}{ll}\text { Defining the whole: Representing fractions } & 137\end{array}$

$\begin{array}{ll}\text { Defining the whole: The language of fractions } & 139\end{array}$

$\begin{array}{ll}\text { Same Whole-Common Denominator } & 150\end{array}$

Different Whole Pieces: Different Common Denominator 151 
$\begin{array}{ll}\text { Number Line } & 154\end{array}$

Understanding What the Numerator and Denominator Represent 161

$\begin{array}{ll}\text { Common Numerator } & 162\end{array}$

$\begin{array}{ll}\text { Comparing and Ordering } & 164\end{array}$

Same number of pieces (common numerator) 164

Compare to a benchmark 166

$\begin{array}{ll}\text { Common missing pieces } & 169\end{array}$

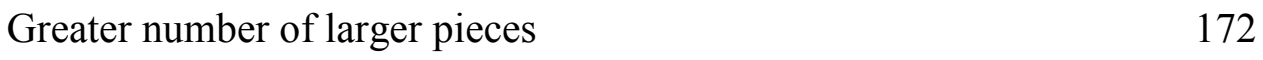

$\begin{array}{ll}\text { Fractions Operations } & 175\end{array}$

$\begin{array}{ll}\text { Fraction addition } & 175\end{array}$

Fraction subtraction with multiplication $\quad 180$

$\begin{array}{ll}\text { Fraction multiplication } & 183\end{array}$

$\begin{array}{ll}\text { Fraction division } & 187\end{array}$

$\begin{array}{ll}\text { Discussion } & 192\end{array}$

CHAPTER V: CONCLUSION 199

$\begin{array}{ll}\text { Implications for Future Research } & 207\end{array}$

$\begin{array}{ll}\text { Limitations of the Research } & 210\end{array}$

$\begin{array}{ll}\text { Significance the Present Study } & 210\end{array}$

REFERENCES 212

APPENDIX A: ARGUMENTATION LOG 232

APPENDIX B: EQUAL SHARING CLASS TASK 1 281

APPENDIX C: EQUAL SHARING CLASS TASK 2 PART 1

APPENDIX D: EQUAL SHARING CLASS TASK 2 PART 2 
APPENDIX E: IDENTIFYING AND CREATING “CONVENIENT” WHOLE TASK 3284

APPENDIX F: CHARLIE BROWN BROBLEM TASK 4

APPENDIX G: PAYCHECK PROBLEM TASK 5 PART 1

APPENDIX H: EQUIVALENT FRACTIONS TASK 5 PART 2

APPENDIX I: FRACTION COMPARISON TASK $6 \quad 288$

$\begin{array}{ll}\text { APPENDIX J: NUMBER LINE TASK } 7 & 291\end{array}$

APPENDIX K: FRACTION ADDITION AND SUBTRACTION TASK 8

APPENDIX L: FRACTION MULTIPLICATIONS AND DIVISION TASK 9 


\section{TABLES}

Table

Page

1. Initial Hypothetical Learning Trajectories

2. HLT Including Instructional Sequence for Fraction Concept and Operation

3. Mathematical Practices Before The Fraction Concepts And Operations Unit Started

4. Mathematical Practices 


\section{FIGURES}

Figure

Page

1. Share 5 Candy Bars Equally Among 3 People

100

2. Share 5 Candy Bars Equally Among 6 people

106

3. Tanny's Group Solution for Share 5 Candy Bars Equally Among 6 People

111

4. Janna's Group Solution for Share 5 Candy Bars Equally Among 6 People

112

5. Five-Thirds of the candy bars

119

6. Area Model

126

7. The Original Paycheck

127

8. Two Separate Pictures to Represent Fractions $\frac{3}{4}$ and $\frac{9}{12}$ Are Equivalent

9. An Area Model to Represent Fractions $\frac{3}{4}$ and $\frac{9}{12}$ Are Equivalent

10. A Discrete Model to Represent Fractions $\frac{3}{4}$ and $\frac{9}{12}$ Are Equivalent

11. Sori's Three-Eighths Representation

12. Tara's Three-Eighths Representation

13. Two-Fifths of a Rectangle

14. Five-Halves of $\frac{2}{5}$ of the Rectangle

15. Linus Greater By the One-Fifths Amount

16. One-Third of the Way Between 1 and $2 \frac{1}{2}$

17. Half-Way Between $\frac{\mathbf{1}}{\mathbf{4}}$ and $\frac{\mathbf{7}}{\mathbf{8}}$

18. Two-Thirds of the Way From $\frac{3}{4}$ to $1 \frac{1}{3}$

19. Cut the $\frac{2}{3}$ into Fourths and the $\frac{3}{4}$ into Thirds and Add $\frac{2}{3}$ and $\frac{3}{4}$ 
20. Multiplying to Create a Common Denominator to Add $\frac{2}{3}$ and $\frac{3}{4}$

21. Two-Thirds of Two-Fifths

184

22. Two-fifths of three-third 185

23. Two and-a Half Servings

189

24. Two-and Three-Eighths Servings

189

25. Time line of Classroom Mathematical Practices

194 


\section{CHAPTER I: BACKGROUND AND RATIONALE}

\section{Research Focus on Content Knowledge of Preservice Teachers}

Effective mathematics learning is often the result of effective teaching with students learning mathematics through experiences that teachers provide for them (NTCM, 2000). Teachers need to have deep mathematics content knowledge in order to understand their students' thinking and so be able to select mathematics tasks which provide meaningful experiences to their students. There is overall agreement that teachers need to have well-formed content knowledge because this affects what they teach and how they teach it (Da Ponte \& Chapman, 2016). It is, therefore, no surprise, that teachers' knowledge of mathematics continues to be an important theme in research on preservice mathematics teacher education (Da Ponte, $\&$ Chapman, 2016). It is reasonable to plan and conduct research which addresses elementary preservice teachers' (PTs') learning, with special attention given to their knowledge of fraction concepts and operations, issues related to this knowledge, and to how its development has been facilitated in mathematics education content courses. That is because preservice teachers are expected to teach important mathematical ideas at elementary level (McCormick, 2015; Behr, Wachsmuth, Post, \& Lesh, 1984). In particular, studying PTs' knowledge for teaching fractions is important because it is widely recognized that the topic is difficult to learn and teach (Rosli, Gonzalez, \& Capraro, 2011).

\section{Mathematical Understandings of Preservice Teachers}

Many research studies have shown that the mathematical understandings that preservice teachers gain from schooling and university mathematics courses do not adequately prepare them to teach primary school mathematics effectively (Ball, 1990a, 1990b; Even, 1993; Ma, 1999; Simon, 1993), particularly given the kind of teaching demanded by recent reforms of the 
National Council of Teachers of Mathematics (NTCM, 2000) and the Common Core State Standards Initiative (CCSSI, 2010). Yet, research documenting the experiences that PTs need in order to develop a deep understanding of rational number (fraction concepts and operations) is limited (Tobias, 2009; Wheeldon, 2008). Several researchers have shown that even practicing primary school mathematics teachers sometimes have insufficient knowledge of fractions (Newton, 2008; Park, Güçler, \& McCrory, 2013; Steenbrugge, et al., 2014). Research has shown that many elementary PTs have poor mathematical knowledge and hold negative attitudes towards mathematics (Matthews \& Seaman, 2007).

In particular, studies have revealed that PTs experience difficulties coping with fractions concepts and operations (Ball, 1990b; Marchionda, 2006). The limited research on elementary PTs' fraction knowledge has also indicated that some PTs have the same misconceptions as elementary and middle school students (Newton, 2008; Silver, 1986; Tirosh, 2000). Often PTs have fragmented understandings of fraction concepts and operations (Graeber, Tirosh, \& Glover, 1989; Tirosh \& Graeber, 1989). For example, Graeber, Tirosh, and Glover (1989) asked preservice teachers to solve: "From 1 kilogram of wheat you get .75 kilograms flour. How much flour do you get from 15 kilograms of wheat?" Many PTs thought the problem could be solved by dividing 15 by 0.75 , because they argued that they were looking for part of the quantity. Thus, many PTs wrongly mismatched the dominant model of multiplication and division of whole and decimal numbers. For example, they thought that one finds $\frac{1}{2}$ of 6 by dividing 2 , one also finds .75 of 15 by dividing 15 by .75 . They concluded that this "involved an overgeneralization of procedures used with unit fractions" (Graeber, Tirosh, \& Glover, 1989, p. 98). There is also a lack of research in the area of so called "pragmatic" PTs' fractions knowledge (Graeber, Tirosh, \& Glover, 1989; Tirosh \& Graeber, 1989). Specifically, studies 
suggest that teachers need to have more than procedural knowledge because the students they are to teach also need more than procedural knowledge (Bartell, Webel, Bowen, \& Dyson, 2013; Işık, Öcal, \& Kar, 2013).

Research shows a strong positive correlation between teachers' mathematical content knowledge and their students' mathematics achievements (Siegler, Carpenter, Fennell, Geary, Lewis, Okamoto, \& Wray, 2010). In addition, many PTs enter and graduate from teacher education programs with insufficient knowledge to teach mathematics effectively (Conference Board of the Mathematical Sciences, 2001; Lo \& Luo, 2012). Teachers tend to rely on how they remember their own experiences in $\mathrm{K}-12$ mathematics classes - which were often dominated by procedural teaching and learning (Schoenfeld, 2002). It appears to be the case that PTs' poor performance with respect to fractions can cause critical problems, and therefore their knowledge of fractions becomes a fundamentally important issue that needs to be addressed.

\section{Understanding Preservice Teachers' Knowledge of Fractions Concepts and Operations}

Many elementary school children lack basic understanding of underlying mathematical concepts, and providing them with procedural explanations will not always address their deficits (Burns, 2011). Adequately preparing PTs for their future roles as a class room teachers is important because elementary school children can also be influenced by their teachers' content knowledge of mathematics (Kahan, Cooper, \& Bethea, 2003). Thus, developing a better understanding of the mathematics content knowledge of preservice elementary teachers in specific domains (Kahan, et al., 2003) is important if we are to support elementary school children's learning to the highest level possible. For example, teachers should not assume that their students understand the magnitudes represented by fractions, even when they can perform arithmetic operations with them (United States Department of Education, 2008). This is because, 
in order to develop proficiency with fractions, students must able to perform operations with them and develop "fraction number sense" so that they can think of fractions as numbers in a system (Olanoff, Lo, \& Tobias, 2014). Thus, a constant review of whether content courses are helping PTs develop strong mathematical content knowledge is desirable. Also, as the relationship between teachers' mathematical knowledge and students' achievement confirms, it is important for research to take account of the learning issues experienced by elementary students needing effective conceptual intervention.

PTs need to develop a deep understanding of mathematical concepts and to experience problem solving and mathematical reasoning in order that they will be able to teach more than mere procedures once they become full-time teachers in their own classrooms (Bartell et al., 2012). Research has illustrated that "having deep conceptual knowledge or understanding may be insufficient knowledge for recognizing conceptual understanding of particular learning goals in children's mathematical work" (Bartell et al., 2013, p. 194). Other types of knowledge (e.g., Pedagogical Content Knowledge-PCK) might be needed to understand their thinking. For example, research shows that some PTs are unable to identify errors that students make when adding fractions, when applying their methods to problem statements, and when attempting to explain what they are doing (or have done) (Isik, Öcal, \& Kar, 2013). PTs have difficulties in identifying and explaining students' errors and have little knowledge of their students' difficulties with word problems. Their main focus is usually whether students' answers are correct, and they rarely apply appropriate sense-making strategies with their students (Da Ponte, \& Chapman, 2016). Even middle school teachers tend to use pictorial models or concrete representations merely for the purpose of illustration rather than as tools to help with sensemaking, reasoning, and making connections (Izsák, 2008). This illustrates the fact that 
difficulties with fractions is also relevant to teachers in schools (Newton, 2008; Park, Güçler, \& McCrory, 2013; Steenbrugge et al., 2014).

More research aimed at understanding PTs' knowledge of fractions concepts and operations, and the impact of content courses on their development of mathematical understandings is needed. PTs have often accepted a set of procedural steps set out by their students as evidence of conceptual understanding. PTs' content knowledge might not be sufficient and this can impact their ability to differentiate between student responses which indicate procedural knowledge versus responses which indicate conceptual understanding (Bartell, Webel, Bowen, \& Dyson, 2013; Newton, 2008). They do not typically have the kind of deep, connected fraction knowledge that expert teachers have (Ma, 1999).

Bartell et al. (2013) examined the role instructional intervention and mathematical content knowledge plays in PTs' ability to recognize children's mathematical understanding of whole numbers and decimals for early grades. Particularly, these authors examined whether PTs recognized when children's responses demonstrated conceptual or procedural understanding. After working with 54 PTs on three content areas: subtraction of decimals, comparison of fractions, and multiplication of fractions they concluded their findings in two primary sections. In the first section, content knowledge was examined at the beginning of the study, and this revealed that this knowledge is necessary but insufficient in supporting PTs' ability to recognize evidence of children's conceptual understanding of mathematics. However, after instructional intervention, the results showed PT had learned to recognize children's conceptual understandings of mathematics. Therefore, different studies with different teaching approaches which incorporate broad areas of fraction concepts and operations may help PTs to be able to analyze children's conceptual knowledge with respect to fractions (Bartell et al., 2013) are 
needed. Further studies along these lines should provide further information on the impact of content courses on PTs' knowledge of fraction concepts and operations.

\section{Understanding the Role of the Content Course}

Preservice elementary teachers' common mathematical knowledge, the basic mathematical skills that a teachers would possess, as well as the special forms of mathematical knowledge, such as knowledge of students and curriculum, are specific to the profession of teaching and positively impact PTs' future teaching (Ball, Thames, \& Phelps, 2008; Hill, Ball, \& Schilling, 2008; Hill \& Lubienski, 2007, Superfine, Li, \& Martinez, 2013). However, studies suggest that PTs' specialized content knowledge require ongoing attention in teacher education (Da Ponte, \& Chapman, 2016). There is a growing consensus that simply knowing more mathematics is insufficient for providing PTs with the knowledge that will be required by and specific to the profession of teaching (Superfine, Li, \& Martinez, 2013). Research has shown that PTs who took specialized content mathematics courses on numbers, place value, fractions, and number sense did better on assessments than PTs who took general mathematics courses (Matthews, Rech, \& Grandgenett, 2010). It appears that more research needs to be conducted into the thinking of elementary PTs as they attempt to make sense of fraction concepts and operations. It will be helpful to conduct studies into how PTs explain their thought processes

and step-by-step solution procedures when solving fractions concepts and operations problems. In particularly, it will be important to conduct a study to understand how an intervention content course helps PTs address their understandings and their abilities to teach effectively fractions content knowledge. 


\section{Preservice Teachers' Lack of Sense-Making: Procedural and Conceptual Knowledge}

Previous research shows that many “prospective teachers' conceptions of fractions are based on misunderstood procedures" (Tobias, 2013, p. 85). Most PTs do not understand why the different fractions algorithms work (Chinnappan, 2000; Menon, 2009; Southwell \& Penglase, 2005; Superfine, Li, \& Martinez, 2013; Whitacre \& Nickerson, 2016), and are also unable to link them with appropriate representations (Silver, 1986). In fact, in recent decades, the focus has shifted to understanding ways that the two kinds of knowledge, procedural and conceptual, are related (Newton, 2008; see also Byrnes \& Wasik, 1991; Hiebert \& Lefevre, 1986; RittleJohnson, Siegler, \& Alibali, 2001, Silver, 1986). For example, in Silver's (1986) study, the connection between procedural and conceptual knowledge became evident in simple fraction tasks when the study's participants, who were college students, tended to add across numerators and denominators guided by their incorrect visual representations of fractions additions. Researchers in many countries have reported that often prospective and practicing teachers' do not understand why algorithms work (Whitacre \& Nickerson, 2016; see also Southwell \& Penglase, 2005). Olanoff, Lo, and Tobias' (2014) extensive review of the literature on preservice elementary teachers' content knowledge of fractions reveals that preservice elementary teachers' "fraction knowledge is relatively strong when it comes to performing procedures, but that they generally lack flexibility in moving away from procedures and using fraction number sense and have trouble understanding the meanings behind the procedures or why procedures work" (p. 267).

\section{Students' Difficulty in Learning and Using the Concept of Fractions}

Elementary PTs' knowledge of fraction concepts and operations has emerged as a central focus of research, as many children are still experiencing significant difficulty in learning and 
using concepts related to rational numbers (Behr, Wachsmuth, Post, \& Lesh, 1984). Much of the research on fractions has documented students' misconceptions and computational errors (Empson \& Levi, 2011, Siegler et al., 2010) and their lack of skill in explaining instructions (Charalambous, Hill \& Ball, 2011). There remains a lack of a clear description of how fractions fit into students' mathematical understanding, beginning from early ages to late adolescence (Carraher, 1996). Difficulties in learning fractions can also lead students to mathematics anxiety and affect their opportunities for further engagement in mathematics and other domains connected with mathematics. According to Rouche, "fractions are like harmful bugs attacking school kids, and their bites result in unending intellectual and moral after-effects" (as quoted in Gabriel, 2016, p. 36). Thus, children's difficulty with fraction concepts and operations raises issues related to elementary PTs' knowledge of the teaching of fractions.

\section{Research Focus and Limitation on One Aspect of Fractions Concepts and Operations}

Studies on teachers' and PTs' content knowledge of fractions concepts and operations are limited (Iş̧1k, Öcal, \& Kar, 2013, Tobias, 2009; Wheeldon, 2008). More specifically, "studies on concepts of PTs' knowledge of fractions focused primarily on one aspect of fractions like ratio, multiplication of fractions, and division of fractions" (Steenbrugge, Lesage, Valcke, \& Desoete, 2014, p. 141). Indeed, most of the research on PTs' understanding of fractions has primarily focused on division of fractions (e.g., Ball, 1990b, 1993; Borko, Eisenhart, Brown, Underhill, Jones, \& Agard, 1992; Li, 2008; Newton, 2008; Rizvi \& Lawson, 2007; Tirosh, 2000).

Much remains to be investigated concerning other operations with fractions that are equally important for students' learning (Rosli, Gonzalez, \& Capraro, 2011). Newton (2008) examined all four fraction operations and collected data on the performance of PTs at the beginning and the end of a content mathematics course in which the pre-service teachers were 
required to connect the meaning of the operations to algorithms. Results showed improvement in PTs' basic fraction operations and concepts and word-problem capacity. The most common misconceptions revealed by her research was that the denominators (rather than the operation) determine the algorithm. For example, several students found the value of $\frac{2}{3} \times \frac{1}{5}$ by finding a common denominator and then keeping that denominator in the product and wrote $\frac{10}{15} \times \frac{3}{15}=\frac{30}{15}$ or 2 as their solution (Newton, 2008).

The study in this dissertation focused on the PTs' knowledge and use of fractions concepts and operations and especially their sense-making. In particular, the study centered on preservice elementary teachers' knowledge of all fraction concepts and operations. Fractions, like ratio and proportion, are "the most protracted in terms of development ... the most mathematically complex, the most cognitively challenging, and the most essential to success in higher mathematics and science" (Lamon, 2007, p. 629). In order to capture the expected complexity, qualitative data were gathered and analyzed. Specifically, I employed this approach to document PTs' mathematical learning as it occurred in the social context of the classroom.

This study examined the role of a current content course for prospective elementary school teachers (PTs) in influencing the PTs' mathematical content knowledge. It examined not only whether the current course incorporates previous research implications, but also sought to make recommendations for modifying the curriculum to help PTs to improve their fraction concepts and operations' content knowledge. So, I expected to explore broadly whether the classrooms activities, in the course, are appropriate for building knowledge of fraction concepts and operation, especially in relation to constructs such as: part-whole, ratio, operator, quotient, and measure (Lamon, 2007). 


\section{Increased Attention on Preservice Elementary Teachers' Knowledge of Fractions}

Research into the teaching and learning of fractions over the past 30 years has focused mainly on student's learning and misconceptions (Ball, Lubienski, \& Mewborn, 2001), and how and why they understand specific areas of fractions. However, "little research documents how PTs and inservice teachers overcome these misconceptions" (Tobias, 2009, p. 2). The extent of the weakness of teachers' and students' fraction knowledge revealed by recent research has led researchers to give increased attention to preservice and inservice teachers' knowledge of fractions by investigating teacher education programs and in particular, preservice elementary teachers' knowledge and beliefs with respect to fractions (English \& Kirshner, 2016; Ma, 1999). A growing number of researchers have drawn attention to the importance of content knowledge and how that relates to their students' performance (Rayner, Pitsolantis, \& Osana, 2009). Some researchers have recommended that there be a shift to focusing on what PTs know or are able to do, "thus moving away from deficiency perspective to one of understanding their sense making" (Da Ponte, \& Chapman, 2016, p. 283).

Olanoff, Lo, and Tobias (2014), in their summary of the literature on preservice teachers' knowledge of fractions, identified future research directions and suggested that there is a "need for a broader study of fractions in both content and methods courses for PTs, as well as research into how PTs' fraction content knowledge develops" (p. 267). Their meta-analysis presented the available data and pointed toward the need for a study of PTs' knowledge of making sense of fractions operations, of issues related with this knowledge, and of how its development has been facilitated in a mathematics education content course. 


\section{Research Focus on Rational Numbers}

It is increasingly recognized that rational-number understanding requires the conceptual coordination of different mathematical knowledge from many different domains comprising partwhole, quotient, ratio, operator, and measure (Behr, Harel, Post, \& Lesh, 1993; see also Jones, Langrall, Thornton, \& Nisbet, 2002), which make the rational number concept complex and broad. Thus, rational numbers still has been receiving additional attention by researchers (English \& Kirshner, 2016).

Both, previous research findings and the current review of studies reflect on issues with prospective teachers' mathematics knowledge (English \& Kirshner, 2016). In their review, Da Ponte and Chapman (2016) compiled findings that reflect and address several issues related to PTs' knowledge of rational numbers. For example, they reviewed Tobias' (2013) study which addressed PTs knowledge of rational numbers, particularly how elementary PTs developed an understanding of language use for defining the whole and their difficulty in distinguishing among the terms of "of," "of one," "of the," and "of each." The researchers identified PTs' lack of appropriate procedural knowledge, and that prevented them from developing profound understandings of concepts related to the multiplicative structure of whole numbers. In particular, the researchers found issues related to PTs' inadequate conceptual knowledge of division, and their inability to make reasonable connections between procedural and conceptual knowledge. They drew attention to the PTs' failure to connect different representations of rational number concepts and pinpointed prospective teachers' limitations with the language of fractions. They found that many PTs could not connect real-world situations and symbolic manipulations. 
Carrying out a study based on understanding current trends in research helps to craft research-based courses and establish a meaningful and effective education experience for prospective teachers (English \& Kirshner, 2016). Accordingly, I conducted a study which investigated PTs' knowledge of fraction concepts and operations, with the aim of documenting how their conceptual understanding of mathematics collectively developed throughout the course. The study sought to provide evidence that would expand and deepen our understanding of how PTs develop reasoning and sense-making strategies for fraction concepts and operations over a nine-day unit in a mathematics education content course.

\section{Preservice Teachers Learning as They Participate in Whole-Classroom Setting}

Most research related to the teaching and learning of fractions has incorporated quantitative methods which have included pre/posttests and/or qualitative methods which include one-on-one interviews (English \& Kirshner, 2016). Though this trend is still continuing, there is also research to suggest that future studies should address how PTs learn as they participate in whole-class settings or groups (Olanoff, Lo, \& Tobias, 2014) because such studies create an opportunity to document the PTs' development during their participation in the course. In addition, "this type of research provides detailed students' conceptions of and development of the mathematics being taught" (Tobias, 2013, pp. 85-86). For example, one recent study documented the role of language in PTs' construction and development of fraction knowledge in a whole-classroom setting (Tobias, 2013). The PTs and the instructor were expected to act in ways which could reflect their intentions to communicate genuinely about their mathematical thinking and reasoning, given the fact that "classroom learning constitutes a reflexive relationship between individuals and social domains" (Tobias, 2013, p. 85). 
The research into the class discourse in the study described in this dissertation normally followed the PTs' work in small groups and documented the various solution methods that the PTs used to solve problems. Discussions, following small-group work, created opportunities for PTs' learning to develop. They also offered a chance for a researcher to investigate "the reflexive nature of teaching and learning” (Wood, Cobb, \& Yackel, 1993, p. 55). These provided an atmosphere that encouraged PTs' individual mathematical constructions and reflections on different methods that other prospective teachers use. They also encouraged PTs to share their mathematical thinking with others (Wood, Cobb, \& Yackel, 1993), and contributed to the mathematical practices of the classroom.

The fractions tasks, in the course that was the context of this study, were open-ended in order to encourage a variety of mathematical solutions from the PTs. The emphasis was on the development of conceptual understandings rather than on standard algorithmic procedures. In this way, the whole classroom setting afforded opportunities and encouraged the elementary PTs in the course to explain their reasoning and thinking - that is to say, their sense-making. Thus, my study analyzed the whole-class setting, provided a detailed account of PTs' reasoning and sense-making with fractions concepts and operations, and documented how this sense-making occurred.

I did not investigate individual students' development of mathematical learning and reasoning with respect to fraction concepts and operations as they participated in the practices of the whole classroom community because "individual students' development may not follow the same route of development as the whole class" (Tobias, 2013, p. 102). In fact, as the PTs engaged in different levels of mathematical understanding, it was expected that the content and 
structure of their participation in classroom discourse would influence the role they assume especially as they participate in small or whole-class discussion (Nillas, 2010).

\section{Application of External Perspective in the Process of Data Collection and Analysis}

As Da Ponte and Chapman (2016) have indicated, most of the qualitative case studies or small-scale studies carried out during the last 10 years have focused on PTs' education, teacher knowledge, and teacher quality of instructions. The research has used instruments and data collection methods involving interviews, observations, classroom productions, audio, and video recording, questionnaires, and tests that drew on an insider perspective. In those studies, teacher educators have been researching their own practice, which may be regarded as one of the positive qualities of teacher researchers in developing knowledge about mathematics teaching through reflections and practical problem solving (English \& Kirshner, 2016). However, my research into PTs' knowledge of fraction concepts and operations will combine an external perspective, as opposed to researching my own practice, in the process of data collection, a perspective drawn from theoretical sources of the teaching and learning of mathematics and based on studies of one of the sections of the course.

\section{Research Questions}

The purpose of my study was to investigate elementary PTs' sense-making with respect to fraction concepts and operations within an elementary mathematics content course, and how their sense making developed. In addition, I was interested in finding how the normative classroom practices developed throughout the course. Thus, my research questions were as follows: 
1. What knowledge do the participating PTs collectively exhibit regarding making sense of fractions concepts and operations, and how does sense-making occur in the class?

2. In what ways do collective social norms and mathematical behaviors regarding fractions emerge within the course? 


\section{CHAPTER II: RELATED LITERATURE}

\section{Introduction}

In this chapter I address literature relevant to PTs' knowledge of fraction concepts and operations. I incorporated a section that focuses on ways in which students conceptualize units (scheme theory) which suggests how PTs' unit building knowledge increasingly developed into complex mathematical practices (Lamon, 2007) of multiplicative reasoning (Steffe, 1992). The review provided me with the resource to trace the conceptual progress of the PTs in their mathematical thinking and reasoning of fraction concepts and operations.

Since a complete understanding of rational number subconstructs and how they relate to each other is important in order to have a 'comprehensive' understanding of rational number (Kieren, 1976), I have included a section that is devoted to interpret the meanings of each rational number components. This will serve as a foundation to understand PTs' development of those fraction concepts and operations and their related sense-making strategies.

I reviewed articles on the use of concrete models and pictures, which are being seen as increasingly important in mathematics classrooms for helping students visualize and explore mathematics concepts deeply — to connect learning with their experience (An, Kulm, \& Wu, 2004). In the context of this study PTs are required to use models to explain and justify their solutions strategies so that their solutions would make sense to themselves and others. Therefore, it is important to conduct a review on models and their use in the classroom in order to understand the PTs' experiences in representing fractions and how their sense-making strategies develop throughout this study.

The need for understanding how children learn fractions was important when developing the tasks for PTs. That is because PTs need mathematical experiences similar to what children 
need. "Since research with adults' development of rational number understanding is limited, research with children was used in conjunction with adults to develop the hypothetical learning trajectory and instructional sequence" (Tobias, 2009, p. 40) of the course for this study.

The literature on fraction operations and contextual support for fraction operations are also reviewed as they relate to PTs' fraction concepts and operations knowledge and the context of this study - the content course.

\section{Scheme Theory in the Construction of Fraction Multiplication}

Prior to the research of Steffe (2002) and his colleague Olive (1999), researchers did not apply scheme theory in investigating ways in which students conceptualize units. They tended to emphasize the importance of sharing and partitioning in conceptualizing units- which were recognized as critical factors in children's construction of fraction multiplication. However, Steffe and his colleague constructed a theoretical framework grounded in scheme theory to study the functioning scheme (repeatable, generalizable actions) that children bring to a specific mathematical task and how children adopt their scheme in response to the specific task at hand. Steffe articulated a theory concerning the way in which children's formation and use of units is progressively elaborated from early counting through multiplication (Lamon, 2007; see also Steff 1992; Steff \& Cobb, 1988; Steffe, Von Glasersfeld, Richards, \& Cobb, 1983). The construction of action and operation schemes which involve composite units is important in the development of children's mathematical understanding, because schemes are not strategies, instead they are constructs by the researcher or teacher to model students' mental structure. Operations are also mental actions that have been abstracted from experience to become available for use.

For example, in Steffe's (1992) research, the first multiplicative concept occurred as an accommodation of the tacitly nested number (TNN), which is explained as a recursive counting 
scheme. Steffe theorizes that students need to be able to reconceptualize and partition four different types of units. These include counting units, composite units, measurement units, and units-of-units. Counting units can be characterized as independent whole number quantities where the attribute of "oneness" is the focus. Composite units can be characterized as a collection of units sharing a common attribute. Measurement units are abstract units that are distinguished by two primary characteristics-they are iterable (i.e., the referent whole can be recreated through the iteration of any one of its fractional parts), and they are intensive quantities that are determined by comparing a portion of the referent whole to the referent whole itself. Units-of-units can be characterized as composite units that are reconceptualized into a new, encompassing unit (Mack, 2001, p. 270). Understanding the concept of unit in fractions, especially the role of composite unit (units of numerosity greater than one), "suggest that unit building may be an important mechanism in accounting for the development of increasingly sophisticated mathematical ideas" (Lamon, 2007, p. 643).

Steffe's (1992) construction of schemes of actions and operation involving composite units promote multiplicative reasoning, which is a key development in children's understanding of fractions. He states that students can reorganize the quantitative operations they used to construct whole number when constructing fractions knowledge. This provides a conceptual progress for children in their mathematical thinking and reasoning of fraction concepts. It may also work for other domains, such as, proportional reasoning, early algebraic, and algebraic situations. A key construct (in Steffe's framework) that distinguishes multiplicative reasoning from additive reasoning is, in additive reasoning, students operate on numbers as composite units. They establish this in a situation that prompt a goal of determining the amount of 1 's in a collection of items, which involves iterating the unit of one to compose the larger units 
$(1+1+1=3$ and gradually the nested nature of their resulting composed quantity become explicit, example, $(1+1+1+1+1=4+1=5)$. When a number is conceived as a composite unit, children can anticipate decomposing units into nested sub-units. For example, a child can think of 13-5=? As $5+?=13$, that is a composite unit of 13 (whole) of which he/she knows one part of (5) and can find the other. This part-whole decompose highlights as a key aspect of additive reasoning.

Learning to reason multiplicatively requires a major shift. It requires a coordination of operations on composite units or a coordination of two or more levels of units (Tzur, Johnson, McClintock, Xin, Si, Woodward, \& Jin, 2013). Multiplicative reasoning entails distributing one unit over items of another and finding the total through coordinated counting activity, "in multiplicative reasoning the referent unit is transformed via the coordinated distribution and the product has to be conceptualized unit of units of units" (Steffe, 1992, Tzur et al., 2013)

\section{Different Meanings of Rational Numbers}

Rational-number concepts and operations are among the most mathematically complex and essential concepts that students come across during their elementary and middle school years. They involve rich set of distinct and integrated subconstructs and processes, such as measurement and coordinate systems (Behr, Lesh, Post, \& Silver, 1983). Rational numbers can be interpreted in terms of at least five subconstructs: part-to-whole comparison, ratio, quotient, operator, and measure of continuous or discrete quantities. Rational number understanding requires a thorough understanding of these subconstructs and how the subconstructs are interrelated to each other (Kieren, 1976). Understanding these subconstructs and operations is central to understanding are rational numbers (Ohlsson, 1988). For the purposes of this study, only part-whole, quotient, measure, and operator were the subconstructs focused on during instruction. 
Part-whole. The part-whole subconstruct interpretation of rational number relates to fractions that are less than or equal to one (Charalambous \& Pitta-Pantazi, 2007). In addition, "this subconstruct is fundamental to all later interpretations and is considered by Kieren (1981) to be an important language-generating construct" (Behr, Lesh, Post, \& Silver, 1983, p. 3) that serves as an instrument to understand the other rational number subconstructs. Therefore, the part-whole interpretation is "considered the conceptual base for the other interpretations of rational numbers, and operations on fractions - equivalence, addition, subtraction, multiplication, and division - form a basis for the formal symbolic computation in the field of rational numbers" (Ni \& Zhou, 2005, p. 29).

Fractions should always be interpreted in relation to a specified whole. "The concept of the whole underlies the concept of a fraction" (Behar \& post, 1992). For instance, the meaning of $\frac{1}{3}$ can differ depending of the nature or specified whole: $\frac{1}{3}$ of a set of candies and $\frac{1}{3}$ of a candy or the distance from 0 to $1 / 3$ on a number line. So, "understanding fractional parts in relation to the whole is a critical foundation for other fraction concepts, such as relative magnitude, equivalence, and operations" (Petit, Laird, Marsden, \& Ebby, 2015, p. 3). Charalambous and Pitta-Pantazi (2007) describe several significant ideas related to part-whole meaning and concept of defining the whole (Tobias, 2013). These include, “(a) the parts, taken together, must exhaust the whole, (b) the more parts the whole is divided into, the smaller the produced parts become, and (c) the relationship between the parts and the whole is conserved, regardless of the size, shape, arrangement, or orientation of the equivalent parts" (p. 296).

Quotient. According to the part-whole interpretation of rational numbers, the symbol $\frac{a}{b}$ usually refers to a fractional part of a single quantity (Behr, Lesh, Post, \& Silver, 1983). Similarly, the quotient meaning of rational numbers evolve from partitioning, which is "the 
major cognitive structure underlying the notion of quotient" (Kieren, 1976, p. 121). Complete understanding of the quotient subconstruct $\frac{a}{b}$ relies on the idea of $a$ out of $b$ equal pieces, with a connection being made from breaking a whole group into $b$ equal parts and then taking $a$ of those equal parts to make the whole (Tobias, 2009). The symbol $a / b$ may also be used to refer to an operation. That is to say, $\frac{a}{b}$ can be interpreted as a divided by $b$, (or $a \div b$ ), which is the indicated division or indicated quotient meaning of rational numbers (Behr, Lesh, Post, \& Silver, 1983).

Understanding of rational numbers as quotients involves at least two types of thinking. For example, first, $\frac{6}{2}$ and $\frac{3}{4}$ interpreted as division results in establishing the equivalence of $\frac{6}{2}$ and 3, and of $\frac{3}{4}$ and 0.75 . But rational numbers can also be considered as elements of a quotient field or fraction field and, as such, can be used to define equivalence, addition, multiplication, and other properties from a purely deductive perspective; all algorithms are derivable from equations via the field properties (Kieren, 1976).

A rational number as quotient also introduces and leads to understanding of the meaning of mixed number or fraction greater than one (Charalambous \& Pitta-Pantazi, 2007). Students who are only introduced to the part-whole meaning of a rational number, which emphasizes the idea of a numerator being less than a denominator, will say any solution with a fraction greater than one would be impossible (Streefland, 1991). But, " having a partition with an answer greater than one will also lead to the discovery of converting mixed numbers into fractions greater than one, and vice versa" (Tobias, 2009)

Measure. The measure subconstruct introduces fractions as lengths or distances, for which some unit of measure is involved (Behr, Lesh, Post, \& Silver, 1983; Kieren, 1976). The measure (number) associated with an object is then the number of units or subunits that "equal" the object measured. They include continuous materials which involve some quantity such as 
length or area — For example Cuisenaire rods, number lines, and sheets of paper. Using a common concrete embodiment, a measure subconstruct of rational number, is introduced through the number line. As opposed to the part-whole subconstruct in which the unit is most often an area or a set of discrete objects, in the number line context, a unit is represented by a length. The idea of subdivision of a unity allows students to develop "strong notion of the unit and subintervals, equivalence, the order and density of the rational numbers, and the operation of addition and subtraction" (Lamon, 2007, p. 659).

Operators. Interpreting a fraction as an operator means that students understand that a fraction such as $\frac{3}{4}$ represents a multiplicative size transformation in which a quantity is reduced to $\frac{3}{4}$ of its original size. By both partitioning and duplicating various portions of the quantity, using a fraction as an operator can lead to understanding unitizing ideas, such as $\frac{3}{4}$ representing $3\left(\frac{1}{4}\right.$ units), $1\left(\frac{3}{4}\right.$ unit), or $\frac{1}{4}$ (3 units). Particularly, the interpretation is characterized as finding a part of a part of a whole. It is a concept that leads to understanding fraction multiplication as function where the first fraction acts on the second and "problem situations associated with this interpretation involve a multiplicative transformation in the size of the unit" (Mack, 2001, p.

269). For example, the problem $\frac{3}{4} \times \frac{2}{3}=?$ can be interpreted as finding three-fourths of twothirds of one whole or reducing or shrinking a quantity whose measure is two-thirds of a unit to three fourths of its original size (Mack, 2001). In this example, $\frac{2}{3}$ is the relevant referent whole.

\section{Partitioning and Conceptualizing Quantitative Units in Fraction Multiplication}

The construction of a fraction composition scheme framework (Steffe, 2002), a progression of development that children might follow in learning to understand fractions, was also developed. This was based on the above idea of partitioning and conceptualizing 
quantitative units, which is the foundation for the development of multiplicative fraction concepts in children. It emphasizes specifically the interiorization of two levels of units, a particular multiplicative concept, which was found to be significant for the construction of a unit fraction composition scheme. However, Hackenberg and Tillema (2009) suggested the interiorization of three levels of a unit (unit of units of units) was necessary for the construction of a general fraction composition scheme.

Hackenberg and Tillema (2009) investigated ways in which students' whole number multiplicative concepts are involved in the construction of fraction composition scheme. To accomplish this, both researchers investigated students' construction of schemes based on the activity of four (two pairs of) sixth grade students who participated in an 8-month long teaching experiment. The researchers were inquiring about how the students operate mathematically and how their methods for operating change over time in the context of teaching, particularly how these students re-conceive prior conclusions about the nature of a particular concept and scheme. The activities and instruction were tailored to the mathematical thinking of the participating students. For example, Sara was one of the students who could not construct a unit fraction composition scheme at the beginning of the teaching experiment. A unit fraction composition scheme is a recursive partitioning (partitioning a partition) which was defined based on research conducted by Olive (1999) and Steffe (2003), who found the operation recursive partitioning as being a critical resource in fourth and fifth grade students' construction of a unit. Sara was given a problem intended to provoke the construction of a unit fraction composition scheme. First, Sara had partitioned a "unit" cake into 15 equal parts and then the researcher asked her to share the one-fifteenth of cake between two people. The researcher also encouraged Sara by asking, how many "mini-parts" it would take to make the whole cake? At the beginning she said "six," 
but later she changed her mind and started to copy one of the mini parts to see how many of them would make up the whole cake. Finally, with some prompting from her friend, she continued to copy until had the same size of cake as the original one and she also found out the mini-part would be $\frac{1}{30}$ of the original cake. However, Sara did not apply recursive partition in this situation, if she had she would have inserted two units into each of 15 units, using her whole number multiplying scheme. Still, the researcher posed a different problem to make sure Sara can apply her multiplying scheme. He asked her, "Can you share this sub sandwich fairly among 17 people? Now each person shares their piece two other people (three people total share each piece). Could you figure out how much one little piece is of the whole sandwich?" Sara immediately partitioned each of the 17 parts into three equal parts and she found the number of pieces by multiplying 17 by 3 and came up with 51 pieces as her answer. She said there would be 51 pieces and one piece would be "one fifty-oneth." In this study, students" whole number multiplicative concepts were found be the foundation for their composition schemes. The interiorization of two levels of unit, a particular multiplicative concept, was found to be necessary for the construction of a unit fraction composition scheme, while the interiorization of three levels of units necessary for the construction of a general fraction composition scheme. This finding contributed to previous research on students' construction of fraction multiplication that has emphasized partitioning and conceptualizing quantitative units.

\section{Children's Thinking}

An important goal of fraction instruction in elementary and middle school is to ensure that students develop procedural fluency with fraction operations. However, procedural fluency alone is not sufficient to ensure proficiency in fraction operations and sense making. Sound conceptual understanding is also equally important to deepen students' understanding of fraction 
concepts and operations. Conceptual understanding of operations in fractions is also built using visual models or pictures, estimation, unit fractions, equivalence, and properties of operations (Petit et al., 2015).

Fraction instruction that includes the use of visual models and reasoning strategies based on an understanding of the magnitude of fractions has led students to understand conceptually reasoning and sense making with fraction operations. Researchers have found that students who make sense of various fraction representations "are more likely to reason with fraction symbols as quantities not as two whole numbers" (Petit et al., 2015, p. 143). Fraction instruction should also be consistent with children's thinking, because children can develop structural knowledge out of action and operational knowledge in the domain of fractions. Though fractions are "the most protracted in terms of development, the most difficult to teach, the most mathematically complex, the most cognitively challenging" and they are also "the most essential to success in higher mathematics and science" (Lamon, 2007, p. 629), research still provides us with some insight that supports children's thinking and their progression in understanding of fractions knowledge from limited (operational) to more extensive (structural) knowledge (Mack, 2001).

The fraction field still lacks a clear explanation of how fractions fit into students' mathematical understanding, beginning from early ages to late adolescence (Carraher, 1996). However, fractions are tightly interwoven with other mathematical domains, such as ratios and proportions. These reference concepts or related idea, will be closely linked to representations, schemes, ideas, and concepts such as relative increase and decrease, rates, functions, operations, measurement, etc. (Carraher, 1996). It seems there is a need for a general framework because the concepts are related each other. So, researchers in mathematics education developed a theoretical framework to document students' thinking and their progression in sophisticated 
strategies in fractions over a long period of time. Researchers have documented students' reasoning about big ideas in fractions, how they can build on their prior knowledge and experiences as "the concept of fractions will rely on former knowledge as well as embody new ideas, it reflects a continuity as well as a break with the past” (p. 244).

\section{Whole Number Intuitive Strategy in Discrete Sets}

Whole number intuitive partitioning strategies do not always smoothly transfer to general conceptions of fractions. Hunting (1983) studied nine fourth-graders, paying special attention to Alan, aged 9 years and 10 months. All the elementary students interviewed were drawn from the same class and were supposed to be of average or above-average ability. Also, different fraction discrete tasks were prepared by the researcher to investigate aspects of Alan's knowledge of partitions and fractions, particularly his cognitive process while he was solving partitioning and fractions problems. And the types of units and their relationships, which are a mechanism for developing a knowledge of fraction, were intentionally made integral features of the tasks.

In Hunting's study, Alan succeeded in solving problems involving $\frac{1}{2}$ and $\frac{1}{3}$ of a set of discrete quantities. For example, when finding $\frac{1}{3}$ of 12 Easter eggs, Alan came up with the correct solution by dividing the eggs into three equal groups to show $\frac{1}{3}$. His solution method could be attributed to his use of sharing actions or sophisticated whole-number strategies.

However, Alan could not correctly respond to the problem presented to him to find $\frac{3}{5}$ of 10 eggs. He just made three equal groups of 3 eggs, leaving 1 leftover egg, to show his answer. From his response, it did not seem that he understood the meaning of the fraction $\frac{1}{5}$ as one group out of five equal groups. Because he responded "one, or half of one maybe" to the question “ $\frac{1}{5}$ of 5 ?" 
The responses of six students in Mack's (1990) study also suggested that their informal knowledge of fractions did not smoothly transfer to discrete sets. During the first instructional session of the research, the six students were asked to partition a discrete set of objects, for example, showing $\frac{2}{3}$ of 6 cookies. Only one student was able to partition the set effectively. The other five students responded that "two cookies" were $\frac{2}{3}$ of all the cookies. However, after they had all received one-to-one instruction, only two students successfully partitioned the set on their own. Still, the other four students solved the problems after it was suggested that they think of the cookies as one big cookie rather than as several small cookies.

\section{Intuitive Strategies for Understanding Fraction Order, Equivalence, and Part-Whole}

Intuitive quantitative reasoning helps children in determining fractional order or equivalence (Lamon, 2007). Children have often powerful intuitive strategies at an early age before they receive substantial instruction. Most children come to school with informal knowledge which is related to a variety of mathematical knowledge that they can draw on (Mack, 1995). For example, when a whole (continuous quantity) is broken into equal parts, they understand that the more parts there are, the smaller the parts will be. But it is difficult for them to explain this concept with fractions. Young children in the early grades also have some understanding of parts and wholes, though they do not always relate this to fraction symbols (Mack, 1990; see also Ball, 1993). For example, Hunting and Sharpley (1991) analyzed and documented responses of 206 four-and five-year old children, who were attending kindergarten and preschool centers in Melbourne, Australia, to problems requiring the sharing of discrete and continuous quantities and problems involving the fractions $\frac{1}{2}, \frac{1}{3}$, and $\frac{1}{4}$. Analysis of their responses to the sharing problems (skipping ropes and sharing the cracker) showed nearly $89 \%$ success for cutting the rope just once to produce skipping ropes for two dolls. Four children 
were observed to cut the rope into two unequal pieces and when they realized their mistake they subdivided the larger piece. Some children folded the string before they decided where to cut. In addition, 94 children were successful in sharing a discrete quantity, the crackers, to four dolls, mostly applying trial and error method to equalize the piles. Only seven students used a systematic one-to-one approach. More than one-half of the children made unsuccessful attempts in sharing the discrete quantity. Appropriate responses were also observed in the case of 73 students who were asked to cut a modeling clay sausage in half, though no children was successful in responding to a question which required them to predict how many pieces would they expect if the sausage were cut into quarters and thirds. So, in this research children conceived sharing in flexible and "idiosyncratic fashion" showing common no-exhaustion of the material which was required to be shared and little evidence of anticipatory thoughts or strategies prior to making subdivisions or checking and resultant shares (Hunting \& Sharpley, 1991). However, "problematic situations involving sharing were considered to be rich context for laying bare the thinking of children as they partitioned quantities into fractional units" (p. 23). As the same time, children use their experiences as sharers and comparers as a starting point to build on their informal knowledge of fractions (Lamon, 2007).

\section{Equivalent Fractions}

Understanding the concept of equivalence of fractions and developing procedural fluency is important to a student's skills not only to compare and order fractions but also to add and subtract them. They are "fundamentally important concepts ... [and] form the framework for understanding fractions and decimals as quantities that can be operated on in a meaningful way" (Post, Cramer, Lesh, \& Harel, 1993, p. 15). Knowledge of equivalent fractions also requires the observation that two equivalent parts of a whole can each be named by the same fractions when 
one part is appropriately partitioned. Similarly, infinitely many equivalent fractions represent the same value and are located at the same point on the number line. These visual models help to show "patterns and relationships built on an awareness of the connection between the size and number of parts in the whole (Petit et al, 2015, p. 132; See also Behr \& Post, 1992; Behr et al, 1984; Payne, 1976).

\section{The Concept of Unit Fraction and Unitizing}

Research has shown that the concept of a unit has been neglected in classroom discussion (Lamon, 1999), despite the fact that teachers are expected to focus on it when they introduce fractions to their students (An, Kulm, \& Wu, 2004). Unit fractions are the building blocks for developing understanding of fractions addition and subtraction. Students begin constructing an intuitive understanding of the idea that fractions are composed of unit fractions when they use area models and number lines to help them conceptualize how to add fractions with common denominators. For example, if we consider the fraction addition problem, $\frac{1}{3}+\frac{1}{2}$ one third and one-half $\left(\frac{1}{3}\right.$ and $\left.\frac{1}{2}\right)$ do not have a common denominator; in another words, the unit fractions are unlike, so the numerators cannot be added. They do not have equal-sized parts. To solve problems involving addition and subtraction of fractions with unlike denominators, students need to combine their understanding of unit fractions with their understanding of equivalent fractions to find a common denominator before they start computing the necessary operations. After dividing the unit ' 1 ', a circle, into six equal-sized parts, the unit fractions become $\frac{1}{6}$ for both circles.

An, Kulm, and Wu (2004) compared 28 U.S teachers in fifth-to-eighth-grade levels and 33 Chinese teachers in fifth-and sixth-grade levels using interviews, classroom observations, and mathematics teaching questionnaire. They found that $93 \%$ of the U.S teachers tended to build 
students' ideas of addition of fractions with various approaches by focusing on connections between concrete or pictorial models rather than employing the concept of unit fraction. In contrast, only $42 \%$ of the Chinese teachers used concrete models and pictures - instead, most of them used definitions and the unit-fraction concept to develop their students' knowledge of fractions addition. The Chinese teachers focused on procedures and rules, which they believed would help their students to transfer skills to a new knowledge or concept. By contrast, 75\% of the U.S teachers believed that using procedures and rules was not effective in building fractions ideas or in developing conceptual knowledge. Although, only $29 \%$ of U.S teachers emphasized concepts in developing fraction ideas, $51 \%$ of Chinese teachers focused on unitizing concepts to build understanding.

Getting to understand the concept of a unit fraction can help students learn fractions with understanding. The concept of a unit can connect students' prior knowledge from whole number addition to fraction addition so that the numbers with like units can be added (An, Kulm, \& $\mathrm{Wu}$, 2004). It can provide a concrete model on which the concept of fractions addition can be built by using fraction pieces and by finding what size pieces both fractions share, or by finding equivalent fractions to add. The different-sized units will largely depend on understanding simple and composite unit concepts (Lamon, 1999), and students' understanding of unit fractions can help them transition from reliance on visual models (area or number lines) to compute problems involving fractions additions and subtractions. "Learning and thinking about the fraction meanings is constrained by the identification of the unit, and the process of unitizing and by the symbolic or graphical representations of the meaning" (Lamon, 1999, p. 167). An, Kulm, and $\mathrm{Wu}$ (2004) explained a unit fraction as a critical concept in developing fractions ideas in students and learning fractions: 
Using unit fractions to build conceptual understanding connects fractions to students' prior knowledge of the concept of whole number and help students to construct fractions in a continuous and systematic way. In addition it places numerators and denominators in the context of a number and it also links numerator and denominator by multiplication and repeated addition, which are components of prior knowledge of fractions. (p. 159)

Unitizing is also another important topic related with the concept of a unit. So, as with whole number the concept of unitizing with fractions plays an important role in understanding fraction concepts and operations. Using the concept of a unit fraction we can group the same whole amount in different ways (Lamon, 2005). For example, $\frac{3}{4}$ can be grouped as one group of $\frac{3}{4}$ or three groups of $\frac{1}{4}$. The unit fraction here is $\frac{1}{4}$.

\section{Comparing and Ordering}

Comparing two fractions involves determining the relative magnitude of the two fractions, whereas, ordering fractions involves placing a set of fractions in order from the least to the greatest, or vice versa. Understanding relationships among fractions determine the type of range of reasoning strategies that students apply as they compare and order fractions.

Researchers have found that students use five types of reasoning when they compare and order fractions:

1. Reasoning with unit fractions (e.g., $\frac{1}{4}<\frac{1}{3}$ because fourths are less than thirds),

2. Extension of the unit fraction reasoning to non-unit fractions (e.g., $\frac{7}{8}>\frac{4}{5}$ because $\frac{1}{8}-$ the distance $\frac{7}{8}$ is away from a whole - is smaller than $\frac{1}{5}$ - the distance $\frac{4}{5}$ is away from a whole),

3. Reasoning based on equipartitioning visual models,

4. Reasoning through the use of a common benchmark or reference fraction, such as $1 / 2$,

5. Reasoning involving equivalence (Behr \& Post, 1992). 
(Petit et al., 2015, p. 81)

An important fraction concept necessary for solving problems involving fraction comparisons and ordering is to understand how the size of the whole (denominator) impacts the fractions being considered. One can also compare and order fractions with the same numerator, but different denominators by extending the unit fraction reasoning strategy. Obviously, with respect to ordering, fractions differ from natural numbers in that one cannot use whole number counting-based procedures for ordering them. Fractions do not have unique successors and a unique preceding number; there are infinitely many numbers between any two fractions. In addition, with respect to the unit, while the unit is the smallest natural number, there is no “smallest” rational number (Stafylidou, \& Vosniadou, 2004).

\section{Fraction Operations}

\section{Whole Number Thinking in Fraction Addition and Subtraction}

Research shows students bring a wealth of knowledge related to whole numbers and have documented that many students' misconceptions related to symbolic representations for fractions which are tied to knowledge of whole numbers" (Mack, 1995, p. 423; see also Behr, Lesh, Post, \& Silver, 1983). For example, Mack's (1995) investigated the development of seven (four thirdgrade and three fourth-grade) students' understanding of fractions during instruction. In Mark's study, the participating students did not receive formal instruction on fraction operations to minimize the impact of prior procedural knowledge on their understanding of representations of fractions. However, all students successfully identified, compared, and added or subtracted fraction quantities when problems were presented verbally, without mentioning fraction names. Because "these students drew on prior knowledge of whole numbers and they explained the meaning of a symbolic representation such as $\frac{3}{5}$ or $\frac{1}{8}$ as "Oh, three-fifths, that's three whole 
pumpkin pies with five pieces in each pie," and "one-eighth, that means one whole cake with eight pieces" (p. 431). Besides, four students initially had one answer to a problem posed verbally in the context of a real-world situation and a different answer to a corresponding problem presented symbolically. Two of the students stuck to their original thinking and convinced themselves that either way works, and decided that both answers were correct. The other two changed their minds and decided that the answer to the symbolic representation $\left(\frac{1}{8}+\frac{1}{8}\right)$ had to be equal to $\frac{2}{16}$. For example, one of the students got an answer of two-eighths to a verbally presented real-world problem involving one-eighth of a pizza and getting one eighth more, but she wrote $" \frac{1}{8}+\frac{1}{8}=\frac{2}{16}$," and she thought she got the first one (the real-world problem) wrong because the answer had to be two-sixteenths since there are two pizzas, one whole pizza with eight pieces and another whole pizza with eight pieces. The results of Mack's (1995) study "suggested that as students build on their informal knowledge, they may construct meanings for fractions represented symbolically that are closely tied to whole-number concepts" (p. 424).

Mack (1990) documented that children come to school with a store of informal knowledge of partitioning, and showed how they could build on their informal partitioning strategy to solve a variety of fraction problems, including the more complex ones, such as subtraction problems with regrouping and converting mixed numerals and improper fractions. She noted that children "are able to relate fraction symbols to informal knowledge in meaningful ways, provided that the connection between the informal knowledge and the fractions symbols is reasonably clear" (p. 29). Mack's (1990) study drew attention to the fact that a major consequence of building on students' informal knowledge of fractions is that students often invent alternative algorithms which are commonly used for addition and subtraction problems. She discussed how these alternative algorithms often had several steps and were quite 
inefficient—although others turned out to be very efficient. However, both (efficient and inefficient) alternative algorithms differed from algorithms that were traditionally taught in schools and students sometimes commented that these algorithms were meaningful to them and preferred them over traditional algorithms (Mack, 1990). For example, six students invented alternative algorithms, building on their informal knowledge with regrouping, for solving problems such as $4 \frac{1}{8}-1 \frac{5}{8}$. First, the students subtracted one from four to get three, next they subtracted $\frac{5}{8}$ from three (because they can't subtract $\frac{5}{8}$ from $\frac{1}{8}$ ), to get $2 \frac{3}{8}$, then they added $\frac{1}{8}$ to $2 \frac{3}{8}$ (because $\frac{1}{8}$ is still left from what they started with) to get $2 \frac{4}{8}$ or $2 \frac{1}{2}$. This "suggests that to construct their algorithm the students first matched the problem to their knowledge of whole numbers and then to their knowledge of problems involving the subtraction of a fraction from a whole number" (p. 26). Another common alternative algorithm was for converting mixed numerals to improper fractions. Students are traditionally taught to convert mixed numerals to improper fractions by multiplying the denominator and whole number together, then adding the numerator to obtain the new numerator for the improper fraction. They are also taught the reverse of that process to convert improper fractions to mixed numerals. All students in this study invented a similar alternative algorithm for converting mixed numerals and improper fractions based on their knowledge of fractions equivalent to one.

\section{Composing and Decomposing: Ways to Deepen Understanding of Fraction Multiplication}

In a different study, Mack (2001) examined the development of six fifth grade students' understanding of multiplication of fractions (how the students develop the schemes for multiplying two fractions) during one-on-one instruction over a three-month period. All the students came to instruction with informal knowledge of partitioning. Before the study began, only one student had received instruction on adding and subtracting fractions, while he was 
attending a fifth-grade class in a different state. The other five students had received instruction which focused on identifying the unit fractions $\frac{1}{2}, \frac{1}{3}, \frac{1}{4}, \frac{1}{6}$, and $\frac{1}{8}$ in pictorial representations in Grades 1-4. They all understood that the more parts a whole is divided into, the smaller the parts become, and they could draw on this knowledge to compare unit fractions with denominators of $2,3,4,6$, or 8 . Their development so far as the multiplication of fractions was concerned was analyzed with attention being given to the ways in which they were and were not able to build on their informal knowledge of partitioning to reconceptualize units, and the manner in which they were and were not able to draw on their knowledge of reconceptualizing and partitioning units to solve problems involving multiplication of fractions in ways which were meaningful to them. Consequently, some of the students were only able to draw on their informal knowledge when they could focus on partitioning a composite unit into a specific number of parts where each part contained only one element (e.g., finding $\frac{1}{4}$ of $\frac{4}{5}$ or $\frac{3}{4}$ of $\frac{2}{3}$ ). Others able to draw on their informal knowledge of partitioning to solve different types of problems involving the multiplication of two proper fractions when they focused on the number of parts and considered the fractional amount each part represented of a unit (e.g., $\frac{3}{4}$ means three-fourths of one whole or three units of one-fourth), and they were also able to reconceptualize and partition units in a variety of ways. However, they had difficulties with conceiving taking $\frac{2}{3}$ of $\frac{9}{10}$ for example. Mack (2000) found that the fifth-grade students who came to instruction with related informal knowledge of partitioning were able to build on their informal knowledge to reconceptualize and partition units to solve problems involving multiplication of fractions in ways that were meaningful to them. Initially, though all of the students in her study thought of partitioning only 
in relation to a unitary whole and they could not apply their knowledge of partitioning to parts of wholes (Mack, 2001).

Research in the natural development of language hierarchies substantiates the above perspective, indicating that more sophisticated thinking can result when one reframes situations in terms of a more collective units (Lamon, 2007). When that happens, a part-whole schema can come in to play and the individual may begin to think about both the aggregate and the individual parts that compose it. In turn, the ability to compose and to decompose a unit into its constituent parts adds the flexibility to one's thinking and reasoning that is needed in the field of rational numbers.

Composing, decomposing, and describing activities (using circular and rectangular plane figures) of the whole helps children to build understanding of the part-whole relationship. Several researchers also suggest that knowledge of partitioning (i.e., the process of dividing a whole or unit into equal-sized parts) may provide a foundation for the development of students' understanding of multiplication of fractions (Mack, 2001; see also Behr et al., 1992; 1993; Olive, 1999; Steffe, 1988; Streefland, 1991; 1993). For students to build on their knowledge of partitioning and develop a deep understanding of multiplication of fractions, they need to be able to understand what the whole is, or reconceptualize units (Behr et al., 1992; Olive, 1999), or make a composition of fractions. Such reconceptualizations enable "the determination of the appropriate unit to be partitioned as well as the unit on which the results of partitionings are based" (Mack, 2001, p. 269).

\section{Intuitive Reasoning: A Foundation for Developing Division and Multiplication Algorithm}

Research on conceptions of the operation of division also shows that students tend to overgeneralize properties of operation with natural number to fractions and to interpret division 
primarily using a primitive, partitive model of division. The activity of constructing quantitative units or "shares" has also received attention in the literature as the foundation for developing a division algorithm. Clement (1980) analyzed the case of David, an 8-year-old third-grade student whose intuitive solution to a word problem on division involved a sharing algorithm based on the following problem: "Jim and his 4 friends found a green paper bag about 2 feet from a rabbit hole. Inside they found 15 green stones. They want to share them equally. How many green stones should each one get?" The problem contained some additional information, stating that the stones to be shared were located "about 2 feet away from a rabbit hole." However, David ignored this unnecessary information and interpreted the text as indicating a total of 4 people sharing the green stones instead of the 5 people designated in the actual problem. There was no information why David used 4 people, but one explanation that the researcher assumed could be that David may have been exposed to school's routine practice of using the printed numerals as they appear in story problems. Thus, the analysis was done on the assumption that David was solving a problem involving 4 people. Nonetheless, David's solution was well articulated in the sense that he solved a story problem normally thought of as a division problem even though he had not had a formal lesson on multiplication or division in school. Besides, David's thinking and intuitive solution exemplifies an important finding with respect to solving story problems - students do not always formulate an arithmetic problem to be solved, instead they seem to "act out" the solution, as David did. The same author, Clement (1977) has also found (as cited in Clement, 1980) that many third-graders are able to solve practical story problems involving multiplication and division with small numbers intuitively, using a variety of methods such as skip counting, drawings, concrete materials, etc., before studying these operations in school. Of course, the initial goals for fraction multiplication and division includes 
students being able to model both operations embedded in story problems with concrete models and pictures, and to be able to explain the process of multiplying and dividing fractions with concrete models and pictures (Cramer, Wyberg, \& Leavitt, 2009).

So, in Clement's (1980) analysis, David read the problem and drew a group of 16 circles, then he noticed his mistake and crossed out the last one, and kept the 15 small circles. The group of circles were referred to him as the "source group". Next, he drew 4 squares which he called "sacks" or "cans" and he equally distributed 12 of the circles from the source group to the squares and showed his thought process for distributing the 12 circles, by drawing small circlers inside the squares. Then, he distributed the 3 circles that remained unused. He cut 2 of the circles in half and distributed a half stone to each square. Finally, for the single remaining stone he said, "We'll put little chunks of that one in each box" which could be called a "half of a half of a half of a stone". He did this because he realized that the initial method of repeatedly giving one stone to each became inapplicable.

\section{Preservice Teachers' Knowledge of Fraction Additions and Subtractions}

This linkage between procedural and conceptual knowledge is evident in simple fraction tasks with PTs (Silver, 1986). In his study of rational numbers, Silver administered written tests to 200 PTs enrolled in a foundational mathematics courses. One common error was that when

PTs were asked to add fractions, they added numerators and denominators (e.g. $\frac{1}{4}+\frac{1}{6}=\frac{2}{10}$ ). Interviews of the PT seemed to suggest that this error derived from faulty pictorial representations (PTs may correctly draw $\frac{1}{4}$ and $\frac{1}{6}$ and then infer 2 shaded parts and 10 total parts). In other words, incorrect procedural knowledge was linked to and supported by incorrect conceptual knowledge. However, PTs' understanding of equivalence both concretely with pictures and symbolically with numbers supports the steps for adding and subtracting fractions 
using common denominators (Cramer, Wyberg, \& Leavitt, 2009) and helps them to connect symbols back to concrete model.

Adding across numerators and denominators was a prevalent and persistent problem in many of the PTs in Silver's (1986) study. However, Newton's (2008) research found that the fraction addition error was not the most common and prevalent problem among PTs. In Newton's (2008) study, the PTs' procedural knowledge error was linked to their prior knowledge, but was not always linked to their whole-number knowledge. In addition, fewer than $10 \%$ of the 85 elementary major PTs who participated in Newton's (2008) study made the fraction addition error at the beginning of the semester and those that did showed the greatest improvement later in the semester.

Since addition and subtraction are strongly related, subtraction errors were also very much similar to those made for addition. For instance, in Newton's (2008) study, for the problem, $6 \frac{2}{5}-2 \frac{4}{5}$ four students subtracted the first numerator from the second rather than regrouping, giving $4 \frac{2}{5}$ as their final answer on the pretest. Students made this mistake for two main reasons - some believed that subtraction is commutative, and some always subtracted the smaller from the larger number. That means the PTs may have applied their understanding of the commutative and associative properties for addition of whole numbers to the addition of fractions, and some also wrongly applied the same properties to fraction subtraction. Furthermore, PTs sometimes subtract a smaller fractional part of one mixed number (a whole number and a fraction less than 1) from the larger fractional part of another, regardless of the context (Tatsuoka, 1984). 


\section{Preservice Teachers' Knowledge of Fraction Multiplication and Division}

In Newton's (2008) study several of the most common multiplication errors seemed to be related to PTs' prior fraction knowledge of why a common denominator is used to add and subtract fractions and is again kept in the final product. However, $19 \mathrm{PTs}$, or $22 \%$ of the total participants, on the pretest mistakenly used a common denominator approach to multiply fractions. For example, several PTs solved $\frac{3}{15} \times \frac{10}{15}$ by finding a common denominator and keeping the denominator in their product (e.g. $\frac{3}{15} \times \frac{10}{15}=\frac{30}{15}$ ). Four of the students kept the denominator in their final answer at the posttest stage when the original fractions had a common denominator (e.g., $\frac{2}{15} \times \frac{7}{15}$ ). In addition, although cross-multiplying is a technique that can be used to compare fractions, 14 students or about $16 \%$ of the total participants used their prior knowledge of this technique mistakenly to multiply fractions (e.g. $\frac{2}{3} \times \frac{1}{5}$ was taken to be equal to $\left.\frac{3}{10}\right)$. Eight students, or about $9 \%$ of the participants, incorrectly multiplied whole number and fractional parts separately when solving problems involving mixed numbers on the pretest. However, coverage of the topic of changing mixed numbers into improper fractions and using distributive property when multiplying mixed fractions helped the PTs to improve their performances at the posttest stage of the study.

Researchers have identified two types of division meanings which are determined by the structure of the model: measurement division and partitive division (Simon, 1993; see also Greer, 1992). In measurement division, one tries to determine how many groups of the intended quantity are contained in the given quantity. In partition division (sometimes termed sharing division) a given quantity is equally divided into a given number of groups and the goal is to determine the size of each group. 
Prior research identified many challenges that PTs face when attempting to apply the above two structures (measurement and partitive division) to fractions division, especially when the divisor is a fraction (Simon, 1993). Although partitive division problems situated in sharing contexts have sometimes been recommended to be used to approach fractions because of their intuitive nature (e.g., Empson 1995; Van de Walle, 2007), their potential is often limited to having whole numbers as the divisor (Lo \& Luo, 2012). It is not intuitive to share a quantity among a fraction group such as " $1 / 4$ " groups. This observation has led to the suggestion that fractions division be introduced through measurement contexts and that there should be much emphasis on the idea that division is the inverse operation of multiplication.

\section{Representing Symbolic Expression Using Words}

Previous studies indicate that U.S. PTs of mathematics have limited mathematics content knowledge with respect to rational numbers which are not whole numbers (Luo, 2009; See also Azim, 1995; Ball, 1990a, 1990b; Graeber, Tirosh, \& Glover, 1989; Simon, 1993; Tirosh, 2000). In addition, several studies have demonstrated that the level of comprehension of fraction concepts and operations is weak among high school students, beginning college students, and elementary teachers (McAllister \& Beaver, 2012). Recent literature in the area of mathematics education has raised attention to the need to create story problems, which can serve as an avenue for developing and assessing students' understanding of important mathematical concepts and for engaging students in meaningful mathematics. Posing story problems writing has been identified as one aspect of mathematics content knowledge which can help students relate the mathematics they are learning to real-life situations (McAllister \& Beaver, 2012). Rudnitsky, Etheredge, Freeman, and Gilbert's (1995) study, indicated that writing story problems can improve students' abilities to solve story-problems. Writing story problems supports students' 
meaningful learning and creates opportunities for students to avoid conceptual errors (Ball, 1990; Ball, Hill, \& Bass, 2005).

However, many PTs struggle to write appropriate word problems to support fraction operations (Dixon et al., 2014). Thus, those PTs who plan to teach mathematics at any grade level need practice constructing well-written and meaningful fraction word problems to prepare them to convey the concept of a fraction and to create rich learning environments for their future students (McAllister \& Beaver, 2012). Barlow and Drake's (2008) study also indicated that the task of writing word problems, which has been recommended as an avenue to assess the strength and weakness of PTs' mathematical thinking and application, can also serve as a tool for teacher educators to assess the mathematical content knowledge of their PTs (Luo, 2009). This is important because mathematics teacher preparation is a critical time for deepening teachers' knowledge of school mathematics and for realizing promising instructional practices (Ma, 1999).

Contextual support for subtracting fractions. PTs' ability to write story problems reflects their "mathematical content knowledge and literacy, which can be classified into a hierarchical system of performance levels and indeed the highest level of mathematical literacy should include a contextual application and an understanding of mathematics" (Luo, 2009, p. 85). However, Dixon et al. (2014) found that many PTs in the United States were unable to provide contextual support for subtracting fractions and experienced significant difficulty writing sensible fraction story problems for given operations. In their research, Dixon et al. (2014) used examples of fraction subtraction problems to argue that knowledge of how to subtract fractions efficiently and accurately is not enough to teach subtraction of fractions efficiently because many PTs do not have a conceptual understanding of either fractions themselves or of the subtraction of fractions and are therefore unable to contextualize and decontextualize fractions subtraction 
problems. Several researchers have also found that preservice elementary teachers have significant difficulty in selecting an appropriate word problem for a given operation (Luo, 2009; see also Ball 1990a, 1990b). In particular, in order to teach fraction subtraction PTs need to know why the subtraction algorithm works, so that they can links the algorithm to appropriate representations, can write word problems for fraction expressions, and can choose an appropriate word problem for a given symbolic expression (Dixon et al., 2014). However, PTs have been found not to exhibit characteristics of making sense of fraction subtractions. In their study, Dixon et al. (2014) drew attention to PTs' errors in constructing story problem for fraction subtraction and to the importance of context and problem structure. For example, in their research, each participant interviewed was asked to write a word problem for $\frac{4}{5}-\frac{1}{2}$ using a situation involving pizza. They were then asked to write a word problem for $\frac{5}{6}-\frac{1}{3}$ using a situation involving gallons of iced tea. They reported that 8 out of 9 PTs incorrectly interpreted the operations. They made similar errors in the sense that their responses had the same structure (Result Unknown), and were unable to represent the quantities in their story problem as the same size whole or unit amount. Instead of keeping the whole constant throughout the subtraction problems, they had represented minuend as part of a whole and the subtrahend as a part of the part. But only one student used the Compare (Difference Unknown) structure to answer both questions.

Similarly, McAllister and Beaver (2012) conducted a study of 72 PTs who were given some fractions operations tasks. Two of the problems were, $\frac{1}{2}-\frac{3}{7}$ and $4 \frac{1}{2}-1 \frac{3}{4}$. For the first problem, only nine PTs could construct appropriate story problems. A typical example offered by the students was "Jane had only $\frac{1}{2}$ of a cookie to give to Jake. If Jake ate $3 / 7$ of that piece of cookie, how much cookie was left over?" (McAllister \& Beaver, p. 2012). That example was 
typically a common mistake of representing the minuend as part of a whole and the subtrahend as a part of the part. Sixty percent of the PTs' errors were made because the PTs wrongly interpreted the fraction operation and wrote a word problem for $a-(a \times b)$, instead of writing a word problem for $a-b$. By contrast, 48 of the 72 students gave correct examples for a mixed numeral subtraction problem. But, the research does not provide answers to why PTs did better on mixed numeral problem than on other fraction operations.

Contextual support for multiplying fractions. Luo (2009) conducted a research study involving 127 preservice elementary teachers who were enrolled in an undergraduate early childhood and elementary education program in the United States of America. All the participants were beginning a mathematics methods course and had already taken classes in whole number operations and in fractions operations. One of the instruments asked participants to find the values of $\left(1 \frac{2}{3} \times 4\right.$ and $\left.\frac{1}{2} \times \frac{1}{3}\right)$, and then to create corresponding word problems. Data analysis revealed that a significant percentage of preservice teachers were unable to construct appropriate word problems for the given multiplication tasks. The percentage of PTs' who correctly represented $1 \frac{2}{3} \times 4$ was $75 \%$ and for $\frac{1}{2} \times \frac{1}{3} 0.37$. For example, one of the incorrect responses, leveled as "poor" according to the grading rubric, was written, "Jo made brownies and split the pan in $\frac{1}{2}$ for his sister. She ate $\frac{1}{3}$ of the $\frac{1}{2}$ of her part. If you took the total pan how much did she eat?" (p. 97). However, this story problem does not actually correspond to " $\frac{1}{2} \times \frac{1}{3}, "$ rather it corresponds to " $\frac{1}{3} \times \frac{1}{2} \times \frac{1}{2}$." An example of a sample story problem, which was regarded by the author as logically and contextually correct, and clearly and coherently described, was "Mary had $1 \frac{2}{3}$ pieces of pie. Joe had 4 times as many pieces. How many pieces of pie does Joe have? (p. 98). In addition, PTs's sematic structures were limited. Their semantic 
structures for this first problem were categorized into "repeated addition," "multiplicative comparison," "other structures," and "none" if the PTs did not write a word problem. The semantic structures for the second problem were categorized into "multiplicative comparison," "equal sharing of a fraction," "part of a fraction," "other structures," and "none." Units of measure are also limited to food-related objects. In this research, earlier conjectures about PTs' difficulty in constructing a story problem without a whole number factor than a whole number factor were confirmed. This is because PTs may not possess mathematical content knowledge associated with fraction and the required knowledge needed to construct story problems (Luo, 2009).

The other most common error among PTs was the multiplication-specific error, that occurred when PTs wrote a word problem for $a+b$, instead of writing a word problem for $a \times b$. For example a student wrote (for $1 \frac{2}{3} \times 2 \frac{3}{5}$ ), "Sam baked cookies. He ate $1 \frac{2}{3}$ of them. Sharon then ate $2 \frac{3}{5}$ of the cookies she made. How many cookies did they eat?" The operation required to solve this is addition instead of multiplication" (McAllister \& Beaver, 2012). Ten percent of the PTs could not write solvable problem for the first problem and 57\% for the second problem.

Contextual support for dividing fractions. Division of fractions "is often considered the most mechanical and least understood topic in the elementary school" (Tirosh, 2000, p. 6; see also Payne, 1976). The task of representing fractions division through either word problems or pictorial diagrams is challenging even for those highly proficient in elementary and middle school mathematics. Ma (1999) concluded, based on her findings of the pedagogical content knowledge of U.S and Chinese elementary teachers, that a group of 23 U.S. elementary teachers had weaker procedural knowledge of fraction division than a group of 72 Chinese teachers, particularly in relation to contextualizing $1 \frac{3}{4} \div \frac{1}{2}$. In her study, none of the U.S. teachers could 
accurately create a corresponding fraction division story problem. Six of them could not create a story at all, and the other 16 teachers made up stories which did not correspond to $1 \frac{3}{4} \div \frac{1}{2}$. Of the 16 U.S. teachers who displayed misconceptions in their stories, 10 of them generated common stories using phrases "divide evenly between two" or "divide into half" that corresponded to division by 2 , not division by $\frac{1}{2}$ (Ma, 1999). The other six teachers used a phrase "take half of the total" in their stories, which confused dividing by $\frac{1}{2}$ with multiplying by $\frac{1}{2}$ (Ma, 1999). An, Kulm, and Wu (2004) also conducted a cross-cultural comparative study, and found that the U.S teachers (in a study designed to investigate the pedagogical content knowledge of U.S and Chinese teachers) were much more likely to emphasize algorithmic processes and much less likely to create story problems than their Chinese counterparts if asked to help their students understand fractions. Simon (1993) found that 70\% U.S PTs in his research were not able to create contextually correct division story problem suitable for middle grade students. In his research, fewer preservice elementary teachers were able to come up with mathematically and contextually correct word problems that would match the given fraction arithmetic expressions, and that was especially true when the divisor was a fraction less than 1.

Many researchers have identified five major problem structures for fraction divisions that can guide studies on how to write story problems, based on the two types of division meanings: measurement and partition. The five problem solutions are "(1) equal-group measurement division, (2) equal-group partition division, (3) comparison measurement division, (4) comparison partition division, and (5) rectangular area division (Lo \& Luo, 2012). Division problems embedded in equal-group measurement division and equal-group partition division structures deal with a certain number of groups, all of equal size. Comparison problems deal with multiplicative comparison situations; one set involves multiple copies of the other. In 
rectangular area problems, the multiplication product consists of a two-dimensional unit, such as a length by width unit for the product of area.

\section{Models}

Petit, Laird, Marsden, and Ebby (2015) explained in their book titled, A Focus On Fractions, that the three different types of models which student most commonly use to solve problems related with fraction concepts and operations involved area models (regions), set models (sets of objects), and number lines. They stated that with the area model, the whole is determined by defined region, such as geoboards, grids, or pattern blocks, and the fraction in the area model indicates the covered part of the whole. By contrast, with the set model, the whole is determined by what is in the set and the equal parts are defined by the equal number of objects and therefore, the fraction indicates the number of objects in the subset of the defined set of objects. In number line also the whole is determined by the unit of distance or length (continuous) and the equal parts are defined by the equal distance and the fraction indicated the location of the point in relation to the distance from zero with regard to the defined unit.

The key difference between a number line, and the other two models, an area model, and set model, is described by Bright et.al. (1988). First, a length represents the unit, and the number line model suggested not only iteration of the units but also simultaneous divisions of all iterated units. Second, the model is continuous, and it has no consecutive visual or physical separations between the units. However, both sets and regions models possess physical separateness. Third, a number line uses symbols to convey part of the intended meaning. The number line requires an integration of two forms of information, visual and symbolic; this integration does not seem essential with other models. Bright et al. (1988), investigated ways how students accurately and inaccurately represent fractions on a number line and the influence of instruction on their 
representation skills, they identified four specific objectives of fraction representations on number line: “a) associate whole numbers to fractions and mixed numbers with points on a number line, $b$ ) use number lines to connect improper fraction names to mixed numbers with points on the number line, c) use number lines to determine which of two fractions is less or whether they are equivalent, and d) use number lines to generate equivalence fractions" (Bright et al., 1988, p. 217). They recognized that number lines are very important in number-sense development because they represent the set of real numbers.

\section{The Use of Models in Classroom}

The use of concrete models and pictures is important in mathematics classroom because models can help students visualize and explore a mathematics concepts deeply, to connect learning with their experience (An, Kulm, \& Wu, 2004), and help them explain their solution strategies efficiently. In general, the use of models and pictorial representations is also a common theme in U.S elementary mathematics textbooks and is mostly noticeable in fraction instruction (Reys, Lindquist, Lambdin, \& Smith, 2007). At the same time, educators are also required "to connect fundamental concepts to a variety of situations, models, and representations" (Conference Board of the Mathematical Sciences, 2001, p. 56), and to link their students' learning with their experience. In fact, teachers in the United States emphasize a variety of activities designed to promote creativity and inquiry in attempting to develop students' understanding of mathematical concepts (An, Kulm, \& Wu, 2004). Cai $(2000,2004,2005)$ found that U.S. teachers have a tendency to use more concrete models and pictures to foster students' understanding than their Chinese counterparts, though representing fraction operations, particularly division, through pictorial models is very difficult and challenging even for those people who are proficient in elementary and middle-school mathematics (Lo \& Luo, 2012). The 
difficulty of representing fraction operations in pictorial or verbal form may be noticeable in mathematics learning and teaching because "the transitions from concrete (hands-on), pictorial, verbal, symbolic representations to such as a number sentence is often addressed, but the discussion on inverse transitions from a symbolic representation to visual, or verbal representations is limited" (Luo, Lo, \& Leu, 2011, p. 175). However, students who experience a variety of ways, such as visual models and written words, to represent fractions and are asked to move back and forth between them develop more flexible understanding of fractions (Lesh, Landau, \& Hamilton, 1983).

Marchionda (2006) concluded that PTs' inability to set up and solve a simple application problem using a picture indicated their lack of conceptual understanding of fraction concepts and operations. In her research, she found that not only were the mean scores for two division problems, which were given to the PTs, lower than the mean scores for the addition problems, but the PTs also had difficulty with both kinds of fraction operation problems (addition and division) when it came to drawing pictures and explaining how their pictures show their solutions. She also found the PTs displayed better fraction knowledge on procedures than on conceptions, and performed differently on fraction addition and division tasks. As far as procedural and conceptual knowledge were concerned, Marchionda (2006) asked, the participants to solve two different application problems in two different ways. The participating PTs also had to decide what operation was required and then solve them by using algorithms and by drawing a pictorial model to represent their solutions. The first fraction operation problem was taken from Elementary and Middle School Mathematics: Teaching Developmentally by Van de Walle (Van de Walle, 2001). "Paul and his brother were each eating the same kind of candy bar. Paul had $\frac{3}{4}$ of his candy bar left. His brother still had $\frac{7}{8}$ of his candy bar. How much candy 
did the two boys have together?" (Marchionda, 2006, p. 70). This was an application problem that requires the skill to set up and solve the problem — but the meaning of the word "have" in the question might have made it harder for the students since it can mean at the start or after they had eaten what they had eaten. Only $37 \%$ of the PTs were able to set this problem up correctly and provide a complete algorithmic response. A complete answer should be written using a mixed number without units because of the contextual nature of the problem. However $17 \%$ of the students used an improper fraction as their answers which made their solutions incomplete. The other 43 participants in the study ( $46 \%$ of all the participants) did not solve the problem correctly. Of these 43 participants, 11 did not set the problem up at all. One participant had the correct answer without any supporting work. The other 31 were able to set the corresponding addition problem up but then did not solve the problem correctly. Marchionda (2006) organized the breakdown of the PTs' flawed work or errors as follows:

- Nine (9.5\%) found a common denominator but added both numerators and denominators, another four (4.2\%) found a common denominator but made another error with addition or performed the wrong operation, and one more made a mistake finding a common denominator and then did not add;

- Six $(6.3 \%)$ did not find a common denominator but added both numerators and denominators and one (1\%) did not find a common denominator and multiplied numerators and denominators;

- Two (2.1\%) attempted to get a common denominator but failed and did nothing else, and one found a common denominator but did nothing else;

- Seven (7.4\%) answered the wrong question (how much they ate) (pp. 70-71). 
Solving the above problem using a picture caused even more difficulty to the PTs. Particularly, explaining their solutions strategies, so that their model would make sense to themselves and others, seemed to make the process more complicated. One possible correct solution could be to model $\frac{3}{4}$ and $\frac{6}{8}$ using separate individual pictures and then show or explain how $\frac{3}{4}$ and $\frac{6}{8}$ are equivalent fractions and why it was necessary to change $\frac{3}{4}$ to an equivalent fraction of $\frac{6}{8}$. This would then be followed by combining the two pictures to show an answer of $1 \frac{5}{8}$, with an explanation accompanying this step as well. However, not a single preservice teacher solved this problem with pictures and explained their solution strategies or process completely; all but 6 of them drew a picture to start the process. Sixteen participants made a mistake in drawing the initial fractions. Ten of these 15 drew different size units to represent the two candy bars. Each of these ten pictorial representations all implied that $\frac{1}{8}=\frac{1}{4}$.

Models for multiplication and division. Many PTs' understanding of the dominant problem models for multiplication and division of whole numbers might have led them to false ideas about the same operations with fractions (Graeber, Tirosh, \& Glover, 1989; Tirosh \& Graeber, 1989). Thus, PTs were found to make decisions on the type of operation required for a given story problem, based on whether a fraction was embedded in that problem. For example, PTs have a tendency to use division to solve the word problem: "The price of one bolt fabric is $\$ 12,000$. What is the cost of $\frac{3}{4}$ of the bolt?" However, they tended to use multiplication to solve the same story problem when $\frac{3}{4}$ is replaced with a whole number (Luo, Lo, \& Leu, 2011).

In Marchionda's (2006) study, the second fractions operation assessment question was a fraction division problem and PTs were asked to solve the problem in two different ways. Very few of the PTs displayed algorithmic competency; Furthermore, no preservice teacher came up 
with an appropriate pictorial representation accompanied by an acceptable explanation. Since the researcher thought that the PTs would find fractions division problem difficult to represent with a picture, she asked the participants to solve other questions in order to see if some type of questions were easier to solve than the others. The first question, in which a whole number was divided by a fraction and the answer was a whole number, was presented as follows: "Megan is making a necklace that will be 16 inches long. To make the necklace she strings a thin wire with $\frac{2}{3}$ inch beads. How many beads will she need to make the necklace?” (p. 78). Only 31\% (15 out of 48) of the PTs, who worked on this problem, set this division problem up and used the standard algorithm to solve it correctly. Most of the PTs who did not solve the problem correctly either did not show their work or made computational errors (e.g., difficulty in multiplying the fractions after inverting), or could not follow through their work after they set up division problems. It was also interesting to see that two PTs recognized how this problem could be solved using a repeated addition approach; however, one added up to only ten inches and the other person made several computational errors. There were only two PTs who gave a complete picture with clear explanation.

The other fractions division problem used by Marchionda's (2006) was a little more difficult than the previous one. This problem was also taken from Elementary and Middle School Mathematics: Teaching Developmentally by Van De Walle: “John is building a patio. Each section requires $\frac{2}{3}$ of a cubic yard of concrete. The concrete truck holds $2 \frac{1}{4}$ cubic yards of concrete. If there is not enough for a full section of concrete at the end, John can put in a divider and make a partial section. How many sections can John make with the concrete in the truck? (Van de Walle, 2001, p. 239)". The problem was administered to 46 preservice teachers. Based on the results, this problem was more difficult for the participants than the previous one, with 
only $11 \%$ of the PTs (five of the 46 ) applying their procedural knowledge appropriately and correctly to provide a complete solution to this problem. The breakdown of PTs' wrong solutions were organized by Marchionda (2006) as follows:

- Two set the problem up as division, found a common denominator but did not divide;

- Three set up the problem correctly but instead of leaving the answer as an improper fraction or changing the number to a mixed number all three used long division to change the improper fraction to a decimal and did not get an exact answer;

- Four set the problem up correctly, found common denominators but got $3 \frac{3}{12}$ as an answer instead of $3 \frac{3}{8}$;

- Three set the problem up as $\frac{9}{2} \div \frac{2}{3}$. After working this problem out and getting an answer of $\frac{8}{27}$, one participant then set the problem up correctly but stated, “Don't know how to divide $2 \frac{1}{4}$ by $\frac{2}{3}$ to get a whole number answer;

- Three tried the problem as either repeated addition or repeated subtraction but were unable to get the correct answer;

- Two set the problem up correctly but made a mistake in changing $2 \frac{1}{4}$ to an improper fraction. (pp. 81-82)

This problem was more difficult for the 46 PTs, who attempted to solve it than the necklace problem, particularly the part of it which asked them to use pictures to represent their solution. Of the 46, 32 did nothing else except draw a circle or a rectangle in order to represent one or more of the initial fractions, which is an evidence of over-emphasis, in the past, on naive area-model approaches. Eleven of the PTs did not even attempt to draw a picture. Only $8 \%$ of the students seemed to have the basic idea of how to use a picture to solve the problem, but even 
these students did not come up with the correct solution. One possible solution is to draw $2 \frac{1}{4}$ rectangles and divide them into thirds. There are $\frac{2}{3}$ or $\frac{8}{12}$ in each whole with one third left. If there are two wholes, then there are three two-thirds with $\frac{1}{4}$ or $\frac{3}{12}$ left. One-fourth or $\frac{3}{12}$ is threeeighths of eight-twelfths. So, the solution is to the problem is $3 \frac{3}{8}$. The area model might be an unnecessary complex approach since the question has nothing to do with rectangles. But it can be one way to solve the problem with a picture. Otherwise, it would be better to model the problem with a line-interval, since the problem is about a necklace. Nonetheless, most of the PTs expressed their frustration for having to draw a picture for the division problem.

\section{Models: Cross-Cultural Comparative Studies}

Research has consistently showed that many PTs in the United States of America are weak in their knowledge of fractions (e.g., Simon, 1993) and a review of many cross-cultural comparative studies have also reported the challenge that PTs face when understanding fraction concepts and operations. Reports on these studies provide specific suggestions for improving PT's knowledge of fraction concepts and operations (Luo, Lo, \& Leu, 2011). In research conducted by Luo, Lo, and Leu (2011) to investigate the similarity and difference between 89 U.S and 85 Taiwanese elementary PTs' basic fractions knowledge, the PTs in both countries found it difficult to establish meaningful understandings of what they are doing. Choosing a picture which could not be used to model the fraction multiplication question, $\frac{3}{4} \times \frac{4}{5}$ or $\frac{4}{5} \times \frac{3}{4}$, was the most challenging problem on the test for both the U.S. and Taiwanese elementary PTs, with a mean score of $19.1 \%$ and $23 \%$ correct for the two groups, respectively. Choosing the model that would not represent the symbolic expression instead of the model that would, might have confused some of the preservice elementary teachers. However, a supplemental discussion 
of this problem with the PTs revealed differences in preservice elementary teachers' understanding of fraction operations. Many preservice elementary teachers in Taiwan and the United States saw that the whole for $\frac{4}{5}$ could be represented as a rectangle containing 5 parts, while the whole for $\frac{3}{4}$ would be represented by a smaller rectangle containing 4 parts. They did not understand that the whole for $\frac{4}{5}$ and $\frac{3}{4}$ should be drawn to the same size - this is the same as saying that the wholes for $\frac{4}{5}$ and $\frac{3}{4}$ should be the same when they are not. For example, the whole for $\frac{3}{4}$ (in $\frac{3}{4} \times \frac{4}{5}$ ) is $\frac{4}{5}$. These preservice elementary teachers focused on just representing each fraction in the number sentence but ignored the embedded operation. For them, the rectangular pictorial model for $\frac{3}{4}+\frac{4}{5}$ would look exactly the same as $\frac{3}{4} \times \frac{4}{5}$, except having a different operation sign in the middle. This type of modeling does not contribute to the conceptualization of possible solution strategies. This may be a difficult aspect of fractions operations which needs additional attention in both countries.

Lo and Luo (2012) found that preservice elementary teachers have difficulties in representing fractions by word problems or pictorial diagrams. Their research focused on the importance of the mathematics knowledge for teaching fraction division to Taiwanese PTs. Their results illustrated that fractions are a very difficult topic for many PTs and $\mathrm{K}-12$ students (Behr et al. 2000; Lamon, 2007). Lo and Luo (2012) concluded that a solid understanding of fractions, as part of a rational-number reasoning, is needed for learning algebra (National Mathematics Advisory Panel, 2008), and that fractions division involving unit fractions is the foundation of all fraction-related skills and concepts (Behr et al., 2000; Lamon, 2007). Lamon (2006) argued that failure to understand the importance of the unit will delay the development of fraction concept in students. Lo and Luo's (2012) research provided evidence that many 
Taiwanese PTs have developed the kind of fractions division knowledge described by Ma (1999), in her research which revealed the rich description of the Chinese elementary teachers' knowledge of fractions division. Ma (1999) described a sequence of the knowledge package of division by fractions that goes from the meaning of addition, to the meaning of multiplication with whole numbers, to the meaning of multiplication with fractions, to the meaning of division with fractions. Lo and Luo (2012) stated that Taiwanese PTs' strategies can serve as a benchmark for common content in fractions division that can be incorporated in prospective elementary teachers' mathematics courses in other countries.

Studies conducted in the United States and Australia have also found that PTs experience difficulties in carrying out the fraction division algorithm (Rizvi \& Lawson, 2007) and to solve word problems which involve the division of fractions (e.g., Borko et al., 1992; Newton, 2008; Rizvi \& Lawson, 2007; Young \& Zientek, 2011). Only 7 out of the 17 Australian prospective teachers in the Rizvi and Lawson (2007) study were able to associate the problem, "It takes $\frac{3}{8}$ of a bottle of milk to fill a large glass. How many of the glasses can be filled with 40 bottles of milk" as a fraction division of $40 \div \frac{3}{8}$," and on several occasions, PTs handled the problem of division of a fractions, in tasks like, $\frac{1}{4} \div \frac{1}{2}$, as if it was division by whole number such as $\frac{1}{4} \div 2$. The average percentage of correct response for 85 US prospective elementary teachers on simple fractions division computations such as $4 \div \frac{1}{4}$ or $29 \div \frac{2}{9}$ was $64 \%$ on the pretest (Newton, 2008).

Some students thought that $4 \div \frac{1}{4}$ must equal 1 , perhaps noticing that 4 and $1 / 4$ were reciprocals, so that they assumed the quotient should be 1 . Or perhaps they were not sure of what to do when whole numbers and fractions were being divided because they thought the denominators and numerators switch places (Newton, 2008). 
$\mathrm{Li}$ and Kulm (2008) found that none of the 46 middle school PTs participants in their study were able to explain why the division algorithm "flip and multiply" worked. In a study that was conducted at an Australian university, 10 of 17 PTs used the "invert and multiply" algorithm for the expressions involving division of fractions (Rizvi \& Lawson, 2007), such as problems like, $\frac{1}{4} \div \frac{1}{2}$ and $\frac{1}{5} \div \frac{1}{2}$. It appeared that most of the participants were not familiar with the repeated subtraction model. None of the PTs used another algorithm to solve these problems and none were able to explain the thinking that lies behind "invert and multiply" algorithm (Rizvi \& Lawson, 2007). Only five participants were being to represent these expressions semantically and pictorially using the repeated subtraction model

Clearly, division of fractions is taught mechanically to many students in parts of world and many students and teachers learn simply "flip and multiply" or "invert and multiply" without being aware of the relationship between the division algorithm and the underlying mathematical concept (Rizvi \& Lawson, 2007). PTs often focus on memorizing, practicing and remembering rules and on mastering standard procedures, and do not exhibit in-depth understanding of mathematical ideas and procedures in making sense of problems on fractions concepts and operations (Ball, 1990a). Furthermore, preservice mathematics teachers' understanding of fractions division is fragmented because they cannot retrieve forgotten rules without the conceptual knowledge to support them to do so. Only few of them are able to provide mathematical explanations for underlying reasons and meanings (Ball, 1990b). However, few would deny that PTs should learn to understand the property that every non-zero real number has a multiplicative inverse. It is, therefore, very important that they learn to make sense of the of "invert and multiply" rule of fractions division. 
The study by An, Kulm, and Wu (2004) shows that there are differences in the ways U.S. and Chinese teachers draw students' attention in mathematics learning. Most U.S. teachers suggested engaging and motivating students to learn the procedure of multiplication through various activities, such as manipulatives, and pictorial representations. In their responses to the question which asked both the U.S and Chinese teachers about their preference whether they would use repeated addition, area, or both combinations to illustrate fraction multiplication to their students, $64 \%$ of the U.S. teachers would prefer to use one representation - area- to illustrate fraction multiplication, but $67 \%$ of Chinese teachers use two representations - area and repeated addition. However, in the An, Kulm, and Wu's (2004) study, only $4 \%$ of responses of U.S. teachers showed examples which connected concrete models or manipulatives to the procedure of multiplying fractions. Most of the teachers failed to make such connections between concrete models and abstract thinking and the lack of this knowledge hindered them, in the sense that they do not learn the information needed to help students to use manipulatives as ways which would help the students to understand fractions multiplication.

\section{Summary}

This chapter has provided a synthesis of research, including scheme theory (Steffe, 2002) that helps PTs to study complex cognitive competences and activities, like fractions, and how this fraction knowledge can develop through experience and learning (Vergnaud, 1996) to a more sophisticated, more extensive, more generalized approach that allows students to think and reason in fractions. Clearly, these frameworks could throw light on how the hypothetical learning trajectories, like the one that informed the instruction experienced by the PTs in this study, might best be constructed and organized. This chapter also provided an overview of the meanings of rational numbers that involve a rich set of distinct and integrated subconstructs and 
processes, such as part-whole, quotient, measure, and operators (Behr, Lesh, Post, \& Silver, 1983) which informed my study of PTs' knowledge and issues of fraction concepts and operations, and of ways to support the development of this knowledge.

Within rational numbers, the literature review focused on several concepts that aid students' development of an understanding of the rational number subconstructs (Lamon, 1996), which include partitioning, unitizing, equivalence, and comparing and ordering. Next, students' thinking and their fraction concepts and operations learning and misconceptions were discussed. For example, how can we assist students' whole number intuitive partitioning strategies to transfer to general conceptions of fractions and to their intuitive strategies for understanding fraction order, equivalence, and part-whole were reviewed. This was followed by a discussion of fraction operations that highlighted how students could build on their informal partitioning strategy to solve a variety of fraction problems, including the more complex ones, such as subtraction problems with regrouping and converting mixed numerals and improper fractions (Mack, 1990), and how they were able to draw on their informal knowledge to partition a composite unit into a specific number of parts, solve different types of problems involving the multiplication of two proper fractions, and reconceptualize and partition units in a variety of ways (Mack, 2000). All of these activities could be related to, for instance, the candy bar and Charlie problems of my study. The chapter concluded with an overview of PTs' knowledge of fractions and models for addition, subtraction, multiplication, and division.

Knowledge of multiple representations are important as students who are able to represent fractions in multiple contexts as well as translate among various representations develop a deeper understanding of the content since students who experience a variety of ways, such as visual models and written words, to represent fractions and to move back and forth 
between them, develop more flexible understanding of fractions (Lesh, Landau, \& Hamilton, 1983, Post et al., 1993). As representations which include area, linear, and set models are grounded through the tools used to represent each model and used as a way for students to represent a solution and solution process (Tobias, 2009) in the study, they were reviewed in this chapter. Reports on many cross-cultural comparative studies that investigated the challenges that PTs face when attempting to understand fraction concepts and operations, and specific suggestions for improving PT's knowledge of fraction concepts and operations (Luo, Lo, \& Leu, 2011) were also examined. 


\section{CHAPTER III: METHDOLOGY}

\section{Theoretical Framework}

\section{Emergent Perspective}

In this study, I used Cobb and Yackel's (1996) emergent or social constructivist perspective to document the classroom mathematical practices that became 'taken-as-shared' during an introductory mathematics content course for PTs. I used this framework because the emergent perspective (a) supports the psychological constructive perspective, which is a theoretical basis to analyze individual students' constructive activities and learning in social contexts, (b) is an appropriate approach to bridge individual students' activities and the classroom community, (c) is an approach that helps researchers account for (interpret) individual students' mathematical learning as it occurs in the social context of a given classroom, and (d) supports the documenting of students' development in a "socially-situated" classroom environment (Simon, 1995).

The social and psychological perspectives. The emergent perspective has two focithe social and the psychological. The social perspective refers to an interactionist theoretical perspective on communal or collective classroom process, which is characterized by "communicative discourses where students are actively involved in the form of mathematical argumentation in which their explanation, justification, and elaboration are the most essential features" (Wood, Cobb, \& Yackel, 1993, p. 59). The psychological perspective refers to a psychological constructivist perspective or individual students' activity as they participate and contribute to the development of the communal classroom community (Cobb \& Yackel, 1996).

Cobb and Yackel's (1996) proposition of the emergent perspectives can coordinate analyses of classroom process which are conducted and controlled in psychological and social 
terms. Their theoretical perspective uses "the complementary nature of the constructive and socio-cultural points of view" (Teppo, 1997, p. 3), which I used to study the mathematical learning of fraction concepts and operation as it occurred within the social context of a classroom. As their propositions emphasize the importance of both the psychological and social classroom processes, without giving priority to either one, the development of individual meaning and the development of social meaning in this class was taken "as being reflexively related in that neither can exist independently of the other" (p. 4). Because they both are important in analyzing classroom mathematical activities, we are not able to deduce an individual's learning from social process or vice versa. Instead, individuals are seen to develop personal meanings as they actively participate in the ongoing negotiation of classroom community norms (Yackel, 2001). However, it should be understood that "the manner in which the teacher acts to direct and control the dynamics of the discourse strongly influences the opportunities for students to be active participants" (Wood, Cobb, \& Yackel, 1993, p. 59) and their engagement in a meaningful dialogue in which they can express their mathematical thinking and reasoning.

Classroom norms. The expectations and the agreements that are established in a given classroom are classroom norms. "Norm is a sociological construct and refers to understandings or interpretations that become normative or taken-as-shared by the group. Thus, norm is not an individual but a collective notion" (Yackel, 2001, p. 6). In analyzing the teaching and learning that occurs in the classroom, it is important to take into account the classroom norms, the social aspects of learning, including social interactions (Cobb, Yackel, \& Wood, 1989; Yackel, 2001), which are particularly relevant to the issues of explanation, justification, and argumentation. Constructs which relate to mathematical explanations and justifications are both social and 
sociomathematical norms in nature. In this study, classroom norms were understood as collective mathematical thoughts and refer to explanations, interpretations, justifications, or understandings that become taken-as-shared by the classroom community (Yackel \& Cobb, 1996). In addition, the norms were understood as the constructs which clarified how we might think of the explanation, justification, argumentation and the PTs' progression in the course. Particularly in this study where understanding and sense-making were the focus of the instruction.

Social norms. Social norms are interactively negotiated by the teacher and the students. They describe the expectations and the role of both the teacher and students to accomplish an explicit goal in the class room. Though social norms are established from the beginning of the course, they are continually negotiated and renegotiated through the course both by the teacher and students (Cobb, Wood, \& Yackel, 1993).

Negotiation of classroom social norms in this study was an important feature because the professor required the PTs to articulate their own understanding, explain and justify their solutions, and make sense of explanations given by other members of the classroom during whole-class discussions. The practice of the negotiation of social norms, which was initiated and guided by the professor, might run against PTs' prior experiences in mathematics classrooms. By analyzing data from my coded transcripts, I was able to identify a number of social norms that characterized the classroom interactions. However, the emergent perspective in this research was used to support documenting the evolution of the class social norms, not individual PTs' knowledge and beliefs on fraction concepts and operations.

Socio-mathematical norms. Sociomathematical norms are specific to mathematics classrooms and include determining what counts as an acceptable mathematical explanation and 
as a different, efficient, and sophisticated mathematical solution. In this study, I used Cobb and Yackel's (1996) frameworks for documenting sociomathematical norms during the class. Analysis of the PTs and the classroom teacher interactions had made it clear what would constitute a mathematical difference when the professor and other elementary PTs accepted some of the contributions but not others. "In responding to the teacher's request for a different solution, the students were both learning what counts as a mathematical difference and helping to interactively constitute what counts as a mathematical difference in their classroom" ( Cobb \& Yackel, 1996, p. 179). This informed me what counts as fractions knowledge of the PTs and what counts as change in their understanding of fractions.

In general, the social and sociomathematical norms came from Cobb and Yackel (1996) which highlight the understanding that PTs are expected to explain and justify their solutions and their ways of thinking is a social norm, whereas the understanding of what counts as an acceptable mathematical explanation is a sociomathematical norm. Similarly, the understanding that PTs should offer solutions different from those already provided by other PTs is a social norm, whereas the understanding of what constitutes mathematical difference is a sociomathematical norm.

Classroom mathematical practices. The emergent perspective helps to talk about the mathematical development of the classroom community as well as individual students. For instance, in the study, the norm of understanding various solution methods that involve fraction concepts and operations was established as a mathematical practice at the beginning of the first few class sessions of the fraction lessons. For example, some of the PTs were able to develop solutions that involved the use of manipulative sets (pattern bocks) to represent a single fraction in different ways and the idea to define a single fraction in infinitely many ways. When they 
performed this, the PTs were obligated to explain and justify their interpretation of equivalent fractions. Later, solutions based on such interpretations were taken as self-evident by the classroom community and had "become an established mathematical practice that no longer stands in need of justification ... can be seen to constitute the immediate, local situations of the students' development” (Cobb \& Yackel, 1996, p. 180). However, individual PTs explanations and justifications could make it possible for a certain group of PTs and may have been inadequate to others or this was not the case for them. So, taken-as-shared does not mean that everyone understands. Although it appeared that several mathematical practices became takenas-shared by the class, this does not necessarily mean that the mathematical ideas were taken-asshared by every preservice teacher (Rasmussen \& Stephan, 2008) as “individual students” development may not follow the same route of development as the whole class" (Tobias, 2013, p. 102).

\section{Socio-Cultural Theoretical Perspectives}

The sociocultural theoretical perspectives "treats intellectual development and the process by which people become increasingly substantial participants in various cultural practices as aspects of a single process" (Cobb, 2007, p. 22). Of course, the central issue here is understanding how the PTs deal with tensions they experience when different practices in which

they have participated are in conflict. In this case the conflict was their past practices of learning fractions in school and those established in this course. The material and resources they used in this course were different. The formal and informal assistance they drew up on varied. However, "sociocultural theory provides only limited guidance because the classroom process on which design focuses are emergent phenomena rather than already established practices into which students are inducted" (Cobb, 2007, p. 24). Nevertheless, it still makes significant 
contribution when comparing the mathematical reasoning the PTs brought into the course with them and the course classroom practices. In addition, the conflict in individual students' mathematical reasoning and interpretations might give rise to internal cognitive conflicts which would prompt mathematical learning (Cobb \& Yackel, 1996).

\section{The Theory of Conceptual Field}

The theory of conceptual field also promotes the PTs fractions sense-making development since the design of the instruction in this study is informed by the theoretical perspectives that support the contribution of the knowledge that PTs bring to classroom in the development of initial mathematical practices regarding the learning of fractions. Since the theory of conceptual field provides a comprehensive framework for studying complex cognitive competences and activities, like fractions, and their development through experience and learning (Vergnaud, 1996), it supports an instructional sequence which is composed of instructional tasks designed to promote fraction concepts and operation learning by identifying effective tasks that promote the learning of PTs at each level. Cognitive competences and activities are required to "face both routine situations that do not need some former knowledge, routine stations (problems) that do demand some new combination of former knowledge and ultimately some construction of former knowledge or discovery of new knowledge" (Vergnaud, 1996, p. 219).

This theoretical perspective helped me to investigate prior conceptions. It is a theoretical framework that helps to investigate the structure of the concepts created and described its level of conceptualization. This is the transformation of a concept in the form it is taught to the form it is conceived by the learners. Learning situations must be organized to build on students' available schemes, promote the next scheme in the sequence, and then link to mathematical 
concepts. The framework establishes the link between situations and schemes, organize hierarchical cognitive tasks, and, document long-term development of students' competences and conceptions. Particularly, in this research it helps to conceptualize how PTs' prior knowledge as a resource from which new and more advanced knowledge can be built and taken as shared in collective classroom activity.

Many students began with unsophisticated understandings of a variety of mathematical concepts that were severely limited in nature and very different from those that are needed for developing an understanding of several sophisticated and structured content domains (Mack, 2001; see also Behr et al., 1992; Greer, 1988). However, some researchers suggest these limited initial understandings still play a critical role as learners seek to understand complex content domains, like fractions (Mack, 2001).

However, although students begin with something that appears to be unsophisticated, limited and context bound thinking (operational knowledge) in their fraction instruction, they can develop the concept of composite units, measurement units, and unit-of-units that create flexible, efficient, and generalizable fraction strategies. They can develop techniques for comparisons so that they can judge relative size of fraction numbers. Using conceptual field's framework that interact with each other helps them to build these fractions concept. Obviously, they need sufficient time in the interpretation of different fraction concepts, without being given rules, so that they can develop fraction sense, sophisticated fraction thinking, and reasoning. Spending an extended amount of time with concrete models is also equally important (Cramer \& Henry, 2002). Yet, "a more significant factor in overall success, no matter where the child was placed, was the development of the central multiplicative structures" (Lamon, 2007), that leads them to 
develop a more sophisticated, more extensive, more generalized approach to think and reason in fractions.

\section{The Domain of Fractions Concepts and Operations}

Within the domain of fraction concepts and operations it is important for preservice teachers to have deep content understandings for all topics. For example, as part of one of the most important areas of preservice elementary teachers' knowledge of fractions operations, PTs are required to develop a deep understanding of the different interpretations of fractions operations. This creates one type of domain specific framework that relates to my use of the emergent perspective because it facilitates systematic inquiry of interpreting fraction concepts and operations. It can help to create learning contexts that students can use to explain and justify their interpretations of fraction concepts and operations in a way that will later become established mathematical practices which no longer stand in need of justification and can come to represent mathematical truth in the classroom.

Four of the five subconstructs of rational numbers (Lamon, 2007) on which the class focused were: part-whole, quotient, operator, and measure. These can be related to learning contexts from which the PTs might gain understanding into the essential nature of rational fraction numbers. These are sub-constructs in which important mathematical ideas about fractions are grounded in real phenomena. They can be used to define and assess PTs' fractions knowledge, and can help the PTs to recognize not only meaning, but also how to associate each meaning with appropriate situations, and operations. In general, these are the constructs that can help students "to develop insight, comfortability, and flexibility in dealing with rational numbers" (Lamon, 2007, p. 636). 
Understanding a fraction as a number involves realizing the same relative amount of a single rational number in different pictorial representation is important. Students in the class were required to get to know all the pieces in the manipulatives set, and relationships between sets, so that they would be able to identify the whole and the unit, when the whole was not always evident. This usually led to the discussions of equivalent fractions. Just as there are infinitely many ways to define the whole, there are also infinitely many ways to define fractions.

So, the five constructs - though I am not focusing on ratio in this research - help to develop PTs' understanding of multiple interpretations of fractions that involve slicing, cutting and slicing of a whole into equal parts, comparing different parts of a whole, and regarding fractions an operators.

\section{The Application of Emergent Perspective in My Research}

The emergent perspective served as part of my theoretical framing to examine how the content course activities and tasks of fraction concepts and operations shaped the elementary PTs through mathematical ideas that became "taken as shared." In other words, it helped me to document how the fraction concepts and operations knowledge were facilitated in the content course. The emergent perspective also helped me identify what mathematical ideas of fractions operations became taken-as-shared and which mathematical ideas of fractions became classroom norms. In this way, I was able to examine the social interactions in the classroom, which, I assumed, would be supporting the intended leaning processes for fraction concepts and operations sense-making. Accordingly, the emergent perspective helped me to treat and interpret the learning process of fraction concepts and operations of the class community in the course as being primarily socially active in nature. 
From a psychological perspective, the PTs had opportunities to "reflect on their own solutions methods" (Wood, Cobb, \& Yackel, 1993, p. 55) as they explained their thinking to other members of the classroom. In addition, the PTs were given the opportunity to "conceptualize their reasoning and thinking while they listen and try to make sense of each other's solutions" (Wood, Cobb, \& Yackel, 1993, P. 55).

Further, from a social perspective, the class discussions created opportunities to learn as the professor and the PTs negotiated mathematical meaning of the fraction concepts and operations "that would enable the PTs to make connections from their individual mathematical constructions with the taken-as-shared meanings of the classroom" (Wood, Cobb, \& Yackel, 1993, p. 56). In such discussions, it was possible for the PTs and professor to "interactively constitute a basis for mathematical communications that created opportunities for the teacher to guide the development of mathematical meanings that fit with those of the wider society" (p. 56). It helped me to document audio- and video-recorded individual students' interpretations, and actions, face-to-face interactions, and discourse in the classroom. It, indeed, supported my goal of investigating PTs' sense making of fraction concepts and operations.

Individual PTs also created meaningful mathematical ideas as they participate in challenging mathematical tasks. "People's reasoning is situated with respect to their participation in specific activities or practices" (Cobb, 2007, p. 6). So, I synchronized a social activity on communal learning with a psychological theoretical perspectives on individual diverse ways of learning as the PTs participate in those communal fraction concepts and operations activities in the classroom. This enabled me to document the collective mathematical development of the class on fraction concepts and operation tasks over the given period of time. It enabled me to document the developing mathematical learning and reasoning of fraction 
concepts and operations of the PTs as they participated in practices of the classroom community, and resulted in analyses that fed back to inform the improvement of instructional tasks (Cobb, Stephan, McClain, \& Gravemeijer, 2001).

Interpreting individual students' cognition, including their reasoning, highlighted the varied nature of the activities of the members of the class community and revealed the qualitative differences in individual preservice teacher's mathematical interpretations, even as they participate in the same mathematical practices (Cobb \& Yackel, 1996). So, I used cognitive psychology theory as part of the wider emergent framework. That permitted me to characterize the nature and quality of specific PTs' mathematical reasoning and learning on specific mathematical topic, fractions concepts and operations. I researched and interpreted how an individual preservice teacher successfully reorganized his/her activity and come to act in a mathematical environment and also how his/her act changes in the course of development. "Such research not only describes the nature of student's conceptions, it can also pinpoint mechanism for learning and causes for mislearning" (Battista et al., 2009, p. 222).

Besides "cognitive psychology becomes an adequate basis for both classroom instructional designs and pedagogical decision making" (Cobb, 2007, p. 21). Therefore, I applied Cobb's (2007) domain-specific framework of the learning process in a particular content domain and this engaged me in interpretation and analyses of the forms of mathematical reasoning that instructors wanted the students to develop. For in my analyses I identified "big mathematical ideas" in relation to fraction concepts and operations, and thereby gave an overall direction in my assessment of the instructional design of the course. The domain-specific framework could alert the instructor to major shifts in students' mathematical reasoning that the design should support. Besides, the domain specific framework could provide insight into 
specific PTs' mathematics learning, reasoning, and argumentation which informed the design of the instructional activities and tasks intended to support future lessons. For instance, fractions concept tasks were intended to support subsequent fractions operations sense-making tasks.

\section{Methods}

\section{The Content Course}

The content course which was the context for the present study is one of the first two required content courses that PTs take during their freshman or sophomore years and comes before the mathematics methods course that they take during their junior or senior year. The content knowledge in this course is designed around developing PTs' mathematical knowledge for teaching, which includes a focus on the development of both common and specialized content knowledge (Ball et al., 2008). The content of the course is intended to assist PTs in making-sense of problems and mathematical procedures involving place value, whole number, decimals, and fractions, and to provide PTs with opportunities to develop their abilities to engage in mathematical tasks central to teaching through working together with the other PTs in the class to make sense of the mathematical ideas and reasoning being used. For example, the course is designed to help them to develop flexibility in their thinking, use different representations such as symbols and manipulatives, make sense of the operations and the algorithms they use, and explain why the procedures they use make sense. A typical semester includes 30 class periods that are each 75 minutes in duration.

PTs in the course usually work in groups on "model-eliciting activities" during fraction concepts and operations lessons. The objective of the course was to create a classroom environment which encouraged the PTs to make an explicit mathematical interpretation to reason, to describe, to explain, and to justify when engaging in fractions tasks or solving 
mathematical problems which typically went through several refinements and possibly changes, through classroom discussions, comments, and feedback.

The tasks have been developed to reflect the primary aim of the course and contribute to the development of an inquiry-based learning environment within the course. Learning mathematics is to be seen as much more than merely memorizing and practicing rules_-it should involve reasoning, sense-making, and problem solving. Developing PTs mathematical knowledge for teaching, therefor, entails a different conception of what mathematics is and how it can be learned, an experience which may be different than what PTs have experienced during their previous mathematics coursework. For example, the PTs are expected to solve mathematics tasks using a variety of different methods — to think and to reason, to solve problems and then to share their mathematical thinking with others and not simply use one "right" method. PTs are encouraged to discover methods that make sense to them and which they can justify to others. Thus, part of the course design aimed to create a learning environment and a set of tasks and activities which require PTs to engage in these types of teaching tasks.

The content section of the fraction concepts and operations of course, which is the context of this study, was also designed to provide an opportunity for preservice teachers to develop deep conceptual understanding of fraction concepts and operations. The section on fraction concepts and operations comprised nine days of class followed by a unit test and was the second unit presented in the course. The professor with whom I collaborated and who is my advisor engaged her students in both collaborative small-group work and whole-class discussion of their mathematical interpretations and solutions.

The teaching and learning of fraction operations and concepts section in this course were structured using a hypothetical learning trajectory which was developed out of a combination of 
previous research with children's and adults' learning and understanding of fraction concepts and operations. The hypothetical learning trajectory incorporated five phases. The first three phases included work with fraction concepts of partitioning, unitizing, defining the whole, finding equivalent fractions, and comparing and ordering. The last two phases focused on the four operations with fractions.

\section{Hypothetical Learning Trajectories}

Over the last few decades, research on learning has focused on understanding of the learning process and the role of mathematical tasks in the learning process, and on how students think and reason, and how this thinking and reasoning changes and develops over time (Mojica \& Confrey, 2009). Some researchers have verified consistent findings related to this construct, which they have articulated in the form of learning trajectories which include:

Descriptions of children's thinking and learning in a specific mathematical domain, and a related, conjectured route through a set of instructional tasks designed to engender those mental processes or actions hypothesized to move children through a developmental progression of levels of thinking, created with the intent of supporting children's achievement of specific goals in that mathematical domain (Clements \& Sarama, 2004, p. $83)$.

While this has contributed to our knowledge base on how students learn, the mathematics education field has just began to explore the degree to which learning trajectories can be integrated into the practice of teaching or in the preparation of PTs (Mojica \& Confrey, 2009). Because, in learning trajectories, students are expected to be challenged with non-routine cognitively-demanding tasks that promote thinking, reasoning, and problem solving and teachers are required to select tasks that engage their students to think deeply about the concept being taught (Simon \& Tzur, 2004). The intention is to determine the goal and to create the tasks that are connected to thinking and learning. In this course, the instructor might have used the learning trajectories to guide the instruction in which the overarching topics are part of the 
curriculum. However, in this research, the learning trajectories helped me to figure out the order that the topics were taught and understand how PTs were able to make sense of successions of experiences and at the same time see clearly how their sense-making strategies progressively developed fraction concepts which would eventually lead to their understanding of the fractions operations. Thus, to understand how the PTs progressively develop concepts, I would like to focus on a hypothetical learning trajectory which includes all three aspects, (a) mathematical goal, (b) the developmental progression of specific fraction concepts and operations domain thinking and learning that the PTs advance through, and (c) the sequence of instructional tasks, which are key to the learning of important mathematical concepts of fractions and the impact of such transition from one level to another on students' learning (Simon \& Tzur, 2004).

"Hypothetical learning trajectories" include "the learning goals, the learning activities, and thinking and learning in which the students might engage" (Simon, 1995, p. 133). Clements and Sarama (2004) conceptualized learning trajectories as it stems from the inseparable interconnection between the psychological development progression and instructional sequence aspects which inform mathematics education. Three important aspects of hypothetical learning trajectories are included in the learning context of this research. First, the learning trajectories of the learning context of this research includes PTs' thinking, learning, and development models which are grounded in theoretical frameworks and empirical research results of fraction concepts and operations. Second, the learning trajectories of the learning contexts of this research includes the instructional sequence which is composed of instructional tasks designed to promote fraction concepts and operation learning at a particular conceptual level (by identifying effective tasks which promote the learning of PTs at each level). PTs should be encouraged to construct concepts and skills which characterize the next level of fraction concepts and operations. For the 
most part, results of research from children's concepts and operations of fractions were applied because of the limited amount of research that analyzes PTs' fraction concepts and operations thinking and learning (Olanoff, Lo, \& Tobias, 2014). Finally, the learning trajectories constructed in the learning context of this research can be reconceptualized as a sequence of taken-as-shared classroom mathematics practices which emerged through interaction (especially through classroom discourse- with practical involvement of the instructor).

A hypothetical learning trajectory "provides the teacher with a rationale for choosing a particular instructional design" (Simon, 1995, p. 135). However, more empirical works are needed if we are to understand how learning of the most difficult mathematical concepts, like fractions concepts, can be developed. Research on the learning of concepts (instructional sequences or transition from one level of activities to another) is necessary and lacking in many conceptual areas like fractions (Simon \& Tzur, 2004). The instructional sequence of the hypothetical learning strategies framework of this research developed from previous research on children's and PTs' understanding of fractions concepts and operations and its learning process (Mack, 1990, 1995, 2001; Olive, 1999; Steffe, 1992, 2002, 2003), which I incorporated in PTs and children's thinking section of my paper. I also used Tobias' (2009) initial hypothetical learning trajectory and instructional sequence from her dissertation on preservice elementary teachers' development of rational number understanding (see Table 1). 
Table 1

Initial Hypothetical Learning Trajectories

\begin{tabular}{cl}
\hline Phase & Main topic \\
\hline 1 & Define Fraction Based on Whole \\
& Compose and Decompose Fractions \\
2 & Unitizing \\
& Multiplicative and Additive Relationship of \\
& Equivalent Fractions \\
& Relational Thinking Comparing Fractions with \\
& Reasoning Ordering Fractions, Fraction Density \\
& Fraction Addition and Subtraction \\
& Fraction Multiplication and Division
\end{tabular}

(Tobias, 2009)

Tobias' (2009) hypothetical learning strategies (HLS) framework was also developed from the results of that research and incorporated several phases of learning in which the activities were designed so that the PTs would work with four of the five constructs (part-whole, measure, quotient, and operator) of rational numbers (Kieren, 1976). The tasks were also designed so that the PTs would work with contextualized situations first before being asked to solve problem out of context. Tobias (2009) used Wheeldon's (2008) learning trajectory which includes defining the whole, and "equal parts," and using fractions to name quantities, developing knowledge of how the number of parts in the whole relates to the magnitude of the denominator which help students to develop fractions properties - such as the larger the denominator the smaller the piece, reasoning strategies to order and compare fractions, 
developing procedural and conceptual understanding of adding and subtracting fractions, and developing procedural and conceptual understanding of multiplying and dividing fractions.

Tobias (2009) provided full descriptions of the five phases of the framework of the hypothetical learning trajectories. The initial hypothetical learning trajectory emphasized using fractions to name quantities or defining fractions based on a whole that includes "relational thinking, partitioning, modeling fractions, different interpretations and models of fractions, the concept of unit, and the relationship of the number of pieces in the whole to the size of the pieces" (Wheeldon, 2008, p. 105). PTs will be able model fractional amounts, given a fraction in symbolic form and vice versa so that they understand fractions are quantities that can be compared, ordered, and used in operations.

Also, understanding fractional parts in relation to the whole is a critical foundation that can also lead into students' understanding of other fraction concepts, such as relative magnitude, equivalence, and operation. However, the goal of the first phase of the hypothetical learning trajectory is to introduce the basic concept of fractions, that fractions should always be defined or understood or interpreted in relation to specified wholes, including fractions less than, greater than, and equal to one. Identifying the whole can be difficult for PTs as the whole is not always clear. For instance, the meaning of the fraction $\frac{2}{3}$ can differ depending on the nature of the whole: $\frac{2}{3}$ of a set of six hexagons - the whole in this case is the specified number of hexagons, which is six. Therefore, two-thirds of the set of six hexagons is four. However, we if say $\frac{2}{3}$ of a regular hexagon. The specified whole in this case is the hexagon. They can use a hexagonal visual model that shows $\frac{2}{3}$ of the hexagon region (which is four triangles) shaded and the remaining $\frac{1}{3}$ (two triangles) is unshaded. Alternatively, $\frac{2}{3}$ can also represent the distance from 0 
to $\frac{2}{3}$ on a number line. In this case, the whole is a defined length on a number line. In this case, two-thirds represents the distance from 0 to $\frac{2}{3}$ based on the length of the defined unit. To show fractions greater than one, for instance, if the whole is six hexagons, students can represent 9 hexagons as $1 \frac{3}{6}$ or $1 \frac{1}{2}$.

Moreover, in order to complete tasks that required comparing and ordering, students can modeled equivalent fractions by "partitioning the equal pieces into smaller pieces" (Wheeldon, 2008, p. 224). So, another goal of the first phase of hypothetical learning trajectory is to represent fractions in different ways using various partitioning strategies (Tobias, 2009). And Tobias (2009) used a pizza-sharing problem that requires students to divide 4 pizza among 5 people and showed students possible solutions, like $\frac{1}{5}+\frac{1}{5}+\frac{1}{5}+\frac{1}{5}=\frac{1}{2}+\frac{1}{4}+\frac{1}{20}$, by partitioning the pizza in different ways. That exemplifies an approach which can lead to a complete understanding of rational-number development through composition and decomposition processes. Alternatively, students can use pattern blocks pieces and a hexagon as a whole and find ways to make this whole out of different pieces. For example, they can use two trapezoids $\left(\frac{1}{2}+\frac{1}{2}\right)$ or they can use one trapezoid and three triangles $\left(\frac{1}{2}+\frac{1}{6}+\frac{1}{6}+\frac{1}{6}\right)$.

Once PTs have an understanding of how fractions can be represented in multiple ways, they can move to the next phase, which comprises two important fraction concepts. The first one, unitizes a three-step process. Step one includes decomposing of fractions into a set of unit fractions - that is to say fractions with a numerator one - which is a partitive unit fraction scheme by which students can establish as one part of a whole consisting of equal parts (Steffe, 2002; Tzur, 1999). After unit fractions are established, as Steffe (2000) highlighted, the next process includes iterating the unit fraction, and finally re-establishing a composite unit of one or 
any sub-part of the whole. For example, the fraction $\frac{3}{5}$ can be decomposed into $\frac{1}{5}+\frac{1}{5}+\frac{1}{5}$. Then, the unit fraction of $\frac{1}{5}$ can then be iterated five times to produce a composite unit of one or $\frac{5}{5}$. Such an approach can establish a multiplicative relationships between a unit fraction and the whole (Olive, 1999; Steffe, 2002, 2003). This helps students to understand $\frac{3}{5}$ is the same as having three one-fifths and similarly $\frac{5}{5}$ is five one-fifths. Or, they can use an iterative fraction scheme (Olive, 1999), by which they can use an iterable unit fraction to construct fractions greater than one, for example, $\frac{1}{5}+\frac{1}{5}+\frac{1}{5}+\frac{1}{5}+\frac{1}{5}+\frac{1}{5}=\frac{6}{5}$ or $1 \frac{1}{5}$.

Conceiving of unit fraction as one of so many equal-sized pieces of a given whole can be used to support students' development of equivalence concepts, which was the second important concept within this phase. By the end of this phase students would understand that equivalent fractions are different names for the same value, represent the same area in an area model, and are located at the same point on a number line. They would also understand multiple strategies for determining how two fractions are equivalent. Students will integrate unitizing strategies within equivalence situations and be able to use more than a common denominator method. Other methods include using an additive strategy, such as $\frac{2}{5}=\frac{2+2}{5+5}=\frac{4}{10}$ and unitizing strategies of establishing unit fractional quantities to some common whole, such as converting both $\frac{2}{5}$ and $\frac{4}{10}$ to $\frac{1}{2.5}$

The next phase of the hypothetical learning trajectory is comparing non-equivalent fraction numbers using equivalence methods. The goal of this phase is for PTs to develop the more efficient reasoning strategies of comparing fractions to a benchmark fraction, comparing using common numerators, comparing using common denominators, and comparing using missing pieces (using the relationship of the size of pieces and the number of pieces) (Tobias, 
2009). Once students were able to identify equivalent fractions and compare and order fractions using strategies, then they used these strategies to find fractions between two given fractions, which was the second goal within this phase. It was within this idea that students were introduced to the fact that there is an infinite number of fractions between any two different fractions. However, the result of Tobias' (2009) study indicated that PTs came in with already well-established density ideas, which were found not to contribute anything new to the established practices, so it was suggested to take this topic out for future work on fractions.

The last two phases focus on fraction operations after PTs developed clear understandings of the magnitude of fractions. The goal of these two phases is for PTs to understand fraction operations conceptually with visual models and reasoning strategies. PTs need to apply their knowledge of fraction concepts from their previous lessons on estimation, unit fractions, equivalence, and understanding properties of operation to develop non-traditional methods for addition, subtraction, multiplication and division.

Through different addition and subtraction problems and situations, students will also develop the knowledge needed to use more modeling of addition and subtraction situations which represent the traditional algorithms. They will understand when and how to add and subtract fractions. Specifically, the importance of same-sized pieces in a whole when they are finding the value of unlike fractions. For addition and subtraction, PTs are expected to develop meaning and make sense by the end of the phase, they should be able to differentiate between these two types of situations and develop estimation strategies to understand the impact of the operations and judge the reasonableness of a problem's solution (Tobias, 2009).

Also, through various multiplication and division situations, PTs are required to model situations and explain their reasoning rather than merely apply known traditional algorithms. 
However, the goal of fifth phase of the hypothetical learning trajectories is for students to develop an understanding of the traditional algorithms as well as the underlying concept of how the whole changes through the problem. Tobias (2009) presented this important concept with the following example:

When multiplying $\frac{1}{2} \times \frac{3}{4}$ the multiplication situation becomes $\frac{1}{2}$ of $\frac{3}{4}$ where $\frac{3}{4}$ is represented out of a whole 1 . The $\frac{1}{2}$ represented as $\frac{1}{2}$ of the $\frac{3}{4}$ which is where the whole changes from 1 to $\frac{3}{4}$. Then the final answer of $\frac{3}{8}$ is out of the original whole of 1 . Thus, the whole changes twice. Within multiplication situations, the solution is in terms of the unit one. In division situations the solution is in terms of the divisor. For example, in the problem $\frac{3}{4} \div \frac{1}{2}$, both $\frac{3}{4}$ and $\frac{1}{2}$ are represented out of a whole of 1 . Finding how many groups of a whole there are in $\frac{3}{4}$ of a whole, there is a whole group of $\frac{1}{2}$ with $\frac{1}{4}$ of a whole of 1 leftover. Thus the leftover pieces though for the final answers needs to be in terms of the divisor of $\frac{1}{2}$. Thus, the final answer is $1 \frac{1}{2}$ not $1 \frac{1}{4}$. These understandings of multiplication and division are not typically highlighted when traditional algorithms are taught. (pp. 51-52)

The above descriptions gives, this is the hypothetical learning trajectory which I used in this study. It was developed as a result of previous research with children's and adults' learning and understanding of fraction concepts and operations (Lamon, 2005; Mack, 1990, 1995, 2001; Steffe, 1992, 2002; 2003, Streefland, 1993; Tobias, 2009; Wheeldon, 2008) and supported the PTs' learning of several fraction concepts and operations topics. From the results of previous research the HLT incorporated several phases of learning in which the activities were designed so that students would work with all five subconstructs of rational numbers (Kieren, 1976) and with several concepts that aid students' development of an understanding of the rational number subconstructs (Lamon, 1996) —in particular partitioning, unitizing, equivalence, and comparing and ordering. The activities were also designed so that students would work with contextualized and non-contextualized situations. The instructional activities included appropriate in-class tasks associated with the topics that the PTs did for each instructional goal (see Table 2). 
Table 2

HLT Including Instructional Sequence for Fraction Concept and Operation

\begin{tabular}{|c|c|c|c|c|}
\hline Phase & Goals & $\begin{array}{l}\text { Overarching } \\
\text { Topic }\end{array}$ & Instructional Activities & Tools \\
\hline 1 & $\begin{array}{l}\text { Using } \\
\text { fractions } \\
\text { to name } \\
\text { quantities } \\
\text { or } \\
\text { amounts }\end{array}$ & $\begin{array}{l}\text { Define Fraction } \\
\text { Based on Whole }\end{array}$ & $\begin{array}{l}\text { Identify a specific fraction's } \\
\text { whole or unit (Appendix E, } \\
\text { problem\# } 30 \text { and 32) } \\
\text { Identifying different wholes } \\
\text { (Appendix E, problem \# 32) } \\
\text { Identify their own wholes and } \\
\text { represent the same quantity with a } \\
\text { different number of same-sized } \\
\text { pieces }\end{array}$ & $\begin{array}{l}\text { Manipulative } \\
\text { sets: } \\
\text { Pattern blocks } \\
\text { Fraction circles }\end{array}$ \\
\hline 2 & $\begin{array}{l}\text { Finding a } \\
\text { unit } \\
\text { fraction } \\
\text { and } \\
\text { developing } \\
\text { a } \\
\text { composite } \\
\text { unit of one }\end{array}$ & Unitizing & $\begin{array}{l}\text { Appendix F, Problems \# 34, a-e, } \\
\text { and Appendix G, Problem } 35\end{array}$ & $\begin{array}{l}\text { Concrete or } \\
\text { pictorial model } \\
\text { Manipulatives } \\
\text { or any } \\
\text { different type } \\
\text { of } \\
\text { representations }\end{array}$ \\
\hline
\end{tabular}




\begin{tabular}{|c|c|c|c|c|}
\hline Phase & Goals & $\begin{array}{l}\text { Overarching } \\
\text { Topic }\end{array}$ & Instructional Activities & Tools \\
\hline 3 & $\begin{array}{l}\text { Understanding } \\
\text { fraction } \\
\text { relationships }\end{array}$ & $\begin{array}{l}\text { Equivalent } \\
\text { Fractions }\end{array}$ & $\begin{array}{l}\text { Use different types of } \\
\text { representations to their whole } \\
\text { (Appendix H, Problems \# 33) }\end{array}$ & \\
\hline 4 & $\begin{array}{l}\text { Understanding } \\
\text { fraction } \\
\text { relationships } \\
\text { Replace rote } \\
\text { procedures with } \\
\text { reasoning to build } \\
\text { meaning }\end{array}$ & $\begin{array}{l}\text { Comparing } \\
\text { Fractions }\end{array}$ & $\begin{array}{l}\text { Comparing fractions by using } \\
\text { common denominator, common } \\
\text { numerator, benchmarks, etc. } \\
\text { (Appendix I, problem \# } 1 \text { and } \\
\text { problems \# 1-15) }\end{array}$ & \\
\hline 5 & $\begin{array}{l}\text { Understanding } \\
\text { fraction } \\
\text { relationships }\end{array}$ & $\begin{array}{l}\text { The relative } \\
\text { magnitude of } \\
\text { fractions, Unit } \\
\text { fractions, } \\
\text { Equivalence, } \\
\text { Ordering } \\
\text { Fractions, } \\
\text { Fraction Density }\end{array}$ & Appendix J, Problems \# 38 & $\begin{array}{l}\text { Number } \\
\text { line }\end{array}$ \\
\hline 6 & $\begin{array}{l}\text { Reasoning with } \\
\text { addition and } \\
\text { subtraction }\end{array}$ & $\begin{array}{l}\text { Fraction Addition } \\
\text { and Subtraction }\end{array}$ & $\begin{array}{l}\text { When and how we add fractions } \\
\text { (Appendix K, Problem \#41C) } \\
\text { Making a whole out of different } \\
\text { pieces and represent each sets of } \\
\text { pieces symbolically (Appendix K, } \\
\text { Problem \# } 43 \text { C) } \\
\text { Develop the idea of getting same- } \\
\text { sized pieces in order to add or } \\
\text { subtract and see how the common } \\
\text { denominator is used to get both } \\
\text { into same-sized units (Appendix K, } \\
\text { Problem \# 41A, 41B, 43 A, 43B } \\
\text { and 43C) }\end{array}$ & $\begin{array}{l}\text { Pictures } \\
\text { Pattern } \\
\text { block } \\
\text { pieces }\end{array}$ \\
\hline 7 & $\begin{array}{l}\text { Reasoning with } \\
\text { multiplication }\end{array}$ & $\begin{array}{l}\text { Fraction } \\
\text { Multiplication }\end{array}$ & $\begin{array}{l}\text { Understanding the connection } \\
\text { between the operations and the } \\
\text { contextual meaning/Identifying } \\
\text { when the whole does and does not } \\
\text { change (Appendix L, Problem \# } \\
\text { 49B) }\end{array}$ & Picture \\
\hline
\end{tabular}




\begin{tabular}{|c|c|c|c|c|}
\hline Phase & Goals & $\begin{array}{l}\text { Overarching } \\
\text { Topic }\end{array}$ & Instructional Activities & Tools \\
\hline 8 & $\begin{array}{l}\text { Reasoning } \\
\text { with } \\
\text { division }\end{array}$ & Fraction Division & $\begin{array}{l}\text { Understanding the connection } \\
\text { between the operations and the } \\
\text { contextual meaning/Identifying } \\
\text { when the whole does and does } \\
\text { not change (Appendix L, } \\
\text { Problem \# } 49 \text { A) }\end{array}$ & Picture \\
\hline 9 & & $\begin{array}{l}\text { Comprehensive } \\
\text { Examination over } \\
\text { Fraction Concepts } \\
\text { and operations }\end{array}$ & & \\
\hline
\end{tabular}

In general, I used Tobias' (2009) hypothetical learning trajectory, which was developed by Wheeldon (2008), as a basis for the organization of the fraction part of the course for this study. The trajectories helped me to focus on the ways in which PTs develop an understanding of fraction concepts and operations and to figure out the order that the class did the activities. The learning trajectories includes five phases of fraction concepts and operations instructions and each phase has its own goal. For instance, the goal of the first phase of instruction is to introduce basic concepts of fraction concepts and operations to PTs and to help them to develop various ways of representing the same fractions. These understandings later became the bases for the Phase Two instructional goal: decomposing fractions into a set of unit fractions, iterating a unit fractions, and developing a composite unit of one, and etc. The instructional sequence activities are also designed in different contexts, taking into consideration the fact that PTs were familiar and had prior experience with learning fraction concepts and operations. Thus, new ideas presented to the class may not have been necessarily a new topic to the PTs and may not have been the sole sources to their development of fraction concepts and operation knowledge (Tobias, 2009). However, the activities were contributed to the established mathematical practices. For example, the instructional activities helped PTs teachers to use fractions to name 
quantities or amounts to find unit fractions and to develop a composite unit of one. The comparing activities were presented with the intention of allowing PTs to use and develop different reasoning strategies: benchmark fractions, common numerators, common denominators, and missing pieces which could replace rote procedures with reasoning which

would build meaning. The four operation activities were presented so that PTs could reason with fraction addition, subtraction, multiplication, and division, and discuss concepts rather than algorithms.

\section{An Overview of Research Methods}

My research was also part of a larger group of research in which the mathematics education department and the course coordinator have designed instruction to promote elementary PTs' fraction concepts and operations and to document improvement in elementary PTs' understanding of fraction concepts and operations and activities related to individual students.

I also needed a research method that could help me to understand and reflect upon the actual learning that occurs in such a classroom. I needed a research method that captured the elementary PTs' thought processes and how they construct knowledge and meaning on fraction concepts and operations tasks. I wanted to understand how the PTs' constructions of knowledge and thought processes were expressed, so that they revealed the nature of their mathematical constructs in a straightforward manner using recorded videotapes of classroom sessions that "often provide direct evidence about the nature of the constructs that students use as well as the mechanisms that contribute to the development of those constructs" (Kelly \& Lesh, 2012, p. $669)$. 
I took advantage of the constructive model or theory of learning which adequately accommodated the social activity in this typical classroom that helped me to see how the preservice teachers' collective activity related to fraction concepts and operations sense making evolved during a fractions concept and operations content course. So I wanted:

to ground student accounts of classroom activities (including thoughts, motivations, and constructed meanings) in a videotape record of specific shared classroom events and to supplement each student's account with an associated data base of other students' accounts, researcher field notes, and transcribed videotape records. (Clarke, 1997, p. 99)

I believed it was also important, to include field notes from classroom observations to complement the video task (Kelly \& Lesh, 2012). So, my data collection combined audio (to capture small group discussions) and videotaping, and participant observations. Analysis of the discussion in the whole classroom setting was focused on the class discourse which normally followed PTs' work in small group settings and the various solutions methods that the PTs used. The discussions following small-group work were a frequent and regular event in the course and offered an opportunity to investigate "the reflexive nature of teaching and learning" (Wood, Cobb, \& Yackel, 1993, p. 55) that created opportunity for the PTs' learning.

Participants and setting. This study was conducted at a large Mid-western Public University in the United States of America in one mathematics content course classroom. This particular course was selected because it is one of the required sequence for elementary PTs. The professor of this section has chosen because she had many years of experience in teaching this particular course and worked as the course-coordinator. She has been also conducting several research on the topics of fractions. There were 28 students in the class and 25 of them agreed to participate in this study, and indicated this by signing an informed consent letter. Participants were all female except for one male. They were all undergraduate PTs majoring in either elementary or special education, and they were all in their freshman year of college. 
The study was conducted during the spring semester of 2017. The mathematics content course was for three-credit hours and the pre-service elementary teachers were required to take it. The stated aim was with to develop student understanding of mathematical concepts and to provide PTs with opportunities to engage in problem solving and mathematical reasoning tasks.

The course activities for this class consisted of five components: In-class tasks, homework assignments, quizzes, tests, and a final examination. Fractions constituted 5 weeks of instructional time, which was the duration of the data collection for this study. Students in the course were placed in seven groups at tables of at least three and no more than five. The classroom was equipped with a document camera.

Ethics and trustworthiness. Participants were presented with a consent document on which they signed their name to document that they agreed to participate in the study. The participants were given adequate opportunity to read the form before it was signed. The purpose of the study, which is to develop a deeper understanding of how prospective teachers solve problems relating to number concepts and operations, was clearly indicated on the consent form. The participants were informed that they were asked to participate in this study because they were working with number concepts and operations in their mathematics content course. In the consent form, the participants gave me permission so that I can collect, scan to create an electronic copy, and analyze their work on various tasks, including video and or audiotaping. They were advised that the tapes would then be kept in a locked file cabinet and excerpts of their work, video tape segments, and audio tape transcriptions without any identifiers, may be used in presentations and/or publications related to this study. However, it was explicitly explained to them that their name would be kept confidential and would not be revealed in the final manuscript(s) or any related presentations. 
Although their participation in this study was voluntary, an anticipated risk was explained to them since they were working in groups to answer questions on the task they might feel that their contribution to the group was not valued. They were told that they were also free to withdraw their consent to participate and may discontinue their participation in the study at any time without consequence. They were provided a second copy of the consent letter for their records. They were provided with numbers to reach if they have any questions or concerns about the research project, including phone number of the Institutional Review Board (IRB) Research Ethics \& Compliance Office.

I engaged in the classroom for 5 weeks so that I was able to develop trust and learn more about the classroom culture where individual PTs were seen to develop their personal understandings as they participate in negotiating classroom norms, including those that are specific to mathematics. I transcribed all parts of the videotape of whole class discussions, which resulted in a much bigger amount of data to deal with and more examples to work with which helped me to gather more information to understand the classroom. The course instructor who was familiar with the methodology also examined the research process and products through “auditing" my coding.

I used several theoretical perspectives that supported my research, although my research was carried out using one main qualitative research method—emergent perspective. For example, I used sociocultural theoretical perspectives that "treats intellectual development and the process by which people become increasingly substantial participants in various cultural practices as aspects of a single process" (Cobb, 2007, p. 22). The sociocultural theoretical perspectives helped me to understand the conflicting students' mathematical reasoning and interpretations that would trigger mathematical learning (Cobb \& Yackel, 1996) in the classroom 
as PTs attempted to achieve consensus about a solution, and explain "a solution process in which a conflict between interpretations or solutions becomes apparent” (Cobb \& Bauersfeld, 1995, p. 22). I also applied Cobb's (2007) domain specific framework that typically include interpretation and analyses of the form of mathematical reasoning that instructors wanted students to develop. For example, preservice teachers were required to develop a deep understanding of the different interpretations of fractions operations. This did help to create learning contexts that PTs can use to explain and justify their interpretations of fractions operations in a way that would later become established mathematical practices that no longer stand in need of justifications or became mathematical truth in the classroom.

Data collection. Data were collected from nine class sessions which focused on fraction concepts and operations. The data collected included video recordings of whole-class discussions, audio recordings of small group discussions, and copies of student work on in-class tasks and homework assignments. One video camera was placed at the right back of the classroom and focused on the whole class and individual students. I was also the camera person who focused the recording on different areas of the classroom. Seven audio recorders were placed at each table to document small group interactions. One audio recorder was also provided to the professor to capture clearly her interaction with the whole class and individual students. The video camera and the audio recorders together were used to capture varying aspects of the classroom activity.

\section{Analytic Process: Documenting Collective Activities}

The social and sociomathematical norms are interactively constituted by the PTs and the professor in the course of classroom activity. They are not usually "developed" with the same method as content knowledge because they do not need claims, data, warrants, and backings to 
show that they are established. In the classroom studied, the PTs contributed to establishing an inquiry mathematics tradition by generating meaningful ways of solving problems instead of following procedural instruction. Methodologically, both social norms and sociomathematical norms were inferred by identifying regularities in patterns of social (classroom) interaction (Cobb and Yackel, 1996) to determine when they were introduced, developed, established and/or already established before the fractions part of the course started. They became established when they shifted from the professor initiating the norm to the students doing things without being prompted by the professor. They were established during whole class discussions. For example, explaining and justifying was established from the beginning because students were giving explanations and justifications when discussing answers to a problem without the professor telling them that they need to explain. Further, my analyses of class discussions across the fraction concepts and operations documented that what was established mathematically was evolved as the semester progressed. These norms also were part of the discussions throughout all 9 days of fraction concepts and operations lessons.

I documented the classroom mathematical practices that become 'taken-as-shared' over time using Rasmussen and Stephan's $(2002,2008)$ three phases for documenting collective activity. In the first phase of the analysis, I transcribed every whole-class discussion. I relied on audio- and video-recording and transcripts to identify claims that were made in discussions over a period of time. I then used Toulmin's (2003) argumentation model to code for claims, data, warrants, and backings that came up during the discussion. The claim is the answer being given to a problem. Data provides evidence in support of the claim. The warrant rationalizes how the data support the claim. Finally, the backing serves to substantiate the validity of the warrant (Toulmin, 2003). Tobias (2009) presented this situation with the following example: 
When solving a problem such as $\frac{3}{4}-\frac{1}{4}$, a claim would be that the answer is $\frac{1}{2}$. Data are used as a way to provide evidence for or to back up the claim (Rasmussen \& Stephan, 2008). For the problem " $\frac{3}{4}-\frac{1}{4}="$ the data could be that $\frac{3}{4}-\frac{1}{4}=\frac{2}{4}$. If the data are challenged, then a warrant is needed. A warrant is a justification for why the data are valid. Within the example, a warrant to link the data and claim would be that $\frac{2}{4}=\frac{1}{2}$. When the warrant is challenged, then backing, Toulmin's fourth component, must be provided to justify why the warrant holds authority thereby validating the entire mathematical argument. For example, if questions still arise on how $\frac{2}{4}=\frac{1}{2}$, then the backing would be that 2 is half of 4 and 1 is half of 2 , thus $\frac{2}{4}=\frac{1}{2}$. (p. 64)

Once claims, data, warrants, and backings were coded, I constructed an argumentation $\log$ (see Appendix A) for each claim so that I was able to identify each aspect of the argument easily and trace changes in the function of these ideas overtime in the next phase. The log was simply a table with one row devoted to each argument, listing a chronological argument number; the claim, data, warrant, and backing of the argument; and any additional notes (Whitacre \& Nickerson, 2016). To check the reliability of the coding, the course instructor who was familiar with the methodology (Toulmin's (2003) argumentation model) involved in this study analyzed the transcripts. I, and the course instructor, first, had to identify the mathematical arguments that were made in the transcription independently and met together to discuss our coding decisions. Once disagreements were resolved, we then identified the taken-as-shared ideas.

In the second phase of the analysis, I took the record of argumentation log and looked across time to see what mathematical ideas expressed in the claims became taken-as-shared or had become established in the class. I consider ideas to be taken-as-shared based on Rasmussen and Stephan's (2008) criteria which were developed to determine when an idea is taken-as shared. The first criterion involves analyzing the episode and looking for where warrants and backings are no longer being stated. If claims and data are no longer challenged, then an idea is taken-as-shared as no further justification is needed. In the second criterion, mathematical ideas 
became taken-as-shared when either the backings and/or warrants for an argument no longer appeared in students' explanations or students used a previously justified claim as an unchallenged justification for future arguments or an element of element of an argument shifting in function, for example, from claim to warrant. Based on the example described earlier, Tobias (2009) presented this situation with the following example:

The warrant was that 2 is half of 4 and 1 is half of 2 . If a future problem is presented, such as $\frac{2}{3} \times \frac{3}{4}$, and a student claims that the answer is $\frac{1}{2}$ because $\frac{2}{4}=\frac{1}{2}$, and this is not challenged, then the idea of $\frac{2}{4}=\frac{1}{2}$ is taken-as-shared. (pp. 67)

I also revisited the details of the classroom argument to check the validity of the taken-asshared ideas because, particularly when there was just a shift in function, a single criterion did not necessarily result in the ideas being considered taken-as-shared and some ideas met several criteria, which built up the evidence for their taken-as-shared status (Whitacre \& Nickerson, 2016).

In the final phase of the analysis, I used a table to organize taken-as-shared ideas for mathematical tasks to describe classroom mathematical practices, which result from more than one mathematical idea (Rasmussen \& Stephan, 2008). Over the course of five weeks of classroom instruction, several mathematical practices related to fraction concepts and operations emerged. The process by which these practices became established were both linear and quite complex, depending on the ideas embodied in the practice, whether they become emerged in a network manner where a web of ideas were or were not built (Stephan \& Rasmussen, 2002). For example, during the same class period a particular mathematical idea that contributed to one of the practices became taken-as-shared while another idea emerged that eventually contributed to a different practice. Then, during the very next class period there were two or more other mathematical ideas that were discussed, involving two or more different practices. 
Interpretive research paradigm. The interpretive research paradigm (Glesne, 1999) helped me carefully examine the PTs' solutions methods, thought processes, reasoning, explanations, justifications etc. for patterns which revealed their understanding, their overall general misconceptions, and their agreements and differences on solutions. As a naturalistic inquiry, the interpretive paradigm is open to any method including patterns, analyzing who or what to sample, and how everything fits together. So, it helped me to guide my research data collection and writing.

I used interpretive and content analytic approaches (the visual and verbal content of the videotape and coded transcripts) to examine the preservice elementary teachers' solution methods and strategies and assign them to the category of my coding frame. The interpretive and content analytic paradigm helped me to study patterns and meanings from the video and content text data of the transcripts that exhibited the elementary PTs' different types of content knowledge of fraction concepts and operations, their overall general misconceptions, their agreements and disagreements on solutions and solution methods, and even their changes with the course intervention. I collected videotapes of whole classroom discussions that helped me to understand the different types of preservice teacher' content knowledge of fraction concepts and operations sense-making. Working in the whole class setting also provided me with the necessary tools to establish more personal relationships with the PTs, helped me to develop better understanding of the elementary PTs as learners, and gave me a chance to become a voice for them in my research (Rogers, Bolick, Anderson, Gordon, Manfra, \& Yow, 2007).

Constant comparative method. I used a constant comparative method (Glaser \& Strauss, 1967), that helped me to determine the ways in which the collective learning was influenced through refining the operational definition of the mathematical ideas that involved in 
each argument or went through the coding of the argument to trace changes in the function of those ideas (Whitacre \& Nickerson, 2016).

In summary, the HLT, the theoretical frame work, data analytic process, taken-as-shared ideas were in general situated interactively in the context of the course. The learning of the class was determined from the ideas that were taken-as-shared (Cobb \&Yackel, 1996) through the fraction concepts and operations unit. The taken-as-shared ideas were established or determined using Rasmussen and Stephan's (2008) three phase approach for documenting collective activity. Individual preservice teacher's contributions to the practices was determined from the data, warrants, and backings they provided to the classroom conversations (Tobias, 2009; Toulmin, 2003). The ways in which the classroom community impacted preservice teacher learning determined with the constant comparative methods (Glaser \& Strauss, 1967) by going through the coding of the argument to trace changes in the function of those ideas (Tobias, 2009; Whitacre \& Nickerson, 2016). The PTs' understanding, overall general misconceptions, and agreements and differences on solutions was determined with the interpretive paradigm by carefully examining their reasoning, explanations, and justifications. 


\section{CHAPTER IV: RESULTS}

In this chapter, I present the results from this study in terms of a social perspective, especially the ways in which individuals interacted with one another and how they were analyzed to produce the findings in relation to my research questions, which were:

1. What knowledge do the participating PTs collectively exhibit regarding making sense of fractions concepts and operations, and how does this understanding develop?

2. In what ways do collective social norms and mathematical behaviors regarding fractions emerge within the course?

I present the collective, social activity related to fraction concepts and operations which evolved and were established over the nine class sessions. I examine the sociomathematical norms established and sustained throughout the study. I discuss the classroom mathematical practices, which became taken-as-shared, ideas for the PTs as they made sense of fraction concepts and operations. The practices are discussed in terms of overarching mathematical topics. The ways that the norms and practices were established are illustrated through wholeclass discussions.

\section{Social Norms}

The social norms are characteristics of classroom participation structures (Lampert, 1990), which view participation in norms as a joint activity between the students and instructor. They include features such as explaining and justifying solutions and solution strategies, making sense of other students' thinking, and questioning when disagreements or misunderstandings occur. Thus, the social norms involve both the students' and the professor's roles in the classroom, and are jointly established by both the professor and the students (Tobias, 2009). They focus on the professor's and the PTs' expectations and obligations in creating ways to 
maintain a problem-solving classroom atmosphere (Cobb \& Bauersfeld, 1995). Professors initiate and guide the renegotiation process while PTs reorganize their individual beliefs, about their own role, other's roles, and the general nature of the mathematical activity (Cobb \& Bauersfeld, 1995). PTs also attempt to achieve consensus about a solution, and explain "a solution process in which a conflict between interpretations or solutions becomes apparent" ( $p$. 22).

The social norms, in this study, are intended to create learning opportunities for PTs as they attempt to fulfil their obligations. In particular, they were intended to move PTs from dependency on standard algorithms to the point where they can reason flexibly about fraction concepts and operations with sense-making. The social norms that were established in whole classroom discussions before this study included: (a) explaining and justifying solutions and solution strategies, (b) attempting to understand or make sense of others' explanations and justifications, particularly when the PTs are reasoning in terms of pictorial models that support them in making sense of standard strategies, and (c) questioning others for clarification or when misunderstanding occurs. There were no any other classroom social norms that were established during my study.

Before the class moved to the fraction concepts and operation lessons, the professor had already used other mathematical activities, which might not be specific to the content of fractions, to introduce the above social norms. Mathematical activities, designed to encourage the PTs to develop alternative methods rather than employing traditional algorithms, were already introduced and set as examples during the whole number concepts and operations unit. Thus, social norms were introduced and established during the whole number concept and operations lessons and sustained through the rest of the semester. 


\section{Explain and Justify}

In this study, explaining a solution meant that PTs had to be able to describe the solution process to arrive at an answer (Tobias, 2009) and justify their thinking to others (Wood, Cobb \&Yackel, 1993). When justifying, usually in response to challenges, PTs had to able to describe mathematically why their explanations were valid. The social norm of explaining and justifying solution strategies was established in the first unit of this course, which focused on whole number concepts and operations. As illustrated in this section, this norm did not need to be reestablished.

On the first day of the fraction concepts and operations sequence PTs were presented with the following task.

For each of the following problems:

Draw a picture to solve. Explain and justify what you did to solve the problem

How much candy would each person receive if 6 people share 5 candy bars equally? How much candy would each person receive if 5 candy bars are shared equally among 3 people?

Since previous research has suggested that the expectation to explain and justify might have to be re-established when the content area shifts (Tobias, 2009; Wheeldon, 2008), the directions for the first fractions task explicitly told PTs to explain and justify. Students were asked to draw a picture to solve the problems and explain and justify their process of using a picture to find the solution. In the first whole-class discussion about the fractions task, Tanny, Irica, and Janna included explanations and justifications when sharing their solutions with the class. (Bolded fonts are used to indicate whether a norm is introduced or sustained by the PTs).

\section{Professor: Ok, Tanny, what did you do with yours?}

Tanny. Ok! I drew a candy bar — so the numbers go down like, one, two, three, four, five candy bars and then, I split [each] up into six people-so each candy 
bar has six, which is the reason why I got 5/6. On top I did shade again that each got $1 / 6$ of each candy — so that they got $5 / 6-5$ out of 6 pieces - each got $5 / 6$ of each candy bar.

Professor: If I am looking at this piece, how much is that?

Tanny: That is one-sixth. There is five of them.

Professor: Irica, how did you get the five one-thirds?

Irica: If you divide the five candy bars into one-thirds or into thirds - it is fifteen one-third size pieces of candy bars, and each person will get five. If you divide fifteen by three- - each person gets five one-thirds size pieces.

Professor: Ok.

Reagan: If you look at the picture - because it is five down and three this way-so five one-third size pieces. $\cdots$

Professor: And then, Janna, what did you do with your problem one?

Janna: I took the six people-I took a number that goes in six, which is three: I divided it by two to get three. I took the first three and divided those in half and then so that each gets one-half and then there is two candy bars leftover. I divided those into thirds because you can't divide it in halves for it to be equal for six people.

Professor: Are you talking about the two leftovers?

Janna: $\quad$ Yeah ... the two leftovers...so, I divided them into thirds and so each got a third. I added one-half and one-third and then I had to make the denominator the same... so it was $\frac{3}{6}+\frac{2}{6}$ equals $\frac{5}{6}$.

During the first whole-class discussion, all PTs who were asked to share their solution automatically included an explanation and justification in their response. Each explained and justified his/her solution process rather than just provide his/her solution. The professor did not need to initiate renegotiation of the classroom norm.

When the class moved to fraction Day 2 tasks, PTs were not prompted by the professor to provide explanations and justifications, and they were not given any written directions to explain and justify. However, PTs were providing explanations and justifications within each answer because they knew that they needed to provide explanations and justifications. For example, Vrittany and Tara did Task 2 Student 3 response (see Appendix C) differently, their methods depended on how they broke up the candy and the professor expressed her agreement with their 
answers because they were able to justify their solutions. Therefore, the norm negotiated to include what it means to explain and justify in conjecture with pictures (see Figure 1).

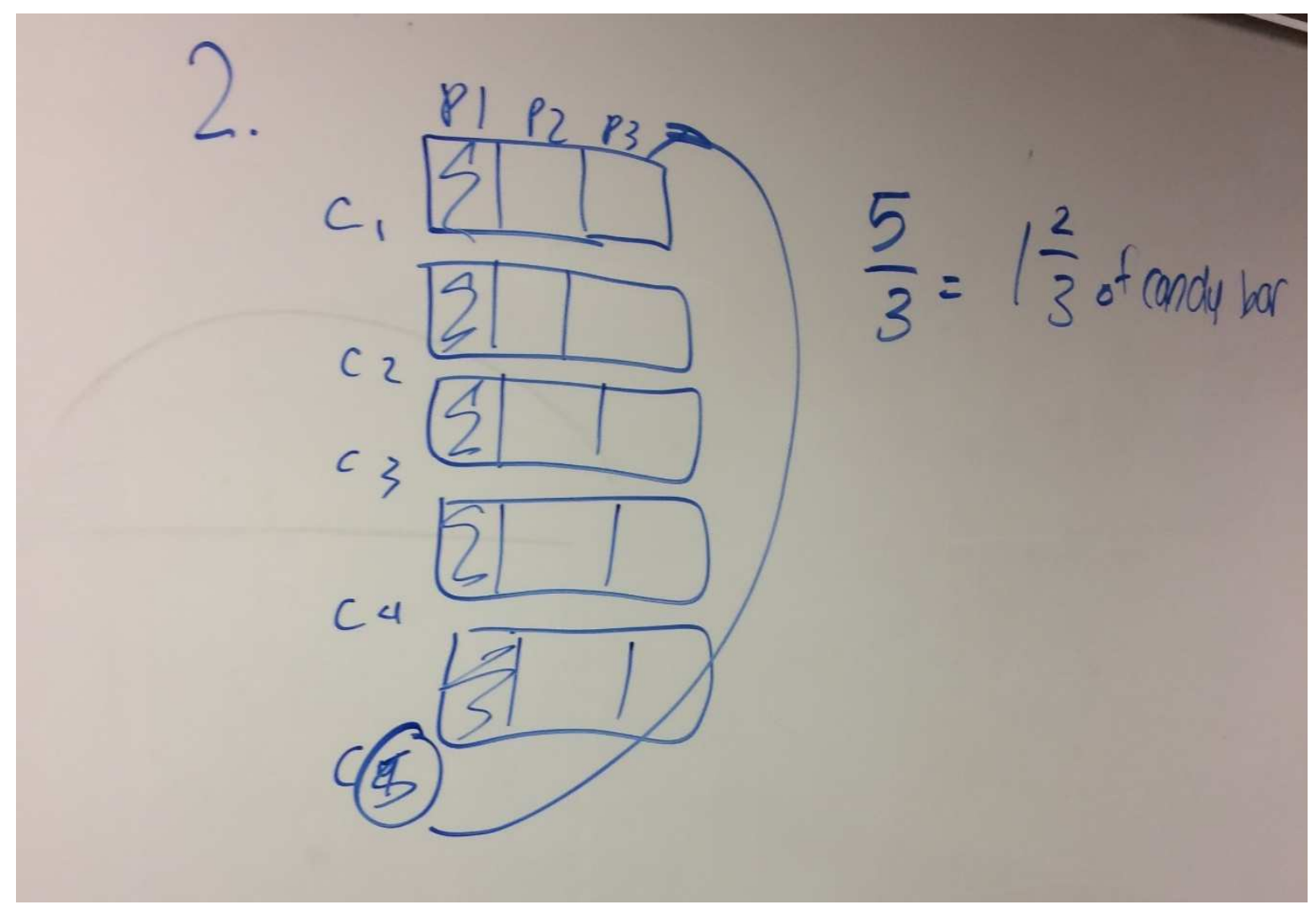

Figure 1. Share 5 candy bars equally among 3 people.

Professor: So, if we are looking at Student 3, the one-third of five candy bars - this is going to be correct for what is up here, and why?

Vrittany: Yea.

Professor: Ok, why?

Vrittany: Five-fifteen, which is one-third. Each person gets five pieces out of the fifteen and reduces to one-third.

[Tara raised her hand]

Professor: Go ahead, Tara

Tara: $\quad$ So, we just did like a box and cut it off into thirds and fifths across because it is the same, like what is one-third of the five candy bars.

Tamie: $\quad$ So instead of looking at like separate candy bars, we just put them altogether. 
Professor: So you can have different pictures for this problem. There may be times, so I just say solve it, draw a picture to solve it and whichever picture you end up using as long as you can justify it - that is Ok. Ok! So, Student 5 was kind of similar - what did Student 5 do?

Though the content area shifted from whole numbers to fraction concepts and operations, the expectations to explain and justify did not need to be re-established. Starting from the first day of fraction concepts and operations, students were providing explanations and justifications within each answer without being prompted by the professor to do so.

\section{Making Sense of Others}

As with the social norm of explaining and justifying, the norm of making sense of others' explanations was also already established before the fraction concepts and operations unit started. This norm was first introduced, in the fraction concepts and operations unit, through the conversations that took place between the professor and PTs when they were engaging together in a mathematics discourse to figure out which explanations and justifications were correct. To facilitate the mathematics communication the professor continually asked questions about what a preservice teacher said in his/her explanation and justification. Particularly, this happened during situations when the PTs were attempting to resolve conflicting interpretations and also when the professor was trying to help the PTs to develop viable solutions. Thus, the norm included the expectation that PTs needed to make sense of what others are doing through restating, repeating, and asking others to repeat what PTs said.

Throughout the following discussion in fractions Day 7, the professor asked the class how they got the answer for a number-line problem, two-thirds of the way from $\frac{3}{4}$ to $1 \frac{1}{3}$ (see Appendix J), Tanny commented that she did not understand another preservice teacher's, Treanna's, solution, and her comment was not initiated by the professor. The professor did not have to ask if someone did not understand, rather Tanny stated this on her own. 
Tanny: Where did you get thirteen and two-thirds?

Treanna: Well, thirteen... in between thirteen and fourteen. The thirteen is that point right there. Thirteen two thirds over twelve.

Tanny: Because I don't know what you did underneath.

Tara: $\quad$ It is thirteen two-thirds over twelve?

Treanna: This is just for the numerator [Pointing to thirteen two-thirds]

Tanny started by asking Treanna where she got her solution, and then commented that she didn't understand what Treanna did in her work. In conversations about other problems, there were also instances of PTs asking if what they said made sense.

Irica: $\quad$ So then, with that we knew that we had we counted up to fourteen sections starting with the nine-twelfths. So then, the fourteen sections are thirteen and two-thirds over twelve. Does that make sense?

The norm of making sense of others' explanations justifications did not need to be reestablished when the fraction concepts and operation unit started. Though the professor sustained this norm through the fraction concepts and operation lessons by asking PTs what, how, and why someone did something, the professor and the PTs both initiated the conversations of explaining others' thinking and asking if what they were doing made sense. The class understood the expectation to help others when misunderstanding occurred. We have seen, PTs directly intervened to explain and justify to other PTs and the professor as the patterns of social interactions extended through the fraction concepts and operation unit.

\section{Questioning}

The social norm of questioning others when misunderstandings occur was also already established before the fraction concepts and operations unit started. This included PTs asking clarifying questions when they did not understand what someone did to solve the problem (Cobb \& Yackel, 1996), or stating when they were unsure of how someone else in the class got their solution. Within this study, questioning came in the form of asking for what the solution is or asking clarifying questions for how someone solved a problem. 
During the first day of fractions, the PTs voiced when they were confused about how someone got their answer. During one of the candy bar sharing problems in Day 1 in Fraction Task 1 (Appendix B), Kanner stated that she did not understand how Tanny got thirtieths. The professor then redirected the conversation back to Tanny to explain how she got the answer.

Kanner: I am still confused on how she gets thirtieths.

Professor: How did you get thirty pieces?

Tanny: $\quad$ Five-sixths of the candy bars - each of the five candy bars divided into six pieces. So five times six is thirty, and you change the fraction, then the six becomes thirty and the five becomes twenty-five, just like converting into equal fractions.

As evidenced, PTs were stating when they were confused about how someone else in the class solved a problem. Though it initially did not come in the form of a question, PTs knew they needed to speak if they did not understand how someone got their solution to a problem.

Later in the fractions unit, PTs' comments did come in the form of questions. Below, in Day 4, Rhannon had to ask Gessica because she did not understand, with this particular problem (Appendix F), the one-fifths could have been split up differently. However, the parallelogram and the triangle could have been one-fifths, just depending on how she wanted the pieces to start with. Since Gessica was looking at just pieces, she can say there were two pieces in one-fifths. Also, if she knew there were two pieces in one-fifths, it would not be difficult for her to figure out how many were going to be in five-fifths. Therefore, Gessica's solution answered the question for how many pieces. For Pulianna both Irica and the professor provided her with the solution to her question saying it is possible to find the solution for this problem in terms of what pieces, instead of breaking it down to triangles or just leave it as the pieces and say "pieces".

Rhannon: How are the two triangles one-fifth?

Gessica: In general, two-pieces are equal to one-fifth.

Professor: What was your final answer?

Gessica: One hexagon, one parallelogram, and two triangles

Professor: Which is how many pieces altogether? 
Gessica: Ten pieces.

Professor: Ok, other questions?

Pulianna: The thing that is confusing me the fact that like the two pieces in the first one can be broken down equal to one of the two triangles. Can we leave the pieces as it is?

Irica: $\quad$ This is talking about how much [pointing towards Gessica's representation]

Professor: That is why I want Gessica to come up here to share this ... With this particular problem, if you think about what Charlie took in terms of pieces as opposed to what it actually worth, how many pieces did he take?

Tanny: $\quad$ Four

There were two occasions where PTs needed to question within the norm of questioning

others. First, a preservice teacher asked a question when he/she did not understand another preservice teacher's thinking and solution process. Second, a preservice teacher asked a question when he/she arrived at a different solution from someone else. However, throughout the remainder of the fraction concepts and operations unit both the PTs and the professor continued to sustain this norm by asking if there were questions.

\section{Sociomathematical Norms}

Sociomathematical norms include determining what constitutes an acceptable, different, sophisticated, and efficient solution and solution process (Cobb \& Yackel, 1996).

Sociomathematical norms are the normative aspects of PTs' mathematical activity. Analysis of the sociomathematical norms have been an explicit focus of interest in this study. So, my overriding motivation was to analyze PTs knowledge of fractions and how their sense-making strategies emerged in the class, and to account for the PTs' fraction concept and operations knowledge development as it occurred in the social context of the classroom. I have already pointed to the importance of social norms and here, I focused on the development. In so doing, I emphasized the role of the professor and the PTs and the unanticipated learning opportunities which emerged. I also point to the importance that the professor's role in representing PTs' offered solutions played in the development of sociomathematical norms. Thus, the 
sociomathematical norms developed or established as part of this study included determining what constituted (a) an acceptable solution and (b) a different solution.

\section{Acceptable Solution}

When the fraction concepts and operation unit started, the class had already established (during the whole number unit) that solutions need to include both an explanation and a justification. However, determining what constitutes an acceptable solution had to be reestablished because, although the PTs knew they needed to explain and justify, the idea of what it means to explain and justify in mathematically meaningful ways had to be developed.

an acceptable solution meant that PTs provided not only how they solved the problem but why their solution method is valid. During the first day of the fraction concepts and operations unit, the PTs were asked first to draw a picture to solve and then to explain and justify what they did to solve the problem and put their group picture on the board for the following problem:

How much candy would each person receive if 6 people share 5 candy bars equally?

When the whole class discussion started, the PTs provided explanations and justifications. However, their solutions and solution methods were not always acceptable. For example, some of the PTs tended to answer five pieces (see Figure 2) or how many pieces each

person would get, instead of answering $\frac{5}{6}$ or how much candy bar each person would get. The professor then discussed in detail that solutions needed to be the exact amount each person got, not how many pieces of something someone receives. 


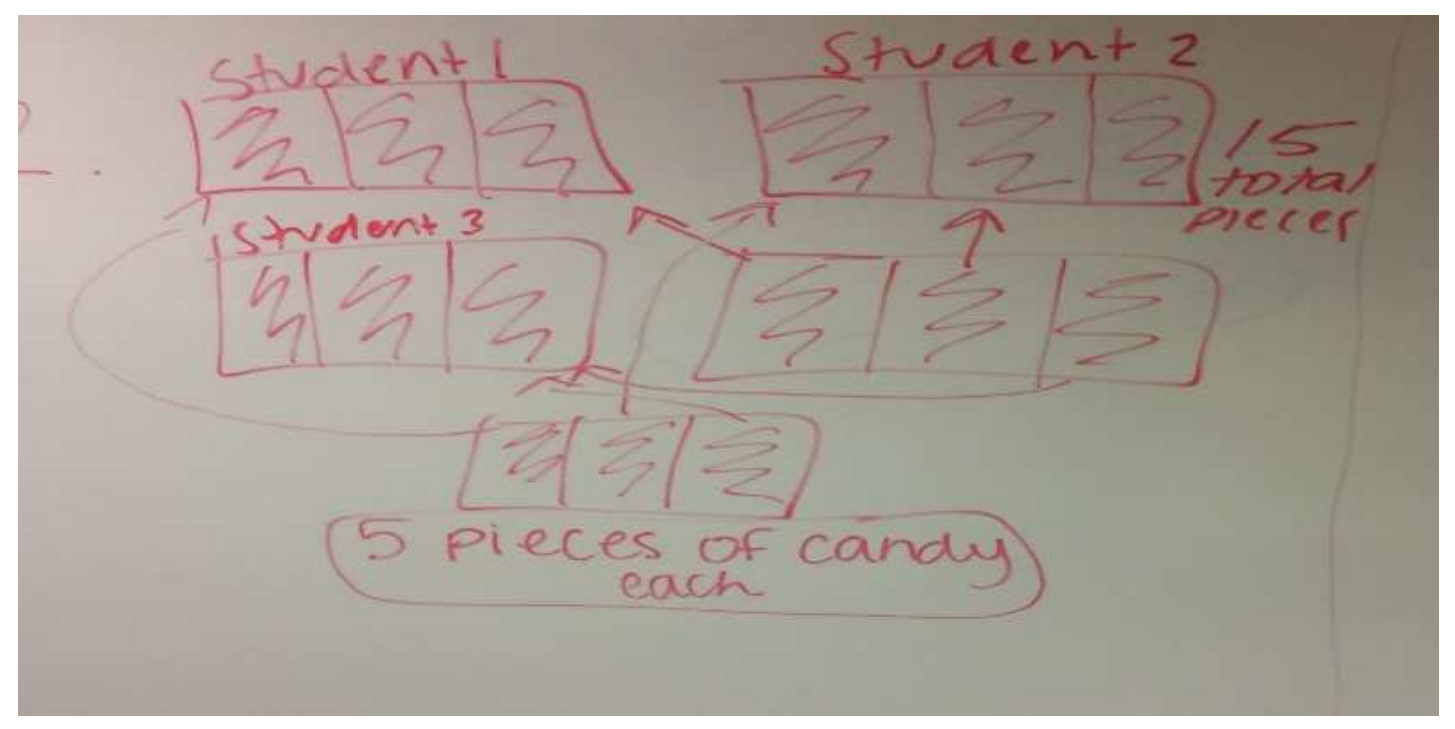

Figure 2 . Share 5 candy bars equally among 6 people.

Professor: Ok! For this particular problem what I would expect you to do is to give me the exact amount that each person gets and that would be where the $\frac{\mathbf{5}}{6}$ would come from. The five pieces technically could be correct if this particular question would have said how many pieces of candy each person would get. But because of the problem specifically saying how much, in this particular case that I would be looking for the five-sixths. Does that make sense?

[The class agreed—nodding their heads]

Professor: What you did with your picture was correct. But you would just need to make sure to give the exact amount, because the five pieces here and the five pieces here [pointing to another solution] aren't the same size to begin with.

As illustrated, the professor introduced the importance of language (particularly how the question was framed) in discussing the idea of an acceptable solution for a problem. Thus, she expected the exact amount of a candy bar each person would get as a solution, which in this case is a fraction less than one. 
When the class moved on to other activities, the idea of defining a whole within a fractional answer was introduced. In the conversation of the second part of fractions Day 3 task (Appendix D), the professor repeatedly was asking the PTs "of what" questions to make it clear that their argument still does not suffice as an acceptable explanation and justification unless they put the whole next to the fraction. Thus, the PTs had to define the whole, though arriving at the correct fraction did not necessarily lead them to mathematically correct and acceptable solutions. Nevertheless, the PTs had difficulties in stating their solution as fractional parts of a whole. For instance, in the following whole-classroom discussion in Day 3, Tamie should have stated her solution as two-fifths of something, but was able to provide a complete response for the "of what" question. However, the idea of acceptable solution was initiated again by the professor.

Tamie: Because there is five squares in total-like the whole.

Professor: Are you talking about each piece?

Tamie: $\quad$ The five pieces. Sorry, yeah ... five pieces is equal to one whole and then two out of the whole are shaded, so it is two-fifths.

Professor: This is two-fifth of what?

This then became initiated by the PTs on the same day, Day 3. In the following discussion, Pulianna and Irica were able to define the whole correctly and represent different mathematically acceptable solutions without being prompted by the professor to do so.

Pulianna: It would be like five-halves of - two halves of one whole.

Irica: I think you can say five-halves of two-fifths...

On Day 6 of instruction, acceptable solutions shifted in the conversation as the PTs were asking what constitutes an acceptable explanation. This is evident in Revin's, explanation for how he compared three-sevenths and six-elevenths. He then asked if his explanation was enough. 
Revin: $\quad$ For that one in the explanation, I just put six-elevenths is more than one-half and three-sevenths is less than one-half. Does that work?

Professor: How do you know that six-elevenths is greater?

Revin: Just five and five tenths over eleven is half and three and three-tenths over seven is half, so three-sevenths is less than half and six-elevenths is greater than half.

Professor: What was your question?

Revin: Would that work as an explanation?

Though PTs knew they needed to explain and justify, they sometimes asked what constituted an acceptable explanation.

Within this same activity, the Professor also pointed out that acceptable solutions for comparing fractions included talking about the size of the pieces.

Yosephenie: The last one is eight-ninths because seven-tenths is missing three-tenths and eight-ninths is missing one-ninth.

Professor: That is Ok as long as you talk about how big the pieces are. So like what I said for thirteen. Even though, this is one away and that one is three away [pointing to the fractions seven-tenths and eight-ninths], the pieces are different sizes, you will have to discuss that too.

When the preservice teachers draw a picture when attempting to solve a problem, their explanation and justification for what they are doing to solve the problem and their final solution should exactly match their drawing. They are expected to explain and justify their solutions in conjunction with their pictures.

When the class considered a subtraction with multiplication problem (See Appendix K, Problem A) in Day 8, one of the PTs, Pulianna, could not come up with an acceptable solution. Marty has $\frac{3}{4}$ of a bag of candy and gives Jane half of his candy. How much of a bag of candy does Marty have left?

In the problem, Pulianna did not realize what the whole for the three-fourths was. She assumed three-fourths was the whole. So, she decided to cut the three-fourths into half, just by removing the fourth box and using the three boxes and she came up with "one-half" as a solution. The 
Professor questioned Pulianna's solutions explanation and justification in relation to the picture and asked her if her final answer was $\frac{3}{8}$, which was an acceptable solution.

Pulianna: So, I just like drew out the problem. Three-fourths basically was the box of four. I crossed out one. You can't have a whole. You only have threefourths of it. And then you left with like three little squares and he gave half of it to Jane. Then cut three in half and then so Jane gets three and he gets three.

Professor: So, your final answer was three-eighths?

Pulianna I got a half and they got three-eighths and one-fourth.

From these exchanges we can see that the PTs knew that they needed to explain and justify. However questioned what constituted an acceptable explanation. In addition, the Professor discussed specific aspects of explanations which were needed for a solution to be fully justified.

There were three aspects or features of acceptable solutions that had to be negotiated by the PTs and the Professor. The first was answering the question in terms of "how much" instead of answering "how many." The second was the idea that just writing a fraction as a solution without specifying the whole did not suffice as an acceptable explanation and justification. The third type of acceptable solutions involved the use of a picture. The class had to negotiate which pictures, including number lines, could be used in solution strategies, however it was not acceptable when the picture did not exactly represent the explanation and justification of the final solution. At last, PTs' explanations and justification were challenged on the grounds that the types of mathematical reasoning they had given were unacceptable.

\section{Different Solutions}

The sociomathematical norm of understanding the fact that problems can be solved in multiple ways was established in whole number concepts and operations unit and sustained through the semester. The sociomathematical norm of different solutions includes different 
answers for the same problem and the application of different processes to get the same answer. Soliciting different solutions from PTs and comparing and contrasting those solutions would also lead to discussion of mathematically significant issues that would develop the PTs' knowledge of fraction concepts and operations. "Consequently, in responding to the teacher's requests for a different solution, the students were both learning what counts as a mathematical difference and helping to interactively constitute what counts as a mathematical difference in their classroom" (Cobb \& Yackel, 1996, p. 8). Thus, the Professor of this study built on the PTs' contribution of different solutions to achieve the instructional goals of fraction concepts and operations. However, understanding what constitutes mathematical difference and explaining this difference in mathematically meaningful ways needed to be renegotiated in the fraction concepts and operations unit.

Although there had been some issues with some of the groups' pictorial representation of the solutions which we have seen in the previous norm, regarding "acceptable solutions," the PTs devised different ways to explain and justify how much candy would each person exactly receive if 6 people share 5 candy bars equally in fractions Day 1. The Professor, through instruction, invited the PTs to come up with different solutions. For example, Tanny's group split up each candy bar in to sixths (see Figure 3). Janna's group divided the first three candy bars in half and the remaining two into thirds, and used fractions addition (see Figure 4). But both of them were able to explain and justify in conjunction with a picture using different solution processes. There were, however, still some language issues.

Professor: OK, Tanny, what did you do with yours?

Tanny: $\quad$ OK! So I drew a candy bar - so the numbers go down one, two, three, four, five candy bars and then, I split up into six people - so each candy bar has six, which is the reason why I got $\frac{5}{6}$. On top I did shade again that each got 
$\frac{1}{6}$ of each candy-so that they got $\frac{5}{6}-5$ out of 6 pieces - each got $\frac{5}{6}$ of each candy bar.

Professor: If I am looking at this piece, how much is that?

Tanny: That is one-sixth. There are five of them.

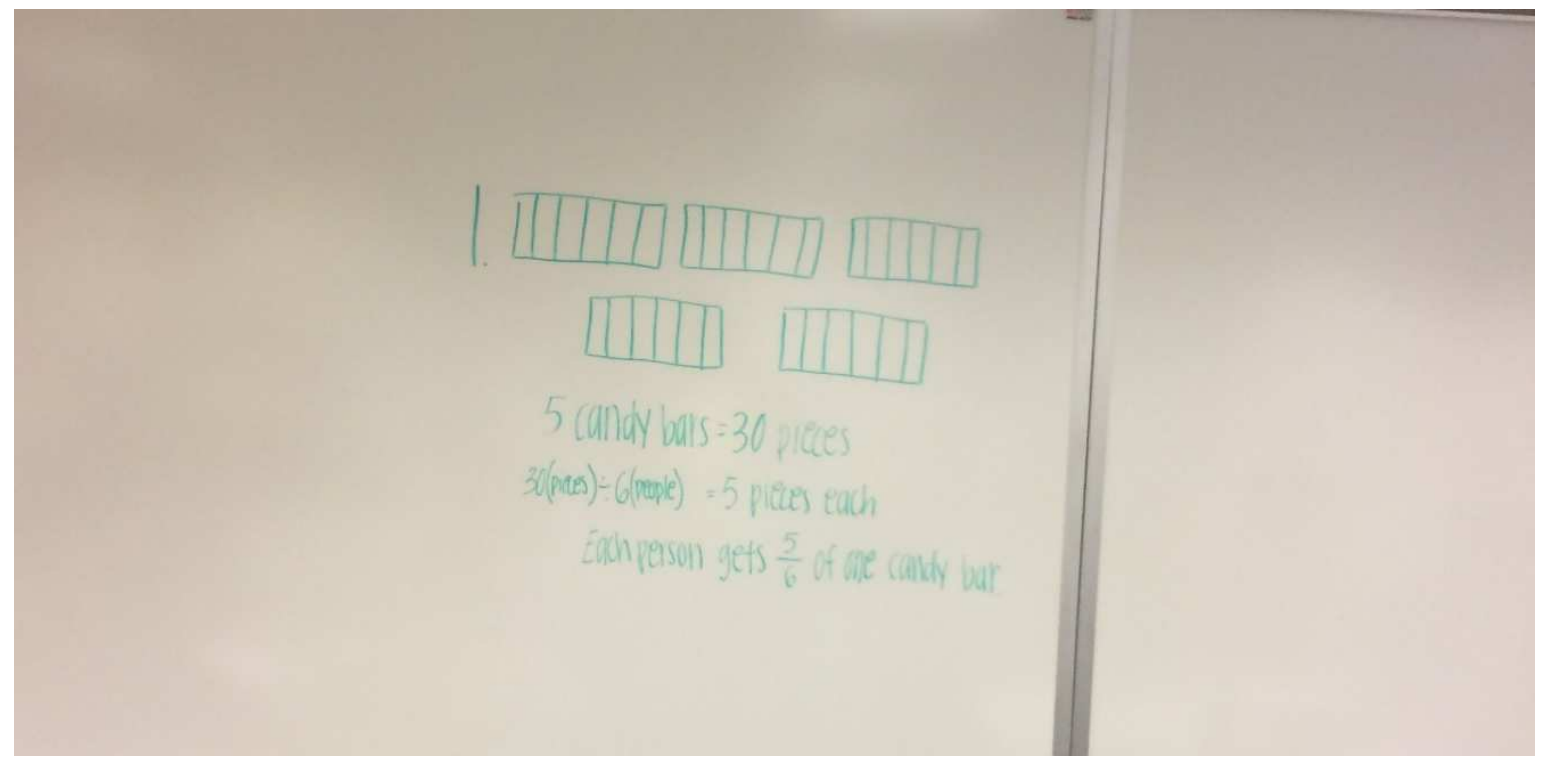

Figure 3. Tanny's group solution for share 5 candy bars equally among 6 people.

Professor: And then, Janna, what did you do with your Problem 1?

Janna: I took the six people — so I took a number that goes in six, which is three: I divided it by two to get three. I took the first three and divided those in half and then so that each gets one-half and then there is two candy bars leftover and then, I took-I divided those in the thirds because you can't divide it in halves when to equal it for six people.

Professor: You're talking about the two leftovers?

Janna: $\quad$ Yes...the two leftovers...so I divided them in the thirds and so each got a third so that I added one-half and one-third and then I had to like to make the denominator the same... so it was $\frac{3}{6}+\frac{2}{6}$ equals $\frac{5}{6}$.

Professor: OK, this one has come from where?

Janna: $\quad$ From the first three, each got a half.

Professor: OK! The one-third was...

Janna: $\quad$ From the two leftovers.

Professor: All right! Are there any question on these at all? [No questions] 


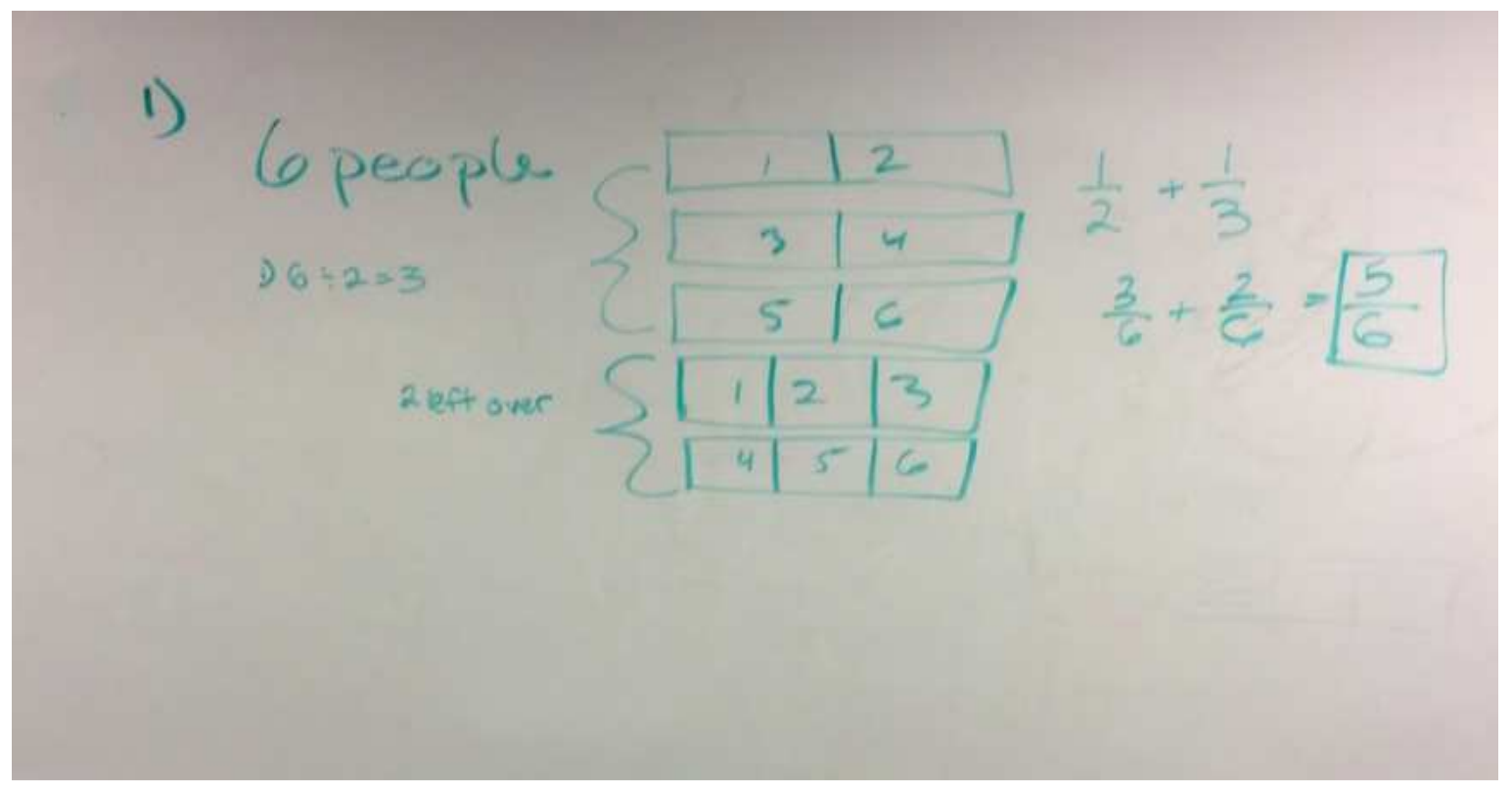

Figure 4. Janna's group solution for share 5 candy bars equally among 6 people.

This was the first instance where the sociomathematical norm of different solutions was introduced in the fraction concepts and operations unit. The Professor explicitly introduced this norm by indicating that there could be different ways to solve a given problem.

Professor: So there are multiple ways you guys are going to be able to draw pictures, to break this up. This is the type of thing we are going to be getting into with fractions, basically from now until the rest of the semester.

Having different solutions was introduced to the class by defining an of what (Tobias, 2013) in the context of fractions and this was negotiated over the course of the first two days of fractions. In the following task, the Professor provided the PTs with five different students' solutions and asked them to figure out which of these solutions were correct and which were incorrect. 
A class of students was asked to find how much candy each person receives if 6 people share 5 candy bars equally. For each response, determine whether or not the solution is correct and why.

Student 1: $\frac{5}{6}$ of the candy bars.

Student 2: $\frac{1}{6}$ of a candy bar.

Student 3: $\frac{5}{6}$ of 1 candy bar.

Student 4: $\frac{5}{30}$ of 5 candy bars.

Student 5: $\frac{5}{6}$ of each candy bar.

For Student 1, the class agreed it was incorrect because Tanny argued it meant that one person gets five-sixths of all of it. There was only 5 pieces left to share among everyone else, so it was impossible.

Professor: OK, if you look at student 1 over here ... what is Student 1 saying?

Tanny: He is saying five-sixths of the candy bars, not one candy bar.

However, when the Professor asked how we would fix the solution to the problem the PTs gave different solutions which established and developed their language use of defining the whole and led to their understanding of what is meant by the phrases of $a$, of one, of the, and of each (Tobias, 2013).

Professor: OK! So, any other questions on Student 1? ..., what would we have to do to fix their answer?

Gessica: Five-sixths of one candy bar.

Professor: Yeah, you can either do $\frac{5}{6}$ of one candy bar or ...

Tanny: Could we say five-thirtieths of the candy bars? - That is $\frac{1}{6}$.

The fraction concepts and operations activities were designed so that PTs would arrive at different solutions. With some in-class tasks, the directions were purposely left open so that PTs 
would understand that multiple solutions could be obtained and that they would be expected to arrive at a consensus about what could be counted as correct mathematical solutions.

As PTs moved to the next task in fractions Day 3, the sociomathematical norm of what constitutes a mathematically different solutions which includes a different answer or a different way to get the same answer was gradually becoming stable or established in the classroom. PTs started to provide different solutions without being prompted to do so by the Professor. This can be seen in the fractions Day 3 task (Appendix E), when the class was discussing the identification and creation of the whole.

Suppose a rectangle is partitioned into five same-sized parts and two of the same-sized parts are shaded.

a. Can you see $\frac{2}{5}$ of something?

b. Can you see $\frac{5}{2}$ of something?

c. Can you see any other fractions represented? How?

Problems "a", "b", and "c" were presented in order to see if the PTs could figure out what the whole might. However, Gessica presented a different solution for problem "b", without being prompted beforehand by the Professor to do so. This was the first instance that a PT suggested that there was a different answer from what was just presented.

Gessica: $\quad$ For " $b$ " I think there is a different answer, so if you change the whole because it doesn't say the rectangle is the whole, so if you change the whole and you said the two shaded are the whole and there is five-pieces total that you could do, five-over two, not halves. But wouldn't it be different like you wouldn't.

The professor had regularly been soliciting solutions which were different from those already discussed using different question formats. She frequently asked, "What is another way?", "Did any of you get a different answer?", etc. Gessica's responses was the first response where a PT provided a different solution without being prompted by the Professor beforehand. Thus, the 
norm of knowing what counts as a different solution was introduced and established early during the unit. In this example it was initiated from the student which indicates it was starting to become established.

Throughout the fraction concepts and operations unit, the professor did not have to reestablish what constituted a different solution. Though some PTs struggled to explain the difference in mathematically meaningful ways, the conversations on what made the solutions different were generated by PTs. However, the Professor played a definite role in engaging the PTs in open-ended discussions to allow for a variety of solutions and in organizing tasks that kept the idea of different solutions in the forefront of the discussions.

\section{Classroom Mathematical Practices}

Classroom mathematical practices are the taken-as-shared ideas, which are the collective activity of the classroom community. They emerged as the professor and the PTs discussed problems and solutions on specific mathematical topics. Classroom mathematical practices describe the accepted means of explanation and justification which develop within the classroom community (Cobb \&Yackel, 1996; Rasmussen \& Stephan, 2008). Although they are related to social and sociomathematical norms, classroom mathematical practices are content-specific and arise in the mathematical arguments that PTs make in the context of whole classroom activity. They describe sets of taken-as-shared ideas related to a particular kind of mathematical activity, whereas social and sociomathematical norms are general ways of participating in the classroom. Classroom mathematical practices that were established as part of this study were determined using Stephan and Rasmussen's (2002) and Rasmussen and Stephan's (2008) three-phase approach for documenting collective activity. The first phase involved transcribing the videos from each class sessions and analyzing the transcripts using Toulmin's (2003) argumentation 
scheme to develop argumentation logs. Argumentation logs were then analyzed to determine which ideas were becoming taken-as shared, and a summary of the findings would be presented. Finally, the last phase involved using the mathematical ideas chart to determine which classroom mathematical practices had emerged during the five-week period. Several ideas appeared to be taken-as-shared before the fraction concepts and operations unit started (see Table 3). These included the idea that (a) fractions are parts of wholes, (b) fractions are comprised of equal parts, (c) partitioning does not have to be equivalent as long as everyone receives the same amount, (d) a unit fraction can be iterated, (e) common denominators can be used to compare fractions. These ideas did not always shift in functions and were never questioned.

\section{Partitioning: Equal-Sharing}

On the first day of instruction, the class was given a task of sharing a whole into equal parts (Appendix B). Thus, the idea of equal sharing was brought into the class discussion. For example, with the following fractions day 1 task, the class began developing different ways of partitioning.

For each of the following problems:

A. Draw a picture to solve;

B. Explain and justify what you did to solve the problem.

1. How much candy would each person receive if 6 people share 5 candy bars equally?

2. How much candy would each person receive if 5 candy bars are shared equally among 3 people?

The PTs used several strategies to partition the five candy bars equally among six people. They partitioned the quantities into fractional units that suggested PTs had prior concepts of a unit fraction. One of the PTs, Tanny, used a common strategy which involved partitioning each candy bar into six pieces. This showed strong evidence of her anticipatory thoughts or strategies prior to making subdivisions when calculating how many pieces would each person expect if the 
candy bars were to be cut into sixths. When asked what she did to get the answer, the warrant for her argument was the common partitioning method which offered her the opportunity to give each of the six people one piece from each candy, for a total of $\frac{5}{6}$ of a candy bar per person.

Professor: Ok, Tanny, what did you do with yours?

Tanny: $\quad$ Ok! I put like — so draw a candy bar — so the numbers are a lot—-goes down - it is like, one, two, three, four, five candy bar and then, I split up into six people - so each candy bar at six, which is the reason why I got $\frac{5}{6}$. Like, on top I did shade again that each got $\frac{1}{6}$ of each candy - so that they got $\frac{5}{6}-5$ out of 6 pieces - each got $\frac{5}{6}$ of each candy bar. (Data)

Professor: If I am looking at this piece, how much is that?

Tanny: That is one-sixth. There is five of them. (Warrant)

Other PTs partitioned by using the biggest pieces possible first. Janna used this method by taking the first three candy bars and dividing them in half. She then divided the two leftover candies into thirds, which gives each person a third. Finally, she reverted to the procedure to add the one-half and the one-third to get her final answer, $\frac{5}{6}$. Her final answer, which was still obtained using partitioning into bigger pieces and the common denominator standard algorithms, was accepted, provided that the mathematical procedures were correctly executed and contributed to the advancement of the mathematical activity. Yet the class had to discuss the mathematical justification for the standard algorithm method. So, Janna referred the denominator as the number of parts the whole was divided into. Within the conversation of combining pieces to arrive an answer of $\frac{5}{6}$, Janna discussed fractions in terms of what the denominator of a fraction represented in order to justify how pieces are combined (see Figure 5).

Professor: And then, Janna, what did you do with your problem one?

Janna: I took the six people—so I took a number that goes in six, which is three: I divided it by two to get three. I took the first three and divided those in half and then so that each gets one-half and then there is two candy bars leftover and then, I took-I divided those in the thirds because you can't divide it in halves when to equal it for six people. (Data) 
Professor: You're talking about the two leftovers?

Janna: $\quad$ Yeah ... the two leftovers ... So I divided them in the thirds and so each got a thirds so that I added one-half and one-third and then I had to like to make the denominator the same ... so it was $\frac{3}{6}+\frac{2}{6}$ equals $\frac{5}{6}$. (Data)

Professor: OK, this one has come from where?

Janna: $\quad$ From the first three, each got a half. (Data)

Professor: OK! The one-third was ...

Janna: $\quad$ From the two leftovers. (Data)

Professor: Alright! Are there any questions on these at all?

[No questions]

Janna explained how she took a number that goes into six, the denominator as being the number of parts the whole is divided into. Even later when she combined the pieces together the denominator stayed the same because it represented how many equal parts into which the whole was divided. Although the data provided some evidence and was never questioned, this was the only instance where this idea was discussed and it did not become a sufficiently familiar idea for it to be claimed that it was taken-as-shared. However, the idea that the denominator represents the number of pieces in the whole was introduced while PTs were working on partitioning and combining pieces together using the biggest possible pieces.

The second task which was presented on the first day of fraction instruction required PTs to share 5 candy bars among 3 people. Tanny claimed each person would receive $\frac{5}{3}$ of a candy bar. She argued using a repeated warrant of the common strategy that she used for problem 1 to validate her solution. She partitioned each candy bar into three equal pieces and gave $\frac{3}{3}$ of a candy bar to each person from the first three candy bars and an additional $\frac{2}{3}$ of a candy bar from the last two. Everyone ended up getting five pieces. 


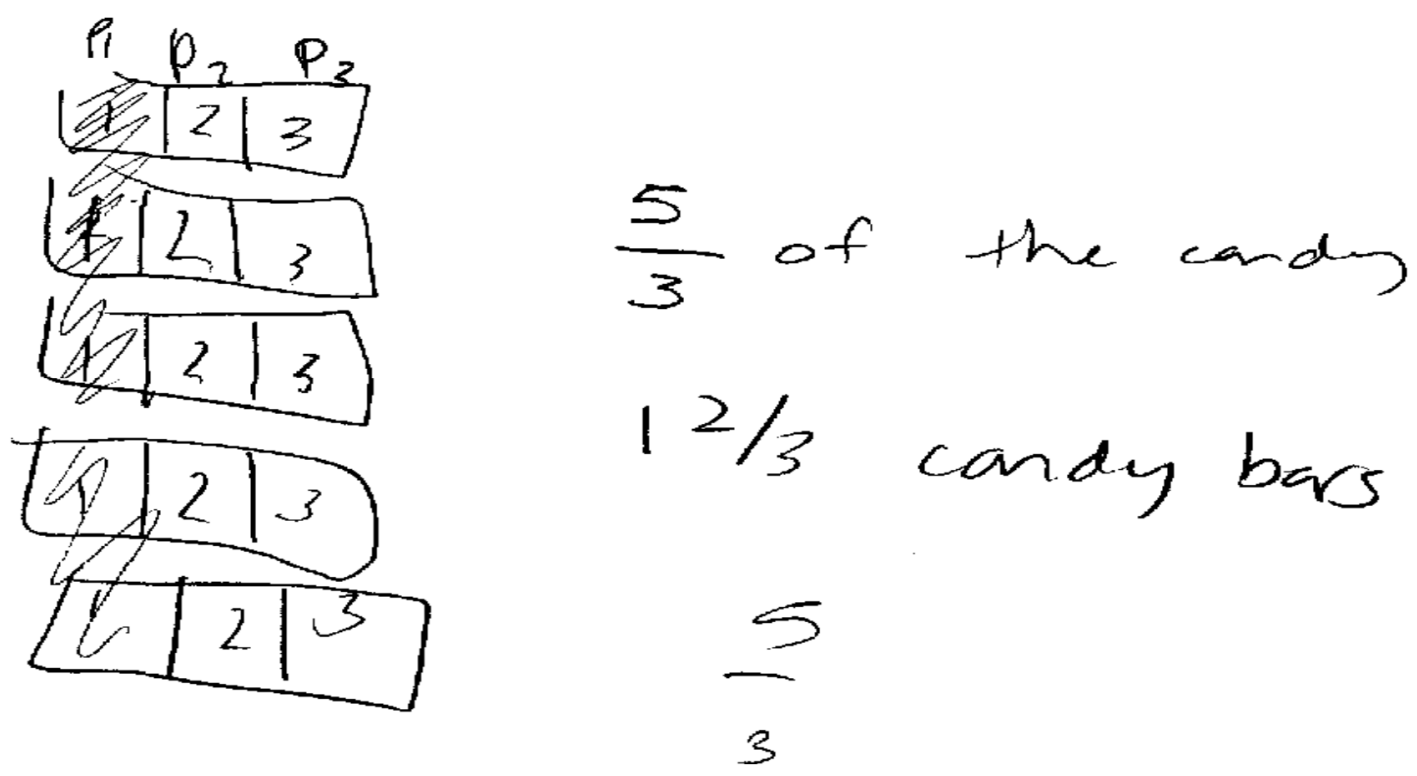

Figure 5. Five-thirds of the candy bars.

Professor: How did you get five-thirds?

Tanny: $\quad$ Because they got five ... pieces..., yes! Yes! The candy bars are three ... (Data)

Professor: OK!

Tanny: $\quad$ And the people are five.

Professor: OK!

Tanny: $\quad$ Then, five over three..., that is what each gets. (Data).

Similarly, Irica used the common partitioning strategy for task 2 and, in her picture, she divided the five candy bars into thirds. Her picture looked like a $5 \times 3$ grid, with fifteen $\frac{1}{3}$ sizepieces. She gave away one piece from each candy bar and ended up with five $\frac{1}{3}$ pieces. Another student, Reagan, provided a warrant for Irica's solution using their group picture (see Figure 2), which showed five rows, with three in each row, with one column completely shaded.

Professor: Irica, how did you get the five one-thirds?

Irica: $\quad$ So, if you divide the five candy bars into one-third or into thirds - it is fifteen one-third-size pieces of candy bars, and each person will get five. If you divide fifteen by three- - each person gets five one-thirds size pieces. (Data)

Professor: OK.

Reagan: If you look at the picture - because it is five down and three this wayso five one-third size-pieces. (Warrant) 
Throughout the discussion of various partitioning situations, not everyone included the idea of fraction being composed of equal parts. For example, in Irica's picture $\frac{5}{3}$ and $1 \frac{2}{3}$ were written as possible solutions, but, nobody mentioned the idea that her partitions were equal. They just took that to be understood. Therefore, the possibility of the partitions had to become equal was already established on the first day of fraction concepts and operations instruction when students were working on problem number 2 (see Appendix B). As the PTs were already familiar with the idea that the partitions had to be equal, this idea may not have been taken-as-shared during the class, but it is a taken-as-shared piece knowledge that the PTs were already had from the beginning. It is a mathematical practice, but not one which was developed in the class.

\section{Unitizing}

Unitizing incorporates three aspects of reasoning with fractions. The first is developing a unit fraction. The second includes iterating with unit fractions. The third is developing a composite fraction or whole of one. Thus, unitizing could help the PTs to think and reason about equal partitioning and shares as they were constructing and reconsidering their results and interpreting them in terms of initial quantity (Lamon, 1996). Unitizing ideas started on Day 1 of fractions when PTs were developing a unit fraction from another fraction. The following wholeclass discussion occurred within the problem of sharing candy bars equally among six people (see Figure 1).

Professor: Ok, Tanny, what did you do with yours?

Tanny: $\quad$ Ok! I put like — um, so draw a candy bar — so the numbers are a lot—goes down - it is like, one, two, three, four, five candy bars and then, I split up into six people - so each candy bar at six, which is the reason why I got $\frac{5}{6}$. Like, on top I did shade again that each got $\frac{\mathbf{1}}{\mathbf{6}}$ of each candy- so that they got $\frac{5}{6}-5$ out of 6 pieces - each got $\frac{5}{6}$ of each candy bar. (Data)

Professor: If I am looking at this piece, how much is that? 
Tanny: That is one-sixth. There are five of them. (Warrant)

Tanny was explaining to the class how to determine how much of a candy bar everyone receives after partitioning each candy bar into sixths. Tanny used unitizing concepts to warrant her data of breaking $\frac{5}{6}$ into 5 one-sixths. She was able to determine the whole for the fraction $\frac{5}{6}$, stating, "Each got $\frac{1}{6}$ of each candy bar."

A similar argument was used by Irica when the class was discussing their solution to sharing 5 candy bars among 3 people in fractions Day 1 . Irica used the unit fraction $\frac{1}{3}$, and also used unitizing concepts to warrant her data of breaking $\frac{5}{3}$ into 5 one-third pieces (see Figure 2). In other words, unitizing in this way, 5 one-third pieces per person, did present the class with a situation involving how to find the whole and remainder and conceptualizing it in division, which the class would discuss later in fraction operations. However, three concepts within unitizing were established, which included identifying or finding a unit fraction from a composite fraction, iterating and developing a composite unit of one or unitizing in terms of the whole, and iterating a unit fraction from composite fraction.

Professor: Irica, how did you get the five one-thirds?

Irica: So, if you divide the five candy bars into one-thirds or into thirds-it is fifteen one-third-size pieces of candy bars, and each person will get five. If you divide fifteen by three- each person gets five one-thirds size pieces. (Data)

Professor: OK.

Reagan: If you look at the picture- because it is five down and three this wayso five one-third-size-pieces. (Warrant)

Irica's group converted $\frac{5}{3}$ into $1 \frac{2}{3}$ and wrote it next to their group picture. From the picture and their conversation, it was clear that Irica's group used the unit fraction $\frac{1}{3}$ as data to justify going from $\frac{5}{3}$ to $1 \frac{2}{3}$. 
Iterating a unit fraction. Finding a unit fraction from a composite fraction did not become taken-as-shared until the fourth class session. During the fourth day of instruction the class was presented with the Charlie Brown problems (see Appendix F, Problem A and Problem B) and they generated a discussion about discrete versus area models. The activities were also designed so that students would understand that they need to find a unit fraction, iterate that unit fraction, and develop a composite unit of one in order to solve the problems using area and discrete models.

In the first problem (Appendix F, Problem A) Reagan used discrete models.

Charlie Brown takes two-fifths of the pattern blocks that Lucy has and gets a blue Parallelogram, a yellow hexagon, and two green triangles. What pattern blocks might Lucy have had before Charlie took any away?

Reagan added two-fifths (a blue Parallelogram, a yellow hexagon, and two green triangles) two times and one-fifth (a trapezoid and a parallelogram) because she wanted to get a whole which would be five-fifths, ten pieces. When the Professor asked Reagan, "How did she get one-fifth?" she responded:

Reagan: I added two-fifths because we want to get a whole which would be fivefifths. So, I knew that if you got two-fifths, four-fifths and then onefifths plus four-fifths, fife-fifths, which is the whole. (Warrant)

Therefore, Reagan introduced iterating a unit fraction from another composite fraction by taking half of two-fifth to figure out what the one-fifths is, and a composite unit one by adding two-fifth two times and one-fifth.

Students took a few minutes to discuss the next problem (See Appendix F, Problem B) in Day 4. When the class reconvened, Irica presented an argument similar to Reagan, but using both area and discrete models so that the solution made sense to the whole class 
Pigpen has three green triangles and three blue rhombi pattern blocks. This is threesevenths of what Lucy has. What pattern blocks might Lucy have had?

Irica: $\quad$ OK, so three green triangle and three blue rhombi, I drew that out and that equals to three-sevenths. So, then, I just doubled it. Three-seventh plus three sevenths is six-sevenths. And I know I need one more sevenths and I figured out if there are nine triangles in a group of three-sevenths, that one sevenths will be three triangle. So, my whole would be twenty-one triangles for seven groups of sevenths. (Data)

Professor: Questions? OK for the area representations, did you guys get something equivalent to twenty-one triangles? [Students nodded their heads in agreement]

Irica: $\quad$ I did. And then for discrete he has three green triangles and three blue rhombi that would be six pattern blocks all together and six pattern blocks equals to three-sevenths. One-seventh has to be a group of two pattern blocks. So I drew three-sevenths which are his six blocks, whatever they need and that $I$ knew one-sevenths is a group of two and I need fourteen of those to get to seven-sevenths, so that would be fourteen pieces. (Data, Claim)

Professor: Alright! Questions?

In the class discussion, Irica came to the board to discuss how her group solved the problem using area and discrete models. In this discussion, Irica used unit fractions and a composite unit of one to assist her to arrive at her answer. Both arguments were represented as data in her discussion and were not questioned. She also used iterating a unit fraction as part of her solution process.

Irica's idea was that she would need seven equal parts because the $\frac{6}{7}$ required her to find $\frac{1}{7}$ of the whole first. Once Irica found the unit fraction of $\frac{1}{7}$, she then introduced iterating a unit fraction as implied from both of her statements involving the area and discrete models. Only data were presented and no one in the class questioned Irica's process of finding a unit fraction from another composite fraction or the composite unit of one. The warrant was no longer needed, the justification for which went without saying because PTs were able to make use of the same strategy repeatedly. It should be noted that, before Irica, Reagan used the same strategy 
when the class was presented with the Charlie Brown problem (Appendix F, Problem A) and introduced iterating a unit fraction from another composite fraction by taking half of two-fifth to figure out what the one-fifths is, and a composite unit one by adding two-fifth two times and one-fifth. It became a familiar idea that that shows that the PTs had developed considerable potential for solving fraction problems and had well-developed schemes for dealing with units and unit relationships. Thus, those two ideas, finding a unit fraction from a composite fraction and then a composite unit of one, became taken-as-shared.

Iterating a unit fraction from composite fraction. In the following problem (see Appendix F, Problem C) in Day 4, the PTs were given a situation where they had to find a unit fraction from a composite fraction to solve a problem using only an area model. This was possible when the PTs could keep pieces or whole pieces in a given problem.

Lucy has four-thirds of the pattern blocks that Linus has. Lucy has five green triangles and a red trapezoid. What pieces could Linus have had?

Yosephenie claimed the solution for the above problem was six triangles or two trapezoids. Tanny provided data for Yosephenie's claim. No-one questioned Yosephenie's claim and Tanny's data. Therefore, there was no need for a warrant for the solution. Once Tanny figured out the unit fraction, she was able to reiterate Linus's pattern blocks (see Figure 6). Although, another preservice teacher, Pulianna, claimed four pieces as a solution for the discrete model, her claim was not accepted for, no-one in the class was able to provide data for her claim.

Professor: What do you guys get as an answer for "c"?

Yosephenie: They are six triangles or two trapezoids. (Claim)

Professor: How did you get it? Did any of you come up with anything different than something equivalent to six triangles?

Pulianna: For discrete it is four pieces. (Claim)

Professor: Ok, I will get to that in a second, so six triangles or two trapezoids. How did you get it? 
Tanny: The whole is six triangles. (Data)

Professor: Ok, so with the picture how would we get it?

Tanny: $\quad$ You just draw five triangles and a trapezoid. Then, you split that in four parts - four one-thirds part- there is two triangle in each. So if you want the whole, it is three times two, which is six. (Data)

Professor: Let me make sure ...

Tanny: That is OK.

Professor: I know you split up the trapezoid into three separate triangles.

Tanny: Huh.

Professor: Yeah.

Professor: OK! What did you say you got for the whole?

Tanny: Six.

Professor: Six?

Tanny: $\quad$ Triangles.

Professor: OK, questions? For you guys this is what you did to get the six triangles or who said six triangles?

Irica: $\quad$ Yeah, that was basically what I did. I just drew it out multiplied it by two to get six. (Data)

Professor: OK, so, can you — what did you say you did for the discrete?

Irica: $\quad$ Hum ... so I just like did a little dot because otherwise I will get confused with the shapes ... so six dots... and I need that was equal to four-thirds and ... so, wait...So, no, I did not do it right then.

Professor: Ok! So, how many pieces were they had to start with? If we were looking at the discrete.

Students: Six.

Professor: The six, yeah, so, with this particular type of problem, if you have six pieces to equal to four-thirds, if you can't break the pieces up. Is this going to work?

Students: No. (Claim)

Professor: Alright, questions?

[No Questions] 


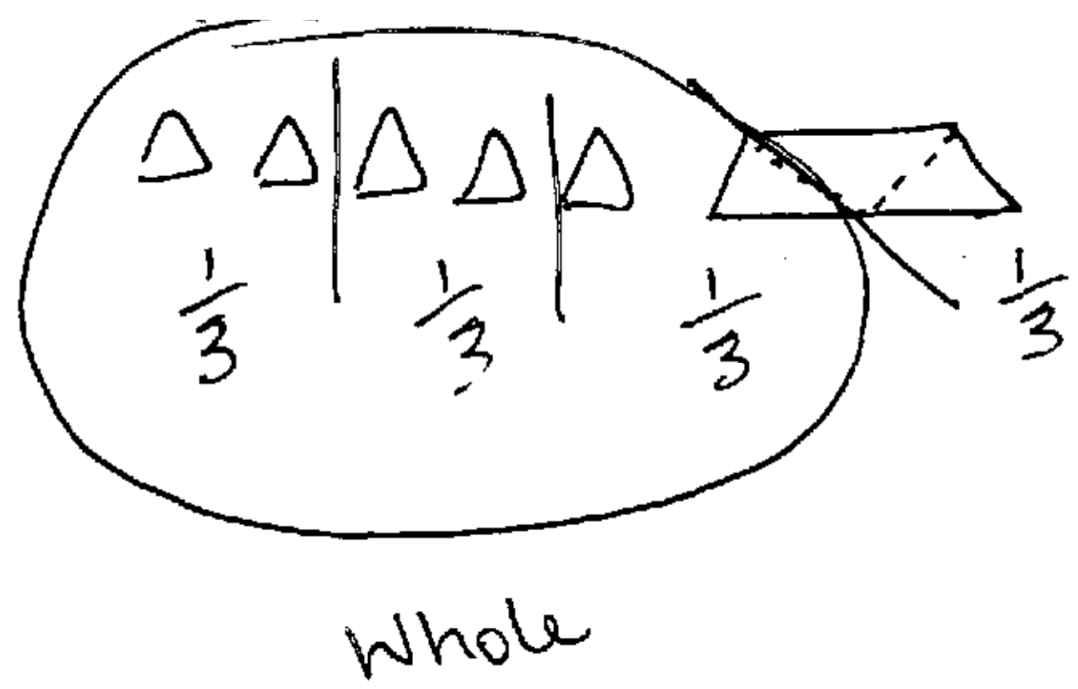

Figure 6. Area model.

As we have seen from the above conversation, Pulianna's claim of four pieces was incorrect. Therefore, in this case, the discrete model did not work and started to fall apart. The discrete representation is only going to work if the PTs could keep pieces whole, as had been possible in the previous problems (see Appendix F, Problems A and B)). But for this problem (see Appendix F, Problem C), the PTs were not going to be able to take six pieces and divide them up evenly into groups of four without actually physically breaking up the piece. This is a type of problem where only the area model was going to work. Therefore, the solution for this problem would be equivalent to, in this case, six triangles. The PTs could say two trapezoids, one hexagon, or split it apart into six triangles.

When the class moved on to the "paycheck problem" (see Appendix G) on fraction Day 5, they were also asked to find a unit, iterate that unit, and develop the composite unit of one in order to solve the problem (see Figure 7).

Gessica: First, I drew a rectangle that represents the whole check she got and then I split it up in to sixths, because it says she spent one-sixth of the money on food. So, I went down, so split it into sixths, so then one box was for food, I put "F". So, "F" for food. And she spends three-fifths for of what 
remains on her house payment. So, now so that, now you have one, two, three, four, five- so five up and down left, three of them go give for the house payment ... house payment, house payment, house payment and then it says she spends a third on other bills, but now you only have two vertical boxes so I split them horizontally into thirds, so one, two, three. One box one-thirds for other bills that is why I put "OB". And finally she spends one-fourth, the remaining on entertainment so you have four boxes left, so then one, two, three, and four. So, one-fourths of that is one box, for entertainment. And this activity leaves her $\$ 150.00$ dollar put for saving, so you have three boxes left. That is way I put "S" for saving. So, each box was $\$ 50.00$, so then to get the total amount, I made pieces just to make little square which is worth's $\$ 50.00$ and then I just added each box and I got \$900.00. (Data)
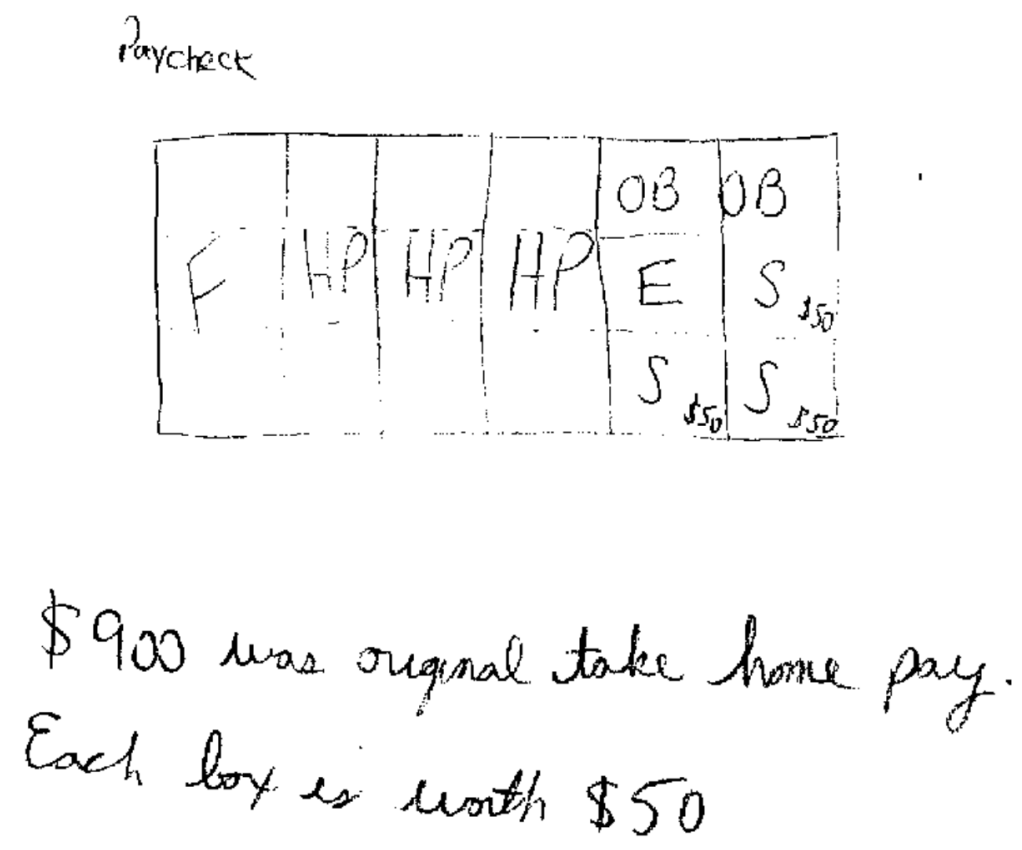

Figure 7. The original paycheck

Gessica's method was consistent with unitizing in that one whole for the problem was equivalent to 18 individual pieces and it takes eighteen 50 pieces or 18 individual $\$ 50$ bills to make the whole. Therefore, Gessica used one-eighteenth to develop a composite unit of one whole, which is $\$ 900$. 
Another preservice teacher, Tara, took one whole to be equivalent to six individual pieces and it took six $\$ 150$ pieces to make the whole. Tara used the one-sixth to develop a composite unit of one, which is also $\$ 900$.

Tara: $\quad$ I did six times one hundred fifty. (Data)

Professor: How did you get that?

Tara: $\quad$ Because each third-every three boxes is one-sixth of the whole big box and three boxes is one hundred fifty. (Warrant)

The preservice teachers developed three mathematical practices within unitizing that became taken-as-shared. These included, (a) finding a unit fraction from a composite fraction, (b) iterating and developing a composite unit of one, and (c) iterating a unit fraction from a composite fraction. However, iterating a unit fraction was also taken-as-shared but seemed to be taken-as-shared before the fraction concepts and operation unit started because, even in fraction Day 1 when $\frac{5}{3}$ and $1 \frac{2}{3}$ were clearly written as possible solutions using pictures, the PTs did not mention the idea that the partitions were equal - they just took the notion of equal partitions as already understood.

\section{Equivalent Fractions}

The PTs used reasoning and sense making to show that two fractions are equal. For example, following the discussion that happened on Day 2, one of the PTs, Kanner, asked how Tanny got one-thirtieth. Tanny explained she got the 30 pieces total when she split each of five candy bars into sixths.

Kanner: I am still confused how she gets thirtieth?

Professor: How did you get thirty pieces?

Tanny: Um, five-sixths of the candy bars - each of the five candy bars divided in to six pieces. So five times six is thirty, and you change the fraction, then the six becomes thirty and the five becomes twenty-five, just like converting into equal fractions. (Data) 
Tanny provided data to justify that $\frac{5}{6}$ of the candy bars is the same as $\frac{25}{30}$ of the candy bars.

She immediately understood a common factor of 5 in 25 and 30. The progression from dividing 5 five candy bars among 6 people to understanding $\frac{25}{30}=\frac{5}{6}$ took time, but was aided by the instruction which allowed concepts of equivalence, multiplication, and division to start to establish as PTs develop understanding of factors and how pieces could be divided with no reminder. Thus, in fractions Day 2, the whole classroom discussion of such strategies introduced. The preservice teacher, Kanner, initiated a question which drew attention to equivalence relationships by helping PTs understand that different partitioning strategies could result in an equivalent amount.

In class Day 5, PTs, such as Yosephenie, were also found to represent equivalent fractions by drawing two separate pictures (see Figure 8).

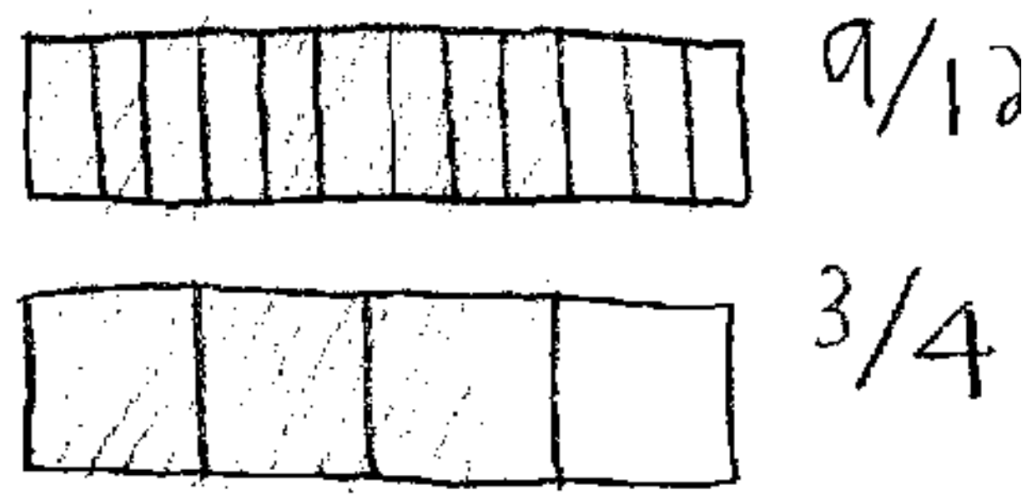

Figure 8. Two separate pictures to represent fractions $\frac{3}{4}$ and $\frac{9}{12}$ are equivalent.

Yosephenie: I drew two separate rectangles. I divided the first rectangle into twelve rectangular pieces and shaded nine of them. I divided the second rectangle into four pieces and shaded three of them. (Data)

Professor: Where is the fourths up here? [Indicating to the first rectangle that was divided into twelve smaller rectangular pieces]

Yosephenie: Um...

Professor: $\quad$ If I said, show me one-fourth up here?

Yosephenie: Three small rectangular pieces. (Data) 
Another preservice teacher, Tara, in Day 5 used an area model, that showed both equivalent fractions came out the same-size whole (see Figure 9)
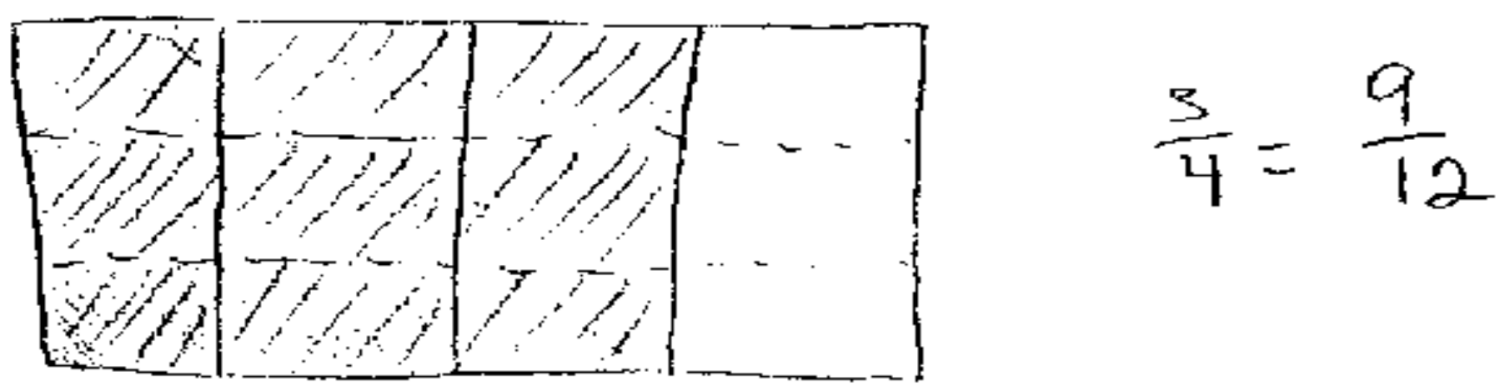

Figure 9. An area model to represent fractions $\frac{\mathbf{3}}{\mathbf{4}}$ and $\frac{\mathbf{9}}{\mathbf{1 2}}$ are equivalent.

Professor: OK, Tara what did you do with yours?

Tara: I started off drawing the three-fourths. First the black box and the long rectangle-there is three shaded in out of four and then, for the nine twelfths, I did horizontally across to make them into twelve-size pieces and there are nine technically shaded but totally different, then I used " $\mathrm{x}$ " in them and there are nine "X"s out of twelve boxes. (Data)

Professor: OK.

Tara: Just you can tell the difference between like the shaded part and then the circle basically the same thing, the blue circle three-fourth shaded in and then I split into twelve-size pieces, again there is nine x's out of twelve. (Data)

Rhannon used a discrete model to represent the two equivalent fractions (see Figure 10)

in Day 5. In her discrete representation, she had all the same, just like with the other triangles.

She had different pieces, but she did not physically cut the piece like the area model which was used above in Tara's representations. 


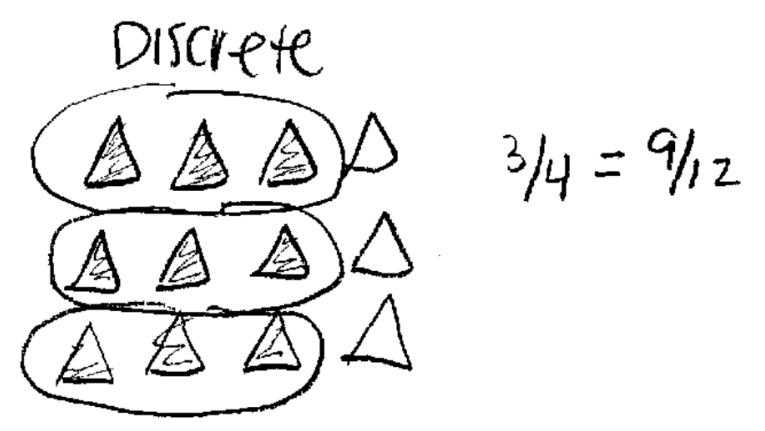

Figure 10. A discrete model to represent fractions $\frac{3}{4}$ and $\frac{9}{12}$ are equivalent.

Professor: OK, and then Rhannon can you talk about yours?

Rhannon: There is twelve total triangles and nine of them are shaded. But the group shows three-fourths - this group three-fourths [Showing to her drawing] (Data)

Professor: Ok, are there questions about the ones up here?

[No Questions]

It is evident that everything else was data and nothing was challenged or questioned by Day 5. Also, when I looked back at the details of the PTs argument and their pictorial representations in which the idea was used for evidence it seemed that the function of this idea shifted in such way which contributed to advancing mathematical activity. Sense was arrived at by justifying the claims using discrete and area model that was important to progress in the collective activity around equivalent fractions.

However, the ideas for equivalent fractions practice met several criteria, which built up the evidence for their taken-as-shared status. Therefore, in fractions Day 7, when Balerie explained what her group did to find the half way between one-fourth and seven-eighths, she said, "We change the one-fourth into eighths. So, it is easier to compare with seven-eighths. So, one-fourths is two-eights." But the professor asked, "Where did you get the eighths from?" Balerie offered her justification and wanted the class to make sense of her strategy involving reasoning about equivalent fraction in relation to the denominator (same-size whole). 
Balerie: We changed all into eighths. So, it is easier to compare since all will have the same common denominator. So, one-fourths is equal to two-eighths. (Warrant)

In fact, she also connected equivalent fractions with the number line, showing that onefourth is equal to two-eighth. This will be discussed in detail later in the section on number line.

Therefore, PTs understood how to partition to find equivalent fractions, especially with pictures that represent the same amount. The big idea with equivalent fractions, which is making sure that they both are out of the same size whole, was taken-as-shared by the class.

\section{Defining the Whole}

Defining a whole: Labeling fractions. PTs need to define wholes to represent fractions. The mathematical practice of understanding and defining the whole was initiated as early as the first day of the instructional sequence, as PTs tried to develop the importance of defining the whole. The first fractions task was designed so that PTs could start developing ways to define the whole representing equal sharing problems by drawings and when giving written explanations and justifications (see Appendix B). The intent of this task was to have PTs solve fractions problems in terms of their relationship to the whole and what that whole represented (Tobias, 2009).

PTs were asked how much candy each person would receive if 6 people share 5 candy bars equally. Tanny, instead of merely naming the exact amount each person receives as $\frac{5}{6}$,

proceeded to provide enough information in her data by labeling her solution as $\frac{1}{6}$ of each candy bar and by justifying her argument. This helped the PTs to develop "the idea of providing enough information when labeling fractions so that an exact amount could be determined as opposed to an arbitrary amount" (Tobias, 2009, p. 115).

Professor: OK, Tanny, what did you do with yours? 
Tanny. OK! I put like — um, so draw a candy bar — so the numbers are a lot—goes down - it is like, one, two, three, four, five candy bar and then, I split up into six people - so each candy bar at six, which is the reason why I got 5/6.

Like, on top I did shade again that each got 1/6 of each candy-so that they got $5 / 6$ - 5 out of 6 pieces - each got $5 / 6$ of each candy bar. (Data)

Professor: If I am looking at this piece, how much is that?

Tanny: That is one-sixth. There is five of them. (Warrant)

The need to define the whole and represent fractions, and the negotiation of an acceptable solution which included explanation and justification continued to the third day of fraction concepts and operation lesson, when students discussed their pictorial representation to the problem presented below (see Appendix E):

Use each of your manipulative sets to represent three-eighths and nine-fifths in three different ways.

In this task, preservice teachers were also asked to represent three-eighths and nine-fifths in different ways (see Figure 10 and 11). Although the Professor had already asked for different solutions and had had one preservice teacher from each group come out and do at least one of his/her representations on the board, it seemed that all of the PTs' contributions were different. They all used different manipulative sets, hexagon, tringles, squares, and circle. But, when the PTs actually went on to explain and justify the representations, all of them failed to put the whole next to the fraction for their answer and none clearly explained relationships between the pieces. Some of them failed to identify the whole or the unit. Writing the fraction to the answer was not going be enough because when we looked at these, there was no way to know whether the threeeighths was three-eighths "of what," and the same comment could be applied to the nine-fifthsnine-fifths was nine-fifths of what? This is because the issue of language and ways of defining a whole still needed to be developed so that the PTs would arrive at an acceptable solution. Although the Professor and the PTs developed an understanding of what constituted acceptable 
solutions on related equal sharing tasks of fractions Day 1 and Day 2, there was a brief regression in the class to progress in the collective activity when the third task on Day 3 was introduced to the PTs. Even if the Professor and the PTs did not discuss the criteria for what counted as an acceptable solution in relation to defining the whole and fraction representation in this new task, the class looked at the different manipulatives that the PTs used. However, the class judged that the explanation and justification were not acceptable. Actually, one can argue also, that the representations, $\frac{3}{8}$ and $\frac{9}{5}$, were not mathematically meaningful unless they could be explained and justified.

The intent of this task was to have all the preservice teachers label their drawings showing three-eighths of something. However, all the groups could not represent three-eighths, a fraction less than one, in mathematically meaningful ways. The need to identify the whole, when the whole is not obvious, became an issue to some of the group. To others, writing their solutions as three-eighths of something that could represent the exact amount was an issue. After every group drew their picture on the board, whole-class discussion started. The Professor wanted to talk about their solutions, but she chose to wait until the end to listen to each group's explanation and justification. For example, Sori did not mention about the whole (see Figure 11) that she used until she asked to do so by the Professor. In fact the Professor wrote "whole-1" next to her picture. Tara did talk about her whole, but she just wrote $\frac{3}{8}$ next to her picture (see Figure 12). PTs understood there were different ways that they could represent three-eighths. Although they got the correct solution, they needed to understand how to define and represent the whole (Tobias, 2013). They failed to understand that it was not going to be enough just to write the fraction for the answer to be acceptable solution. Yet, the Professor supported PTs' 
attempts to explain and justify their solutions and help them to develop an understanding of what it means to define the whole.

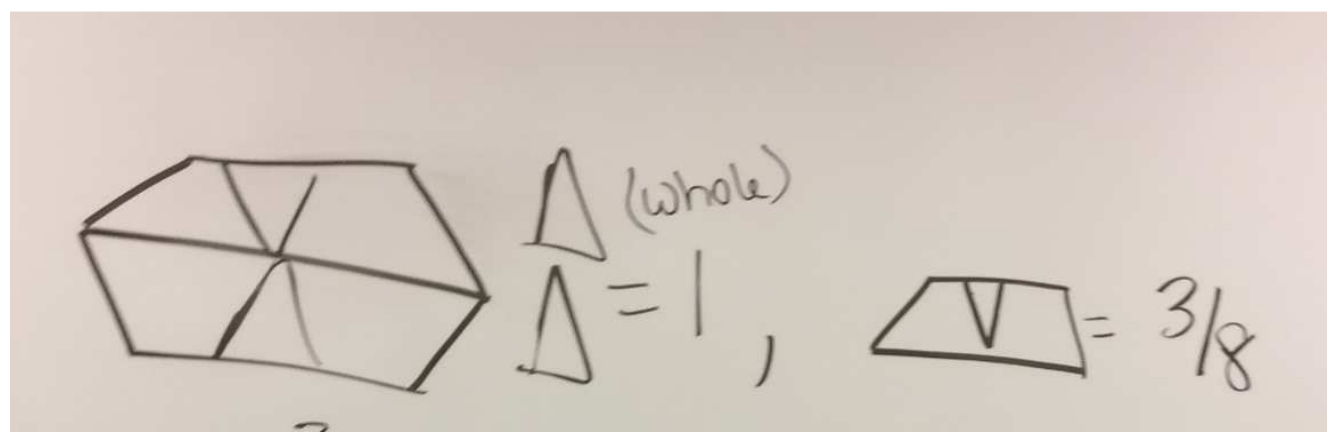

Figure 11. Sori's three-eighths representation.

Sori: $\quad$ I just put 8 ones together and then it will be eight and then I just took three of them - that is three-eighths. (Data, Claim)

Professor: So your whole is what?

Sori: $\quad$ It is a hexagon - or two trapezoids and two tringles. (Warrant)

Professor: OK! [While the Professor writing "Whole =1" next to the trapezoid and the two triangles]. How did you get three-eighths?

Sori: $\quad$ Because we just take three blocks away. (Backing)

Tara: $\quad$ For my whole, I drew a hexagon and two triangles, because there are eight triangles altogether and then for the three-eighth, I drew three triangles - it is three-eighths. (Data, Claim)

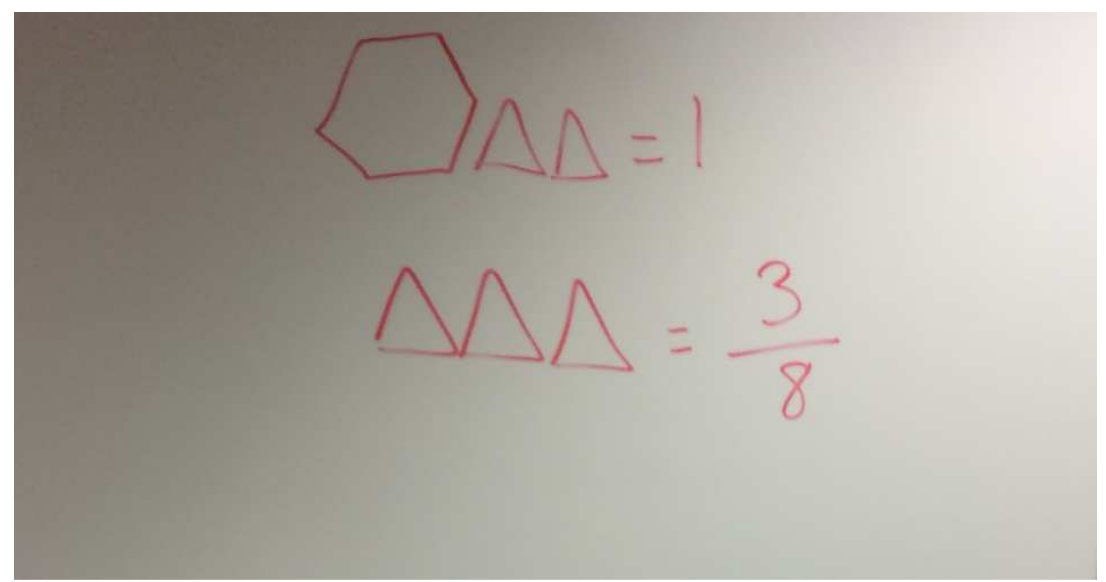

Figure 12. Tara's three-eighths representation. 
During the discussion which took during the second part of fractions Day 3 task

(Appendix E), the Professor repeatedly asked the preservice teachers "of what" questions, to make it clear that their argument still would not suffice as acceptable explanations and justifications unless they put the whole next to the fraction. Thus, the PTs had to define the whole, arriving at the correct fraction did not necessarily lead them to mathematically correct and acceptable solutions.

Professor: OK! The thing that you are going to have to be careful here is when you actually go to explain and justify these things is, it is not going to be enough just to write the fraction for the answer. You're going to have to put the whole here too. So, if we looked at these first three-eighths, that is here, the three-eighths is three-eighth of what? Which is what?

Revin: $\quad$ A hexagon - and two triangles. (Claim)

Tanny: $\quad$ Six triangles or a hexagon and two triangles. (Claim)

Professor: Which is going to give you how much all together.

Gessica: $\quad$ Eight triangles. (Claim)

Professor: So, there is going to be a couple of different ways that you can represent this. If you want the hexagon is the whole hexagon, you're working hard to get the specific what the whole is. This is going to include, basically every single fraction problem that we are going to do, here. There is like a couple of exceptions which we get into that as we get are going through topics. But you can't just say any answer is three-eighths, you going to think of three-eighths of what? In this particular case, it is going to mean threeeighths of eight triangles or if you took the hexagon, like you did here, you would say $\frac{3}{8}$ of a hexagon and two triangles.

However, an acceptable solution which uses "of what" was introduced and developed as PTs continually shared their explanations and justification in connections with the pictures they had, and these led them to start labeling fractions progressively. Although Revin, Tanny, and Gessica's made different claims which stated the "whole," they still used the Professor's hint presented in the form of a guiding question, "the three-eighths is three-eighth of what?" and did not labeling the fractions automatically. In fact, their claims were all accepted and the Professor also made a summarizing note in reference to the PTs' claims. However, the idea was still not 
taken-as-shared. There was no strong evidence to indicate this became taken-as shared idea even if data were no longer challenged. Yet, this led to the introduction of very important fraction language - stating that a fraction solution by itself is nothing and does not make sense without talking about what the whole is.

Defining the whole: Representing fractions. The instructional activities used in the next sessions (Appendix E) of fraction Day 3 continued to focus on the use of manipulative sets to represent fractions in different ways and on the issue of identifying and creating a convenient whole or unit. PTs' pictorial representations of three-eighths and nine-fifth in different ways, which involved more than labeling the whole, was an indication of a shift from telling the Professor the fractions and the whole to getting used to identifying and creating the whole as a means of justification. With this in mind, the professor constantly asked the PTs to talk about their whole. The PTs suggested several different methods to represent the fractions three-eighths and nine-fifths, including using hexagons, triangles, squares, and circles. But the professor was continually asking about the whole. To guide this development the professor asked, "So, what is your whole? So, your whole is what? The whole is represented by what in your picture? ... Of what?"

Identifying and creating the whole, which was the central focus for the fraction concept and operations unit and this was an area where most of the PTs encountered difficulties throughout the fraction lessons. From the conversations, we can see, for the most part, the professor contributed to the PTs' explanations by further questioning so that a joint mathematical practice of identifying and creating of a convenient whole emerged and was taken-as-shared.

When defining the whole, there were a couple of different ways that the PTs used to represent different fractions. PTs were expected to name fractions in terms of what the whole 
represented, not just in terms of their relationships to the whole. For example, in the case of representing $\frac{3}{8}$ and $\frac{9}{5}$, if the PTs wanted the hexagon as the whole, they had to work hard to get the specific fraction. The Professor said, "But you can't just say any answer is three-eighths, you are going to think of three-eighths of what?" In this particular case, it is going to mean threeeighths of eight triangles or if they took the hexagon, like they did here, they would say it threeeighths of a hexagon and two triangles."

Bigger issues with defining the whole came with fractions greater than one, such as ninefifths. PTs needed to make sure that they still realized that the whole in this particular case, even if they thought of two circles - each has five $\frac{1}{5}$-size pieces — was actually going to be one circle. Those PTs who said two circles had to be careful because two circles would mean that they have a whole group of two circles, each with five $\frac{1}{5}$-size pieces, and in addition they would have another group of two circles, each with four $\frac{1}{5}$-size pieces shaded, which would give them $\frac{9}{10}$ of two circles as Vrittany claimed and justified in her solution. For those PTs who said that the whole was two circles, drawing two circles together would represent their one and then another full circle and $\frac{3}{10}$ of a circle, which would end up being $\frac{4}{5}$.

Some of the PTs used squares for this, and a couple of the pattern blocks pieces came up with for this one, but essentially, this is how this one ended up working. So, from the following fractions Day 3 conversation, at this point the PTs seemed to understand the need to specify correctly what the whole was and the fact that, depending on what blocks they used to represent, the whole potentially could change, was taken-as-shared.

Professor: If you look at the $\frac{9}{5}$ one, which is here, the $\frac{9}{5}$ is $\frac{9}{5}$ of what? $\frac{9}{5}$ of one circle or two?

Tanny: Two circles. (Claim) 
Professor: So that is the question. So, is it going to be nine-fifths of one circle or are they going to be $\frac{9}{5}$ of two? Why?

[No response from the students]

Professor: So, take like two minutes to talk about at your tables. Is it $\frac{9}{5}$ of one circle or $\frac{9}{5}$ of two circles?

[Students start to discuss in groups]

Professor: So what are we thinking?

Pulianna: One. (Claim)

Professor: Why is it one?

Pulianna: Because of the candy bar problem. (Warrant)

Professor: What would the fraction we use out of two circles?

Vrittany: Nine-tenths. (Claim)

Professor: How did you get it nine-tenths?

Vrittany: Because there is five sections of each circle, there will be ten sections like "ten triangles" or pieces all together and there is nine of them shaded in, so if you have two, there will be nine parts of the ten. (Data)

Professor: So which is it, the one circle or two for the whole?

Vrittany: One. (Claim)

Professor: Questions? ... Ok, Questions about this problem at all? [Pause - No-question]

In this case the whole ended up being the one circle. That was why the class had been asked to consider candy bar activity when they started this unit. Pulianna recognized that, and used to justify Vrittany's claim. Defining wholes for fractions greater than one were also more difficult for the PTs.

Therefore, defining the whole for fractions greater than one started to be developed in the class, and shifted in function in the discussion. The idea of needing to define the whole shifted from a data (when PTs had been working with their manipulative sets to represent three-eighths and nine-fifths in fractions Day 3 in the previous discussion) to warrant now. So, the idea of the whole could potentially change depending of what blocks PTs used actually taken-as-shared.

Defining the whole: The language of fractions. As explained earlier, when the class moved to fraction Day 2, the idea of defining or labeling a whole using correct language was brought into the conversation. For example, Tanny used this argument as a warrant for her 
solution of Student 1's response (Appendix D) in determining whether or not the solution is

correct and why students were asked to consider how much candy each person would receive if 6 people were to share 5 candy bars equally.

Tanny: $\quad$ So five-sixths of all the candy bars. He said the candy bars are the whole. (Warrant)

Professor: So, you are saying this means [indicating to the five candy bars] all of them.

Tanny: $\quad$ All of the candy bars, because he should have said each of you trying to do five-sixths of one candy bar. So ... yeah, then I just divided 30 pieces - 30 little pieces over there. See all of them-25 on top- 5 in each and the bottom is 30 . So if you color 25 pieces - all said that candy is 25 pieces, and there is only 5 pieces left to share among everyone else, so it is impossible! (Backing)

Within Tanny's answer of "incorrect," the idea of defining or labeling the whole wrongly became the warrant for why Student 1's response was incorrect. During the conversation, the professor questioned Tanny about what she meant when she said the candy bars are the whole. Thus, there was a need for a backing for what was meant by the "whole." Tanny explained that it meant all of the candy bars. Obviously, we should not just say a fraction by itself, like fivesixths, because that is not going to mean anything until we actually put a whole with it. But when we put the whole, we also have to use the correct fraction language. So, with this particular student, as Tanny explained, if we are using a whole of all five candy bars, which in this case was not going to work because like if one person gets five-sixths of all of these, that means he/she is getting almost everything. There would then only be five pieces left, which may be given for the other five people. So, Student 1's response is not going to give everyone the same amount. If one person gets five-sixths of all of it, he/she would get 25 out of 30 pieces. Therefore, there would not be enough candy to share among the other people. The PTs who said Student 1 was correct because of the lack of knowledge of fraction language immediately drew 
back from their initial thinking. Tamie, one of the PTs who said Student 1 was correct, was rejected on the ground that her explanation and justification were wrong.

Professor: Tamie [One of the students who said they were correct], can you say again what you just said earlier?

Tamie: I don't know [Students laughing]

Tamie: $\quad$ Automatically we just assumed it was correct ..., I guessed we missed the wording "of" but ... (Warrant)

Professor: OK! So, is Student 1 is correct or incorrect?

Tamie: $\quad$ So incorrect...

Students: Incorrect.

However, the taken-as shared idea of identifying the correct way of labeling the whole or understanding the language of fractions also continued to be used in later tasks in fractions Day 2. PTs were providing a label to explain and justify the correctness and incorrectness of a solution without being prompted to do so.

In the passage below, Balerie claimed Student 5 was incorrect, but her backings were wrong because she failed to realize that when we have the five candy bars to start with and Student 5 comes up and says each person - it meant everyone is going to get $\frac{5}{6}$ of each candy bar. As Janna explained, that is going to mean, there will be $\frac{1}{6}$ of each candy bar left for the other five people so that they could have at least one from each candy bar, which makes it impossible to divide the candy bars equally. It was very similar with Student 1, who was also incorrect, and was used as a warrant for Student 5. Student 5 could have done it the same way. With their whole being all 5 of them together, that is essentially what Student 5 is doing, but Student 1 is doing each one individually, saying one person is going to get $\frac{5}{6}$ from each one.

Professor: Then, Student 5?

Balerie: Isn't it basically the same as Student 3. (Backing)

Professor: So, yea! How are five and three similar?

Balerie: $\quad$ Each candy bar and one candy bar the same thing. (Backing) 
Janna: $\quad$ So, it will be the same one. Each will be like ... each like 5/6 of every single one ... not all the five. (Backing)

Professor: Say that again.

Janna: $\quad$ Five-sixths of each candy bar means five-sixths of like— the first bar, the second bar, the third bar, the fourth bar, the fifth bar. Five-sixths of one is just one bar not the whole. (Backing)

Professor: I am not going to draw the whole picture out, but ... pretend I have all the five candy bars up here, you are saying 5/6 of each one means this [showing the drawing that depicts five-sixths of each candy bar shaded]

Janna: Yeah!

Professor: So, did you say they were correct or incorrect?

Janna: $\quad$ I do think they were incorrect ... (Claim)

Balerie: Incorrect

Jenna: $\quad$ I don't know..., now they really want $5 / 6 \ldots$ get all of those ... there is like 1/6 of each candy bar left...right? (Data)

Tanny: I think it is similar to number one, Student 1, which was also incorrect. (Warrant)

Mathematical practices also continued to emerge in fractions Day 2 as the PTs discussed their solutions to a subsequent instructional activity which involved finding how much candy each person receives if 5 candy bars are shared equally among 3 people, and asking the preservice teachers to determine whether or not the following students' responses were correct and why.

Student $1: \frac{5}{3}$ of the candy bars.

Student 2: $1 \frac{2}{3}$ of 1 candy bar.

Student 3: $\frac{1}{3}$ of 5 candy bars.

Student 4: $1 \frac{2}{3}$ of 2 candy bars.

Student 5: $\frac{1}{3}$ of each candy bar.

Vrittany argued Student 3's response was correct and provided the data. Tara provided the data and warrant, one-third of the five candy bars, to justify the claim. Understanding the 
fraction language (of what) when labeling the whole (5 candy bars) were the bases for her solution.

Professor: So, if we are looking at Student 3 the one-thirds of five candy bars- this is going to be correct for what is up here, and why?

Vrittany: Yeah.

Professor: OK, why?

Vrittany: Five-fifteen which is one-thirds. Each person gets five pieces out of the fifteen and reduces to one-thirds. (Data)

[Tara raised her hand]

Professor: Go ahead, Tara

Tara: $\quad$ So, we just did like a box and cut it off into thirds and fifths across because it is the same, like what is one-third of the five candy bars. (Data, Warrant)

Tamie: $\quad$ So instead of looking at like separate candy bars, we just put them altogether. (Backing)

Professor: You just put them together.

Tara: $\quad$ Like the second candy bar on top of each other.

Tamie: Which is like one whole unit.

Professor: Yeah, I saw ...

Tara: $\quad$ We shaded in ...

Professor: Some other people did it this way too, though — like this ...

Tara: ... Yeah, and then we shaded so that the top part is in thirds and we shaded in one-third of the fifteen pieces. So, it is five down in just one column-like that. (Data)

Professor: OK!

Tara: And then, that is one-third of the five candy bars, which is fifteen pieces. (Warrant)

Similar to Student 1 from the previous task — concerned with $\frac{5}{6}$ of all the candy bars-

Student 5 was also incorrect. With this particular problem, as Tanny explained, as soon as they said all of the candy bars, they were just going to mean or refer to all of the candy bars and so, it was going to be impossible to give $\frac{5}{3}$ of everything. In addition, Tanny argued that the improper fraction $\frac{5}{3}$ and its equivalent, the mixed number $1 \frac{2}{3}$, are the same and showed that the person was giving more than the candy bars he had. With the introduction of defining the whole of one in fraction Day 1, it seemed it was easier for PTs to work with mixed numbers. So even though 
Student 1 says five-thirds, they were more than welcome to change this one into one and twothirds - if they would like it and if that was easier for them.

Professor: OK! So, Student 5 was kind of similar - what did Student 5 do?

Tanny: $\quad$ Each circle is one-third of each candy bar, so like, instead of like the oneone idea, each one say one, two, three - he circles the one-three each candy bar that is how we get. (Data)

Professor: In order numbers behind this - like that [showing the drawing].

Tanny: Yeah!

Professor: Did you say this one is correct or incorrect?

Tanny: $\quad$ Correct. (Claim)

Professor: OK! We will jump back up to Student 1. So, how many of you got Student 1 to be correct?

[No Hands]

Professor: Incorrect for Student 1?

[Seven students raised their hands] (Claim)

Professor: OK, why did you say incorrect? ...

Tanny: $\quad$ The same thing, like number 1 in the other side of this sheet, like he seems he is going to give five-thirds of all the candy bars which is basically he said, he is giving more than the candy bars-like more than the candy bars he did even have. (Warrant)

Professor: OK! Questions?

Although Tanny claimed what Student 4 was saying ( $1 \frac{2}{3}$ of 2 candy bars) was correct stating that we could draw two candy bars and split them into thirds and color the $1 \frac{2}{3}$, she failed to further validate her data, especially in relation to the given whole. However, the class questioned her judgement. Because, essentially what happened with Student 4, as Tara explained, if our whole is two candy bars and if we wanted to show one-third of two candy bars, we are going to have two pieces. Two-thirds is going to be the two from each one and threethirds is going to get us up to - the full two candy bars. So, right after that Student 4 is going to be incorrect because when they solved the problem each person is only getting 5 pieces. But, as soon as we do three-thirds of two that is actually going to give us 6 pieces already for each person and there is no candy left. 
Overall, the whole purpose of this type of task was to provide PTs opportunities so that they could talk about the language to be used with fractions. In every problem that they did in this task, they were not only required to tell the Professor the fraction, but they were also expected to tell her the whole which was being used and so that they were able to understand everything that they saw coming after the word "of" and had taken-as-shared the language to be used with fractions. Although the PTs started to understand and develop fraction language through fractions Day 1 and Day 2 tasks, throughout the fraction concepts and operations unit they still had difficulties with the difference between the languages of fractions, such as a candy bar, of one candy bar, of each candy bar, of the candy bars.

The instructional sequence of the third day of fractions task specifically targeted language issues (see Appendix E). The task was designed so that PTs could identify a specific fraction and a part, with a rectangle or a circle being the whole. The directions were left open so that a whole was not specified on purpose so that PTs could change it if they needed to do so. They just started with a picture where they had a rectangle that was cut into five pieces, with two of them shaded. The purpose of the problems was to see if they could figure out what the whole might be for this problem. If they could or if they could not, they would just explain that too. The task included fractions less than and greater than one.

When PTs were asked if they could see two-fifth of something, Tamie answered "Yes" and provided the warrant stating that five small squares equals one whole and two of the wholes are shaded (see Figure 13). Her solution was not accepted by the class because the professor wanted her to provide the exact amount to label the whole. So, the professor asked Tamie to answer two-fifths of what? Then, she said five-fifths. This illustrated how PTs continued to 
struggle defining the whole in terms of the solution without being prompted by the Professor to do so.
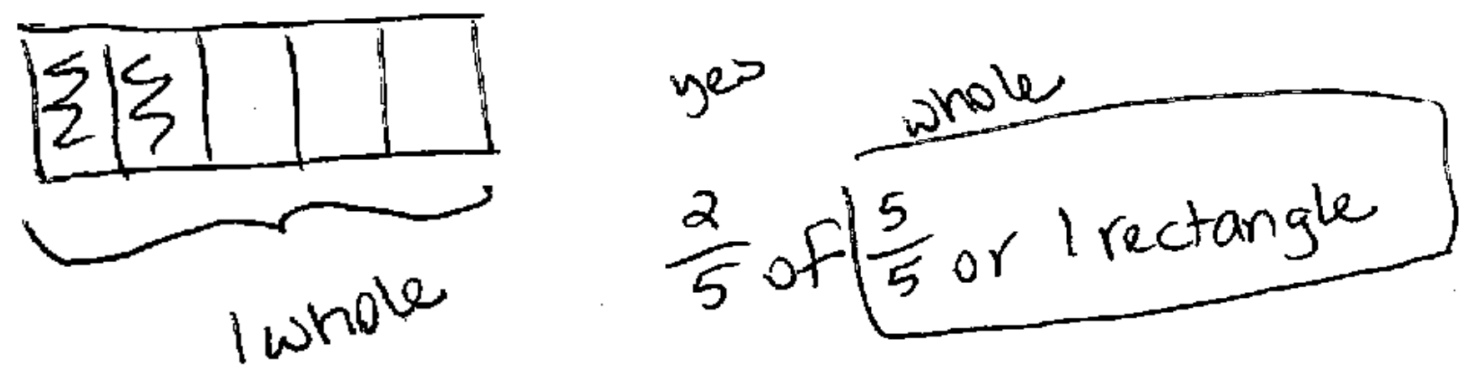

Figure 13. Two-Fifths of a Rectangle.

Professor: So for part "A," what did you guys get for that one?

Tamie: $\quad$ Yes. (Claim)

Professor: Yes? OK! How?

Tamie: $\quad$ Because there is five squares in total-like the whole. (Data)

Professor: Are you talking about each piece?

Tamie: The five pieces. Sorry, yeah ... there is five pieces equal to one whole and then two out of the whole are shaded, so it is two-fifths. (Warrant, Claim)

Professor: So, if we were to fill in this up "something", I will come to you in a second Irica, what would we replace the word "something" with, so if I said this is the two-fifths of ... what? Which is what?

Tamie: $\quad$ Five-fifths. (Claim)

Gessica: One. (Claim)

PTs valued the need to define the whole when discussing fractions. However, it became evident in the next conversation that there was still not a shift from the Professor highlighting that the PTs should define the whole to the PTs including the whole in their solutions. When the PTs asked "Can you see $\frac{5}{2}$ of something?" Irica said "yes" and argued that if the smaller rectangles are the rectangles that represent half-size pieces, it is possible to see $\frac{5}{2}$ something. Basically, what Irica was saying, for a rectangle to be equal to five-halves, two smaller rectangles together are going to be the whole. If each piece is one-half, she said we will have 
five total, which is five-halves. Gessica was also saying exactly the same thing, but differently.

She was confused with five-halves and the five over two. However, both Irica and Gessica's solutions were still missing the whole to work. So, the Professor had to ask the preservice teaches to define the whole. Pulianna automatically responded that the whole would be like fivehalves of two halves of one whole. Then, Irica provided the backing for Pulianna's claim by explaining that it was just saying that two-fifths of a rectangle is the whole and the whole is going to be five halves (see Figure 14). There was no need for a warrant and the class accepted the solution without further argument.
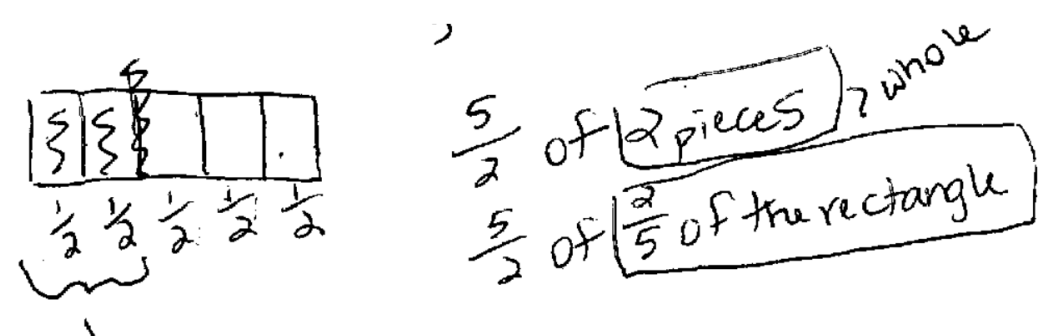

Figure 14. Five-halves of $\frac{2}{5}$ of the rectangle.

Professor: Irica, did you have a question?

Irica: $\quad$ Yeah! So, since it does not, in the question, tell us that it is the whole on purpose, so, like " $b$ " is true because of the one-half size pieces, because we don't know like if the rectangle actually is the whole because it does not say.

Professor: Oh! I see what you are saying ... what were you saying for the "b" part something about one-half?

Irica: If those smaller sections are the rectangles that represent half-size pieces, so two of those were a whole. It would take two and half of them to make one whole - which is five haves! (Data, Claim)

Gessica: No, wait! like for "b" I think there is a different answer, so if you change the whole because it doesn't say the rectangle is the whole, so if you change the whole and you said the two shaded parts are the whole and there is fivepieces total that how you could do, five-over two, not halves. But wouldn't it be different like you wouldn't ... (Data) 
Professor: I think that is the whole.

Tanny: $\quad$ Look one-half plus one-half is the whole, it is basically one-half — did you get it? (Warrant)

Gessica: No.

Tanny: $\quad$ Each piece is one-half. There are five pieces, five halves. It is basically what you are saying — exactly same thing, you are saying it differently. (Backing)

Gessica: $\quad$ Then never mind.

Professor: Yeah, I think you just referring to [Drawing]..., OK! So if you guys, I am not followed this so hard, so far, the conversation has been if we make these first two pieces a whole, Irica and Gessica were both saying that let us is going make each of pieces equal to one-half and you said there is five total, each does work. Right Irica?

Irica: $\quad$ Yeah.

Professor: OK! So, what is it that I will have that something here for this to work?

Pulianna: It would be like five-halves of - two halves of one whole. (Claim)

Professor: You could also say this is two-fifth of the rectangle if you want to keep the amount - that is in there, but you guys see where that one is coming from ... Are there any questions?

Irica: $\quad$ I think you can use by saying five-halves of two-fifths because ... Two-fifths of the rectangle is the whole. OK! (Claim, Backing)

It was clear from the above conversation that for the whole rectangle to be five halves, the two pieces together are going to be the whole. Just like Irica and Gessica explained, the fact that each of these is going to be equal to one-half, or the whole. So, they are going to have five halves total of these two smaller pieces out of the rectangle. Therefore, basically everything that is coming after the word "of" represents the whole, which is taken-as -shared by the PTs. In addition, Pulianna's and Irica's solutions of "five-halves of two halves of one whole" and "fivehalves of two-fifths" consecutively, and Irica's backing for Pulianna's claim that stated "twofifths of the rectangle is the whole" clearly show the establishment of the most important mathematical idea of fraction language in creating an acceptable solution that states a fraction solution by itself does not make sense without talking about what the whole is, which was actually introduced earlier in fractions Day 3. 
In the next class task, PTs also continued to define their wholes. The central idea of the task was to strengthen PTs' understanding of the whole and how it changes based on how many circles the PTs have taken into account. The problems for this task specifically asked the PTs to define both the fractions and the whole for the shaded part so that they did not need to worry about the unshaded part. If problems just said, "Do you see any other fractions?" like the previous problems, they could then just technically talk about the unshaded part. But, this part of the following problem specifically focused on the shaded part.

\section{There are nine circles, four of which are shaded. What fractional part is shaded?}

Professor: So we will go ahead and talk about this. I put the answers that I saw while I was walking around. There was another answer I saw, five-ninths, coming from a couple of different groups from you. The thing you that you need to be careful with this problem even though this problem I know we just did the other side of this sheet, it looks like four-ninths was the most common answer I saw while I was walking around, so if that is true the whole is going be what?

Etephanie: Nine-ninths, four-ninths of nine circles. (Claim)

Professor: I am OK if you guys saying four-ninths of nine circles. That would be enough for this one. Question on that?

[No Question]

Etephanie's claim was accepted and there was no need for data, warrant, and backings because nine over nine is still the same as a group one nine circle.

Balerie claimed the shaded part represent four-thirds. Her data were questioned and she provided more information to support her evidence.

Professor: Ok, four-thirds which came from a couple of groups ... where did that come from? How could the shaded represent four-thirds? (Question)

Balerie: $\quad$ The three circles. (Data)

Professor: Can you elaborate little bit on that?

Balerie: Basically one whole set is three circles ... a group of three circles. (Warrant)

Professor: OK, yeah, go ahead.

Gessica: You said three circles. Is that three groups of circles?

Balerie: Yes. 
The three circles are just telling us about the whole that Balerie used. She did not even care there were nine circles altogether. She could just say that this represented four-thirds of three circles. That implied there were three circles in one whole.

The whole idea was a whole would just change depending on how many circles they have taken into account, which was already taken-as-shared by the class during fraction Day 3 tasks of representing fractions in different ways.

\section{Same Whole-Common Denominator}

The discrete model is only going to work to solve problems if PTs can keep whole pieces or when fractions came out of the same whole was taken-as-shared in the fourth day of class as the PTs and the professor discussed problem 34a (See Appendix F).

Charlie Brown takes two-fifths of the pattern blocks that Lucy has and gets a blue parallelogram, a yellow hexagon, and two green triangles. What pattern blocks might Lucy have had before Charlie took any away?

For the above problem, Gessica ended up with something equivalent to 10 pieces. Her claim was accepted, provided that she still talked about the fifths and how she got the fifths. Gessica was able to take 10 pieces evenly divided up between into groups of 5 without actually, physically breaking up a piece.

Gessica: So, Charlie Brown takes two-fifths of the pattern blocks that Lucy has and so I think that would mean he takes two-fifths, the whole being fivefifths - that is what Lucy has. So, I drew my rectangle and I split it up into fifths so each rectangle is one-fifths. From that I figured out that onefifth is two pieces because he took a total of four pieces from her-one parallelogram, one hexagon, and two green triangles. So, then I just took them put in the boxes so one-fifth will be a hexagon and a parallelogram, one-fifth will be two triangles, that I originally took it. So, I had a question mark because that would be what we want. I just did triangles so then we have the one hexagon, the one parallelogram, two triangles from four a total of eight triangles one parallelogram and one hexagon. (Claim, Data)

Professor: Questions?

Rhannon: How are the two triangles fifth? 
Gessica: In general two-pieces are equal to one-fifths. (Warrant))

Professor: What was your final answer?

Gessica: One hexagon, one parallelogram, and two triangles. (Claim)

Professor: Which is how many pieces altogether?

Gessica: $\quad$ Ten pieces. (Claim)

For this problem Gessica talked about the pieces. She just left them as the pieces, instead of breaking them down to triangles to figure out like how many triangles fit into them, because she was able to keep the whole pieces. Thus, Lucy was going to have at least a blue parallelogram, a yellow hexagon, and two green triangles for Charlie Brown to take them physically from her. So, the final answer for this problem, even though it was equivalent to 25 triangles, the PTs had to realize Lucy can't have 25 triangles to start with because Charlie can't take a hexagon and a parallelogram, although she had triangles. This is the only problem where this actually happened. But, PTs were going to have to make sure that within their final answer that Lucy has these pieces that Charlie actually took from her, otherwise Charlie was not going to able to take them to begin with.

\section{Different Whole Pieces: Different Common Denominator}

The idea that a common denominator will only work when both fractions are from the same-sized whole started with in fractions Day 4 as the class discussed Charlie Brown's problem number 34d (see Appendix F).

Two-fifths of Charlie Brown's allowance is the same as $\frac{1}{3}$ of Linus' allowance. Whose allowance is greater, and by how much?

Yosephenie claimed Charlie Brown's allowance is one-fifteenth greater. She found the fractions' common denominator to figure out whose allowance was greater and by how much. But she failed to prove her solution with a picture, and her solution was not accepted. However, another preservice teacher, Rhannon, came up with a pictorial representation of her solution for this problem. Rhannon claimed the solution is one-fifth and proved her response with a picture 
(see Figure 15) that showed there was a missing part in which Linus went over one-fifths. In her solution, with Charlie being the whole with only five pieces and Linus has six pieces, in this particular case, Linus is going to end up greater by the one-fifths amount.

Professor: OK, then what about part "e." "e" is similar but the wording is a little bit different.

Yosephenie: What I did was find a common denominator for two-fifths and one-third. So, I found a common denominator for Charlie and Linus, which is fifteen. So Charlie will have six-fifteenths, Linus will have five fifteenths, then you could use this to figure Charlie Brown's allowance is one-fifteenth greater. (Data, Claim)

Professor: You said it is one-fifteenth greater.

Yosephenie: Yeah.

Professor: Do you have a picture for this one?

Yosephenie: No

Rhannon: The picture I draw for it, can I show? I just got one-fifths. (Claim) Professor: One-fifths, OK.

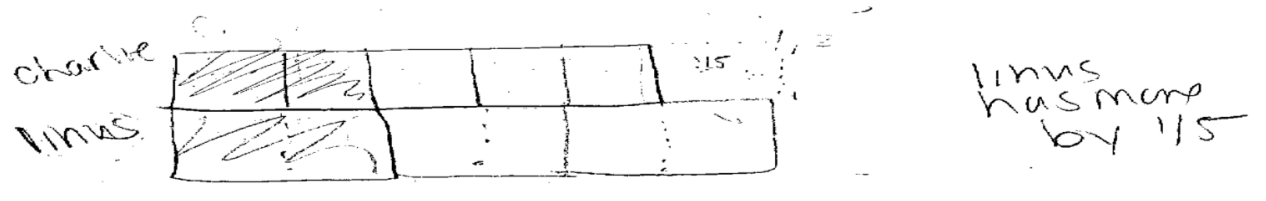

Figure 15. Linus greater by the one-fifths amount.

Rhannon: This is what I drew. So it says that one-thirds is the same as two fifths. So, this is the two-fifths and this is the one-third (showing the picture). So, it just said as the picture shows Linus has one-fifths more than Charlie Brown. (Data)

Professor: Where did you get one-fifth from?

Rhannon: Because It says two-fifths ...this is the same ...this right here (showing the missing one fifths) what Charlie ... it is the same fractions... the picture is equal up, there is one fifths is missing right here out of this, so Linus has more. (Data)

Professor: Alright, so is it one-fifteenths or is it one-fifteenths greater than one-fifths? How many of you are not sure?

\section{[Next class day]}

Rhannon: So, I was drawing out - this is broken into fifths, and because of it is the same as I just drew underneath that this two-fifths the same as to this onethirds. [Pointing to the drawing] So, when you are looking at, like, how it is greater by -who is greater than here, Charlie is greater by one-fifths 
because he has one-fifths more than Linus does. [Actually her drawing shows Linus is greater than Charlie's by one-fifth] (Data)

Professor: Wait, can you say Charlie is greater?

Rhannon: Linus, Linus is greater than by one-fifths. (Claim)

Professor: OK! Questions?

Students: I agree ... I agree.

Professor: How did you get Linus to be one-fifth greater?

Rhannon: Because if you see there is like a missing part, if it is the same as and Linus goes over one-fifths. (Warrant)

Professor: If you looking at this who is the whole?

Students: Linus. (Claim)

Tanny: $\quad$ The whole is Charlie. (Claim)

Professor: OK!

Gessica: $\quad$ So it is one-fifth. (Claim)

Professor: It is one-fifth?

Gessica: Yeah.

Professor: Do have a question about the one-fifteenths?

The PTs accepted Rhannon's solution. With this particular problem, the most important thing was to relate two-fifths of Charlie is equal to one-thirds of Linus's to begin with. Thus, the PTs could have several representations which show that. They could have done squares, rectangles or they might have done other pattern blocks and whatever they ended up taking is fine, just as long as they showed that two-fifths is equal to one-third. Well, two-fifths is not equal to one-third.

Professor: Let us say, if we did this with pattern blocks, for example what could I use to represent two-fifths...I will come back to the common denominator in a second. So, how can I show two-fifths with pattern blocks? There are multiple ways. If this is two-fifth what does one-third look like [showing the two triangles next to each other]?

Gessica: $\quad$ Four. (Claim)

Professor: One-third, Well, what were we were told in the problem about two-fifths?

Vrittany: Two-fifths equals to one-thirds. (Data)

Professor: So, with particular problem to start with, you were told from the beginning that two-fifths is equal to one-third. So, wherever you pick for the twofifths that is what is going to have to be equal to the one-thirds. So, if you did two triangles, one-thirds is going to be equal the two triangles. If you did say two hexagons, the one-thirds will also be two hexagons. So, whatever you picked to begin with, that is not going, you just have to make sure the area equals to start with. If this is two-fifths, what is five-fifths?

Vrittany: Five triangles. (Claim) 
[The professor put three more triangles]

Professor: I know, like what we did with the other problems, there were some of you that said this was two-fifths, another group would be four-fifths and you can add half of that to get the whole. But, do you guys see from where this is coming [showing the one-fifth triangle]?

[The class agreed]

Professor: OK, what is going to be the whole for that one [showing the one-thirds' part]?

Vrittany: Six triangles. (Claim)

[She puts four more triangles to make the whole six]

Professor: Yeah, you can have. Be careful with the way the sentence is getting worded, because this problem right here is telling you that they both are the same, two-fifths is equal to one-thirds. The difference between this problem and part "a", "b", and "c" is when you end up getting their wholes, are their wholes the same?

Revin: $\quad$ No. (Warrant)

Professor: I think, I heard "No", with this one Charlie Brown has five or something depending on how he started with the two-fifths. Linus ends up with six or something, because they don't have the same wholes that is why the common denominator is not working here.

Common denominators, which the PTs were going to get into when they got into

fractions addition, only work when both fractions come from the same-sized whole to start with. So, if the fractions had the same amount, then PTs would have been able to do that. But, in this problem, since their allowances were different, the common denominator was not going to work.

\section{Number Line}

PTs approached the tasks of locating a fractional amount on a number line in different ways in fractions Day 7. For example, for the first number line problem 38a (see Appendix I), which required PTs to find the point on the number line that is one third of the way between 1 and $2 \frac{1}{2}$, one of the PTs, Etephanie, first re-partitioned the number line into-thirds between 1 and $2 \frac{1}{2}$ or cut that into three same-sized pieces and then was able to label the location (see Figure $16)$. 
Professor: So, I want to start with part "a" first. Did any of you guys get anything different than what is up here for part "a"? [Indicating the picture below that was posted on the board] You can explain this first?

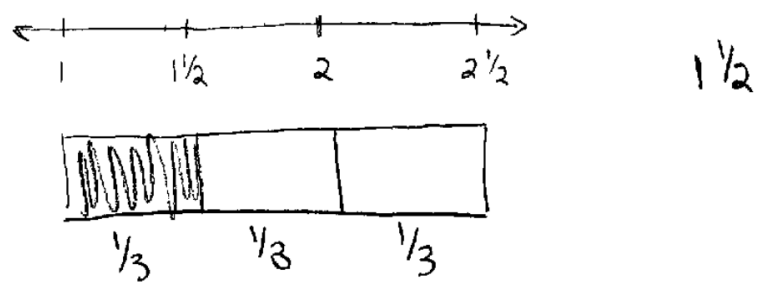

Figure 16. One third of the way between 1 and $2 \frac{1}{2}$.

Etephanie: I will try.

Professor: OK, go ahead.

Etephanie: So, it says one-thirds of the way between one and two and one- half, so I drew the rectangle below it, because it makes sense to me. Ok, so, there is one, one and one- half, two, and two and half. So, if ... you can have each section like where one shaded, then two ... (Data)

Professor: Are you looking here [Indicating to the rectangular box]?

Etephanie: Yeah, under the number line. (Data)

Etephanie: There is like, one, two and three. Then, I shaded one to represent one and one-half. (Data)

Professor: You are saying, this is one-third of the whole thing?

Etephanie: Yeah.

Professor: OK, so your final answer was what again?

Etephanie: One and one-half. (Claim)

Professor: OK, anyone not getting one and half for this one? ... Are there questions on this one?

Etephanie's final claim and data were accepted without a warrant. The repartitioning method was used to associate whole numbers, fractions, and mixed numbers and locate them on a number line, although the task did nothing more than reiterate the partitioning strategies that became taken-as-shared within the previous task.

Finding equivalent fractions to locate a fractional amount on a number line was also taken-as-shared. Partitioning units of a number line model would demonstrate the concept that to every point on the number line there are infinitely many equivalent fractions (Bright, Behr, 
Post, \& Wachsmuth, 1988). For the second number line problem, 38b (see Appendix J), PTs were to find the point on the number line that was half way between $\frac{1}{4}$ and $\frac{7}{8}$. First, the PTs found an equivalent fraction for one-fourth. Then, they partitioned the number line to generate equivalent fractions to show eighths and sixteenths (see Figure 17). Blaire changed one-fourths into eighths to locate half way between two-eighths and seven-eighths and another preservice teacher, Pulianna, took half of one-eighth to label the same point.

Professor: Balerie, can you explain what you guys did for "b"?

Balerie: We change the one-fourth into eighths. So, it is easier to compare with seven-eighths. So, one-fourths is two-eights. And we drew on a number line and then, half way between two -eighths and seven-eighths, it is between four-eighths and five-eighths. So, four and half-eighths. Since this half mark lies between four-eighths and five-eighths and we got four and half-eighths. (Data, Claim)

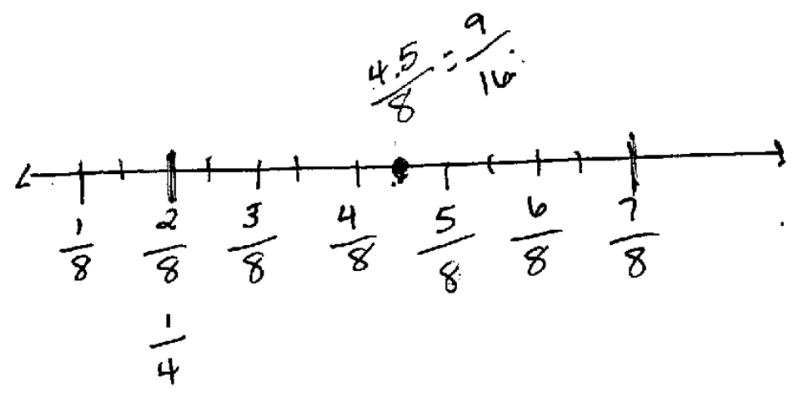

Figure 17. Half way between $\frac{1}{4}$ and $\frac{7}{8}$.

Professor: Where did you get the eighths from?

Balerie: We changed all into eighths. So, it is easier to compare since all will have the same common denominator. So, one-fourth is equal to twoeighths. (Warrant)

Professor: You said the one-fourth here [indicating two-eighths]?

Balerie: Yeah.

Professor: OK, then what did you do?

Balerie: And then so the half-way between two-eighths and seven-eighths is in between four-eighths and five-eighths. So, four and half-eighths. (Data)

Professor: How did you know that this is the half way mark?

Balerie: $\quad$ You can do it ... count or like cap spaces or divide seven by two ... like you could do all the way or you can put half mark in between each fractions, 
then it is easier to see half way of the space between one-eighths and seveneighths. (Data)

Professor: OK, you are saying your final answer for this point was what?

Balerie: $\quad$ Four and half-eighths. (Claim)

Professor: OK, how many of you got four and half-eighths?

[Students in two tables raised their hands]

Professor: How many of you turned this into sixteenths?

[Four students raised their hand]

Professor: Because I know several of you did that too, when you did that, what did you end up with the answer?

Reagan: Nine-sixteenths. (Claim)

Professor: So, if we are looking at the number line. How are you going to know that this is a sixteenth here?

[No responses]

Professor: What do you know about sixteenths and eighths?

Tara: $\quad$ Sixteenths are smaller than eighths. (Data)

Professor: OK, they are smaller than eighths and then, how are they related to each other?

Pulianna: Sixteenths is half of eighths. (Warrant)

Since the PTs knew that two-sixteenths is going to be equal to one-eighth, they broke each eighth in half to get sixteenths. Thus, "the automatic generation of equivalent fraction representations, through further partitioning or unpartitioning in the number line, in "the mind's eye" could facilitate flexibility in perception" (Bright, Behr, Post, \& Wachsmuth, 1988, p. 230). The class accepted either answer in this particular case as long as the preservice teachers' solutions' pictures actually showed which ever solutions they got, which actually significantly enhanced their performance. However, although the number line was the context of the problem, there is no evidence that the PTs used the number line itself, rather than their general understanding of fractions, to generate these equivalent fractions.

Moreover, the idea for PTs to build on their prior experience with equivalence, unitizing, the idea of finding a unit fraction, iterating a unit fraction, and developing a composite unit of one in the previous tasks helped them to see that the number line is representing the common 
denominator, which was developed with the following number-line problem, 38c (see Appendix

J).

Find the point on the number line that is: Two-thirds of the way from $3 / 4$ to $1^{1 / 3}$

Since the PTs had two unequal pieces in this problem, a fourth and a third, one thing that they were going to have to do was to get the pieces to be in equal-size. Although there were multiple ways to do it, Treanna knew that this is fourths and thirds, so she split these up to get them into to the same-size pieces by finding their common denominator (see Figure 18).

Treanna: OK, so the problem says two-thirds the way from three-fourths to one and one-thirds. So, I started off by putting three-fourths at the start of a number line and one and one-thirds at the end. So, I first looked at it and I just started the easiest way, finding a common denominator. So, if you turn one and one-thirds into a mixed number, it becomes four-thirds. The common denominator will be twelve. So, I took three-fourths times three, both the numerator and denominator, and I got nine-twelfths. And then, I took fourthirds and multiplied it by four from the top to the bottom that is sixteentwelfths. So, I just build in from nine-twelfths to ten-twelfths, eleventwelfths, twelve-twelfths, thirteen-twelfths, and so on until sixteen-twelfths. So, then, I counted, if you could see like from nine-twelfths to ten-twelvetwelfths, elven-twelfths, and so on. That was seven spaces. So, I knew that it goes on into twenty-one spaces. I knew that it says two-thirds; I know that seven goes into twenty-one three times. So, it says two-thirds, it will be two sevens, I kind of shaded, you guys see right there? So it is kind of twothirds, seven plus seven is fourteen. So, that since you have that you know that there is going to be other spaces in between nine-twelve, ten-twelfths, eleven-twelfths that will be three spaces. So, I counted like these three little spaces until I got fourteen and I got here between thirteen-twelfths and fourteen-twelfths. But it is right thirteen and two-thirds over twelve and so, I knew that I had to multiply the top and the bottom, thirteen and two-thirds over twelve by three-over one, I got thirty-nine plus two to get forty-one for the top number, and thirty-six for the bottom. I got forty- one over thirtysix. (Data, Claim) 


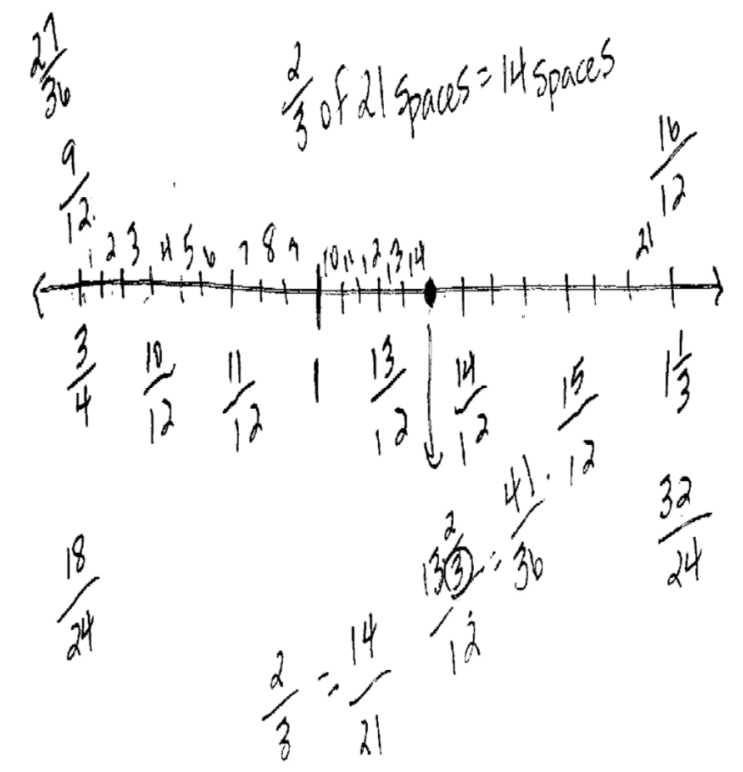

Figure 18. Two-thirds of the way from $\frac{\mathbf{3}}{\mathbf{4}}$ to $1 \frac{\mathbf{1}}{\mathbf{3}}$.

Professor: What questions do you have?

Treanna: Everything. [Laughing]

Vrittany: What is the forty-one over thirty-six? Question?

Treanna It is like how you're looking at it. See how we move from thirteen-twelfths to fourteen-twelfths, three spaces and so you know that two-thirds is second line in your box that you color into, that would be the point, because it says two-thirds the way from three-fourths to one one-thirds. (Data)

Tanny: Where did you get thirteen and two-thirds?

Treanna: Well, thirteen ... in between thirteen and fourteen. There still be thirteen that point right there. Thirteen two thirds over twelve. (Data)

Tanny: $\quad$ Because I don't know what you did underneath.

Tara: $\quad$ It is thirteen two-thirds over twelve. (Data)

Treanna: This is just for the numerator [Pointing to thirteen two-thirds]...I am sorry ... this for the numerator. (Data)

Professor: OK, I think this is what several of you did. With the twelfths any way, Treanna, what did you do after this?

Treanna: [Inaudible]

Professor: OK, Treanna, what did you do after this?

Treanna: So there is like seven sections. Each section broke it up like nine-twelfths, ten-twelfths, and then we broke each section up into thirds. So we did that with all the sections. (Data)

Professor: So, what part of the problem told that you are going to be splitting in two thirds?

Treanna: The two-thirds. (Data) 
Professor: OK, do you guys see the stuffs so far?

[Class agreed]

Professor: So, the two-thirds in this case is going to tell us that you could take each of those pieces and cut it up in the three, and what did you do

Irica: Then, we counted how many like sections there are. There are twenty-one in total. (Data)

Professor: I won't write all of these, but ... OK.

Irica: $\quad$ So then, we knew that seven goes in twenty-one three times so it is like three sevens basically, so we took two of the sevens and added them together to get fourteen ... fourteen over twenty-one is equivalent to twothirds. (Data)

Professor: I think you said two-thirds is equal to fourteen over twenty-one.

Irica: $\quad$ Yes.

Professor: OK.

Irica: $\quad$ So then, with that we knew that we had counted up to like fourteen sections starting like the nine-twelfths. So then, we were like the fourteen sections is, that is for like thirteen and two-thirds over twelve is. That makes sense? That tally mark is thirteen two-thirds over twelve. (Data)

Professor: Do you guys see where that is coming from? So, if you counted by thirds with each of these you would have three and a third, three and two-thirds. Oh, well, I should start with the nine. But, anyway it is going to go up. You are saying this one is thirteen and two-thirds, what?

Irica: And then, so like our like fraction with that tally mark is thirteen two-thirds over twelve. And multiplied the numerator and denominator by three. Like thirteen two-thirds multiplied by three to get thirty-nine and add the two to get forty-one and twelve times by three is thirty-six. I got forty-one over thirty-six. (Data)

The class had some questions on the data, but Treanna and Irica were able to explain the evidence to support the data with the professor's guidance. Therefore, the solution for the problem was accepted by the class. The PTs' strategies to solve the problem shows how they have built on their knowledge of partitioning to develop a deep understanding of multiplication of fractions so that they were be able to reconceptualize units or make a composition of fractions (Behr et al., 1992; Olive, 1999) in order to define the denominators further. Treanna had counted by twelfths up to fourteen sections starting at the nine-twelfths. When she was on the fourteen sections she was able to locate the point, thirteen and two-thirds over twelve. Since she understood the multiplicative structure, she also knew that she had to multiply the numerator and 
the denominator, thirteen and two-thirds over twelve by $\frac{3}{3}$ to get $\frac{41}{36}$, instead of counting by onethirty-sixth to get the same point. Of course, the figure shows recursive partitioning. However, the idea of reconceptualizing units or a composite unite was taken-as-shared in the fourth day of instruction, which is used here to define the denominator. Such reconceptualizations enabled the PTs to determine the appropriate unit to be partitioned as well as the unit on which the results of partitionings are based (Mack, 2001).

\section{Understanding What the Numerator and Denominator Represent}

The class looked at different fractions and their comparisons to one another using a common denominator. To get started, the professor asked the PTs to write three fractions that are greater than seven-eighths and three fractions that are less than seven-eighths with the same denominator of eight. PTs knew that they could use a common denominator to compare fractions as evident from their use of the common denominator idea within some of the problems already described. The conversation, at the beginning of fractions Day 6, then focused around what the numerator and denominator represent within a fractional amount.

Professor: What is one fraction less than seven-eighths?

Gessica: $\quad$ Six over eight. (Claim)

Professor: OK, how do you know?

Gessica: $\quad$ Six is less than seven. (Data)

Professor: OK, six is less than seven what is the eight telling us?

Tanny: The denominator is the same. (Warrant)

Professor: Which is going to mean what?

Pulianna: We are going to have the same whole for this. (Warrant)

Professor: What is going to be important about the pieces?

Tanny: The eight tell us the same-sized pieces. (Backing)

Professor: What is the seven is going to tell us?

Rhannon: How many are shaded. (Backing)

When Tanny and Pulianna's warrants were questioned, Tanny introduced the idea that the denominator represents the size of the piece as backing for the argument. In addition, 
Rhannon provided the backing to introduce the idea that the numerator represents the number of pieces which were shaded.

Nevertheless, in the following fractions Day 6 conversation, no one ever questioned Pulianna and Gessica's claims below for fraction less than-seven-eighths. The same number of pieces was not shifting to data or warrant and were not even being questioned. It appeared that comparing with common denominator in relation to the numerator was taken-as-shared before the next task, comparing and ordering activities were presented.

Professor: What are two more fractions that are less than seven-eighths?

Pulianna: Five-eighths, Four-eighths. (Claim)

Professor: OK! What about fractions that are greater?

Gessica: Nine-eighths. (Claim)

The five-eighths and the four-eighths both end up less than one in this particular case. Eight-eighths, as the PTs talked equals to one. Seven-eighths is going to be less than one but greater than those three fractions, $\frac{4}{8}, \frac{5}{8}$, and $\frac{6}{8}$, that automatically make those three fractions less than seven-eighths.

\section{Common Numerator}

This strategy continued to be developed when the class moved to investigate PTs' solutions for the three fractions that are greater than seven-eighths, keeping the same numerator of seven. To develop the idea of using common numerators to compare fractions in relation to the denominator, the problems were intentionally written with fractions that already had a common numerator. When the common denominator strategy introduced, the idea of the denominator, the size of pieces was also presented. The common numerator strategy was posed when the class was discussing one of the PT's solution, seven-elevenths, for a fraction which is less than seven-eighths. This shows how the bigger pieces coming from a smaller denominator 
shifted to warrant and the idea that the less you cut something into the bigger the pieces become, was introduced in the following fractions Day 6 episode.

Professor: How do we know for example that seven-elevenths is smaller than seveneighths?

Gessica: Because the whole of eleven is greater than the whole of eight. (Data)

Professor: Keep going ...

Gessica: So, you have the same amount of pieces, but the whole is getting bigger, so then technically you have like, with the seven-eighths you have more eighths than you do elevenths. (Data)

Professor: OK you said you have the same number of pieces where is that coming from?

Gessica: The numerators-which both are seven. (Data)

Professor: So, they both have seven pieces. Now what do we think of the elevenths verse the eighths.

Gessica: The eighths is going to be like, if you have more eighths than you do elevenths. (Data)

Professor: What do mean by more pieces?

Gessica: With the eighths you have one missing and with the elevenths you have three missing. (Data)

Professor: I got you. OK, and with eighths how big are when they compared to the elevenths?

Gessica: What do you mean?

Professor: So, if I cut something up in the eight and I cut something up into eleven and it happens from the same something. Which one will have the bigger pieces?

Gessica: The Eighths. (Warrant)

Professor: Why?

Gessica: Because it is less you have to cut into pieces. (Backing)

Gessica immediately noted the whole or the size of the pieces of seven-elevenths is greater than the whole of seven-eighths, though they both were going to have the same number of pieces because they have the same numerator. Gessica moved on to using the common denominator to justify that eighths has bigger pieces than the elevenths since both fractions have the same numerator. However, her warrant was questioned. Then, she argued the seven-eighths is less than what we have to cut into pieces than the elevenths, which in turn made it to end up being bigger pieces and a greater fraction. Therefore, the idea of that the number of pieces into which a fraction is broken is inversely related to the size of the pieces (Tobias, 2009), which 
actually was taken-as-shared within the common numerator comparing activities, had to be used in order to make sense of the missing pieces strategy. Obviously, comparing with common denominator was taken-as-shared before the comparing and ordering activities were presented to the class.

\section{Comparing and Ordering}

Several reasoning strategies were established as a taken-as-shared ways of comparing and ordering fractions using contextualized and non-contextualized problems in fractions Day 6. The reasoning strategies that the PTs developed included (a) same number of pieces (common numerator), (b) a benchmarks, (c) missing pieces, and (d) common denominator.

Same number of pieces (common numerator). One way of comparing fractions is the same number of pieces. The first practice established within these tasks was comparing fractions using same number of pieces. The first problem presented to the class was to figure out which

one is greater, $\frac{2}{17}$ or $\frac{2}{19}$. To develop the concept of using the same number of pieces (common numerator) to compare fractions, the problem was purposely written with fractions that had a common numerator.

Tanny: $\quad$ Two-seventeenths. (Claim)

Professor: Why?

Tanny Because seventeen pieces of one whole versus nineteen pieces of the same whole, like, each individual will receive two bigger pieces. (Data)

Professor: OK, you said these pieces are bigger? [Indicating to two-sevenths]

Tanny: Yeah.

Professor What do you say about the two?

Tanny: They both have two, you know these two bigger pieces added up. [Inaudible] (Data)

In the above fractions Day 6 episode, Tanny looked at how big the pieces are, because both fractions have two in the numerator, which means they both have the same number of pieces to begin with. Tanny ended by comparing the size of the pieces to get the answer. She 
compared the same number of pieces automatically—two pieces versus two pieces, but the seventeenths versus the nineteenths helped her to see clearly the bigger pieces versus the smaller. So, she provided data to explain that you have two bigger pieces versus two smaller pieces, which automatically made the two-seventieths greater. Tanny's common numerator reasoning strategy was not questioned within the discussion. She merely presented her data, and warrants and backings were not needed. When we have the same numerator, we are going to have the same number of pieces already, so we are not going to be able to tell which fraction is greater until we look at how big the pieces actually are.

Problem number seven $\left(\frac{3}{7}\right.$ and $\left.\frac{6}{11}\right)$ could be like this, too. But, with this problem, it depended on how the PTs did it. In the subsequent fractions Day 6 episode, Reagan had to change the numerator of one of the fractions $\frac{3}{7}$ to get it to be the same number of pieces with the other fraction. Once, she ended up having with the same number of pieces, she was able to look how big the pieces were to figure out which one was greater.

Reagan: Six-elevenths. (Claim)

Professor: Why?

Reagan: Because when you convert three-sevenths to six-fourteenths, then sixelevenths is greater than six-fourteenths. (Data)

Professor: How do you know six-elevenths is greater?

Reagan: Because six-elevenths is closer to one, which actually more than a half. (Warrant)

Professor: So, if you are looking at the six-fourteenths verses six-elevenths, why did you convert this one to be six over fourteen?

Reagan: Because I want them to have the same numerator. (Warrant)

Professor: Ok, then, how does the elevenths compare to the fourteenths?

Reagan: $\quad$ Six-elevenths is closer to six over six, which is the whole. (Data)

Professor: What do we know about the size of the pieces here also?

Revin: $\quad$ Bigger. (Warrant)

Professor: Yes, they are also bigger.

The idea of common numerators shifting in the discussion from data to a warrant. So, Reagan solved the problem by using the common denominator. However, she was questioned to 
justify her evidence. So, she had to present a warrant to justify the data. She explained why she changed the numerator of one of the fractions so that both fractions would have the same numerator and then she was able to decide six-elevenths is more than a half and it is greater than three-sevenths. But her data were still questioned. Another preservice teacher, Revin provided a warrant about the size of the pieces of $\frac{6}{11}$, which is bigger than $\frac{3}{7}$. As a result, the PTs understood the reasoning strategy of comparing fractions using common denominators (the number of pieces), which then became taken-as-shared by the class same day in fractions Day 6 .

Compare to a benchmark. The second practice established within these activities was comparing fractions to a benchmark. The first set of fractions that students had to compare using a benchmark were $\frac{1}{2}$ and $\frac{17}{31}$. Vrittany's explanation and justification in the next fractions Day 6 episode included finding half of one of the fractions to check whether it is more than or less than the benchmark. She used a one-half benchmark strategy to compare these fractions, the class established the idea of comparing fractions to half.

Professor: What did you guys get for three?

Vrittany: Seventeen over thirty-one is greater. (Claim)

Professor: Why?

Vrittany: I took thirty one and divide thirty one by two that was fifteen and fivetenths to get like one-half. (Data)

Professor: You said that this is equal to half [While writing fifteen point five over thirty one]

Vrittany: Yeah, and then, if that is the one-half, seventeen is the greater numerator so that is the greater fraction. (Data)

In the next problem, Revin actually used one-half as a benchmark for problem seven, comparing $\frac{3}{7}$ and $\frac{6}{11}$, where he said three-sevenths is less than half and six-elevenths is bigger than half in the following fractions Day 6 conversation. Although his data were accepted, he was still needed to provide more explanations on his data. 
Revin: $\quad$ For that one in the explanation, I just put six-elevenths is more than onehalf and three-sevenths is less than one-half. Does that work? (Data)

Professor: How do know you that six-elevenths is greater?

Revin: Just five and five-tenths over eleven is half and three and five-tenths over seven is half, so three-sevenths is less than half and six-elevenths is greater than half. (Data)

Although the class understood Kevin's evidence, the one-half strategy still came as a data when the Professor prompted it.

For the third problem, PTs had to compare two fractions, $\frac{1}{4}$ and $\frac{25}{99}$. When the class discussed solution to the problem in the subsequent fractions Day 6 episode, Pulianna used the strategy of comparing to one-fourth. In Pulianna's explanation and justification, the one-fourth strategy was introduced and the evidence presented to support her claim was not questioned by the class and there was no need for a warrant to justify her data. However, since the fractions in this problem could also be solved in multiple ways, Vrittany changed the one-fourth into equivalent fraction, twenty-five over hundred and claimed $\frac{1}{4}$ is less than $\frac{25}{99}$. Thus, she ended up having the same number of pieces for both fractions and was able to consider how big the pieces were to figure out which one was greater. Vrittany's data were questioned and she had to provide a warrant to justify her evidence. Then, warrant was also questioned and Rhannon had provided backing for Vrittany's warrant.

Professor: Problem four which one is greater?

Pulianna: Twenty-four and three-fourths over ninety-nine, which is equal to onefourth and is less than twenty-five-ninety ninths. (Claim and Data)

Professor: OK, did any of you do this one differently?

Vrittany: I know that one-fourth, I put it out of one hundred, and it is twenty-five out of a hundred which is less than twenty-five over ninety-nine. (Data)

Professor: Why?

Vrittany: Because there is less...the denominator is less. (Warrant)

Professor: What do you mean the denominator is less, which one?

Vrittany: The ninety-nine is less than a hundred that fraction is less. (Warrant)

Professor: Why? 
Vrittany: Because you have the same number over less. (Warrant)

Professor: So it does. Yeah, so we know the twenty-five, I will get back to this in a second, for the twenty-five out of one hundred versus twenty-five out of ninety-nine. What do we know about the ninety-nine verses the hundred in terms of how big the pieces are?

Rhannon: Ninety-nine split individually is bigger than a hundred - the pieces will be bigger. (Backing)

Earlier when the common denominator strategy was introduced, the idea of the denominator determining the size of the pieces which explains that bigger pieces are associated with coming a smaller denominators, was also presented and it came as a backing when the professor prompted it. PTs weren't saying it automatically on their own. This indicates that the idea was not yet taken-as-shared.

Depending on how the PTs did this problem, either method was valid. The PTs who worked with the fourths being twenty-five out of a hundred, were still going to have to justify the fact that the ninety-nine was going to have bigger pieces. If they did the one-fourth is equal to twenty-four and three-fourths out of ninety nine, then for this particular one, they are going to have the same-sized pieces, but with the twenty-five there was going to have more of them, even though this was not much more.

For the next problem, $\frac{15}{17}$ and $\frac{19}{18}$, Yosephenie used the strategy of comparing to one in fractions Day 6. In this case, nineteen-eighteenths is greater than one and fifteen-seventeenths less than one and that is going to make the nineteen-eighteenths greater. No one questioned Yosephenie's comparing to one strategy. Thus, comparing to one became taken-as-shared.

Yosephenie: Nineteen-eighteenths pieces are more than a whole-one. (Data, Claim) Professor: What do you know about fifteen-seventeenths?

Yosephenie: It is less than one. (Data)

With these type of fraction comparison problems, the PTs looked for another fraction to compare the two given fractions. For example, with problem number three, one-half ended up 
being the benchmark and for problem four, one-fourth became the benchmark. For problem five, one was the benchmark because one of them was less than one and one of them was greater than one. Depending on the fractions, the benchmark could change and either be equal to one of the two fractions or between one of the two fractions.

Common missing pieces. Another benchmark strategy is finding missing pieces or finding another fraction to compare the two given fractions. In fractions day 6 , Irica was comparing, $\frac{8}{9}$ and $\frac{12}{13}$, by just looking at how many pieces in each fraction were missing. She claimed $\frac{12}{13}$ is greater because, although both fractions are missing one piece each, $\frac{12}{13}$ is missing a very small amount to be a whole. However, her data was questioned by the professor and she had to provide a warrant to support her evidence.

Irica: Yeah, so I think this is the one that I split into the candy bar. So, if you split a candy bar into a thirteen pieces, the pieces are going to be smaller than they would be if they were in pieces of nine. The partition is smaller. So, if you have twelve-thirteenths, that means, there is a lesser amount of the candy bar missing to be a whole. So, in eight-ninths of that candy bar there is going to be the larger amount left that needs more to be a whole. (Claim, Data)

Professor: So how much is left?

Irica: If you are comparing one-ninth and one-thirteenth, one-thirteenth is smaller. (Warrant)

Professor: So, your answer is twelve-thirteenths is greater?

Irica: $\quad$ Correct.

Professor: I know I was jotting while she was still talking. Did you guys pick up on what she did for this particular problems?

Students: Yes.

Professor: Yes, OK, questions on this one. [No Question]

For question 11, which asked for, $\frac{13}{15}$ and $\frac{17}{19}$, to be compared, Tara claimed, in the following fractions Day 6 episode, seventeen-nineteenths is greater because 10 and 11 are almost exact same problems except 10 is missing one piece and 11 is missing two pieces. Tara 
explained which piece is smaller and which piece is bigger, and argue that the fraction with the smaller amount that is leftover, is the greater fraction

Tara: Seventeen-nineteenths is greater. It is kind of like Number 10 where it needs less to be a whole. Problem 10 is missing one piece. This one is missing two. It needs two pieces. It needs two-nineteenths to be equal to one whole as opposed to thirteen-fifteenths, which needs more, like two-fifteenths. It is like Problem ten. So seventeen-nineteenths takes less to make the whole. (Claim, Data)

Problem 12 required PTs to compare $\frac{2}{7}$ and $\frac{3}{8}$. In the next fractions Day 6 conversation, Irica provided a valid strategy, but, had difficulties explaining her method. Irica compared both fractions to one-half. This led her to justify that the larger fraction needed a smaller amount to become one-half. For this particular problem, the one-eighth ended up being closer to one-half than the one and one-half-sevenths because the sevenths are bigger to begin with. Tara provided the warrant for Irica's response (data) and explained that the one and one-half is going to mean we are going to have more than just one piece than the one piece we need for the three-eighths.

Irica: We said that three-eighths is the larger fraction because three is one lessone-eighth less than half of eight-eighths and two-sevenths is one and onehalf less than one-half of seven-sevenths. So it is closer to a half. (Data, Claim)

Professor: Which one?

Irica: $\quad$ Three-eighths $\ldots$ because four-eighths will be half of eight-eighths and three and one-half -sevenths will be half of seven-sevenths. (Data)

Professor: OK, how do you know for sure that one-eighth is less than one and one-halfsevenths?

Irica: What?

Professor: You are telling me-what you said was this is one-eighth less than half [Showing three-eighths], and this is one and one-half less than half [Showing three-sevenths] Right?

Irica: $\quad$ Yes.

Professor: OK, so, the question is how do you know that the one-eighth is less than one and half-sevenths?

Irica: Well, because the piece will be larger, if there is less amount, smaller amount. Seven-sevenths are going to be larger than eight-eighths. (Warrant)

Professor: What is this going to tell us ... the one and the one and half? 
[Irica is a little bit confused] So, trying to put this together, you said sevenths will be bigger pieces?

Irica: $\quad$ Correct

Professor: OK, and how is the one and one-half did not tell you for sure that overall this is bigger? [Showing three-eighths]

Irica: $\quad$ Oh, because the fractions that you were comparing are two-sevenths and three-eighths, if one is smaller than one and half-sevenths, you are comparing two-sevenths which is half larger than you just have, the threeeighths has to be larger than three-sevenths. Sorry! [Laughing] (Data)

Professor: That is OK! Well, so, if we get back to what you did before, you were talking about how far these fractions are away from half. So, if this is one unit away from half [Showing three-eighths] and this one is one and onehalf unit away from half [Showing three-sevenths]. You know that these pieces are bigger. How is that going to help us?

Tara: The smaller piece is closer to the half. One piece closer to the half. (Warrant)

Professor: Yeah, that is what I was trying to get you to tell us. Didn't you do this differently? Anyone else do this one differently? What did we do for 10 and 11 ?

[No answer]

Professor: Which strategy did we use for 10 and 11 ?

[No Response]

Professor: You guys know what I am asking?

Students: No [Laughing]!

Professor: If you haven't just told me ... Ok, so if we look at problem number ten how did we solve it?

Tamie: $\quad$ The pieces are smaller. (Warrant)

Professor: Before that.

Tamie: $\quad$ How many more pieces we need, like, to get a whole.

Professor: So, will that work?

Tara: $\quad$ No.

Professor: So how many more pieces do we need here?

Professor: How many pieces do we need here? [Indicating two-sevenths]

Students: One and one-half. (Data)

Professor: How many here? [Indicating three-eighths]

Students: One. (Data)

Professor: Yeah, so this method that Irica talked about was fine. You could also think about, they both have missing pieces. We will take this back up with these last three problems here on Thursday. Make sure you bring back your blue card so that we can use it.

It is evident here also that the idea which states the larger something is broken into the smaller the pieces become changes from a backing to a warrant. As we have seen, there were three different types of problems with the benchmark strategy that were-taken-as shared by the 
class in fractions Day 6. The first one was when one of the fractions was equal to the benchmark. The second one was when both fractions were above/below the benchmark. The third one was when the benchmark was between both fractions. The benchmark strategy was also going to be where the missing pieces idea came in, which happened in Problem 10, 11, and technically in 12 . With the benchmarks, there were couple of things that we looked at on those problems. One of them was to look at the number of missing pieces. Another one was going to be comparing with another fraction, like the PTs did on Problem 5.

Greater number of larger pieces. The last benchmark strategy is known as greater number of larger pieces, which PTs used in Problems 13, 14, and 15 of fractions comparison (see Appendix I). This is not actually a comparing strategy, this concept was "indirectly developed from the common numerator and missing pieces strategy where students had to compare the size of the pieces" (Tobias, 2009, p. 169). This was where the PTs were going to end up with a situation where one of the fractions was going to have more-bigger pieces already. So, all three of those problems had a fraction where one of them not only had bigger pieces but also had more of them, which automatically made that fraction greater. In fact, the PTs had to be careful with this strategy because it does not necessarily always work every time. For example, if we look at Problem 12, which is similar to Problem 14, the two-sevenths is going to have the bigger pieces and the three-eighths is going to have more pieces. The more-bigger piece strategy is not going to work in this situation.

To introduce the concept of greater number of larger pieces in fractions Day 6, the following problem presented two fractions, $\frac{18}{25}$ and $\frac{16}{27}$, with $\frac{18}{25}$ having more-bigger pieces.

Professor: Which one is greater?

Yosephenie: Eighteen over twenty-five. (Claim)

Professor: How did you get it?

Yosephenie: Twenty-five is a smaller denominator than twenty-seven. (Data) 
Professor: [Writing] OK, can you guys in the back see this OK?

Students: Yeah!

Professor: $\quad$ OK, so, if you didn't hear, you said 18 over 25 is greater because..., what did you say about the smaller denominator?

Yosephenie: Will have a bigger pieces here. (Data)

Professor: And then what about the numerator?

Yosephenie: Numerator has more pieces. (Data)

Here it is evident that the idea that the more something is cut into the larger the pieces are shifts from backing to warrant. As the class discussed their method for solving the problem, Yosephenie used the greater number of larger pieces, which is based on the idea from the previous topics of looking the size of the piece and the number of pieces together, to determine which of, $\frac{18}{25}$ or $\frac{16}{27}$, was greater. Yosephenie provided data for using the strategy of looking for the bigger pieces and more pieces, which then told her which one had more-bigger pieces since she understood the idea that the number of pieces into which a fraction is broken is inversely related to the size of the pieces. No-one questioned Yosephenie's argument. The idea of morebigger pieces did not need a warrant, and was not questioned. It became taken-as-shared. Another preservice teacher, Pulianna looked at the problem in a slightly different way. She found the halves of both fractions, although the pieces were not the same-size. She further explained the strategy by saying 18 over 25 is $5 \frac{1}{2}$ over 25 more than a $\frac{1}{2}$ and 16 over 27 is $2 \frac{1}{2}$ over 27 more than a $\frac{1}{2}$. However, during this conversation, her strategy was questioned and a warrant was needed for her explanation of $\frac{18}{25}$ being bigger. She was still required to answer how $5 \frac{1}{2}$ over 25 is more than $2 \frac{1}{2}$ over 27 , still using more-bigger strategies.

Pulianna: So, I don't know if this is correct. This is hundred percent of my logic. If I found the halves of them, so, for 18 over 25 I got 12.5 and for 16 over 27 I got 13.5. 18 over 25 is $5 \frac{1}{2}$ over 25 more than a $\frac{1}{2}$ and 16 over 27 is $2 \frac{1}{2}$ more than a half. So 18 over 25 has more bigger pieces (Data) 
Professor: I think I followed that. You said you looked at the halves and said this one is $5 \frac{1}{2}$ away [Indicating one of the fractions: 18 over 25 ]

Pulianna: Yeah!

Professor: Ok, that is fine to do. The only thing you have to be careful is the pieces are not the same-size. If they are not the same size, you still are going to have to tell me how, you know for sure that, in this case the $5 \frac{1}{2}$ and the $2 \frac{1}{2}$ that these are both missing to get to be up here. How do you know for sure that $5 \frac{1}{2}$ over 25 is going to be more than $2 \frac{1}{2}$ and over 27 ?

Pulianna: It is bigger pieces? (Warrant)

Professor: So this automatically is going to have bigger pieces, then what did you say about the top one?

Pulianna: It is going to be more pieces. (Warrant)

Professor: In that case, that is fine. So, you just have to be careful if you do that. You can't just say well this is $5 \frac{1}{2}$ pieces more and $2 \frac{1}{2}$ more, so this one is greater. You are going to talk about how big the pieces are also. Anyone else did this differently? [Pause-No response]

This strategy continued to develop and was used in succeeding problems. However, this benchmark strategy that used more-bigger pieces shifted and was not questioned within the following fractions Day 6 conversations. Tanny, Rhannon, and Yosephenie contributed to this strategy when they provided justification while comparing $\frac{2}{9}$ and $\frac{3}{8}$ and $\frac{7}{10}$ and $\frac{8}{9}$. But, this time they only needed to present the data for what they did. Although, in the previous conversations on this strategy, the class contributed warrants and backings to the discussion, these were not needed in subsequent conversations.

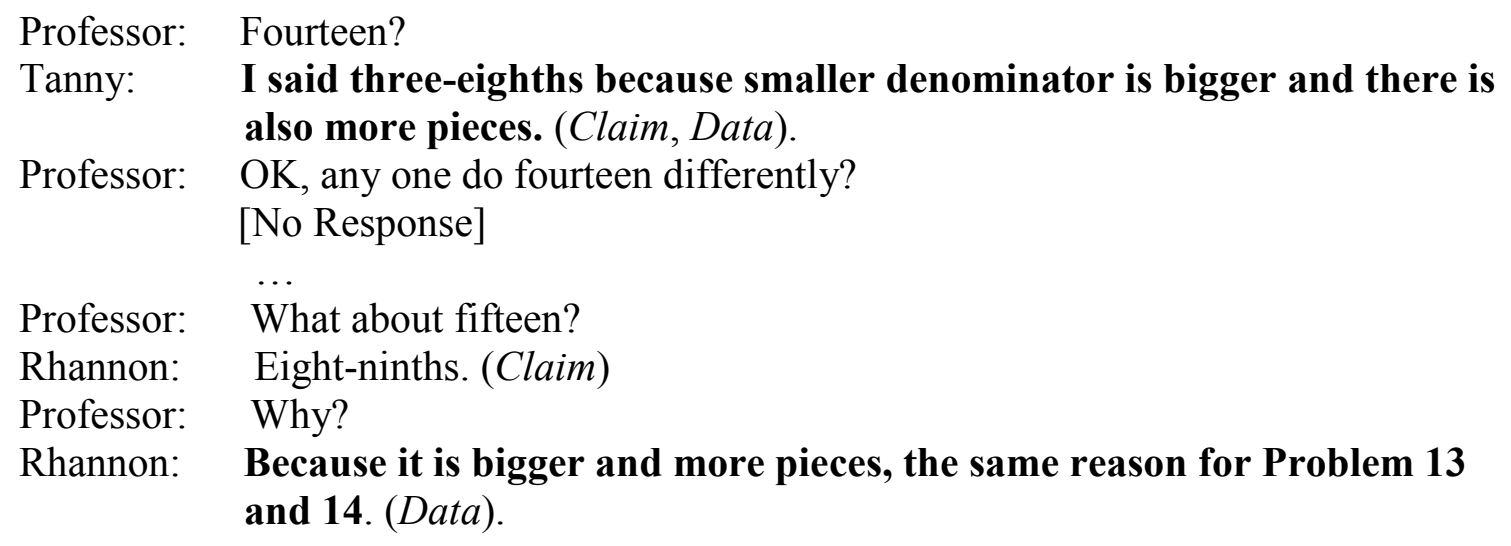


Professor: So, with this last three ... this is a specific strategy name. I want to talk about strategy names in just a second, but, are there questions at all over any of the 15 problems that we have done?

Yosephenie: The last one is eight-ninth because seven-tenths is missing three-tenths and eight-ninths is missing one-ninths. (Data)

Professor: That is OK as long as you talk about how big the pieces are. So, kind of like what I said for Problem 13. Even though, this is one away and that one is three away [pointing to the fractions $\frac{7}{10}$ and $\frac{8}{9}$ ], the pieces are different sizes, you will have to discuss that too. So, other questions? [No questions]

With this fraction comparison, there were different reasoning strategies that became taken-as-shared. Some of the problems were still related with other problems that the class had been working on because, as it was explained earlier, this is not actually a comparing strategy, but it was a concept which developed from the common numerator and missing pieces strategy.

\section{Fractions Operations}

The last two days of the fraction concepts and operations unit focused on fraction operations. The operations were first presented in contextualized situations followed by noncontextualized problems. During these activities, the PTs were asked to (a) solve the problem with a picture, (b) write a number sentence which matched the situation represented in the word problem, and (c) explain and justify their solution method.

Fraction addition. Fractions addition concepts were discussed starting on the first day of the fractions unit. The candy sharing activity that the class was presented asked the PTs to determine how much of a candy each person would receive. When determining how much of a candy each person would receive, some PTs had to add quantities together to find the solution. Initial discussion focused around common denominators and the idea that the denominator stays the same and the numerators are combined.

Janna: I took the six people - so I took a number that goes in six, which is three: I divided it by two to get three. I took the first three and divided those in half and then so that each gets one-half and then there is two candy bars leftover 
and then, I took-I divided those into the thirds because you can't divide it in halves when to equal it for six people. (Data)

Professor: You're talking about the two leftovers?

Janna: Yeah...the two leftovers...so I divided them in the thirds and so each got a thirds ... uh ... so that I added one-half and one-third and then I had to, like, to make the denominator the same ... so it was $\frac{3}{6}+\frac{2}{6}$ equals $\frac{5}{6}$. (Data)

Professor: OK, this one has come from where?

Janna: $\quad$ From the first three, each got a half. (Data)

Professor: OK, The one-third was...

Janna: $\quad$ From the two leftovers. (Data)

Professor: Alright! Are there any question on these at all?

[No questions]

Early discussions involving fraction addition occurred on a procedural level. Janna could not conceptually justify why she did not combine the denominators when she was adding the numerators. The data for Janna's argument was not even questioned, though what she did was nothing more than keeping the denominator the same and adding the numerators. It seemed the class understood the procedure to solve the problem. Nobody asked questions. Therefore, it seemed, there was no need for a warrant or backing.

When the focus shifted to considering fractions in relation to a number line, the fraction concept states that in order to combine or take away fractions, the pieces must be the same size. Thus, the denominators must be the same. So, the PTs were going to need to get the pieces equal. For example, in fractions Day 7, the class was asked to find the point on the number line that is two-thirds of the way from $\frac{3}{4}$ to $1 \frac{1}{3}$ (see Appendix J, Problem C). The problem focused on determining how to split one-fourth and one-third in a way to get them to be comprised of the same-size pieces.

Professor: [Drawing] OK, that is the three-fourths and the one and one-third. Where would one be at here? [Indicating to the number line]

Irica: $\quad$ Twelve-twelfths. (Data)

Professor: OK, it will be twelve-twelfths, is it going to be closer to three-fourths? Or it is going to be closer to one and one-third?

Tamie: $\quad$ Three-fourths ... (Data) 
Professor: If I want to put it exactly? ... I think I heard three-fourths. Why is one closer to three-fourths?

Tamie: $\quad$ One-fourth is less than one-third. (Data)

Professor: So, I will put it ... a little more towards to the left, but we can talk about the stuff when we did comparing fractions on Thursday. So, this distance right here is going to be one-fourth. This distance right here is going to be onethird. So, if I am looking at fourths versus thirds, are these two pieces going to be equal?

Tanny: What?

Professor: So, if I have a fourth here and if I have a third here, are these two pieces are going to be equal to each other?

Vrittany: No.

Professor: No. What is one ... There is actually multiple ways to do it, but what is one way to do it?

Janna: $\quad$ Finding their common denominator. (Data)

Professor: OK, so, in this case, which one do you want to use?

Janna: $\quad$ I did twelve. (Data)

Professor: You did twelve. OK, I think this is what several of you did. With the twelfths anyway. Treanna, what did you do after this?

Treanna: So there is like seven sections. Each section broke it up like nine-twelfths, ten-twelfths, and then we broke each section up into thirds. So we did that with all the sections. (Data)

Professor: So, what part of the problem told that you are going to be splitting in two thirds?

Treanna: The two-thirds. (Data)

Professor: OK, do you guys see this so far?

[Class agreed]

Professor: So, the two-thirds in this case is going to tell us that you could take each of those pieces and cut it into the three, and what did you do?

Irica: $\quad$ Then, we counted how many like sections there are. There are 21 in total. (Data)

Professor: I won't write all of these, but ... OK.

Irica: $\quad$ So then, we knew that seven goes in twenty-one three times so it is like three sevens basically, so we took two of the sevens and added them together to get $14 \ldots 14$ over 21 is equivalent to $\frac{2}{3}$. (Data)

Professor: I think you said $\frac{2}{3}$ is equal to 14 over 21 .

Irica: $\quad$ Yes.

Professor: OK.

Irica: $\quad$ So then, with that we knew that we had we counted up to like 14 sections starting like the $\frac{9}{12}$. So then, we were like the 14 sections is, that is for like 13 and $\frac{2}{3}$ over 12 is. That make sense? That tally mark is 13 and $\frac{2}{3}$ over 12. (Data)

Professor: You are saying this one is 13 and $\frac{2}{3}$, what? 
Irica: $\quad$ And then, so like our like fraction with that tally mark is 13 and $\frac{2}{3}$ over 12 . And multiplied the numerator and denominator by 3 . Like 13 and $\frac{2}{3}$ multiplied by 3 to get 39 and add the 2 to get 41 and 12 times by 3 is 36 . I got 41 over 36. (Data)

Professor: OK, those of you who were confused with this part before, does this help? Are there questions?

[No question- the class agreed on the solution.]

Irica's argument explains what each of the little tick marks are representing. From $\frac{9}{12}$ to $\frac{10}{12}$, which is $\frac{1}{12}$. When PTs split up twelfths into three pieces, they got thirty-sixths. For each space, they then counted $\frac{12}{36}, \frac{13}{36}, \frac{14}{36}, \frac{15}{36}$ until they would get up forty-one-thirty-sixths.

The idea of breaking up a denominator into other denominators was introduced in fractions Day 1 and developed during the number-line activity on fractions Day 7 and continued during the fraction addition problem in fractions Day 8. So, the class moved on to ways to develop a common denominator by dividing each piece into the number of pieces given in the denominator of the other fraction when they worked on the following contextual fraction addition problem (see Appendix L, Problem C).

Calvin has two-thirds of a bag of candy and Hobbes has three-fourths of the same size bag of candy. Their mother puts the amounts of candy together. How much candy is there?

One of the PTs, Hanna, made more conceptually-based argument and decided to cut the $\frac{2}{3}$ into fourths and the $\frac{3}{4}$ in thirds to create 12 pieces in each (see Figure 19 and 20), which is the same number of pieces as multiplying both denominators together as it is shown below, numerically. This helped the PTs to make sense of the numbers and procedures (Reed 1999) and to build on their prior knowledge with equivalence that had served as resource as this activity evolved. 


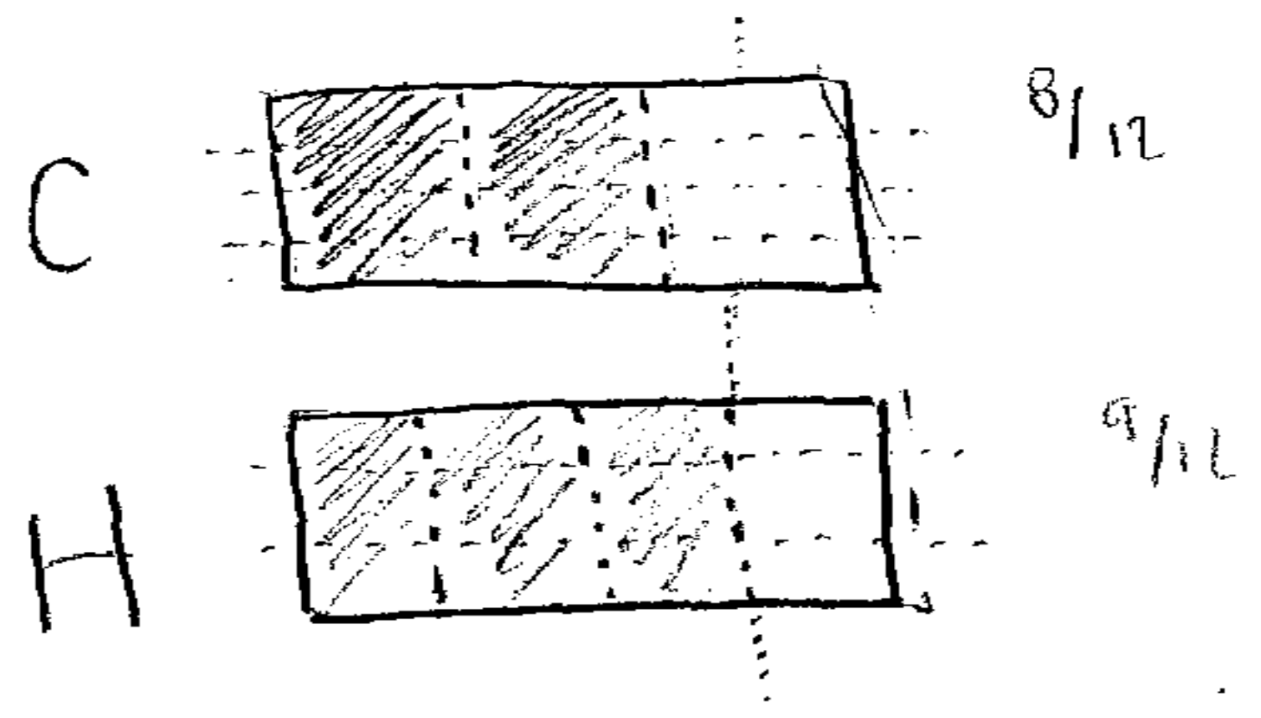

Figure 19. Cut the $\frac{2}{3}$ into fourths and the $\frac{3}{4}$ into thirds and add $\frac{2}{3}$ and $\frac{3}{4}$.

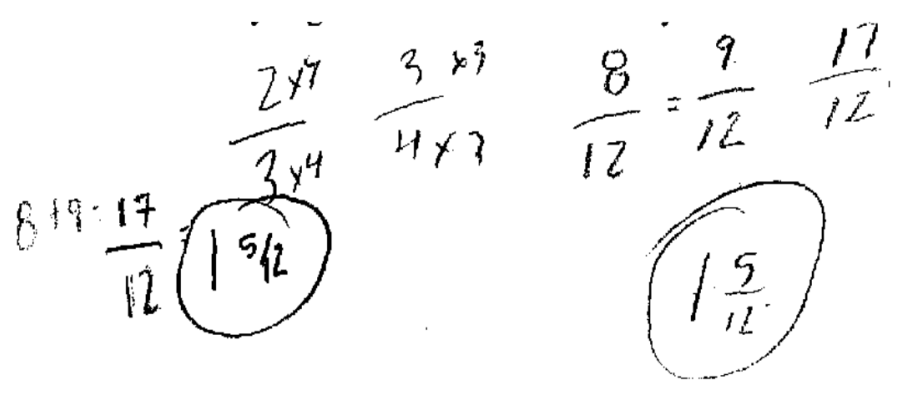

Figure 20. Multiplying to create a common denominator to add $\frac{2}{3}$ and $\frac{3}{4}$.

On dividing the unit, a rectangle, into 12 equal-sized parts, the unit fraction became $\frac{1}{12}$ for both rectangles. The unit fraction is now the same, and it makes it easier to think flexibly with the same-sized units to compute the necessary operation. 
Therefore, the idea that the denominator represents the number of pieces in the whole which was introduced in fractions Day 1 and was developed in fraction Day 6 came up here again. Particularly, the idea of cutting pieces up to create common denominators using pictures became taken-as-shared idea in the context of adding fractions. Previously, we encountered the first idea, which explained that the denominator does not change when combining two or more fractions as the whole remains the same that was taken-as-shared.

Fraction subtraction with multiplication. The class also considered a subtraction with multiplication problem (See Appendix K, Problem A) in fractions Day 8 Marty has $\frac{3}{4}$ of a bag of candy and gives Jane half of his candy. How much of a bag of candy does Marty have left?

Pulianna's group came up with different claims. However, a way was developed using picture to find a common denominator for the two given fractions. In the problem, Pulianna did not realize what the whole for the three-fourths was. She assumed three-fourths was the whole. So, she decided to cut the three-fourths into half, just by removing the fourth box and using the three boxes, she came up with one-half as a solution. However, her final answer of one-half was rejected.

Pulianna: So, I just like drew out the problem. Three-fourths basically was the box of four. I crossed out one. You can't have a whole. You only have threefourths of it. And then you left with like three little squares and he gave half of it to Jane. Then cut three in half and then so Jane gets three and he gets three. (Data)

Professor: So, your final answer was three-eighths?

Pulianna I got a half and they got three-eighths and one-fourth. (Claim)

From the above conversation, Pulianna's group understood that the whole for the threefourths is four-fourths. They then had three-fourths of a bag of candy and took out one-half of the three-fourths, which is where the three-eighths came from. 
Professor: OK, according to the problem. So if we are just looking at the three-fourths of this problem, what is the whole for it?

Irica: $\quad$ Four-fourths. (Data)

Professor: OK, which is represented by what?

Tanny: $\quad$ The entire candy bar. (Data)

Professor: If we look at the one-half, what is the whole for the one-half?

Sori: $\quad$ Three-fourths. (Data)

Professor: OK, does every one see this so far?

[Class agreed]

[No questions]

So the whole for the three-fourths is a whole bag of candy, which is four-fourths and the

whole for the half is three-fourths. Technically, Irica was taking half of the three-fourths which

she had at the start. Thus, her method of dividing each piece into a number of pieces listed in the denominator of the other fraction was not questioned.

Professor: OK, if we look at the question the problem asking, what is going be the whole for the answer? So the question in the problem asks us for what?

Tara: $\quad$ It would be the four-fourths. (Data)

Professor: I know, I think almost all of you cut the bag of half candy into eighths because when you do three-fourths and cut into half to get ... you end up with 8 pieces total. So, if we are looking at this particular problem, we were asked to figure out how much Martin has left. So, if Martin has this much. And we know that the whole is going be the whole bag of candy, what fraction of the whole bag is this?

Students: Three-eighths. (Claim)

Professor: Three eighths. So, do you guys see where this is coming from? OK, getting to the question or the number sentence for this particular problem. There were different things I saw with this one, but what are we starting with in this problem at the very beginning of it.

Student: Three-fourths. (Data)

Professor: OK what do we do to the three-fourths? [No Responses]

Professor: OK, so, I know it has been a while since we have talked about this. But, because we are doing half of the three-fourths and we talked about this stuff when we did whole number multiplications, you are going to have to represent this in your equation that you write for this also. So half of threefourths is going to get written as one-half times three- fourths in this particular case. Write a number sentence questions that was going to match the problem exactly.

Professor: Subtraction, so, what did we end up starting with in the first part of this problem here? So, where did we start at the very beginning of the problem?

Jamie: $\quad$ Four-fourths. (Data) 
Professor: Four-fourths. Marti started with three-fourths of it. So, the expression if we already put it - the answer of the equation for this particular problem is going to be this. So you started with three-fourths of a bag of candy and took out one-half of the three-fourths. That is where the three-eighths came from. Questions?

[No Questions]

With the subtraction task, the practice of keeping the whole the same and slicing pieces with common denominator both became evident. This shows, the idea of cutting up the other denominator that became taken-as-shared earlier during the fraction addition section appeared here again and, therefore, the PTs did not finding anything different when the topic moved on to subtraction. However, this practice helped the PTs to make sense of the algorithms for subtraction. When subtracting fractions the whole remains the same, which is why the denominators do not get combined (Tobias, 2009). In addition, the pieces must be the same size.

Later discussion focused around the number sentence to represent the above situation. None of the PTs solved this problem, none were able to write a number sentence that exactly matched the situation. Although they understood it was a subtraction problem, they were not able to write a complete number sentence.

Once the PTs understood the situation, the Professor immediately went on to explain how the PTs were going to write the equation, making sure that the fractions referred to different wholes. "You started with three-fourths of a bag of candy and took out one-half of threefourths - that is where the three-eighths is coming from." Thus, Marty started with three-fourths of it, which is three-fourths times four-fourths and half of three-fourths is going to get written as $\frac{1}{2}$ times $\frac{3}{4}$ in this particular case. So, when we put everything together, the expression for this particular problem is going to be $\left(\frac{3}{4} \times \frac{4}{4}\right)-\left(\frac{1}{2} \times \frac{3}{4}\right)$. This lack of understanding or misconception 
does not emerge when subtracting whole numbers in context or when subtracting fractions devoid of context, even when visual images are used (Juli, Dixon, \&Tobias, 2013).

Fraction multiplication. Newton's (2008) study showed that several of the most common multiplication errors of students seemed to be related to prior fraction knowledge which students had developed in classroom discussions about why a common denominator is used to add and subtract fractions, and why a common denominator is again kept in the final product. In this study, however, the PTs' practices did not pertain to the algorithms in fraction operations. Rather the tasks were designed so that the PTs would be able to make connection between a concrete model and abstract thinking that would help them to understand fraction multiplication (see Figure 21)

The fraction multiplication problem was presented in fractions Day 9 in the context of Charlie Brown's pie being three-fifths of a pie and Lucy's is two-thirds of the amount that Charlie Brown has (see Appendix L).

Charlie Brown has three-fifths of a pie. Lucy has two-thirds of the amount that Charlie Brown has. How much pie does Lucy have?

Professor: What did you get for the answer?

Students: Six-fifteenths ... six-fifteenths. (Claim)

Professor: Anyone have anything different than six-fifteenths? Ok, how did you guys do this one? I agree. I really did not look at the second one while I was walking around. Do you any of you have a picture for this one? [Rhannon raised her hand]

Professor: What did you do?

Rhannon: I did ... I split it into fifteen boxes and then I shaded for Charlie... (Data)

Professor: Can you bring it up here? OK!

[Rhannon went to the document camera to show her work] 

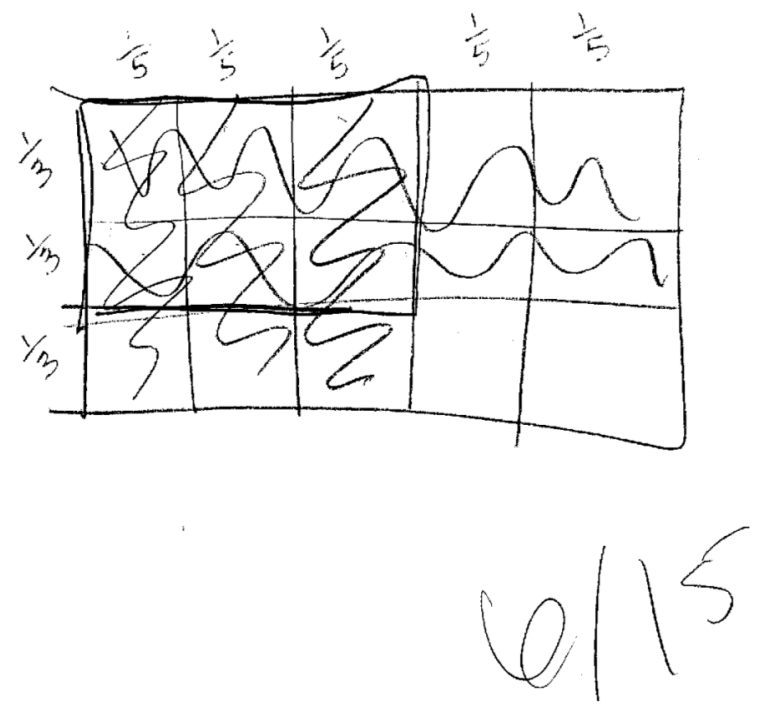

Figure 21. Two-thirds of two-fifths.

Rhannon: This is fifths ... and this is thirds [Showing how the rectangular figure is partitioned]. So, I shaded three-fifths of it and Lucy has two-thirds, so Linus' two-thirds is this way. And then multiplication just whenever the two boxes ... like the shading overlap. So, that box shows there is six of them are shaded out of fifteen [Indicating the overlapped rectangular area] (Data)

Rhannon claimed six-fifteenths, and came to the board to explain the problem outside of the procedure and started introducing the idea of a "new whole." Rhannon showed that in fraction multiplication the whole changes through the problem. The initial whole was used to represent the first fraction, in this case, $\frac{3}{5}$. The whole group of $\frac{3}{5}$ became the new whole so that $\frac{2}{3}$ of the $\frac{3}{5}$ could be taken. For the answer, $\frac{6}{15}$, the whole changed back to the initial whole of one or $\frac{15}{15}$

Another PT, Pulianna, looked at the problem differently. She started with three-fifths and directly took two-thirds of three-fifths (see Figure 22). 

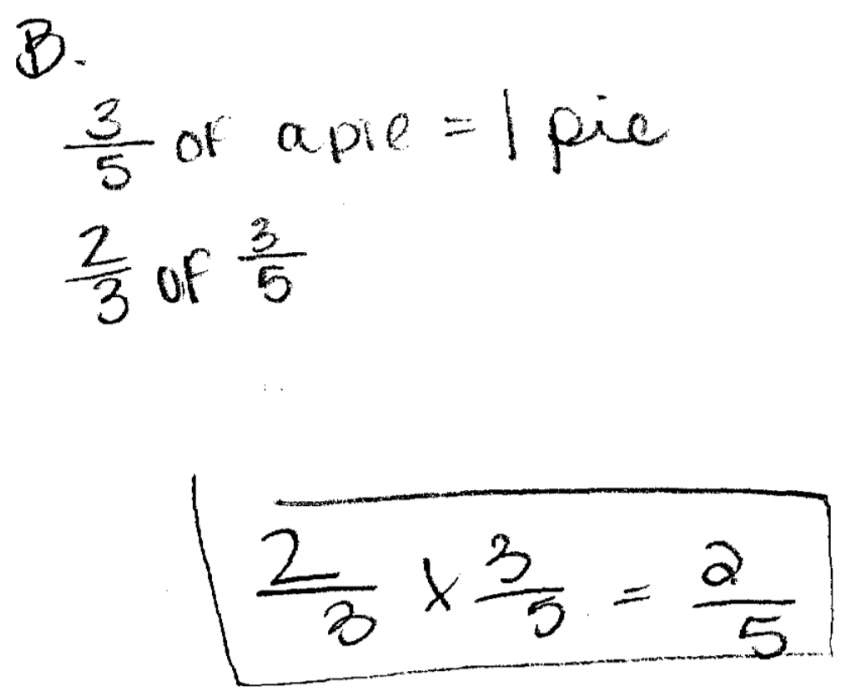

\section{Charlie Broun}

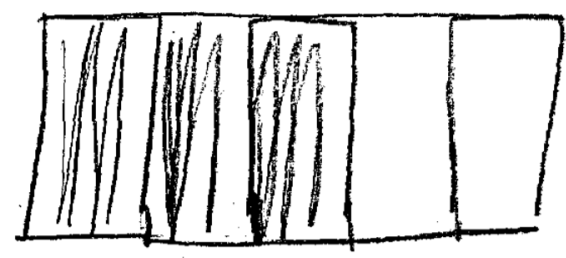

Lucy has $\frac{2}{5}$ of a pie all that was

Figure 22: Two-fifths of three-third.

Pulianna: So, Charlie Brown has three-fifths, the picture shows three-fifths and it says that Lucy has two-thirds of what Charlie brown has, so he just has like two of the three pieces. (Data)

Professor: The three-fifths. What is the whole for three-fifths?

Pulianna: Five-fifths. (Data)

Professor: OK, five-fifths or the whole pie. What is the whole for the two-thirds? [No responses]

Tanny: $\quad$ Was it a third of it, may be equal to the fifths ... like ... if you draw out, let say, two-thirds on it. It is the same pie, be like the same length, it is just the fifths splitting into the three pieces. (Question)

Professor: Say it again. I want to make sure I understand what you are asking.

Tanny: $\quad$ Like, I don't know. Never mind.

Professor: I will come back to you. So, OK, say three-fifths the whole of the pie, what is the whole for the two-thirds?

Tanny: $\quad$ Three over three ... Three over three. (Data)

Professor: Well, how much.

Tanny: $\quad$ Oh, fifteen over fifteen...right! I don't know ... (Data)

Professor: So, before we get to that, so if we look here the three-fifths of a pie means the whole is one pie. If we look at the two-thirds, two-thirds of what?

Tanny: Charlie Brown's pie. (Data)

Professor: If that is Charlie Brown, how much were we told Charlie Brown has?

Tanny: $\quad$ He has three-fifths. (Data)

Professor: Yea, he has three-fifths. And then, can you say what you did?

Pulianna: I started that Charlie Brown had three-fifths and Lucy has two-thirds of that. (Data)

Professor: OK, so this two. [Indicating to the two pieces].

Pulianna: Yeah, Lucy has two-fifths. (Data)

Professor: Of what? 
Pulianna: Of the whole pie. (Data)

Lucy has two-thirds of the amount that Charlie Brown has, which means that Charlie Brown is not going to be the whole. Again, with Pulianna's strategy the whole can change with this particular problem. Because of Charlie's three pieces, essentially Pulianna was going to be taking two of those pieces to figure out what Lucy has, which is going to be two-fifths of the whole thing. Therefore, the idea became taken-as shared for the whole to change with multiplication as it is with division because the practices that were established here did not pertain to the algorithms in division and multiplication. But, with addition and subtraction they end up staying same the whole time.

Professor: Questions?

Tanny: Is six-fifteenths right? What is the answer?

Professor: Both are correct.

Tanny: Oh!

Professor: Yeah, so if you did it, two-fifths is actually the same thing as six-fifteenths, Tanny: It is?

Professor: That they are equivalent to each other. Part of these ... it is going to count down how many pieces you are breaking into. So either one of these will be.

Tanny: That makes sense... [Laughing] two-fifths is the same number.

Within the multiplication problem, the first problem which arose was not that of how to write a number sentence, but how to solve the problem. The purpose of having the PTs to write a number sentence was to have them determine if the above problem should be represented as three-fifths times two-thirds or two-thirds times three-fifths. However, writing a number sentence for this particular multiplication situation that was placed in a context, was also an issue for the PTs. Thus, the professor had to wait long until the class responded to her question. Tara presented her claim as a question. Though it is a multiplication equation, her response was still incorrect. 
Professor: OK, did you guys get an equation for this one? For number three.

[No response ... Long pause ... the professor was waiting]

Tara: Is it three-fifths times two-thirds. (Claim)

With this problem, in particular, they were not supposed to do three-fifths of two-thirds. They were supposed to do two-thirds of three-fifths, which is actually going to make the number sentence two-thirds times three-fifths, instead of three-fifths times two-thirds. So, the order is going to matter in this particular case, even though the PTs started with the three-fifths because they were doing two-thirds of it. That is where the two-thirds comes from, and depending on how they solve the problem, they may end up with two-fifths of what this much for its equivalent. However, with multiplication just like with division, we have seen the whole also changes. So, PTs do have to be careful with this type of situation.

Fraction division. Apart from showing the connection between the operation and the contextual meaning, the big idea for fraction division includes students being able to model the operation embedded in story problems with concrete models and pictures and to be able to explain the process (Cramer, Wyberg, \& Leavitt, 2009). The discussion of fraction division did not occur until the first division task (see Appendix L) that the class was presented with in fractions Day 9.

Justin has 15/8 pounds of hamburger. Each serving of chili requires 3/4 pound of hamburger. Using the entire hamburger, exactly how many servings of chili can he make?

The PTs gave different answers to this problem. The two most common ones were two and three-eighths and two and one-half. One preservice teacher, Tanny, drew the problem on the board and used her picture to determine what to do with the leftover piece. Some of the PTs referred to this piece as $\frac{1}{2}$ because it represented half of the serving (see Figure 23), whereas other students, like Tanny, represented the reminder in terms of the whole and arrived at an 
answer of two and three-eighths (see Figure 24). In fact, as a measurement division, the total and the amount in each group was given and the PTs were only required to determine the number of groups of servings that can be made. In this case it is most common to use contexts to support this measurement division when dividing fractions by fractions because sharing among a part of a group is difficult to visualize (Dixon et al., 2014).

As evident from the conversation, although Tanny initially responded with an answer of two and three-eighths, Pulianna rejected Tanny's solution, arguing the three-eighths is actually $\frac{1}{2}$ of a six-eighths using a measurement meaning of division. By the end of the discussion the class determined the correct answer was two and one-half.

Tanny: $\quad$ So it says we have fifteen-eighths pounds of hamburger. Say, they started out and do fifteen-eighths size-pieces that is why we put $\mathrm{X}$ on the last one. We just want to use sixteen six-eighths pieces but we just disregard the last one and then we know that each serving chili needs three-quarters of a pound of hamburger and three-quarters, you can change to eighths by multiplying by two over two... so three-fourths is equal to six-eighths. So you can count out six- eighth size-pieces to see how many serving you get. So we counted up first six one serving, there is still more serving for another serving, we count out six more pieces. I know I can make two serving and with the remainder three. So, each gets two and three-eighths servings. (Data, Claim)

Professor: OK, did you guys follow that?

Etephanie: Maybe two and half. (Claim)

Tanny: No, last one disregard because it is only fifteen-eighths pieces, I just did sixteen and it just because... I just ... so that you just can see the eighths and it is not the sevenths. They get out of the whole split into eight pieces only seven of them are part of what we had. (Data)

Pulianna: They should get two-and-half servings because three-eighths is half of six-eighths. (Warrant)

Tanny: $\quad$ Oh!

This illustrates "by translating from story problems to pictures to language the PTs develop mental images that support their number sense for fraction division as well as meaningful symbolic work with fractions division" (Cramer, Wyberg \& Leavitt, 2009, p. 11). 


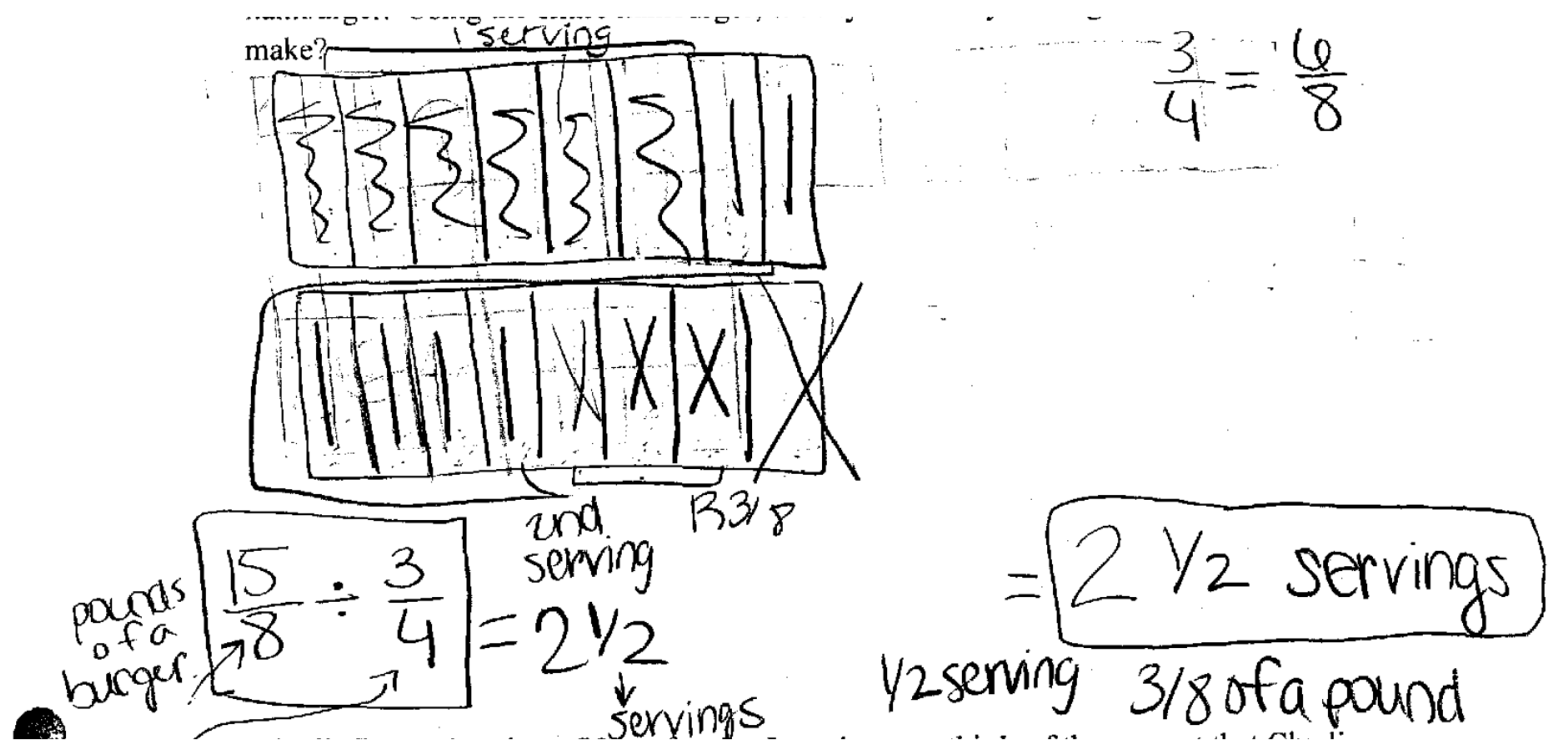

Figure 23: Two and-a half servings.

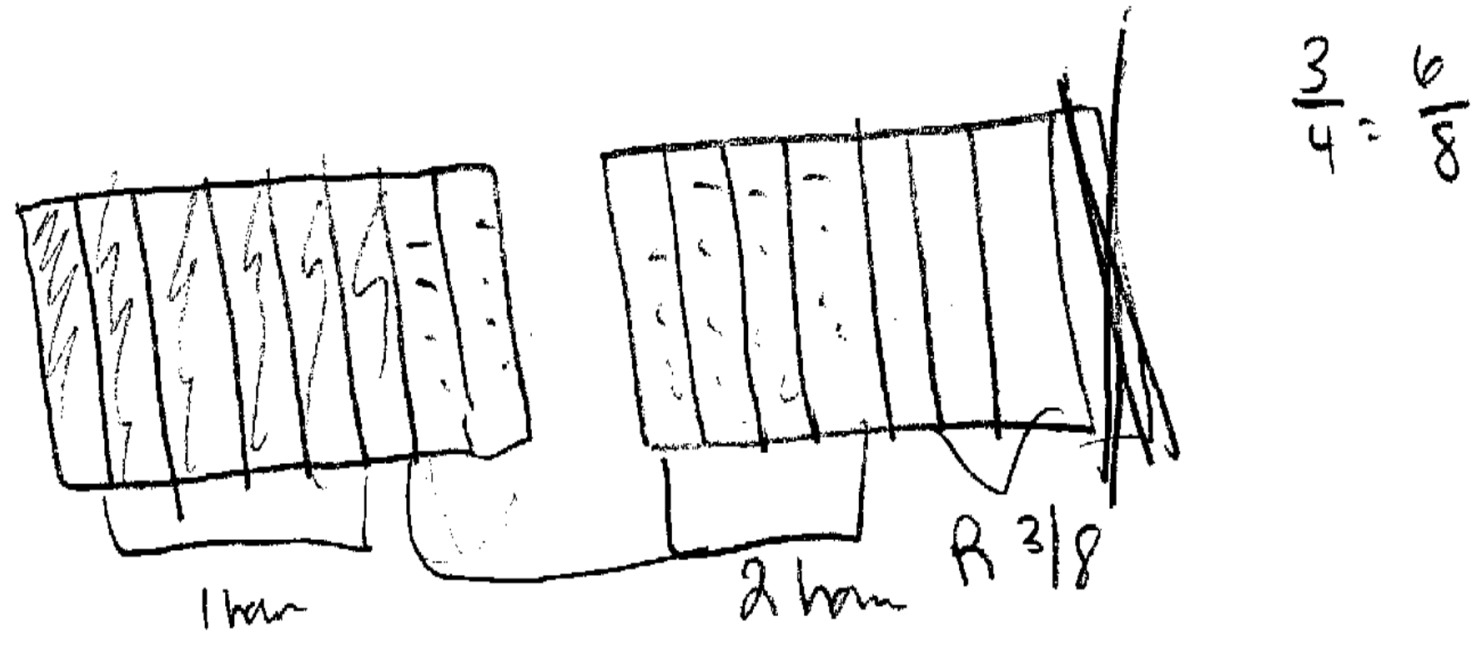

Figure 24: Two and three-eighths servings.

The discussion actually occurred after Tanny explained her solution on the board by drawing a rectangle and unitizing to the whole to represent the division illustrated in Figure 24. 
The remaining picture was $\frac{3}{8}$ of one whole rectangle, but half of the serving. This conversation then led the class to discuss what $2 \frac{3}{8}$ and $2 \frac{1}{2}$ would each mean in terms of the situation.

Professor: Janna, what were you doing?

Janna: The same thing. Since six pieces is the whole ... like serving. There is three left. So, that is half of a one whole serving, which means I had onehalf as well. Two and half. (Data)

Tanny: $\quad$ Is it about serving of chili?

Professor: What is the question asking for?

Tanny: How many servings of chili.

Professor: OK, if it had asked for how many servings, do we all agree with the two?

Students: Yeah.

Professor: OK, so if we look at the two, the two represent what?

Students: How many whole servings. (Data)

Professor: Ok, the two is two serving, is the three-eighths, three-eighths of the serving?

Students: No ... no.

Professor: what is the three-eighths so?

Janna: $\quad$ It is half of the hamburger. (Data)

Professor: Yeah, three-eighths is half of the hamburger. You guys are saying one-half of the serving? [Drawing]

Pulianna: Yeah.

Professor: OK, so, if we look at the two and the one-half of the three-eighths, which one is going to be referring to servings? In this case ...

Etephanie: The whole servings or all the servings. (Data)

Professor: In this particular problem you are actually going to do all of the servings, because the problem said using all of the hamburger ... if it would have just said how many full servings can you make them, you would have just stuck with the two. So the answer for this two and half or two and three-eighths?

Students: Two-and-half. (Claim)

Professor: Yeah, in this case it is going to be two and half, because you are looking for servings in this particular problem and how much of it is accounted. Are there ... Go ahead! [Pulianna raised her hand]

Reagan: $\quad$ So I know, how like ... about the confusion. So, if it says how many servings instead of how many pounds, then you would use the two and onehalf. But if it said how many pounds, then it would be three-eighths. (Backing)

Professor: Yeah, so if the question would have said how many pounds of hamburgers are left over, then you would have said three-eighths. But, because it is asking for servings, you are going to relate back to how many in the serving, which was six pieces and you could say three-sixths here too. Yeah, did you have questions?

[No question]

Tamie: I was going to say if six-eighths is one serving and three eighths is what is left of a pound, you know, that is half of six-eighths. (Data) 
Professor: Yeah. So questions?

[No questions]

With this particular problem, PTs were trying to figure out how many times $\frac{3}{4}$, in this case, goes into $\frac{15}{8}$ fifteen-eighths. Most of them have this on their paper and they understood this is a division problem. They started with $\frac{15}{8}$ and they divided by $\frac{3}{4}-$ to see how many time it is going to go completely. In this case, some of them were able to figure out it goes $2 \frac{1}{2}$, where both components of the mixed number solution $\left(2 \frac{1}{2}\right)$ were representative of the same amount or servings, and others said it should be $2 \frac{3}{8}$. Thus, with division, as we have seen, one of the issues was the PTs' inability to understand that their whole is going to change throughout the problem and need to make sure that the left over amount gets represented out of what it is that the PTs were taking out of it, not out of the whole thing. The $\frac{15}{8}$ was the pounds of hamburger and by the $\frac{3}{4}$ was how many pounds were in the serving. Therefore, the solution for this problem is related to the servings, not to the pounds. However, there may be a time when PTs have to say the answer is $2 \frac{3}{8}$ of a pound. But that solution would be correct if the question was how much hamburger is left over after the full servings. Yet, for this particular case, since PTs were looking for the serving, their answer was also going to be out of the servings. However, it was not apparent from the discussion of the problem if representing the reminder in the context of division situations become taken-as-shared simply because one preservice teachers presented a backing. Since, this was the only division problem the class was presented, the ideas cannot be fully developed. 


\section{Discussion}

Social and sociomathematical norms were established and sustained within the fraction concepts and operations unit. The social norms of explaining and justifying, making sense of others, questioning, and the sociomathematical norm of determining what constitutes a different solution were established before the fraction concepts and operation unit, though they continued to be sustained and negotiated by the Professor and the PTs throughout the fractions unit. The only sociomathematical norm that had to be reestablished was what constituted an acceptable solution. The idea of acceptable use of pictures in explanations and justifications, and the idea of what constitutes an acceptable mathematical explanation and justification had to be reestablished. There were no classroom conversations directed at determining whether the PTs understood what it means to have a more sophisticated and efficient solutions in this study, which was a norm I initially expected would be established in the classroom.

It is evident from the results that PTs began the semester with some prior knowledge of fractions. The instructional sequence activities were also designed in different contexts, taking into consideration the fact that PTs were familiar and had prior experience with learning fractions concepts and operations. PTs' prior knowledge which comprised fractions are parts of wholes, fractions are comprised of equal parts, a unit fraction can be iterated, and common denominators can be used to compare can serve as a productive starting point. Classroom tasks can influence PTs' prior knowledge as part of a sequence in which they learn to reason flexibly and sensibly about fraction concepts which involve partitioning, understanding partitioning that do not have to be equivalent as long as everyone receives the same amount, realizing the denominator represents the size of the piece, and fractions are composed of equal parts to reasoning the concept of unitizing and developing the language of fraction in terms of what the 
denominator represents, to connecting partitioning, unitizing, and the size of the piece to equivalence concept, to making sense of fractions comparison using various learned concepts including partitioning, uniting, size and number of pieces, and equivalence-into the idea of fraction operations.

The result indicates that several mathematical ideas became taken-as-shared as the class developed strategies on making sense of fraction concepts and operations. The next figure (see Figure 25) provides the time table of the classroom mathematical practices that I have described. It shows when the set of mathematical practices were being used and provides the order by which the mathematical ideas which became taken-as-shared overlapped throughout the fractions concepts and operations unit. Most of the ideas were introduced during the first day of fractions concepts and operations and established on different days of the instruction. Ideas that were discussed were not necessarily taken-as-shared immediately. This was the background to finding a unit fraction from a composite - a task which was introduced on fraction Day 1 and was established in fractions Day 5. PTs were able to provide justification in defining the whole on Days 1, 2 and 3, but did not justify reasoning about equivalent fractions in relation to the denominator (same-size whole) and the idea that the denominator represents the number of pieces in the whole until Day 7. Finding a unit fraction from a composite fraction and iterating and developing a composite unit of one ran in parallel, and came on Days 1, 2, 3, 4, and 5. The idea that the denominator stayed the same, which introduced fraction addition, because it represented how many equal parts the whole divided into was introduced in fraction Day 1 but it was only being taken-as-shared in fraction day 8 during fractions additions. Multiplication started on Day 4 but taken-as-shared on fraction Day 9. Some of the practices became taken-as- 
shared in a single day of instruction. Such practices included the larger something is broken into the smaller the pieces become and the whole to change with multiplication fractions.

\begin{tabular}{|c|c|c|c|c|c|c|c|c|}
\hline 1 & 2 & 3 & 4 & 5 & 6 & 7 & 8 & 9 \\
\hline $\begin{array}{l}\text { Fractions are } \\
\text { composed of } \\
\text { equal parts. }\end{array}$ & & & & & & & & \\
\hline
\end{tabular}

A fraction solution is nothing
by itself and does not make
sense without talking about
the whole/The whole does
not change unless it is
specified

Finding a unit fraction from a composite fraction Iterating and developing a composite unit of one Iterating a unit fraction from composite fraction

\begin{tabular}{|l|}
\hline The idea \\
which \\
states the \\
larger \\
something \\
is broken \\
into the \\
smaller \\
the pieces \\
become \\
\hline
\end{tabular}

Both equivalent fractions are out of the same size whole

The denominator/whole remains the same with fraction additions and subtractions

The whole to change with multiplication

Figure 25. Time line of Classroom Mathematical Practices. 
In addition, the whole-class room discussion contributed to the establishment of several mathematical practices, which included (a) equal-sharing: partitioning; (b) unitizing; (c) finding equivalent fractions; (d) defining the whole (defining a whole: labeling fraction, defining the whole: representing fraction, defining the whole: the language of fractions), (e) comparing and ordering, (f) ideas related to common denominator in addition, and subtraction, and (g) ideas related to the need for the whole to change with multiplication. Several established practices fell under an overarching topic. For example, unitizing included (a) finding a unit fraction; (b) iterating a unit fraction; (c) developing a composite unit of one; and (d) unitizing in terms of the whole. The practices are summarized in the table below (see Table 4).

Table 3

Mathematical Practices Before the Fraction Concepts and Operations Unit Started

\begin{tabular}{lc}
\hline $\begin{array}{c}\text { Hypothetical Learning } \\
\text { Trajectories }\end{array}$ & $\begin{array}{c}\text { Ideas Appeared To Be Taken-As-Shared Before The } \\
\text { Fraction Concepts And Operations Unit Started }\end{array}$ \\
\hline Equal Sharing: Partitioning candy & $\bullet \quad$ Fractions are parts of wholes \\
& \\
bars to create equal share/Fair share & $\bullet \quad$ Fractions are composed of equal parts
\end{tabular}

- Partitioning does not have to be equivalent as long as everyone receives the same amount

Unitizing

Compare with reasoning
- A unit fraction can be iterated

- Common denominators can be used to compare fractions 
Table 4

Mathematical Practices

Hypothetical Learning Trajectories

Taken-As-Shared Ideas

(The Days listed Are When Those Ideas

Were Taken-As-shared)

\section{Unitizing}

Defining the whole

Defining the whole: Labeling fraction

Defining the whole: Representing fraction,

Defining the whole: The language of

fractions

Same whole pieces (same common

denominator)

Equivalence
- Finding a unit fraction from a composite fraction. Day 4

- Iterating and developing a composite unit of one. Day 5

- Iterating a unit fraction from composite fraction Day 5

- A fraction solution by itself is nothing and does not make sense without talking about what the whole is. Day 3

- Everything that is coming after the word "of", when defining fractions, represents the whole. Day 3

- The whole does not change unless it is specified - the whole could potentially change depending on what blocks PTs actually used. Day 3

- The discrete model is only going to work to solve problems if PTs can keep whole pieces (when fractions came out of the same whole). Day 4

- Both equivalent fractions are out of the same size whole. Day 7 


\begin{tabular}{|c|c|}
\hline Hypothetical Learning Trajectories & $\begin{array}{l}\text { Taken-As-Shared Ideas } \\
\text { (The Days listed Are When Those } \\
\text { Ideas Were Taken-As-shared) }\end{array}$ \\
\hline \multirow[t]{5}{*}{ Comparing with Reasoning } & $\begin{array}{l}\text { - Comparing with common denominator } \\
\text { (the size of the pieces) in relation to } \\
\text { the numerator. Day } 6\end{array}$ \\
\hline & $\begin{array}{l}\text { - Comparing fractions using common } \\
\text { numerator (same number of pieces) } \\
\text { Day } 6 \\
\text { - Fractions can be compared to a certain } \\
\text { specific bench mark Day } 6\end{array}$ \\
\hline & $\begin{array}{l}\text { - The larger something is broken into } \\
\text { the smaller the pieces become Day } 6\end{array}$ \\
\hline & $\begin{array}{l}\text { - More-bigger piece is coming from a } \\
\text { smaller denominator and bigger } \\
\text { numerator Day } 6\end{array}$ \\
\hline & $\begin{array}{l}\text { The greater the denominator the } \\
\text { smaller the piece. Day } 6\end{array}$ \\
\hline Fraction Addition & $\begin{array}{l}\text { - The pieces must be the same size (the } \\
\text { denominators/whole stays the same) } \\
\text { Day } 8\end{array}$ \\
\hline Fraction Multiplication & $\begin{array}{l}\text { - The whole to change with } \\
\text { multiplication as it is with division } \\
\text { Day } 9\end{array}$ \\
\hline
\end{tabular}

Sixteen taken-as-shared mathematical practices were established through the nine days of instruction in this chapter. The practices were presented to show the ways in which the social and individual impacted one another. On the one hand, individual PTs impacted the collective classroom environment either by introducing a new idea in the form of a data, warrant, or backings or contributing additional supporting evidence in the form of data, warrant, and backings to sustain ideas. On the other hand, although no evidence has been reported that 
demonstrates conclusively that any individual participant's thinking was changed because examining individual students' learning was beyond the scope this study, it appears to have been highly likely that the classroom community actually impacted individual PTs' knowledge development and reorganization. First, when a correct solution was presented which some PTs did not think was correct, those students were challenged to change their thinking to accept the ideas as correct. Second, when a mathematically incorrect idea was presented that students thought was correct, students reorganized that they had to change their thinking so that they would no longer accept that idea as correct when the classroom community had rejected it (Tobias, 2009). 


\section{CHAPTER V: CONCLUSION}

This was a five-week classroom study that focused on the issues and ways in which preservice elementary teachers learned to make sense of fraction concepts and operations. This dissertation has documented the emergence and evolution of the classroom mathematical practices of the participating PTs. The research literature pointed to deficiencies in PTs' knowledge of fractions, and the need for PTs to have deep mathematics content knowledge in order to understand their students' thinking when attempting to provide meaningful experiences to them. Developing and supporting PTs' content knowledge of fraction concepts and operations is a pressing issue in mathematics education, and this study focused on the fraction concepts and operations unit in the course, which was the second unit presented to the class. This chapter provides a discussion of the results as well as some implications of the results for future study. Limitations of the study are also discussed

In this study, I investigated the PTs learning of fraction concepts and operations. The results of the study were also presented in terms of the collective classroom processes, which were characterized by "communicative discourses where the PTs are actively involved in the form of mathematical argumentation in which their explanation, justification, and elaboration are the most essential features" (Wood, Cobb, \& Yackel, 1993, p. 59) which foster the emergence of taken-as-shared ideas to emerge in the class.

I have pointed to features of classroom social norms and sociomathematical norms using the tasks that were designed so that the PTs would work with contextualized and noncontextualized situations, work together to solve the problems in their small groups, and then discuss the problems in a whole class setting (Wood, Cobb, \& Yackel, 1993). I saw the impact of one form of social norm on another one. For instance, in the study, it appeared that the 
sociomathematical norm of "acceptable" solution had to be renegotiated first to see its impact on the PTs' ability of the sociomathematical norm of offering different mathematical solutions. I have further documented the mathematical practices of the classroom using Stephan and Rasmussen's (2002) and Rasmussen and Stephan's (2008) approaches to argumentation with Toulmin's (2003) model, which together provided me with a reason why an emphasis on explanation and justification in the classroom could help PTs to reason flexibly in fractions concepts and operations sense-making. For example, I was also able to determine individual students' contributions to the mathematical practices from the data, warrants, and backings that they provided to the classroom conversations (Toulmin, 2003).

Practically, Toulmin's (2003) argumentation model appeared to be helpful in documenting the classroom activity in this study. By going analyzing the classroom discussions' argumentation $\log$ and identifying when an idea shifted position in an argument (warrants or backings dropping off) and/or was no longer questioned by the class, the analysis illustrated when the class community developed different fractions concepts and operation and how. For example, when and how they developed partitioning strategies, equivalence, unitizing, fractions language, etc. These understandings did not necessarily develop linearly — which was also the case in Stephan and Rasmussen's (2002) study. Rather, the analysis illustrated that some takenas-shared ideas were featured in more than one practice, and were sometimes complex, and emerged in a non-sequential manner. For example, recognizing that the denominator does not change when adding and subtracting two or more fractions, because the whole remains the same, was taken-as-shared in both fraction addition and subtraction tasks and likewise the idea that the whole needs to change was taken-as- shared in fraction multiplication before it was also seen to be important in fraction division. This is similar to Stephan and Rasmussen's (2002) 
findings in which the introduction and establishment of the first practice may not precede the introduction and establishment of the second practice in time. Thus, a mathematical idea can become taken-as-shared as the same time another idea is introduced, that can contribute to the development of a different mathematical practice. In this study, the mathematical ideas interconnected to the extent that at one point they were emerging before any one idea became taken-as-shared, which highlights how the important mathematical ideas could be linked with each other. For example, before the class was introduced to equivalent fractions, the concept that that both equivalent fractions are out of the same-size whole was already introduced in fraction Day 2, developed in Day 5, and later this was taken-as-shared by the class in fraction Day 7. In addition, the application of constant comparative methodology (Glaser \& Strauss, 1967) helped me to determine the ways in which the collective learning was influenced by refining the operational definition of the mathematical ideas involved in each argument.

The fraction concepts and operations unit was designed so that PTs would work on both the various fraction concepts and operations and the four subconstructs of rational numbers, which included the part-whole, quotient, operator, and measure meanings of rational numbers (Kieren, 1976). These meanings were emphasized throughout the classes on fraction concepts and operation tasks. For example, the partitioning situations (sharing division) were presented as a quotient situation of sharing a number of candy bars with a set number of people, in which the candy bars were equally divided into the given number of groups of people to determine the size of each group. Related equivalence reasoning strategies that have the potential to be transformed into more generalized symbolic procedures developed and helped the PTs to come up with different solutions, though that transformation may not be guaranteed. However, in future studies the professors may guide such types of transformation "by acknowledging and valuing 
the meaning and variety of PTs generated strategies in equal sharing and emphasizing a common focus on constructing strategies that work for as many different number combinations and problem context are possible" (Empson, 2001, p. 424). In addition, the measurement context was presented that provided the PTs with the support they needed to build meaning and makesense of fraction division using a common denominator approach, particularly, when some of the PTs were able to figure out the solution for the division problem, saying it went $2 \frac{1}{2}$ instead of 2 $\frac{3}{8}$ and stressing the fact that both components of the mixed number solution $\left(2 \frac{1}{2}\right)$ were representative of the same amount or servings presented to justify their claim. This connection between the operation and the contextual meaning helped some of the PTs to translate the contextual problem (story problem) to pictures and then to language so that they could develop a mental image which supported their number sense and algorithmic reasoning for fraction division (Cramer, Wyberg \& Leavitt, 2009). It helped some of the PTs to look at fraction division as an understanding of how many groups of the intended quantity are contained in the given quantity, and to realize the big mathematical idea about the connection between the operations and the contextual meaning. However, more measurement division problems with a reminder need to be incorporated in the future so that ideas can be fully developed in the class.

Similar to Tobias' (2009) findings, there were several ideas that related to the mathematical practices that appeared to be taken-as-shared before the fraction concepts and operations unit started. These included the idea that (a) fractions are parts of wholes, (b) fractions are comprised of equal parts (which did not involve fraction greater than one), (c) a unit fractions can be iterated, and (d) common denominators can be used to compare fractions. These ideas did not always shift in functions and were never questioned. According to Rasmussen and Stephan's (2008), ideas considered to function taken-as-shared for documenting collective 
activity if one or more of the following criteria were satisfied: (a) warrants or backings are no longer being stated when only data are needed and that data are never questioned, (b) an argument is shifting roles, example, from claim to warrant, or (c) data or warrant is used repeatedly in support of different claims.

The study drew attention to difficulties which some PTs had in connecting different representations of rational number concepts and prospective teachers' limitations with the language of fractions - an issue which was previously addressed in Tobias' (2013) research on PTs' development of fraction language for defining the whole. However, in the class discussion, the PTs understood the fact that they could not change the whole unless it was specified. They realized that if they did change the whole, it was going to change the fraction that was being represented. They began to understand the importance of keeping both pieces, the fraction and the whole, in their solutions, and realized it was going to meant nothing — just say what the fraction is, without talking about what the whole is.

There were situations where the class raised two important mathematical questions for discussion. One is whether some of their strategies made sense mathematically and the other is whether some of their strategies could be generalized (Empson, 2001). In particular, the PTs realized that there are situations where neither the area nor a discrete model are relevant to problem situation. So, some strategies may not be generalized. However, unlike the case with whole numbers, the whole for a fraction task may not necessarily be a discrete set of objects (Mack, 1993, Tobias, 2009). It can also be a quantity such as an area-and so that both of them, the discrete and the area models, can be used to arrive at correct mathematical solutions. This was also evident from the Charlie Brown problems that the class discussed. 
The linear model of fraction is related to measurement, and PTs often found it difficult to work with number lines. They became confused by the fact that they label points with fractions as coordinates, which represent distance. Therefore, they were unable to realize that defining the unit distance is crucial with number-line work. However, the idea for PTs to build on their prior knowledge with equivalence, on the unitizing idea of finding a unit fraction, on iterating a unit fraction, and on developing a composite unit of one in different tasks helped them to see that the number-line representations of distance between same-sized pieces can be important. Thus, the number-line tasks that were presented in the fraction concepts and operations component not only reiterated the concepts that had already been established, but also helped PTs to apply those concepts in placing fractions on a number line in multiple ways. Besides, as explained earlier, classroom tasks also influenced PTs' prior knowledge as participated in the progression in which they learned about fraction concepts which involved understanding that the denominator represents the size of the piece, and fractions are composed of equal parts, to reasoning with respect to the concept of unitizing, and to developing the language of fraction in terms of what the denominator represents, to connecting partitioning, unitizing, and the size of the piece to equivalence concept.

The contextualized problems, which were presented for the class, were designed to develop the PTs' knowledge in making sense of fractions concepts and operations. Contextualized problems, which require fraction operations, also helped the PTs to make sense of the numbers and procedures (Reed, 1999). I was able to observe many PTs' pictures and found that many supported the contexts of problems. That said, often PTs experienced issues related to translating contextual problems to pictures and then to language which provided meaningful explanations. 
At the beginning of the fraction concepts and operation unit, which was concerned with fraction addition, using a picture was difficult for the PTs. In particular, some had difficulty in explaining their solution strategies so that their model would make sense to themselves and to others. However, later, the PTs' understanding of equivalence developed both concretely with pictures and symbolically with numbers and this development supported their procedural steps for adding and subtracting fractions using common denominators (Cramer, Wyberg, \& Leavitt, 2009). Experiences with the tasks helped PTs to connect symbols back to concrete models. Above all, identifying the unit fraction made it easier for PTs to think flexibly with the samesized units to compute the necessary operation. The different-sized units were largely dependent on an understanding of simple and composite unit concepts (Lamon, 1999). The important idea that fractions are composed of unit fractions that can help students in their transition from reliance on visual models (area or number lines) to making calculations involving fractions additions and subtractions.

The multiplication and division tasks were designed so that PTs would develop concepts related to the meaning of multiplication and division and to interpretations of the solution. The key idea related to the contextual division problem that was introduced was the concept of representing the remainder in division. This concept was discussed in relation to the equivalence of unitizing to the whole, when equivalent fractions came out the same-size whole and arose again in the context of division showing the connection between the operation and the contextualized meaning. Therefore, the PTs used context to visualize sharing among a part of a group (Dixon et al., 2014). Thus, the idea that the whole can change became as taken as-shared with division because the practices of visualizing contextual meaning that were established here did not pertain to the algorithms. However, as students who experience a variety of ways, such 
as visual models and written words, to represent fractions are asked to move back and forth between them to develop more flexible understanding of fractions (Lesh, Landau, \& Hamilton, 1983), incorporating tasks in the future that particularly address the inverse transition from a number sentence representations to verbal representations - such as when writing logically and contextually correct, and story problems, is important. This helps PTs overcome the difficulty of representing fraction operations in pictorial and verbal forms (Luo, Lo, \& Leu, 2011). Writing story problems improves students' abilities to solve story-problems, supports students' meaningful learning, and creates opportunities for them to avoid conceptual errors (Ball, 1990b; Ball, Hill, \& Bass, 2005). This helps to realize promising instructional practices (Ma, 1999). Although it appeared that the mathematical ideas, which have been discussed above, became taken-as-shared by the class, this does not necessarily mean that the mathematical ideas were taken-as-shared in the same way by every preservice teacher (Rasmussen \& Stephan, 2008) because 'individual students' development may not follow the same route of development as the whole class" (Tobias, 2013, p. 102). However, a study of individual students' classroom learning was also beyond the scope of this study as part of theoretical and practical concern (Rasmussen \& Stephan, 2008). This is something, which needs to be investigated in future research.

However, in the study, the characterization of learning as an individual constructive activity was realized in two ways as these constructions were seen to occur as PTs participated in their way of learning the fraction concepts and operations, and these contributed to the mathematical practices of the classroom community. The PTs were also influenced as consensual meanings (Cobb \& Yackel, 1996) emerged in the class. They reorganized their activities and knowledge in two ways as a result of their ideas being either accepted or rejected 
by the classroom community (Tobias, 2009). This was "a process of emergence in which students' constructive activities and the practices in which they participate are considered to be reflexively related" (Cobb \& Yackel, 1996, p. 21).

Although the fractions tasks utilized in the course were open-ended—in order to encourage a variety of mathematical solutions or ways of representations from the PTs, most fraction concepts and operations were introduced and came to be taken-as-shared as PTs used area models to show their pictorial representations and justifications. The data analysis showed PTs could work with rectangles, triangles, trapezoids, hexagons, and circles. Particularly, they focused most on rectangles throughout the fraction activities. This might have been related to their prior experience in schools, where the area-model approach has been given much attention and is given priority in the teaching and learning of fractions (Cramer \& Henry 2002; NCTM 2000; Zhang, Clements, \& Ellerton, 2015). According to Zhang et al. (2015), "if students are to understand fractions conceptually, they must become acquainted with a wider range of models" (p. 40). Incorporating concept-rich activities which promote high quality teaching which can also be transferred into real-life situations with the application of variety of models, apart from area-model approaches, might assist preservice elementary teachers to develop "comprehensive concept images of fractions and facilitate their conceptual understandings of fractions" (Zhang et al., 2015, p. 146).

\section{Implications for Future Research}

This study provided an account of collective activity related to fractions concepts and operations. It included whole-classroom activities and described ways in which individual students participated in a whole class environment. For, example, the whole class discussions encouraged PTs' individual mathematical constructions and reflections on different methods that 
other PTs used. They also encouraged PTs to share their mathematical thinking with others (Wood, Cobb, \& Yackel, 1993) so that they will contribute to the mathematical practices of the classroom, given the fact that "classroom learning constitutes a reflexive relationship between individuals and social domains" (Tobias, 2013, p. 85). This study has several implications for the ways in which preservice teachers may be taught fraction concepts and operations. Understanding the knowledge that preservice teachers bring to teacher education programs as well as the ways in which they develop that understanding can help teachers and researchers provide better-designed instruction for preservice teacher education students. In addition, PTs can make significant progress collectively because the hypothetical learning trajectory and classroom tasks were designed so that PTs would gradually develop fraction concepts, which would eventually lead to understanding of fraction operations.

However, in extending the work of Tobias and colleagues, future studies focusing on the ways in which PTs develop an understanding of fraction concepts and operations will need to reexamine the importance of incorporating the social norms (explain and justify, making-sense of others, and questioning) and the sociomathematical norms of different solutions, which are usually established during the whole-number concepts and operations unit and sustained throughout later themes. Instead, they should focus on how acceptable, sophisticated, and efficient solution and solution process develop and the mathematical practices develop concepts, which lead to deeper conceptual understandings of the procedures or why the different fractions algorithms work.

In future studies, better-designed contextual tasks may need to be presented within the comparing and ordering problems. Although PTs' adapted strategies which made use of underlying concepts by using common denominators, common numerators, benchmarks, and 
changing to decimal form, all the problems were non-contextual so that they did not have connection with contextual meanings. Besides, often many PTs were not able to write mathematically correct number sentences corresponding to subtraction with multiplication story problems, and had issues with a measurement meaning of fraction division, and were not fully able to develop fraction multiplications and divisions, and therefore more research is needed in this area.

As explained earlier, I agree with Tobias's (2009) statement that "when the tasks incorporated the linear and set models, students either turned the situation into a problem where an area model could be used or students relied on area model concepts to solve the problem" (p. 211). PTs in this research still exhibited the same behavior. For example, they rarely made use of their number-line knowledge in fraction operation tasks. So, for future studies, the tasks may also need to be redesigned so that the number line and set models can be further developed.

Previous research also analyzed the knowledge that preservice teachers bring to teachers education programs but have done mainly in terms of fraction division (Ball, 1990a; Ball 1990b; Tirosh, 2000). The result indicated that PTs come to teacher-education programs with several understandings and misconceptions related to fraction concepts and operations. All that said, the fact remains that there are relatively few research studies on PTs' knowledge of fraction concepts and operations, particularly, studies documenting the ways in which PTs develop an understanding of fraction concepts and operations with sense-making. Therefore, this sought to add to the limited research documenting PTs' development of rational number understandings (Wheeldon, 2008; Tobias, 2009). 


\section{Limitations of the Research}

The lack of multiple instruments could be regarded as limitations for my research study. For example, in this study, no pre and post-test, or a retention paper-and-pencil instruments, were taken into consideration. Besides, the study was based on only one elementary PTs knowledge of fraction concepts and operations, and carried out using only one main qualitative research methods - emergent perspective. As discussed earlier, although it appeared that several mathematical practices became taken-as-shared by the class, this does not necessarily mean that the mathematical ideas were taken-as-shared by every preservice teacher (Rasmussen \& Stephan, 2008) as “individual students' development may not follow the same route of development as the whole class" (Tobias, 2013, p. 102).

\section{Significance of the Present Study}

This research has contributed to our understandings of how preservice elementary teachers construct fractions concepts and operations. It broadens our understandings about the mathematical content knowledge of PTs: their understanding of the concept of fraction operations that broadens our view of what PTs' knowledge of fraction concepts and operations is and should be. I believe the findings of this study can provide mathematics educators with a stronger information of preservice elementary teachers' knowledge of fractions concepts and operations. Most importantly, it gives support to improve our content course and able us to provide PTs with important knowledge of fraction concepts and operations in developing the mathematics they are to teach or it helps how we might cultivate our PTs' fraction knowledge (Newton, 2008). As a result, my research will contribute to knowledge and can be used as a guide for further research on fraction concepts and operations to improve teacher education programs. The findings of this study are also consistent with Roy, Tobias, Safi, and Dixon's 
(2014) results which also identified the socio mathematical norm of what constitutes an acceptable solution as the only norm that had to be re-established when transitioning between whole number and rational number instructional units.

Contrary to Tobias (2009) findings, in my study, the number line tasks did more than reiterating the partitioning strategies that became taken-as-shared and it should be incorporated within future iteration. Obviously, the PTs used the repartitioning method to associate whole number, fractions, and mixed numbers. However, most importantly, the number line was found to contribute to the established practices. For instance, the big idea with equivalent fractions, which is making sure that they both are out of the same-size whole, was introduced in Day 2, developed in Day 5, and taken-as-shared by the class in Day 7 while the PTs were working on the number line tasks. The PTs used number line to generate equivalent fractions. The idea for PTs to build on their prior experience with equivalence, unitizing idea of finding a unit fraction, iterating a unit fraction, and developing a composite unit of one in the previous tasks helped them to see that the number line is representing the common denominator, which was taken-asshared within the number line tasks too. 


\section{REFERENCES}

An, S., Kulm, G., \& Wu, Z. (2004). The pedagogical content knowledge of middle school, mathematics teachers in China and the US. Journal of Mathematics Teacher Education, 7(2), 145-172.

Azim, D. S. (1995). Preservice elementary teachers' understanding of multiplication involving fractions. In D. T. Owens, M. K. Reed, \& G. M. Millsaps (Eds.), Proceedings of the seventeenth annual meeting of the North American Chapter of the International Group for the Psychology of Mathematics Education (pp. 226-232). Columbus, OH.

Ball, D. L. (1990a). The mathematical understandings that prospective teachers bring to teacher education. The Elementary School Journal, 90(4), 449-466.

Ball, D. L. (1990b). Prospective elementary and secondary teachers' understanding of division. Journal for Research in Mathematics Education, 21(2), 132-144.

Ball, D. L. (1993). Halves, pieces, and twoths: Constructing representational contexts in teaching fractions. In P. T., Carpenter, E., Fennema, \& A. T., Romberg (Eds), Rational numbers: an integration of research (pp. 157-196). Hillsdale, NJ: Lawrence Erlbaum Associates.

Ball, D. L., Lubienski, S. T., \& Mewborn, D. S. (2001). Research on teaching mathematics: The unsolved problem of teachers' mathematical knowledge. Handbook of Research on Teaching, 4, 433-456. New York, NY: Macmillan.

Ball, D. L., Hill, H. C., Bass, H. (2005). Knowing mathematics for teaching: Who knows mathematics well enough to teach third grade, and how can we decide? American Educator, 29(3), 14-46.

Ball, D. L., Thames, M. H., \& Phelps, G. (2008). Content knowledge for teaching: What makes it special? Journal of Teacher Education, 59(5), 389-407. 
Barlow, A. T., \& Drake, J. M. (2008). Division by a fraction: Assessing understanding through problem writing. Mathematics Teaching in the Middle School, 13(6), 326-332.

Bartell, T. G., Webel, C., Bowen, B., \& Dyson, N. (2013). Prospective teacher learning: Recognizing evidence of conceptual understanding. Journal of Mathematics Teacher Education, 16(1), 57-79.

Battista, M., Smith, M. S., Boerst, T., Sutton, J., Confrey, J., White, D., \& Quander, J. (2009). Research in mathematics education: Multiple methods for multiple uses. Journal for Research in Mathematics Education, 40(3), 216-240.

Behr, M. J., Harel, G., Post, T., \& Lesh, R. (1992). Rational number, ratio, proportion. In D. A. Grouws (Ed.), Handbook of research on mathematics teaching and learning (pp. 296333). New York, NY: Macmillan.

Behr, M. J., Harel, G., Post, T., \& Lesh, R. (1993). Rational numbers: Toward a semantic analysis-emphasis on the operator construct. In T. P. Carpenter, E. Fennema, \& T. A. Romberg (Eds.), Rational numbers: An integration of research (pp.13-47). Hillsdale, NJ: Lawrence Erlbaum Associate.

Behr, M., Lesh, R., Post, T., \& Silver E. (1983). Rational number concepts. In R. Lesh \& M. Landau (Eds.), Acquisition of Mathematics concepts and processes (pp. 91-125). New York, NY: Academic Press.

Behr, M. J., \& Post, T. R. (1992). Teaching rational number and decimal concepts. In T. R. Post (Ed.), Teaching mathematics in grades K-8: Research-based methods (2nd ed., pp. 201248). Boston, MA: Allyn and Bacon. 
Behr, M., Wachsmuth, I., Post, T., \& Lesh, R. (1984). Order and equivalence of rational numbers: A clinical teaching experiment. Journal for Research in Mathematics Education, 15(5), 323-341.

Borko, H., Eisenhart, M., Brown, C. A., Underhill, R. G., Jones, D., \& Agard, P. C. (1992). Learning to teach hard mathematics: Do novice teachers and their instructors give up too easily? Journal for Research in Mathematics Education, 23(3), 194-222.

Bright, G. W., Behr, M. J., Post, T. R., \& Wachsmuth, I. (1988). Identifying fractions on number lines. Journal for Research in Mathematics Education, 19(3), 215-232.

Burns, M. K. (2011). Matching math interventions to students' skill deficits: A preliminary investigation of a conceptual and procedural heuristic. Assessment for Effective Intervention, 36(4), 210-218.

Byrnes, J. P., \& Wasik, B. A. (1991). Role of conceptual knowledge in mathematical procedural learning. Developmental Psychology, 27(5), 777-786.

Carraher, D. W. (1996). Learning about fractions. In L. P. Steffe, P. Nesher, P. Cobb, B. Sriraman, \& B. Greer. (Eds.), Theories of mathematical learning (pp. 241-266), Mahwah, NJ: Lawrence Erlbaum.

Cai, J. (2000). Mathematical thinking involved in U.S. and Chinese students' solving processconstrained and process-open problems. Mathematical Thinking and Learning, 2, 309340.

Cai, J. (2004). Why do U.S. and Chinese students think differently in mathematical problem solving? Impact of algebra learning and teachers' beliefs. Journal of Mathematical Behavior, 23, 135-167. 
Cai, J. (2005). U.S. and Chinese teachers' knowing, evaluating, and constructing representations in mathematics instruction. Mathematical Thinking and Learning, 7, 135-169.

Carraher, D. W. (1996). Learning about fractions. In L. P Steffe, P. Nesher, P. Cobb, B. Sriraman, \& B. Greer. (Eds.), Theories of Mathematical Learning (pp. 241-266), Mahwah, NJ: Lawrence: Erlbaum Associate. Inc.

Charalambous, C. Y., Hill, H. C., \& Ball, D. L. (2011). Prospective teachers' learning to provide instructional explanations: How does it look and what might it take? Journal of Mathematics Teacher Education, 14(6), 441-463.

Charalambous, C. Y., \& Pitta-Pantazi, D. (2007). Drawing on a theoretical model to study students' understandings of fractions. Educational Studies in Mathematics, 64, 293-316.

Chval, K., Lannin, J., Jones, D., \& Dougherty, B. (2013). Developing essential understanding of rational numbers, Grades 3-5. Reston, VA: National Council of Teachers of Mathematics.

Chinnappan, M. (2000). Preservice teachers' understanding and representation of fractions in a Java Bars environment. Mathematics Education Research Journal, 12(3), 234-253.

Clarke, C., Fisher, W., Marks, R., Ross, S., \& Zbiek, R. M. (2010). Developing essential understanding of rational numbers for teaching mathematics in grades 3-5. Essential understandings. Reston, VA: National Council of Teachers of Mathematics.

Clarke, D. J. (1997). Chapter 7: Studying the classroom negotiation of meaning: Complementary accounts methodology [Monograph]. Journal for Research in Mathematics Education, $98-111$. 
Clement, J. (1980). Cognitive microanalysis: An approach to analyzing intuitive mathematical reasoning processes. DOCUMENT RESUME SE 036 089, 53. Retrieved from http://files.eric.ed.gov/fulltext/ED212478.pdf\#page=60.

Clements, D. H., \& Sarama, J. (2004). Learning trajectories in mathematics education. Mathematical Thinking and Learning, 6(2), 81-89.

Cobb, P. (2007). Putting philosophy to work. In F. K. Lester (Ed.), Second handbook of research on mathematics teaching and learning (pp. 3-38). Charlotte, NC: Information Age Publishing and Reston, VA: National Council of Teachers of Mathematics.

Cobb, P., \& Bauersfeld, H. (Eds.). (1995). The emergence of mathematical meaning: Interaction in classroom cultures. Hillsdale, NJ: Lawrence Erlbaum.

Cobb, P., Stephan, M., McClain, K., \& Gravemeijer, K. (2001). Participating in classroom mathematical practices. Journal of the Learning Sciences, 10(1/2), 113-163.

Cobb, P., \& Yackel, E. (1996). Constructivist, emergent, and sociocultural perspectives in the context of developmental research. Educational Psychologist, 31(3-4), 175-190.

Cobb, P., Yackel, E., \& Wood, T. (1989). Young children's emotional acts while doing mathematical problem solving In D. B. McLeod \& V. M. Adam (Eds.), Affect and mathematical problem solving: A new perspective (pp. 117-148). NY: Springer-Verlag.

Common Core State Standards Initiative. (2010). Common Core State Standards for Mathematics (CCSSM). Washington, DC: National Governors Association Center for Best Practices and the Council of Chief State School Officers. Retrieved from https://scholar.google.com/scholar?q=Common+core+state+standards+initiatives $+2010 .+$ common + core + state + standards + for + mathematics $\& b t n G=\& h l=e n \&$ as_sdt $=0 \% 2 \mathrm{C} 14$. 
Conference Board of the Mathematical Sciences. (2001). The mathematical education of teachers, Vol. 2: Issues in mathematics education. Providence, RI: American Mathematical Society.

Cramer, K., \& Henry, A. (2002). Using manipulative models to build number sense for addition of fractions. In B. Litwiller, \& G. Bright. (Eds.), Making Sense of Fractions, Ratios, and Proportions (pp. 41-48). Reston, VA: National Council of Teachers of Mathematics.

Cramer, K., Wyberg, T., \& Leavitt, S. (2009). Rational Number Project: Fraction operations and initial decimal ideas. Retrieved from: http://www.cehd.umn.edu/ci/rationalnumberproject/RNP2/RNP2_TeacherGuide.pdf.

Da Ponte, J. P., \& Chapman, O. (2016). Prospective mathematics teachers' learning and knowledge for teaching. In L. D., English, \& D., Kirshner. (Eds.), Handbook of international research in mathematics education (pp. 275-290). New York, NY: Routledge.

Dixon, J. K., Andreasen, J. B., Avila, C. L., Bawatneh, Z., Deichert, D. L., Howse, T. D., \& Turner, M. S. (2014). Redefining the whole: Common errors in elementary preservice teachers' self-authored word problems for fraction subtraction. Investigations in Mathematics Learning, 7(1), 1-22.

Empson, S. (2001). Equal sharing and the roots of fraction equivalence. Teaching Children Mathematics, 7(7), 421-425. Retrieved from: http://www.jstor.org/stable/41197637.

Empson, S. B., \& Levi, L. (2011). Extending children's mathematics: Fractions and decimals. Portsmouth, NH. Heinemann.

English, L. D. (2002). Handbook of international research in mathematics education. Mahwah, NJ: Lawrence Erlbaum Associates. 
English, L. D., \& Kirshner, D. (Eds.). (2016). Handbook of international research in mathematics education. New York, NY: Routledge.

Even, R. (1993). Subject-matter knowledge and pedagogical content knowledge: Prospective secondary teachers and the function concept. Journal for Research in Mathematics Education, 24(2), 94-116. doi:10.2307/749215.

Gabriel, F. (2016). Understanding magnitudes to understand fractions. Australian Primary Mathematics Classroom, 21(2), 3640.Glaser, B. G., \& Strauss, A. L. (1967). The discovery of grounded theory: Strategies for qualitative research. New York: Aldine.

Glesne, C. (1999). Becoming qualitative researchers: An introduction (2nd ed.). Don Mills, Ontario, Canada: Longman.

Graeber, A., Tirosh, D., \& Glover, R. (1989). Preservice teachers' misconceptions in solving verbal problems in multiplication and division. Journal for Research in Mathematics Education, 20(1), 95-102. doi: 10.2307/749100.

Greer, B. (1988). Non conservation of multiplication and division: Analysis of a symptom. The Journal of Mathematical Behavior, 7, 281-298.

Greer, B. (1992). Multiplication and division as models of situations. In D. A. Grouws (Ed.), Handbook of research on mathematics teaching and learning (pp. 276-295). New York, NY: Macmillan.

Hackenberg, A. J., \& Tillema, E. S. (2009). Students' whole number multiplicative concepts: A critical constructive resource for fraction composition schemes. The Journal of Mathematical Behavior, 28(1), 1-18. 
Hiebert, J., \& Lefevre, P. (1986). Conceptual and procedural knowledge in mathematics: An introductory analysis. In J. Hiebert (Ed.), Conceptual and procedural knowledge: The case of mathematics (pp. 3-22). Hillsdale, NJ: Lawrence Erlbaum.

Hill, H. C., \& Lubienski, S. T. (2007). Teachers' mathematics knowledge for teaching and school context: A study of California teachers. Educational Policy, 21(5), 747-768.

Hill, H. C., Ball, D. L., \& Schilling, S. G. (2008). Unpacking pedagogical content knowledge: Conceptualizing and measuring teachers' topic-specific knowledge of students. Journal for Research in Mathematics Education, 39(4), 372- 400.

Huang, T. W., Liu, S. T., \& Lin, C. Y. (2009). Preservice teachers' mathematical knowledge of fractions. Research in Higher Education Journal, 5, 1-8.

Hunting, R. (1983). Alan: A case study of knowledge of units and performance with fractions. Journal for Research in Mathematics Education, 14(3), 182-197.

Hunting, R. P., \& Sharpley, C. F. (1991). Pre-fraction concepts of preschoolers. In R. Hunting \& G. Davis. (Eds.), Early fraction learning (9-26). New York, NY: Springer.

Hunting, R., \& Davis, G. (Eds.). (2012). Early fraction learning. New York, NY: Springer.

Işık, C., Öcal, T., \& Kar, T. (2013). Analysis of pre-service elementary teachers’ pedagogical content knowledge in the context of problem posing. In meeting of Eighth Congress of European Research in Mathematics Education (CERME 8), Antalya, Turkey.

Izsák, A. (2008). Mathematical knowledge for teaching fraction multiplication. Cognition and Instruction, 26, 95-143.

Jones, G. A., Langrall, C. W., Thornton, C. A., \& Nisbet, S. (2002). Elementary students' access to powerful mathematical ideas. In L. D. English. (Ed.), Handbook of international research in mathematics education (pp. 113-116). Mahwah, NJ: Lawrence Erlbaum. 
Juli K., Dixon, J. K., \& Tobias, J. M. (2013). The whole story: Understanding fraction computation. Mathematics Teaching in the Middle School, 19(3), 156-163. doi:10.5951/mathteacmiddscho.19.3.0156.

Kahan, J. A., Cooper, D. A., \& Bethea, K. A. (2003). The role of mathematics teachers' content knowledge in their teaching: A framework for research applied to a study of student teachers. Journal of Mathematics Teacher Education, 6(3), 223-252.

Kelly, A. E., \& Lesh, R. A. (Eds.). (2012). Handbook of research design in mathematics and science education. New York, NY: Routledge.

Kieren, T. E. (1976). On the mathematical, cognitive, and instructional foundations of rational numbers. In R. Lesh (Ed.), Number and measurement: Papers from a research workshop (pp. 101-144). Columbus, OH.

Lamon, S. J. (1996). The development of unitizing: Its role in children's partitioning strategies. Journal of Research in Mathematics Education, 27, 170-193.

Lamon, S. (1999). Teaching fractions and ratios for understanding: Essential content and instructional strategies for teachers. Mahwah, NJ: Lawrence Erlbaum Associates.

Lamon, S. J. (2005). Teaching fractions and ratios for understanding: Essential content knowledge and instructional strategies for teachers. Mahwah, NJ: Lawrence Erlbaum Associates.

Lamon, S. J. (2007). Rational numbers and proportional reasoning: Toward a theoretical framework for research. In F. K. Lester (Ed.), Second handbook of research on mathematics teaching and learning (pp. 629-667). Charlotte, NC: Information Age Publishing and Reston, VA: National Council of Teachers of Mathematics. 
Lamon, S. J. (2012). Teaching fractions and ratios for understanding: Essential knowledge and instructional strategies for teachers. New York, NY: Routledge/Taylor \& Francis Group.

Lampert, M. (1990). When the problem is not the question and the solution is not the answer: Mathematical knowing and teaching. American Educational Research Journal, 27(1), 29-63.

Lesh, R., Landau, M., \& Hamilton, E. (1983). Conceptual models and applied mathematical problem-solving research. Acquisition of mathematics concepts and processes (pp. 263343). Orlando, FL: Academic Press.

Li, Y. (2008). What do students need to learn about division of fractions? Mathematics Teaching in the Middle School, 13, 546-552.

Li, Y., \& Kulm, G. (2008). Knowledge and confidence of prospective mathematics teachers: The case of fraction division. ZDM-The International Journal on Mathematics Education, 40, 833-843.

Lo, J.-J., Grant, T. J., \& Flowers, J. (2008). Challenges in deepening prospective teachers' understanding of multiplication through justification. Journal of Mathematics Teacher Education, 11(1), 5-22.

Lo, J. J., \& Luo, F. (2012). Prospective elementary teachers' knowledge of fraction division. Journal of Mathematics Teacher Education, 15(6), 481-500.

Luo, F. (2009). Evaluating the effectiveness and insights of pre-service elementary teachers' abilities to construct word problems for fraction multiplication. Journal of Mathematics Education, 2(1), 83-98. 
Luo, F., Lo, J. J., \& Leu, Y. C. (2011). Fundamental fraction knowledge of preservice elementary teachers: A cross-national study in the United States and Taiwan. School Science and Mathematics, 111(4), 164-177.

Ma, L. (1999). Knowing and teaching elementary mathematics: Teachers' understanding of fundamental mathematics in China and the United States. Mahwah, NJ: Lawrence Erlbaum Associates.

Mack, N. K. (1990). Learning fractions with understanding: Building on informal knowledge. Journal for Research in Mathematics Education, 21(1) 16-32.

Mack, N. K. (1993). Learning rational numbers with understanding: The case of informal knowledge. In T. P. Carpenter, E. Fennema \& T. A. Romberg (Eds.), Rational numbers: An integration of research (pp. 85-105). Hillsdale, NJ: Erlbaum.

Mack, N. (1995). Confounding whole-number and fraction concepts when building on informal knowledge. Journal for Research in Mathematics Education, 26(5), 422-441.

Mack, N. (2001). Building on informal knowledge through instruction in a complex content domain: Partitioning, units, and understanding multiplication of fractions. Journal for Research in Mathematics Education, 32(3), 267-295.

Mack, N. K. (2000). Long-term effects of building on informal knowledge in a complex content domain: The case of multiplication of fractions. The Journal of Mathematical Behavior, 19(3), 307-332. 
Marchionda, H. (2006). Preservice teachers' procedural and conceptual understanding of fractions and the effects of inquiry-based learning on this understanding (Doctoral Dissertation, Clemson University). Retrieved from http://tigerprints.clemson.edu/cgi/viewcontent.cgi?article=1037\&context=all_dissertation s.

Matthews, M., Rech, J., \& Grandgenett, N. (2010). The impact of content courses on pre-service elementary teachers' mathematical content knowledge. Retrieved from University of Nebraska, Teacher education faculty Publications Website: http://digitalcommons.unomaha.edu/cgi/viewcontent.cgi?article=1021\&context=tedfacpu b.

Matthews, M. E., \& Seaman, W. I. (2007). The effects of different undergraduate mathematics courses on the content knowledge and attitude towards mathematics of preservice elementary teachers. Issues in the Undergraduate Mathematics Preparation of School Teachers, 1, 1-16.

McAllister, C. J., \& Beaver, C. (2012). Identification of error types in preservice teachers' attempts to create fraction story problems for specified operations. School Science and Mathematics, 112, 88-98.

McClain, K., \& Cobb, P. (2001). An analysis of development of sociomathematical norms in one first-grade classroom. Journal for Research in Mathematics Education, 32(3), 236-266.

McCormick, K. K. (2015). Making fractions meaningful. Teaching Children Mathematics, 22(4), $230-238$.

Menon, R. (2009). Preservice teachers' subject matter knowledge of mathematics. International Journal for Mathematics Teaching and Learning, (January), 1-8. 
Mojica, G. F., \& Confrey, J. (2009). Pre-service elementary teachers' understanding of an equipartitioning learning trajectory. In Proceedings of the 31st Annual Meeting of the North American Chapter of the International Group for the Psychology of Mathematics Education. Atlanta, GA: Georgia State University.

National Council of Teachers of Mathematics. (2000). Principles and standards for school mathematics. Reston, VA: Author.

Newton, K. J. (2008). An extensive analysis of preservice elementary teachers' knowledge of fractions. American Educational Research Journal, 45(4), 1080-1110.

Ni, Y., \& Zhou, Y. D. (2005). Teaching and learning fractions and rational numbers: The origins and implications of whole number bias. Educational Psychologist, 40(1), 27-52.

Nillas, L. A. (2010). Preservice teachers' mathematical understanding: The role of discourse. Illinois State University.

Ohlsson, S. (1988). Mathematical meaning and application meaning in the semantics of fractions and related concepts. Number Concepts and Operations in the Middle Grades, 2, 53-92.

Olanoff, D., Lo, J. J., \& Tobias, J. M. (2014). Mathematical content knowledge for teaching elementary mathematics: A focus on fractions. Mathematics Enthusiast, 11(2), 267-309.

Olive, J. (1999). From fractions to rational numbers of arithmetic: A reorganization hypothesis. Mathematical Thinking and Learning, 1, 279-314.

Park, J., Güçler, B., \& McCrory, R. (2013). Teaching prospective teachers about fractions: Historical and pedagogical perspectives. Educational Studies in Mathematics, 82(3), 455-479. doi: 10.1007/s10649 012-9440-8.

Payne, J. N. (1976). Review of research on fractions. In R. Lesh (Ed.), Number and measurement (pp. 145-188), Athens, GA: University of Georgia. 
Petit, M. M., Laird, R. E., Marsden, E. L., \& Ebby, C. B. (2015). A focus on fractions: Bringing research to the classroom. New York, NY: Routledge.

Ponte, J. P., \& Chapman, O. (2008). Preservice mathematics teachers' knowledge and development. In L. D. English (Ed.). Handbook of international research in mathematics education: Directions for the 21st century (2nd ed., pp. 225-263). New York, NY: Routledge.

Post, T. R., Cramer, K., Behr, M., Lesh, R., \& Harel, G. (1993). Curriculum implications of research on the learning, teaching, and assessing of rational number concepts. In T. P. Carpenter, E. Fennema, \& T. A. Romberg (Eds.), Rational numbers: An integration of research (pp. 327-362). Hillsdale, NJ: Lawrence Erlbaum.

Rasmussen, C., \& Stephan, M. (2008). A methodology for documenting collective activity. In A. E., Kelly, R. A., Lesh, \& J. Y., Baek. (Eds.), Handbook of design research methods in education: Innovations in science, technology, engineering, and mathematics learning and teaching (pp. 195-215). New York, NY: Routledge.

Rayner, V., Pitsolantis, N., \& Osana, H. (2009). Mathematics anxiety in preservice teachers: Its relationship to their conceptual and procedural knowledge of fractions. Mathematics Education Research Journal, 21(3), 60-85.

Reed, S. K. (1999). Word problems: Research and curriculum reform. Mahwah, NJ: Lawrence Erlbaum.

Reys, R., Lindquist, M., Lambdin, D., \& Smith, N. (2007). Helping children learn mathematics. Hoboken, NJ: John Wiley \& Sons. 
Rittle-Johnson, B., Siegler, R., \& Alibali, M.W. (2001). Developing conceptual understanding and procedural skill: An iterative process. Journal of Educational Psychology, 93(2), $345-362$.

Rizvi, N. F., \& Lawson, M. J. (2007). Prospective teachers' knowledge: Concept of division. International Education Journal, 8(2), 377-392.

Rogers, D., Bolick, C. M., Anderson, A., Gordon, E., Manfra, M. M., \& Yow, J. (2007). "It's about the kids": Transforming teacher-student relationships through action research. The Clearing House: A Journal of Educational Strategies, Issues and Ideas, 80(5), 217-222.

Rosli, R., Gonzalez, E. G., \& Capraro, M. M. (2011). A case study of three preservice teachers on the units and unitizing of fractions. In Proceedings of the 33rd annual meeting of the North American Chapter of the International Group for the Psychology of Mathematics Education (pp. 1682-1689).Retrieved from https://www.researchgate.net/profile/Roslinda_Rosli2/publication/269519905_A_Case_S tudy_of_Three_Preservice_Teachers_on_the_Units_and_Unitizing_of_Fractions/links/54 8e67a10cf2d1800d842495.pdf.

Roy, G. J., Tobias, J. M., Safi, F., \& Dixon, J. K. (2014). Sustaining Social and Sociomathematical Norms with Prospective Elementary Teachers in a Mathematics Content Course. Investigations in Mathematics Learning, 7(2), 33-64.

Rudnitsky, A., Etheredge, S., Freeman, S. J., \& Gilbert, T. (1995). Learning to solve addition and subtraction word problems through a structure-plus-writing approach. Journal for Research in Mathematics Education, 26(5), 467-486.

Schoenfeld, A. H. (2002). Making mathematics work for all children: Issues of standards, testing, and equity. Educational Researcher, 31(1), 13-25. 
Siegler, R., Carpenter, T., Fennell, F., Geary, D., Lewis, J., Okamoto, Y., \& Wray, J. (2010). Developing effective fractions instruction for kindergarten through 8th Grade. IES Practice Guide. NCEE 2010-4039.

Silver, E (1986). Using conceptual and procedural knowledge: A focus on relationships. In J. Hiebert (Ed.), Conceptual and procedural knowledge: The case of mathematics (pp. 181198). Hillsdale, NJ: Lawrence Erlbaum Associates.

Simon, M.A. (1993). Prospective elementary teachers' knowledge of fraction division. Journal for Research in Mathematics Education, 24, 233-254.

Simon, M. (1995). Reconstructing mathematics pedagogy from a constructivist perspective. Journal for Research in Mathematics Education, 26, 114-145.

Simon, M. A., \& Tzur, R. (2004). Explicating the role of mathematical tasks in conceptual learning: An elaboration of the hypothetical learning trajectory. Mathematical Thinking and Learning, 6(2), 91-104.

Southwell, B., \& Penglase, M. (2005). Mathematical knowledge of pre-service primary teachers. In H. L. Chick \& J. L. Vincent (Eds.), Proceedings of the 29th Conference of the International Group for the Psychology of Mathematics Education (Vol. 4, pp. 209-216). Melbourne, Australia: PME.

Stafylidou, S., \& Vosniadou, S. (2004). The development of students' understanding of the numerical value of fractions. Learning and Instruction, 14(5), 503-518.

Steenbrugge, H. V., Lesage, E., Valcke, M., \& Desoete, A. (2014). Pre-service elementary school teachers' knowledge of fractions: A mirror of students' knowledge? Journal of Curriculum Studies, 46(1), 138-161. 
Steffe, L. P. (1988). Children's construction of number sequences and multiplying schemes. In J. Hiebert \& M. Behr (Eds.), Number concepts and operations in the middle grades (pp. 119-140). Reston, VA: National Council of Teachers of Mathematics.

Steffe, L. P. (1992). Schemes of action and operation involving composite units. Learning and Individual Differences, 4(3), 259-309.

Steffe, L. P. (2001). A new hypothesis concerning children's fractional knowledge. The Journal of Mathematical Behavior, 20(3), 267-307.

Steffe, L. P. (2002). A new hypothesis concerning children's fractional knowledge. Journal of Mathematical Behavior, 102, 1-41.

Steffe, L. P. (2003). Fractional commensurate, composition, and adding schemes: Learning trajectories of Jason and Laura: Grade 5. The Journal of Mathematical Behavior, 22(3), $237-295$.

Steffe, L. P., \& Cobb, P. (1988). Construction of arithmetical meanings and strategies. New York, NY: Springer-Verlag.

Steffe, L. P., von Glasersfeld, E., Richards, J., \& Cobb, P. (1983). Children's counting types: Philosophy, theory, and application. New York, NY: Praeger Special Studies.

Stephan, M., \& Rasmussen, C. (2002). Classroom mathematical practices in differential equations. The Journal of Mathematical Behavior, 21(4), 459-490.

Streefland, L. (1991). Fractions in realistic mathematics education: A paradigm of developmental research. Boston, MA: Kluwer.

Streefland, L. (1993). Fractions: A realistic approach. In T. P. Carpenter, E. Fennema, \& T. A. Romberg (Eds.), Rational numbers: An integration of research (pp. 289-325). Hillsdale, NJ: Lawrence Erlbaum. 
Superfine, A. C., Li, W., \& Martinez, M. V. (2013). Developing preservice teachers' mathematical knowledge for teaching: Making explicit design considerations for a content course. Mathematics Teacher Educator, 2(1), 42-54. doi:10.5951/mathteaceduc.2.1.0042.

Tatsuoka, K. K. (Ed.). (1984). Analysis of errors in fraction addition and subtraction problems. Computer-based Education Research Laboratory, University of Illinois.

Teppo, A. R. (1997). Diverse ways of knowing [Monograph]. Journal for Research in Mathematics Education, 9, 1-177.

Tirosh, D. (2000). Enhancing prospective teachers' knowledge of children's conceptions: The case of division of fractions. Journal for Research in Mathematics Education, 31(1), 525.

Tirosh, D., \& Graeber, A. O. (1989). Preservice elementary teachers' explicit beliefs about multiplication and division. Educational Studies in Mathematics, 20(1), 79-96. Retrieved from http://www.jstor.org/stable/3482563.

Tobias, J. M. (2009). Preservice elementary teachers' development of rational number understanding through the social perspective and the relationship among social and individual environments (Doctoral dissertation). University of Central Florida, Orlando, FL. Retrieved from https://scholar.google.com/scholar?q=jennifer+tobias $+\% 282009 \% 29 \& b t n G=\& h l=e n \& a s$ _sdt $=0 \% 2 \mathrm{C} 14$.

Tobias, J. M. (2013). Prospective elementary teachers' development of fraction language for defining the whole. Journal of Mathematics Teacher Education, 16(2), 85-103. 
Toulmin, S. E. (2003). The uses of argument (updated edition). New York, NY: Cambridge University Press.

Tzur, R. (1999). An integrated study of children's construction of improper fractions and the teacher's role in promoting that learning. Journal for Research in Mathematics Education, 30(4), 390-416.

Tzur, R., Johnson, H. L., McClintock, E., Xin, Y. P., Si, L., Woodward, J., \& Jin, X. (2013). Distinguishing schemes and tasks in children's development of multiplicative reasoning. Retrieved from:https://www.math.purdue.edu/ rhkenney/Kenney_Homepage/Links_to_Publication s_files/PNA_Published.pdf.

United States Department of Education (USDOE). (2008). The final report of the national mathematics advisory panel. Retrieved from http://www .ed.gov/about/bdscomm/list/mathpanel/ report/final-report.pdf.

Van de Walle, J. (2001). Elementary and middle school mathematics, teaching developmentally. New York, NY: Addison Wesley Longman, Inc.

Vergnaud, G. (1983). Multiplicative structures. In R. Lesh \& M. Landau (Eds.), Acquisition of mathematics concepts and processes (pp. 127-174). New York, NY: Academic Press.

Vergnaud, G. (1996). The theory of conceptual fields. In L. P. Steffe, P. Nesher, P. Cobb, B. Sriraman, \& B. Greer. (Eds.), Theories of mathematical learning (pp. 219-239), Mahwah, NJ: Lawrence: Erlbaum.

Vogt, W. P., Gardner, D. C., \& Haeffele, L. M. (2012). When to use what research design. New York, NY: Guilford Press. 
Wheeldon, D. A. (2008). Developing mathematical practices in a social context: An instructional sequence to support prospective elementary teachers' learning of fractions (Doctoral dissertation). University of Central Florida, Orlando, FL. Retrieved from http://stars.library.ucf.edu/cgi/viewcontent.cgi?article=4537\&context=etd.

Whitacre, I., \& Nickerson, S. D. (2016). Prospective elementary teachers making sense of multidigit multiplication: Leveraging resources. Journal for Research in Mathematics Education, 47(3), 270-307.

White, A. L., Jaworski, B., Agudelo-Valderrama, C., \& Gooya, Z. (2012). Teachers learning from teachers. In M. A. Clements, A. J. Bishop, C. Keitel, J. Kilpatrick \& F. Leung (Eds.), Third international handbook of mathematics education (pp. 393-430). New York, NY: Springer.

Wood, T., Cobb, P., \& Yackel, E. (1993). The nature of whole-class discussion. Journal for Research in Mathematics Education. Monograph, 6, 55-122. doi: 1. Retrieved from http://www.jstor.org/stable/749933 doi: 1.

Yackel, E. (2001). Explanation, justification and argumentation in mathematics classrooms. Proceedings of the Conference of the International Group for the Psychology of Mathematics Education, 25th, Utrecht, The Netherlands, Volumes 1-4, SE 065634.

Yackel, E., \& Cobb, P. (1996). Socio-mathematical norms, argumentation, and autonomy in mathematics. Journal for Research in Mathematics Education, 27, 458-477.

Young, E., \& Zientek, L. (2011). Fraction operation: An examination of prospective teachers' errors, confidence, and bias. Investigations in Mathematics Learning, 4, 1-24.

Zhang, X., Clements, M. A., \& Ellerton, N. F. (2015). Engaging students with multiple models of fractions. Teaching Children Mathematics, 22(3), 138-147. 


\section{APPENDIX A: ARGUMENTATION LOG}

Partitioning: Equal-Sharing (Fractions are composed of equal parts)

That is one-sixths. There is five of them.

Day 1: Introduced as a Warrant

Share 5 Candy Bars Equally Among 6 People

\begin{tabular}{|c|c|c|c|c|}
\hline Claim & Data & Question & Warrant & Backing \\
\hline$\frac{5}{6}$ & $\begin{array}{l}\text { So, I draw a candy } \\
\text { bar-so the numbers } \\
\text { are a lot-goes } \\
\text { down-it is like, one, } \\
\text { two, three, four, five } \\
\text { candy bar and then, I } \\
\text { split up into six } \\
\text { people-so each candy } \\
\text { bar at six, which is the } \\
\text { reason why I got } \frac{5}{6} \text {. } \\
\text { Like, on top I did } \\
\text { shade again that each } \\
\text { got } \frac{1}{6} \text { of each candy- } \\
\text { so that they got } \\
\frac{5}{6}-5 \text { out of } 6 \text { pieces- } \\
\text { each got } \frac{5}{6} \text { of each } \\
\text { candy bar } \\
\text { Tannv }\end{array}$ & $\begin{array}{l}\text { If I am looking at this piece, how } \\
\text { much is that? } \\
\text { Professor }\end{array}$ & $\begin{array}{l}\text { That is one- } \\
\text { sixths. } \\
\text { There is five } \\
\text { of them. } \\
\text { Tanny }\end{array}$ & \\
\hline
\end{tabular}


Day 1: Used as data for a new problem and questioned by the professor as further information is needed

Because they got five ... pieces ... yes! Yes! The candy bars are three.

If you look at the picture- because it is five down and three this way-so five one-third sizepieces.

Share 5 Candy Bars Equally Among 3 People

\begin{tabular}{|c|c|c|c|c|}
\hline Claim & Data & Question & Warrant & Backing \\
\hline$\frac{5}{3}$ & $\begin{array}{l}\text { The people are five ... } \\
\text { Then, five over three ... } \\
\text { that is what each get, the } \\
\text { candy bar. } \\
\text { Tanny }\end{array}$ & $\begin{array}{l}\text { How did you get five- } \\
\text { thirds? } \\
\text { Professor }\end{array}$ & $\begin{array}{l}\text { Because they got } \\
\text { five ... pieces ... } \\
\text { yes! Yes! The candy } \\
\text { bars are three ... } \\
\text { Tanny }\end{array}$ & \\
\hline & $\begin{array}{l}\text { So, if you divide the five } \\
\text { candy bars into one- } \\
\text { thirds or into thirds-it is } \\
\text { fifteen one-thirds size - } \\
\text { pieces of candy bars, and } \\
\text { each person will get five. } \\
\text { If you divide fifteen by } \\
\text { three-each person gets } \\
\text { five one-thirds size } \\
\text { pieces } \\
\text { Irica }\end{array}$ & & $\begin{array}{l}\text { If you look at the } \\
\text { picture- because it } \\
\text { is five down and } \\
\text { three this way-so } \\
\text { five one-third size- } \\
\text { pieces. } \\
\text { Reagan }\end{array}$ & \\
\hline
\end{tabular}


Day 1: Used as data for a new problem - not questioned

$\frac{3}{6}+\frac{2}{6}=\frac{5}{6}$.

Share 5 Candy Bars Equally Among 6 People

\begin{tabular}{|c|c|c|c|c|}
\hline Claim & Data & Question & Warrant & Backing \\
\hline$\frac{5}{6}$ & $\begin{array}{l}\text { I took the six } \\
\text { people-so I took a } \\
\text { number that goes in } \\
\text { six, which is three: I } \\
\text { divided it by two to } \\
\text { get three. I took the } \\
\text { first three and } \\
\text { divided those in half } \\
\text { and then so that each } \\
\text { gets one-half and } \\
\text { then there is two } \\
\text { candy bars leftover } \\
\text { and then, I took-I } \\
\text { divided those in the } \\
\text { thirds because you } \\
\text { can't divide it in } \\
\text { halves when to equal } \\
\text { it for six people ... } \\
\text { Yea ... the two } \\
\text { leftovers ... so I } \\
\text { divided them in the } \\
\text { thirds and so each } \\
\text { got a third ... uh ... } \\
\text { so that I added one- } \\
\text { half and one-third } \\
\text { and then I had to like } \\
\text { to make the } \\
\text { denominator the } \\
\text { same ... so it was } \frac{3}{6}+ \\
\frac{2}{6} \text { equals } \frac{5}{6} . \\
\text { From the first three } \\
\text { each got a half. The } \\
\text { one-thirds was from } \\
\text { the two leftovers } \\
\text { Janna }\end{array}$ & & & \\
\hline
\end{tabular}


$\frac{5}{6}=$ Five one-sixths

Day 1: Introduced as Warrant

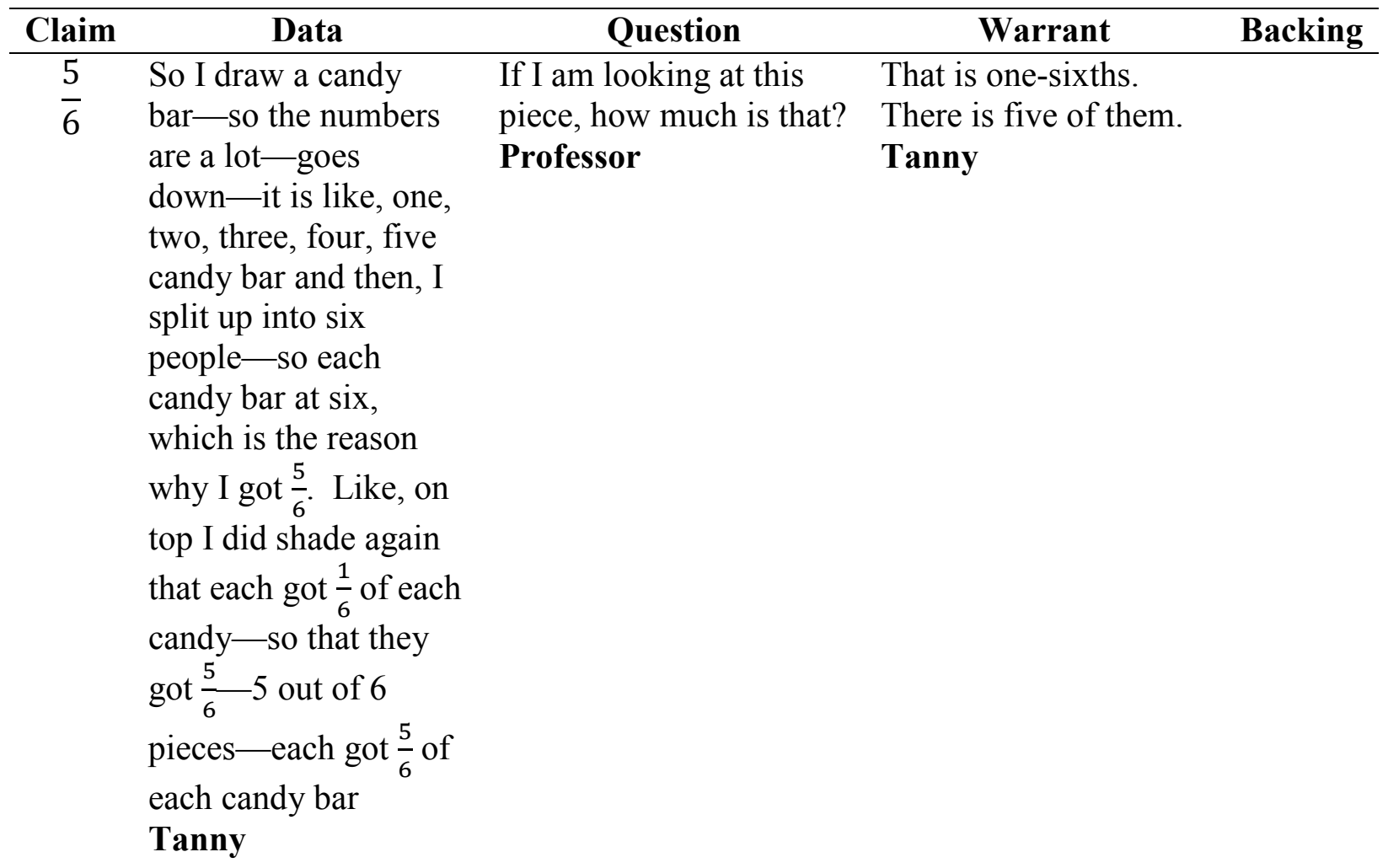


Day 1: Shifts from warrant to data but questioned by the professor as further information was

needed

$\frac{5}{3}=$ Five one-thirds

\begin{tabular}{|c|c|c|c|c|}
\hline Claim & Data & Question & Warrant & Backing \\
\hline$\frac{5}{3}$ & $\begin{array}{l}\text { So if you divide the five candy bars } \\
\text { into one-thirds or into thirds-it is } \\
\text { fifteen one-thirds size -pieces of } \\
\text { candy bars, and each person will get } \\
\text { five. If you divide fifteen by } \\
\text { three- each person gets five one- } \\
\text { thirds size pieces }\end{array}$ & $\begin{array}{l}\text { How did } \\
\text { you get } \\
\text { five-thirds? } \\
\text { Professor }\end{array}$ & $\begin{array}{l}\text { If you look at the } \\
\text { picture- because it } \\
\text { is five down and } \\
\text { three this way-so } \\
\text { five one-third size- } \\
\text { pieces. } \\
\text { Reagan }\end{array}$ & \\
\hline
\end{tabular}

Day 4: Used as data for a new problem - not questioned

$\frac{4}{3}=$ Four one-thirds

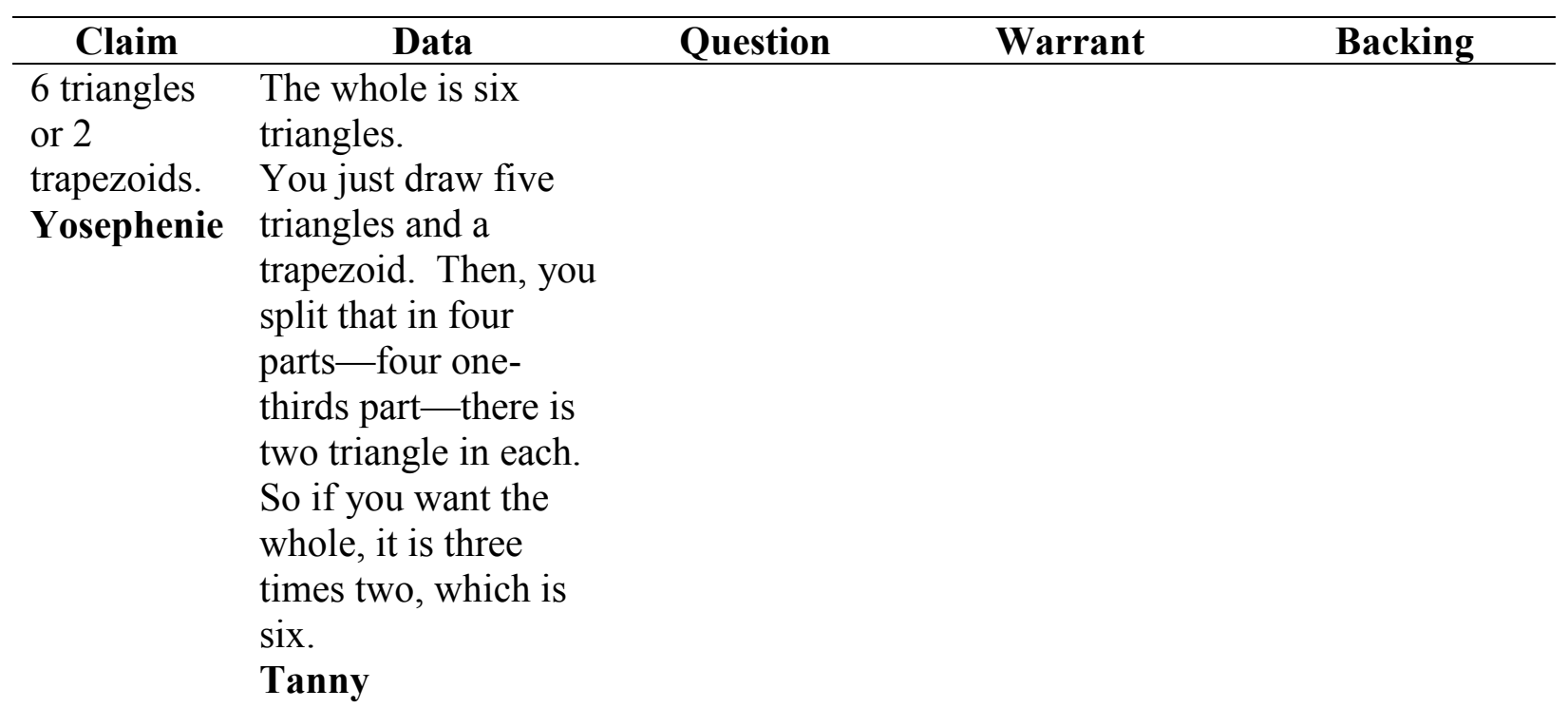


Unitizing (Iterating and developing a composite unit of one)

Day 1: Introduced as a Data

$\frac{5}{3}=$ Five one-thirds $=1 \frac{2}{3}$

\begin{tabular}{|c|c|c|c|c|}
\hline Claim & Data & Question & Warrant & Backing \\
\hline$\frac{5}{3}$ & $\begin{array}{l}\text { So if you divide the } \\
\text { five candy bars into } \\
\text { one-thirds or into } \\
\text { thirds-it is fifteen } \\
\text { one-thirds size - } \\
\text { pieces of candy bars, } \\
\text { and each person will } \\
\text { get five. If you } \\
\text { divide fifteen by } \\
\text { three-each person } \\
\text { gets five one-thirds } \\
\text { size pieces (Their } \\
\text { picture shows } \frac{5}{3} \text { and } \\
1 \frac{2}{3} \text { as possible } \\
\text { solutions) } \\
\text { Irica }\end{array}$ & $\begin{array}{l}\text { How did you get five- } \\
\text { thirds? } \\
\text { Professor }\end{array}$ & $\begin{array}{l}\text { If you look at the } \\
\text { picture- because it } \\
\text { is five down and } \\
\text { three this way-so } \\
\text { five one-third size- } \\
\text { pieces. } \\
\text { Reagan }\end{array}$ & \\
\hline
\end{tabular}

'Table Continues' 
Day 4: Shifts from data to warrant—questioned by the professor as further information was

needed

25 Triangles $=$ Five-fifths

Charlie Brown takes two-fifths of the pattern blocks that Lucy has and gets a blue Parallelogram, a yellow hexagon, and two green triangles. What pattern blocks might Lucy have had before Charlie took any away?

\begin{tabular}{|c|c|c|c|c|}
\hline Claim & Data & Question & Warrant & Backing \\
\hline 25 & Alright guys! Ok, so first of & And the how & I added two- & \\
\hline triangles & all it says Charlie Brown & did you get & fifths because & \\
\hline Tanny & takes two-fifths of the pattern & one-fifths? & we want to get a & \\
\hline & blacks that Lucy has. So, we & Professor & whole which & \\
\hline All of & know that Charlie has two- & & would be five- & \\
\hline them. & fifths, and so I wrote out & & fifths. So, I & \\
\hline Reagan & two-fifths as a rhombus and & & knew that if you & \\
\hline & so we need ... So, since & & got two-fifths, & \\
\hline & Charlie takes two-fifths of & & four-fifths and & \\
\hline & what Lucy has, we know we & & then one-fifths & \\
\hline & need to find the whole. And & & plus four-fifths, & \\
\hline & so, I added two-fifths to two- & & fife-fifths which & \\
\hline & fifths to get four-fifths, so & & is the whole. & \\
\hline & since it is four fifths, you & & Reagan & \\
\hline & want to get the whole which & & & \\
\hline & would be five-fifths, we & & & \\
\hline & know that Charlie needs & & & \\
\hline & one-fifth. & & & \\
\hline & Reagan & & & \\
\hline
\end{tabular}


Day 4: Used as data for a new problem - not questioned

Twenty-one triangles $=14$ pieces

Pigpen has three green triangles and three blue rhombi pattern blocks. This is three-sevenths of what Lucy has. What pattern blocks might Lucy have had?

\begin{tabular}{ll}
\hline \multicolumn{1}{c}{ Claim } & \multicolumn{1}{c}{ Data } \\
\hline Twenty- & Okestion so three green triangle \\
one & Warrant \\
triangles. & that out and that equals to \\
& three-sevenths. So, then, I \\
& just doubled it. Three - \\
& seventh plus three sevenths is \\
& six-sevenths. And I know I \\
& need one more sevenths and I \\
& figured out if there are nine \\
triangles in a group of three- \\
sevenths, that one sevenths \\
will be three triangle. So my \\
whole would be twenty-one \\
triangles for seven groups of \\
sevenths. \\
Irica \\
I did. And then for discrete he \\
has three green triangles and \\
three blue rhombi that would be \\
six pattern blocks all together \\
and six pattern blocks equals to \\
three-sevenths. One sevens has \\
to be a group of two pattern \\
blocks. so I drew three- \\
sevenths which are his six \\
blocks, whatever they need and \\
that I knew one-sevenths is a \\
group of two and I need four of \\
those to get to seven-sevenths, \\
so that would be fourteen \\
pieces. \\
Irica
\end{tabular}




\section{Unitizing (Iterating a unit fraction from composite fraction).}

Day 4: Introduce as data but questioned by the professor as further information was needed

And so, I added two-fifths to two-fifths to get four-fifths, so since it is four fifths, you want to get the whole which would be five-fifths, we know that Charlie needs one-fifth.

Charlie Brown takes two-fifths of the pattern blocks that Lucy has and gets a blue Parallelogram, a yellow hexagon, and two green triangles. What pattern blocks might Lucy have had before Charlie took any away?

\begin{tabular}{|c|c|c|c|c|}
\hline Claim & Data & Question & Warrant & Backing \\
\hline 25 & Alright guys! Ok, so first of & And the how & I added two- & \\
\hline triangles & all it says Charlie Brown & did you get & fifths because & \\
\hline Tanny & takes two-fifths of the pattern & one-fifths? & we want to get a & \\
\hline & blacks that Lucy has. So, we & Professor & whole which & \\
\hline All of & know that Charlie has two- & & would be five- & \\
\hline them. & fifths, and so I wrote out & & fifths. So, I & \\
\hline Reagan & two-fifths as a rhombus and & & knew that if you & \\
\hline & so we need ... So, since & & got two-fifths, & \\
\hline & Charlie takes two-fifths of & & four-fifths and & \\
\hline & what Lucy has, we know we & & then one-fifths & \\
\hline & need to find the whole. And & & plus four-fifths, & \\
\hline & so, I added two-fifths to two- & & fife-fifths which & \\
\hline & fifths to get four-fifths, so & & is the whole. & \\
\hline & since it is four fifths, you & & Reagan & \\
\hline & want to get the whole which & & & \\
\hline & would be five-fifths, we & & & \\
\hline & know that Charlie needs & & & \\
\hline & one-fifth. & & & \\
\hline & Reagan & & & \\
\hline
\end{tabular}




\section{Day 5: Taken as-shared as a Data-not questioned)}

Solve the following problem pictorially

Emily receives her paycheck for the month. She spends $\frac{1}{6}$ of it on food. She then spends $\frac{3}{5}$ of what remains on her house payment. She spends $\frac{1}{3}$ of what is then left for her other bills. Finally she spends $\frac{1}{4}$ of the remaining money for entertainment. This activity leaves her with $\$ 150$ that she puts into savings. What was her original take-home pay?

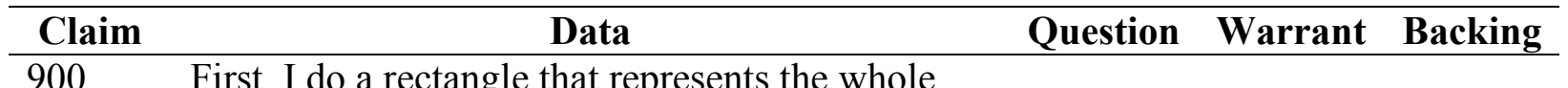

First, I do a rectangle that represents the whole

Gessica check she got and then I split it up in to sixths, because it says she spent one-sixths of the money on food. So, I went down, so split into sixths, so then one box was for food, I put "F" So, F for food. And she spends three-fifths for of what remains on her house payment. So now so that, now you have one, two, three, four, five- so five up and down left, three of them go give for the house payment ... house payment, house payment, house payment and then it says she spends a third on other bills, but now you only have two boxes two vertical boxes so I split horizontally into thirds, so one, two, three. One box one-thirds for other bills that is why I put OB. And finally she spends one-fourths, the remaining on entertainment so you have four boxes left, so then one, two, three, and four. So, one-fourths of that is one box, for entertainment. And this activity leaves her $\$ 150.00$ dollar put for saving, so you have three boxes left. That is way I put "S" for saving. So each box was $\$ 50.00$, so then to get the total amount, I made pieces just to make little square which worth's $\$ 50.00$ and then I just added each boxes and I got $\$ 900.00$.

\section{Gessica}


talking about what the whole is)

Each got $\frac{1}{6}$ of each candy

Day 1: Introduced as Data

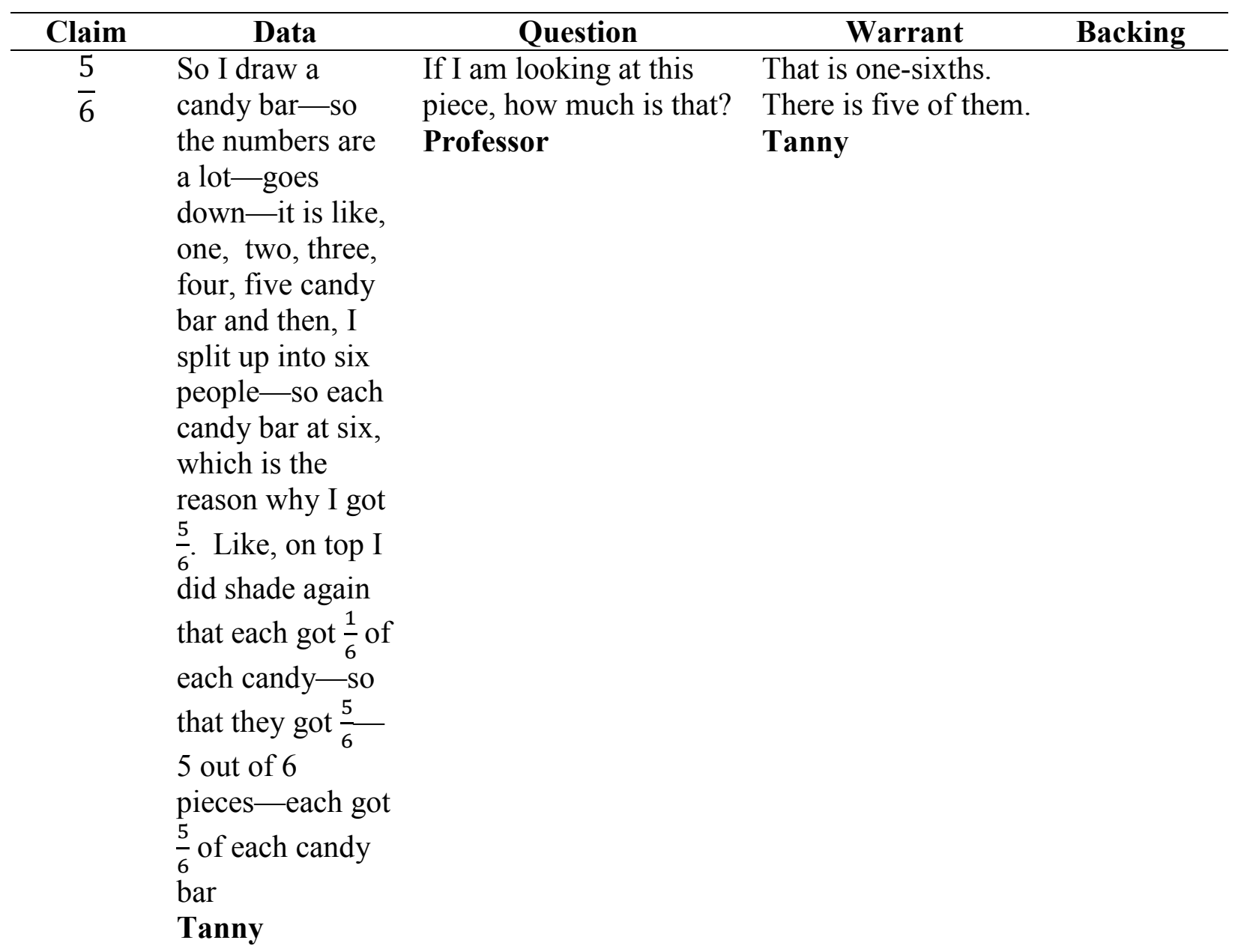


Day 3: Shifts from data to warrant but questioned by the professor as further information was

needed

It is a hexagon-for two trapezoid and two tringles

The circle is one and the shaded area is three-eighth

Use each of your manipulative sets to represent three-eighths in three different ways.

\begin{tabular}{|c|c|c|c|c|}
\hline Claim & Data & Question & Warrant & Backing \\
\hline$\frac{3}{8}$ & $\begin{array}{l}\text { So, I kind of just put } \\
\text { together like } \\
\text { something-just like, I } \\
\text { put } 8 \text { ones, triangles } \\
\text { together and then it } \\
\text { will be eight and then I } \\
\text { just took three of them } \\
\text { - that is three- } \\
\text { eighth...we just took } 3 \\
\text { blocks away. }\end{array}$ & $\begin{array}{l}\text { So your } \\
\text { whole is } \\
\text { what? } \\
\text { Professor }\end{array}$ & $\begin{array}{l}\text { It is a hexagon-for } \\
\text { two trapezoid and } \\
\text { two tringles. } \\
\text { Sori }\end{array}$ & \\
\hline & $\begin{array}{l}\text { Sori } \\
\text { I just like...divide it, } \\
\text { take it and shade it- } \\
\text { three-eighth. } \\
\text { Pulianna }\end{array}$ & $\begin{array}{l}\text { What is your } \\
\text { whole? } \\
\text { Professor }\end{array}$ & $\begin{array}{l}\text { The circle is one and } \\
\text { the shaded area is } \\
\text { three-eighth } \\
\text { Pulianna }\end{array}$ & \\
\hline & $\begin{array}{l}\text { For my whole I drew a } \\
\text { hexagon and two } \\
\text { triangles, because } \\
\text { there are eight } \\
\text { triangles altogether } \\
\text { and then for the three- } \\
\text { eighth, I drew three } \\
\text { triangles - it is three- } \\
\text { eighths. } \\
\text { Tara }\end{array}$ & & & \\
\hline
\end{tabular}


The single - all "five triangles".

Use pattern blocks to represent nine-fifths in three different ways.

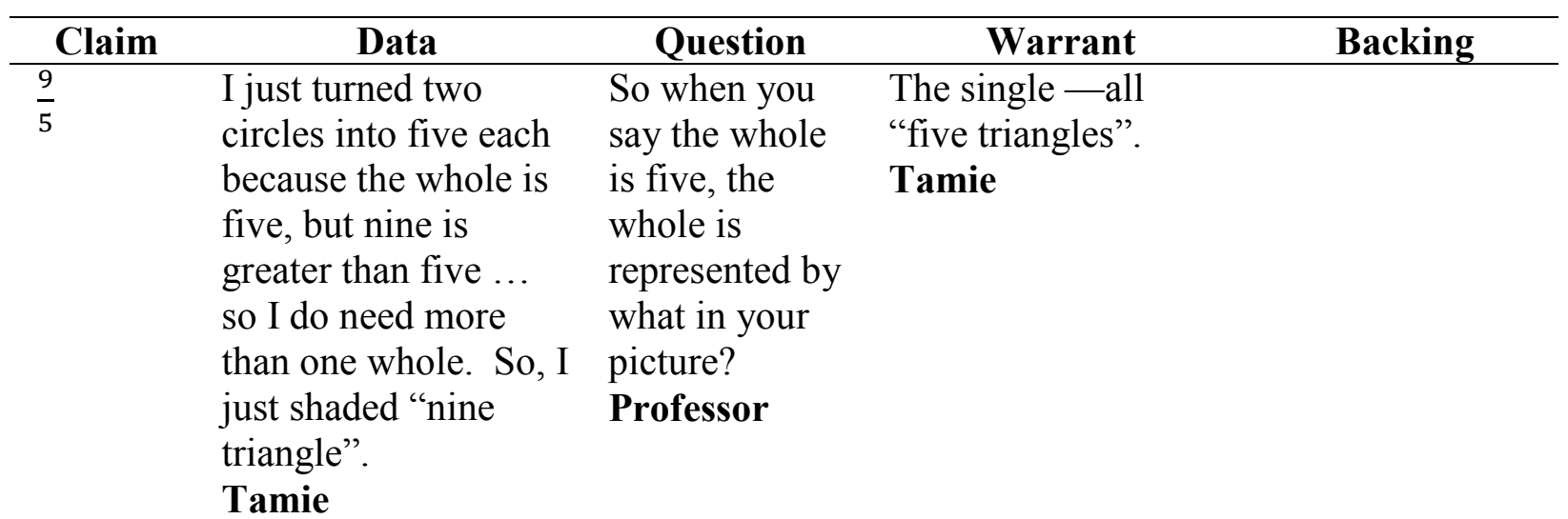

So, I kind of like did a candy bar... one bar is five [Pointing to the first candy bar], so that - that is like the whole ... and this is four-fifth of a whole [Pointing to the second candy bar]. It is a mix number, one and four-fifths. So, together it is nine fifths.

\section{Pulianna}


Day 3: Shifts to claim-not questioned

Can You See $\frac{5}{2}$ of something?

\begin{tabular}{|c|c|c|c|c|}
\hline Claim & Data & Question & Warrant & Backing \\
\hline It would be & If those smaller & & & \\
\hline like five- & sections are the & & & \\
\hline halves of- & rectangles that & & & \\
\hline two halves & represent half- & & & \\
\hline of one & size pieces, so & & & \\
\hline whole. & two of those were & & & \\
\hline Pulianna & a whole. It would & & & \\
\hline I think you & take two and half & & & \\
\hline can use by & of them to make & & & \\
\hline saying five- & one whole- & & & \\
\hline halves of & which is five & & & \\
\hline two-fifths & haves. & & & \\
\hline because ... & Irica & & & \\
\hline Two-fifths & & & & \\
\hline of the & & & & \\
\hline rectangle is & & & & \\
\hline the whole. & & & & \\
\hline $\mathrm{OK} !$ & & & & \\
\hline Irica & & & & \\
\hline
\end{tabular}


Defining the whole (Everything that is coming after the word "of", when defining fractions, represents the whole)

Five-sixths of one candy bar

Day 2: Introduced as Backings

Share 5 Candy Bars Equally Among 6 People. How Much Each Person Does Receive?

Student 1: $\frac{5}{6}$ of the Candy Bars

\begin{tabular}{|c|c|c|c|c|}
\hline Claim & Data & Question & Warrant & Backing \\
\hline Incorrect & $\begin{array}{l}\text { Five-sixths of all } \\
\text { the candy bars, } \\
\text { you just draw five } \\
\text { candy bars. Five- } \\
\text { sixths of that } \\
\text { would be like ..., } \\
\text { uh ... twenty five- } \\
\text { thirtieths. So, } \\
\text { people get twenty } \\
\text { five of those little } \\
\text { pieces and that } \\
\text { would be for one } \\
\text { person and you } \\
\text { would never have } \\
\text { enough up right } \\
\text { now for other } \\
\text { people. } \\
\text { Tanny }\end{array}$ & $\begin{array}{l}\text { Here are the } \\
\text { five candy } \\
\text { bars, } \\
\text { splitting } \\
\text { equally } \\
\text { among six } \\
\text { people, how } \\
\text { we are going } \\
\text { to get the } \\
\text { answer? } \\
\text { Professor }\end{array}$ & $\begin{array}{l}\text { So five- } \\
\text { sixths of } \\
\text { all the } \\
\text { candy bars. } \\
\text { He said the } \\
\text { candy bars } \\
\text { are the } \\
\text { whole. } \\
\text { Tanny }\end{array}$ & $\begin{array}{l}\text { All of the candy bars, because he } \\
\text { should have said each of you } \\
\text { trying to do five-sixths of one } \\
\text { candy bar. So ... yea, then I just } \\
\text { divided thirty pieces - thirty } \\
\text { little pieces over there. See all of } \\
\text { them-twenty-five on top- five } \\
\text { in each and the bottom is thirty. } \\
\text { So if you color } 25 \text { pieces - all } \\
\text { said that candy is } 25 \text { pieces, and } \\
\text { there is only } 5 \text { pieces left to share } \\
\text { among everyone else, so it is } \\
\text { impossible! } \\
\text { Tanny }\end{array}$ \\
\hline
\end{tabular}


Five-sixths of each candy bar means five-sixths of like-the first bar, the second bar, the third bar, the fourth bar, the fifth bar. Five-sixths of one is just one bar not the whole

Student 5: $\frac{5}{6}$ of each candy bar

\begin{tabular}{|c|c|c|c|}
\hline Claim & Question & Warrant & Backing \\
\hline Incorrect & $\begin{array}{l}\text { So, it will be the same one. } \\
\text { Each will be like ... each } \\
\text { like } \frac{5}{6} \text { of every single one } \\
\ldots \text { not all the five. } \\
\text { Jenna } \\
\text { I don't know ... now they } \\
\text { really want } \frac{5}{6} \ldots \text { get all of } \\
\text { those... there is like } \frac{1}{6} \text { of } \\
\text { each candy bar left...right? } \\
\text { Janna }\end{array}$ & $\begin{array}{l}\text { I think it is } \\
\text { similar to } \\
\text { number } \\
\text { one, } \\
\text { student } \\
\text { one, which } \\
\text { was also } \\
\text { incorrect. } \\
\text { Tanny }\end{array}$ & $\begin{array}{l}\text { Isn't it basically the same as } \\
\text { student three? } \\
\text { Five-sixths of each candy bar } \\
\text { means five-sixths of like-the } \\
\text { first bar, the second bar, the } \\
\text { third bar, the fourth bar, the fifth } \\
\text { bar. Five-sixths of one is just } \\
\text { one bar not the whole } \\
\text { Janna } \\
\text { Each candy bar and one candy } \\
\text { bar are the same thing. } \\
\text { Balerie }\end{array}$ \\
\hline
\end{tabular}

Day 3: Shifts from backings to Claims - not questioned

$\frac{5}{2}$ of $2 \frac{1}{2}$ of $\frac{2}{5}$ It would take two and half of them to make one whole-which is five halves.

Can You See $\frac{5}{2}$ of something?

\begin{tabular}{|c|c|c|c|c|}
\hline Claim & Data & Question & Warrant & Backing \\
\hline It would be like five-halves & If those smaller & & & \\
\hline of - two halves of one & sections are the & & & \\
\hline whole. & rectangles that & & & \\
\hline Pulianna & represent half-size & & & \\
\hline I think you can use by & pieces, so two of those & & & \\
\hline saying five-halves of two- & were a whole. It & & & \\
\hline fifths because ... & would take two and & & & \\
\hline Two-fifths of the rectangle & half of them to make & & & \\
\hline is the whole. OK! Irica & $\begin{array}{l}\text { one whole-which is } \\
\text { five halves. Irica }\end{array}$ & & & \\
\hline
\end{tabular}


Defining the whole (The whole does not change unless it is specified -the whole could potentially change depending on what blocks PTs actually used)

Each got $\frac{1}{6}$ of each candy

Day 1: Introduced as-a Data

Share 5 Candy Bars Equally Among 6 People

\begin{tabular}{|c|c|c|c|c|}
\hline Claim & Data & Question & Warrant & Backing \\
\hline$\frac{5}{6}$ & $\begin{array}{l}\text { So, I draw a candy } \\
\text { bar-so the numbers } \\
\text { are a lot-goes } \\
\text { down-it is like, one, } \\
\text { two, three, four, five } \\
\text { candy bar and then, I } \\
\text { split up into six } \\
\text { people—-so each candy } \\
\text { bar at six, which is the } \\
\text { reason why I got } \frac{5}{6} \text {. } \\
\text { Like, on top I did } \\
\text { shade again that each } \\
\text { got } \frac{1}{6} \text { of each candy- } \\
\text { so that they got } \\
\frac{5}{6}-5 \text { out of } 6 \text { pieces- } \\
\text { each got } \frac{5}{6} \text { of each } \\
\text { candy bar } \\
\text { Tanny }\end{array}$ & $\begin{array}{l}\text { If I am looking at this piece, how } \\
\text { much is that? } \\
\text { Professor }\end{array}$ & $\begin{array}{l}\text { That is one- } \\
\text { sixths. } \\
\text { There is five } \\
\text { of them. } \\
\text { Tanny }\end{array}$ & \\
\hline
\end{tabular}


Day 1: Shifts to a Backing

He should have said each of you trying to do five-sixths of one candy bar

Share 5 Candy Bars Equally Among 6 People. How Much Each Person Does Receive?

Student 1: $\frac{5}{6}$ of the Candy Bars

\begin{tabular}{|c|c|c|c|c|}
\hline Claim & Data & Question & Warrant & Backing \\
\hline Incorrect & $\begin{array}{l}\text { Five-sixths of all } \\
\text { the candy bars, } \\
\text { you just draw five } \\
\text { candy bars. Five- } \\
\text { sixths of that } \\
\text { would be like ...., } \\
\text { uh ... twenty five- } \\
\text { thirtieths. So, } \\
\text { people get twenty } \\
\text { five of those little } \\
\text { pieces and that } \\
\text { would be for one } \\
\text { person and you } \\
\text { would never have } \\
\text { enough up right } \\
\text { now for other } \\
\text { people. } \\
\text { Tanny }\end{array}$ & $\begin{array}{l}\text { Here are the } \\
\text { five candy } \\
\text { bars, } \\
\text { splitting } \\
\text { equally } \\
\text { among six } \\
\text { people, how } \\
\text { we are going } \\
\text { to get the } \\
\text { answer? } \\
\text { Professor }\end{array}$ & $\begin{array}{l}\text { So five- } \\
\text { sixths of } \\
\text { all the } \\
\text { candy bars. } \\
\text { He said the } \\
\text { candy bars } \\
\text { are the } \\
\text { whole. } \\
\text { Tanny }\end{array}$ & $\begin{array}{l}\text { All of the candy bars, because he } \\
\text { should have said each of you } \\
\text { trying to do five-sixths of one } \\
\text { candy bar. So ... yea, then I just } \\
\text { divided thirty pieces - thirty } \\
\text { little pieces over there. See all of } \\
\text { them - twenty-five on top - five } \\
\text { in each and the bottom is thirty. } \\
\text { So if you color } 25 \text { pieces - all } \\
\text { said that candy is } 25 \text { pieces, and } \\
\text { there is only } 5 \text { pieces left to share } \\
\text { among everyone else, so it is } \\
\text { impossible! } \\
\text { Tanny }\end{array}$ \\
\hline
\end{tabular}


Day 3: Taken-as shared as Data

The $\frac{\mathbf{9}}{\mathbf{5}}$ is $\frac{\mathbf{9}}{\mathbf{5}}$ of what? $\frac{\mathbf{9}}{\mathbf{5}}$ of one circle or two?

\begin{tabular}{|c|c|c|c|c|}
\hline Claim & Data & Question & Warrant & Backing \\
\hline $\begin{array}{l}\frac{9}{5} \text { of } \\
\text { one }\end{array}$ & $\begin{array}{l}\text { Because of the candy } \\
\text { bar problem. } \\
\text { Pulianna }\end{array}$ & & & \\
\hline
\end{tabular}

$\begin{array}{ll}\frac{9}{10} \text { of } & \text { Because there is five } \\ \text { Two } & \text { sections of each circle, } \\ \text { there will be ten } \\ \text { sections like "ten } \\ \text { triangles" or pieces all } \\ \text { together and there is } \\ \text { nine of them shaded in, } \\ \text { so if you have two, } \\ \text { there will be nine parts } \\ \text { of the ten. } \\ \text { Vrittany }\end{array}$




\section{Equivalent Fractions (Both equivalent fractions are out of the same size whole)}

Day 2: Introduced as Warrant

$\frac{5}{6}=\frac{25}{30}$ Multiplication of numerator and denominator were used to make sense of equivalent

fractions

Share 5 candy bars equally among 6 people. How much each person does receive?

Student 1: $5 / 6$ of the candy bars

\begin{tabular}{|c|c|c|c|c|}
\hline Claim & Data & Question & Warrant & Backing \\
\hline Incorrect & $\begin{array}{l}\text { Five-sixths of all } \\
\text { the candy bars, you } \\
\text { just draw five } \\
\text { candy bars. Five- } \\
\text { sixths of that } \\
\text { would be like ..., } \\
\text { uh ... twenty five- } \\
\text { thirtieths. So, } \\
\text { people get twenty } \\
\text { five of those little } \\
\text { pieces and that } \\
\text { would be for one } \\
\text { person and you } \\
\text { would never have } \\
\text { enough up right } \\
\text { now for other } \\
\text { people. } \\
\text { Tanny }\end{array}$ & $\begin{array}{l}\text { I'm still } \\
\text { confused how } \\
\text { she got } \\
\text { thirtieth. } \\
\text { Kanner } \\
\text { How did you } \\
\text { get thirty } \\
\text { pieces? } \\
\text { Professor? }\end{array}$ & $\begin{array}{l}\text { Um, five-sixths of } \\
\text { the candy bars- } \\
\text { each of the five } \\
\text { candy bars divided } \\
\text { in to six pieces. So } \\
\text { five times six is } \\
\text { thirty, and you } \\
\text { change the } \\
\text { fraction, then the } \\
\text { six becomes thirty } \\
\text { and the five } \\
\text { becomes twenty- } \\
\text { five, just like } \\
\text { converting into } \\
\text { equal fractions. } \\
\text { Tannv }\end{array}$ & $\begin{array}{l}\text { All of the candy bars, } \\
\text { because he should } \\
\text { have said each of you } \\
\text { trying to do five-sixths } \\
\text { of one candy bar. So } \\
\text {.., yea, then I just } \\
\text { divided thirty pieces } \\
\text { — thirty little pieces } \\
\text { over there. See all of } \\
\text { them-twenty-five on } \\
\text { top- five in each and } \\
\text { the bottom is thirty. } \\
\text { So if you color } 25 \\
\text { pieces - all said that } \\
\text { candy is } 25 \text { pieces, and } \\
\text { there is only } 5 \text { pieces } \\
\text { left to share among } \\
\text { everyone else, so it is } \\
\text { impossible! } \\
\text { Tanny }\end{array}$ \\
\hline
\end{tabular}

'Table Continues' 
Day 5: Shifts from warrant to data - different manipulatives were used to make sense of equivalent fractions - not questioned

$\frac{3}{4}=\frac{9}{12}$

Show in at least two different way using pictorial representations that the fractions $\frac{3}{4}$ and $\frac{9}{12}$ are equivalent

\begin{tabular}{|c|c|c|c|c|}
\hline Claim & Data & Question & Warrant & Backing \\
\hline
\end{tabular}

$\frac{3}{4}=\frac{9}{12} \quad \begin{aligned} & \text { I know I drew two separate rectangles. I } \\ & \text { divided the first rectangle into twelve }\end{aligned}$

rectangular pieces and shade nine of them

I divided the second rectangle into four

pieces and shaded three of them.

$\cdots$

One-fourths is three small rectangles.

Yosephenie

I started off drawing the three-fourths.

First the black box and the long rectangle-there is three shaded in out of

four and then, for the nine -twelfths, I did

horizontally across to make them into twelve-size pieces and there is nine technically shaded but totally different, then I used " $x$ " in them and there is nine "X"s out of twelve boxes ... Just you can tell the difference between like the shaded part and then the circle basically the same thing, the blue circle three-fourth shaded in and then I split into twelve -size pieces, again there is nine x's out of twelve.

\section{Tara}

There is twelve total triangles and nine of them are shaded. But the group shows three-fourths-this group three-fourths.

\section{Rhannon}


Day 7: Shifts from data to warrant-a number line was used to make sense of equivalent

fractions but questioned by the professor as further information was needed

$\frac{1}{4}=\frac{2}{8}$

Find the point on the number line that is half way between $\frac{1}{4}$ and $\frac{7}{8}$.

\begin{tabular}{|c|c|c|c|c|}
\hline Claim & Data & Question & Warrant & Backing \\
\hline $\begin{array}{l}\text { Four } \\
\text { and } \\
\text { half- } \\
\text { eighths. }\end{array}$ & $\begin{array}{l}\text { We change the one- } \\
\text { fourths into eighths. So } \\
\text { it is easier to compare } \\
\text { with seven-eighths. So } \\
\text { one-fourths is two- } \\
\text { eights. And we drew } \\
\text { on a number line and } \\
\text { then, half way between } \\
\text { two -eighths and } \\
\text { seven-eighths, it is } \\
\text { between four-eighths } \\
\text { and five-eighths. So, } \\
\text { four and half-eighths. } \\
\text { Since this half mark } \\
\text { lies between four- } \\
\text { eighths and five-eighths } \\
\text { and we got four and } \\
\text { half-eighths ...You can } \\
\text { do it ... count or like } \\
\text { cap spaces or divide } \\
\text { seven by two ... like } \\
\text { you could do all the } \\
\text { way or you can put half } \\
\text { mark in between each } \\
\text { fractions, then it is } \\
\text { easier to see half way } \\
\text { of the space between } \\
\text { one-eighths and seven- } \\
\text { eighths. } \\
\text { Ralerio }\end{array}$ & $\begin{array}{l}\text { Where did } \\
\text { you get the } \\
\text { eighths from? } \\
\text { Professor }\end{array}$ & $\begin{array}{l}\text { We changed all into } \\
\text { eighths. So it is easier } \\
\text { to compare since all } \\
\text { will have the same } \\
\text { common denominator. } \\
\text { So one-fourth is equal } \\
\text { to two-eighths. } \\
\text { Balerie }\end{array}$ & \\
\hline
\end{tabular}


Same Whole-Common Denominator (The discrete model is only going to work to solve problems if we can keep whole pieces - when fractions came out of the same whole)

In general, two-pieces are equal to one-fifths. Two pieces in one-fifths

Day 4: Introduced as a warrant-later shifted to data as more PTs participated and not questioned

Charlie Brown takes two-fifths of the pattern blocks that Lucy has and gets a blue Parallelogram, a yellow hexagon, and two green triangles. What pattern blocks might Lucy have had before Charlie took any away?

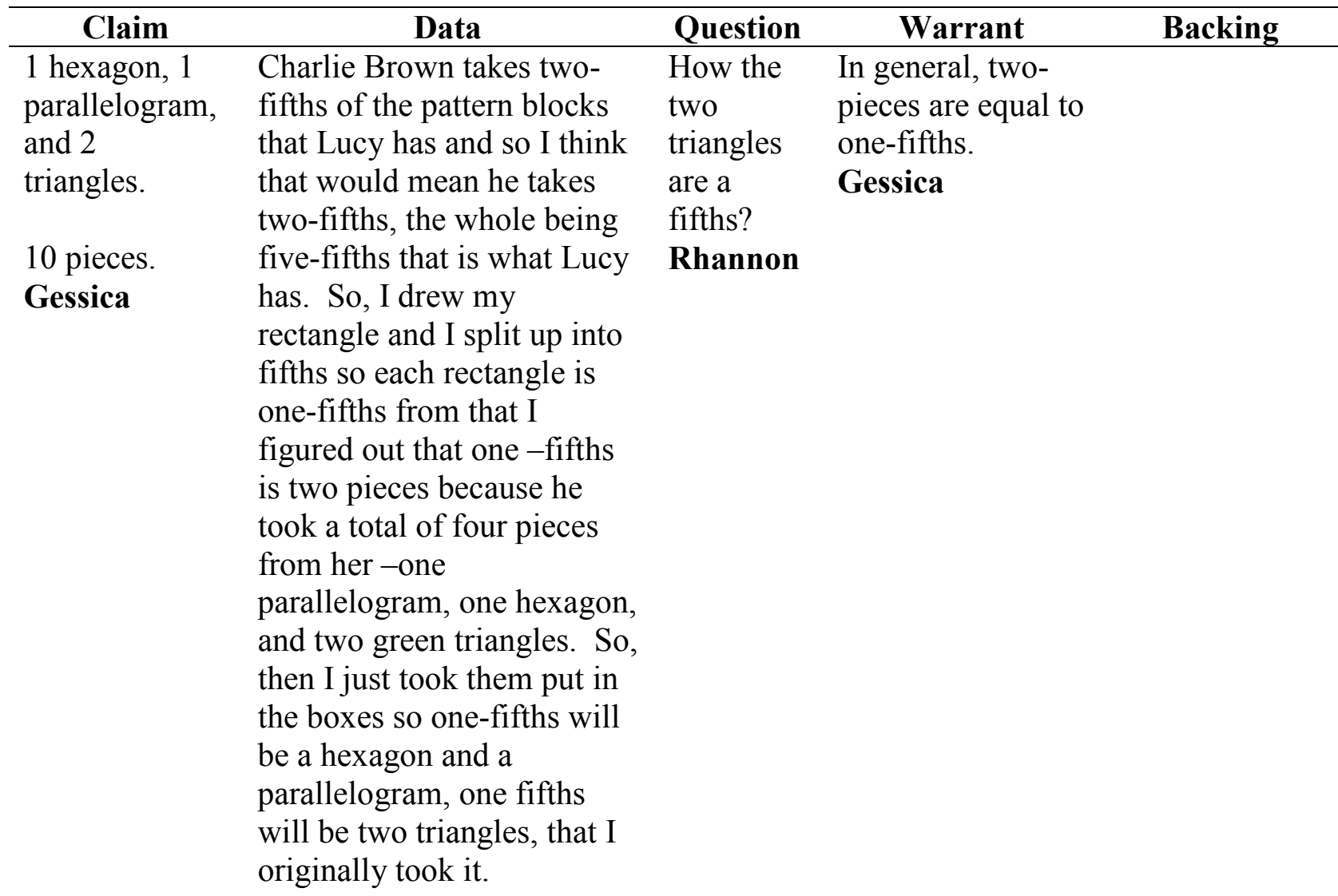




\begin{tabular}{lllll}
\hline Claim & Data & Question & Warrant & Backing \\
\hline
\end{tabular}

So, I had question mark because that would be what we want.

I just did triangles so then we have the one hexagon, the one parallelogram, two triangles from four a total of eight triangles one parallelogram and one hexagon.

\section{Gessica}

She is putting one-

fifths.

\section{Tanny}

She splitting up...there is twofifths... two pieces in one-fifths.

Irica 


\section{Comparing with common denominator (the size of the pieces) in relation to the numerator}

The denominator is the same. We are going to have the same whole for this. The eight tell us the same size pieces.

Day 6: The idea that the denominator represents the size of the pieces introduced and warrants were questioned and backings were provided for the argument.

Keeping the same denominator of eight, write three fractions that are less than seven-eighths.

\begin{tabular}{|c|c|c|c|}
\hline Claim & Data & Question & Warrant \\
\hline \multirow[t]{2}{*}{$\frac{6}{8}$} & $\begin{array}{l}\text { Six is less than seven. } \\
\text { Gessica }\end{array}$ & $\begin{array}{l}\text { What is the } \\
\text { eight telling } \\
\text { us? } \\
\text { Professor }\end{array}$ & $\begin{array}{l}\text { The denominator is } \\
\text { the same. } \\
\text { Gessica }\end{array}$ \\
\hline & & $\begin{array}{l}\text { Which is } \\
\text { going to mean } \\
\text { what? } \\
\text { Professor }\end{array}$ & $\begin{array}{l}\text { We are going to have } \\
\text { the same whole for } \\
\text { this. } \\
\text { Pulianna }\end{array}$ \\
\hline
\end{tabular}

The eight tell us the same size pieces.

Tanny

[Seven is] How many are shaded.

Rhannon

The denominator is the whole, so if you make the circle is eight pieces those six-eights pieces are less than seven-eighths pieces. Eight-eighths is the full circle-one whole.

\section{Tanny}


Day 6: The same number of pieces was not shifting to data or warrant and were not even being questioned. It appeared that comparing with common denominator in relation to the numerator was taken-as-shared.

What are two more fractions that are less than seven-eighths?

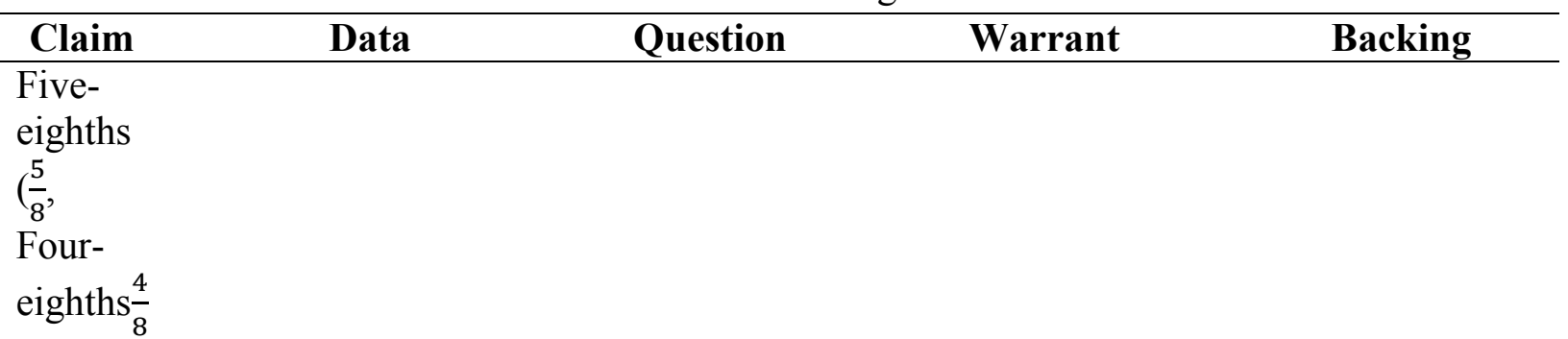

What about fractions that are greater than seven-eighths?

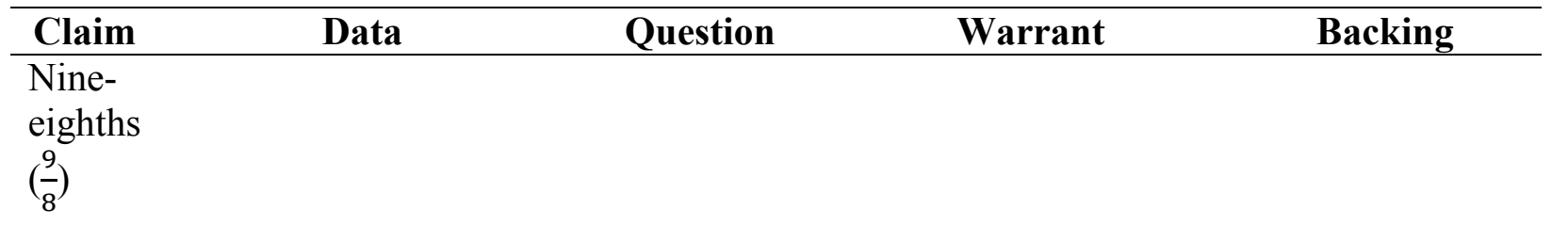




\section{Comparing fractions using common numerator (same number of pieces)}

Day 6: Day 6: Introduced as a Data. Data were never questioned.

Which one is greater, $\frac{2}{17}$ or $\frac{2}{19}$.

\begin{tabular}{|c|c|c|c|c|}
\hline Claim & Data & Question & Warrant & Backing \\
\hline$\underline{2}>\frac{2}{2}$ & Because seventeen & & & \\
\hline $17 \quad 19$ & pieces of one whole & & & \\
\hline & verses like nineteen & & & \\
\hline & pieces of the same & & & \\
\hline & whole, like, each & & & \\
\hline & individuals will & & & \\
\hline & receive two bigger & & & \\
\hline & pieces. & & & \\
\hline & Tanny & & & \\
\hline
\end{tabular}


Day 6: The idea of common numerators shifting in the discussion from data to a warrant. The data were questioned and warrants were provided. The reasoning strategy of comparing fractions using common numerator (the number of pieces) was taken-as-shared by the class.

$\frac{6}{11}>\frac{3}{7}$

Because six-elevenths is closer to one, which actually more than a half. The size of the pieces are bigger

\begin{tabular}{|c|c|c|c|c|}
\hline Claim & Data & Question & Warrant & Backing \\
\hline$\frac{6}{11}>\frac{3}{7}$ & $\begin{array}{l}\text { Because when you } \\
\text { convert three-sevenths } \\
\text { to six fourteenths, then } \\
\text { six-elevenths is greater } \\
\text { than six -fourteenths. }\end{array}$ & $\begin{array}{l}\text { How do you } \\
\text { know six- } \\
\text { elevenths is } \\
\text { greater? } \\
\text { Professor }\end{array}$ & $\begin{array}{l}\text { Because six-elevenths } \\
\text { is closer to one, which } \\
\text { actually more than a } \\
\text { half. } \\
\text { Reagan }\end{array}$ & \\
\hline & $\begin{array}{l}\text { Six-elevenths is closer } \\
\text { to six over six, which } \\
\text { is the whole. } \\
\text { Reagan }\end{array}$ & $\begin{array}{l}\text { Why did you } \\
\text { convert this } \\
\text { one to be six } \\
\text { over } 14 ? \\
\text { Professor }\end{array}$ & $\begin{array}{l}\text { Because I want them } \\
\text { to have the same } \\
\text { numerator. } \\
\text { Reagan }\end{array}$ & \\
\hline
\end{tabular}


Fractions can be compared to a certain specific bench mark

$\frac{17}{31}>\frac{1}{2}$ I took thirty one and divide thirty one by two that was fifteen and five-tenths to get like one-half

Day 6: Introduced as a Data

\begin{tabular}{|c|c|c|c|c|}
\hline Claim & Data & Question & Warrant & Backing \\
\hline $\begin{array}{ll}17 & 1\end{array}$ & I took thirty one and & & & \\
\hline$\overline{31}>\overline{2}$ & divide thirty one by & & & \\
\hline & two that was fifteen & & & \\
\hline & and five-tenths to get & & & \\
\hline & like one-half. Yeah, & & & \\
\hline & and then, if that is the & & & \\
\hline & one-half, seventeen is & & & \\
\hline & the greater numerator & & & \\
\hline & so that is the greater & & & \\
\hline & fraction. & & & \\
\hline & Vrittany & & & \\
\hline
\end{tabular}


Because six-elevenths is closer to one, which actually more than a half. Day 6: The one-half strategy came as a warrant when the Professor prompted it.

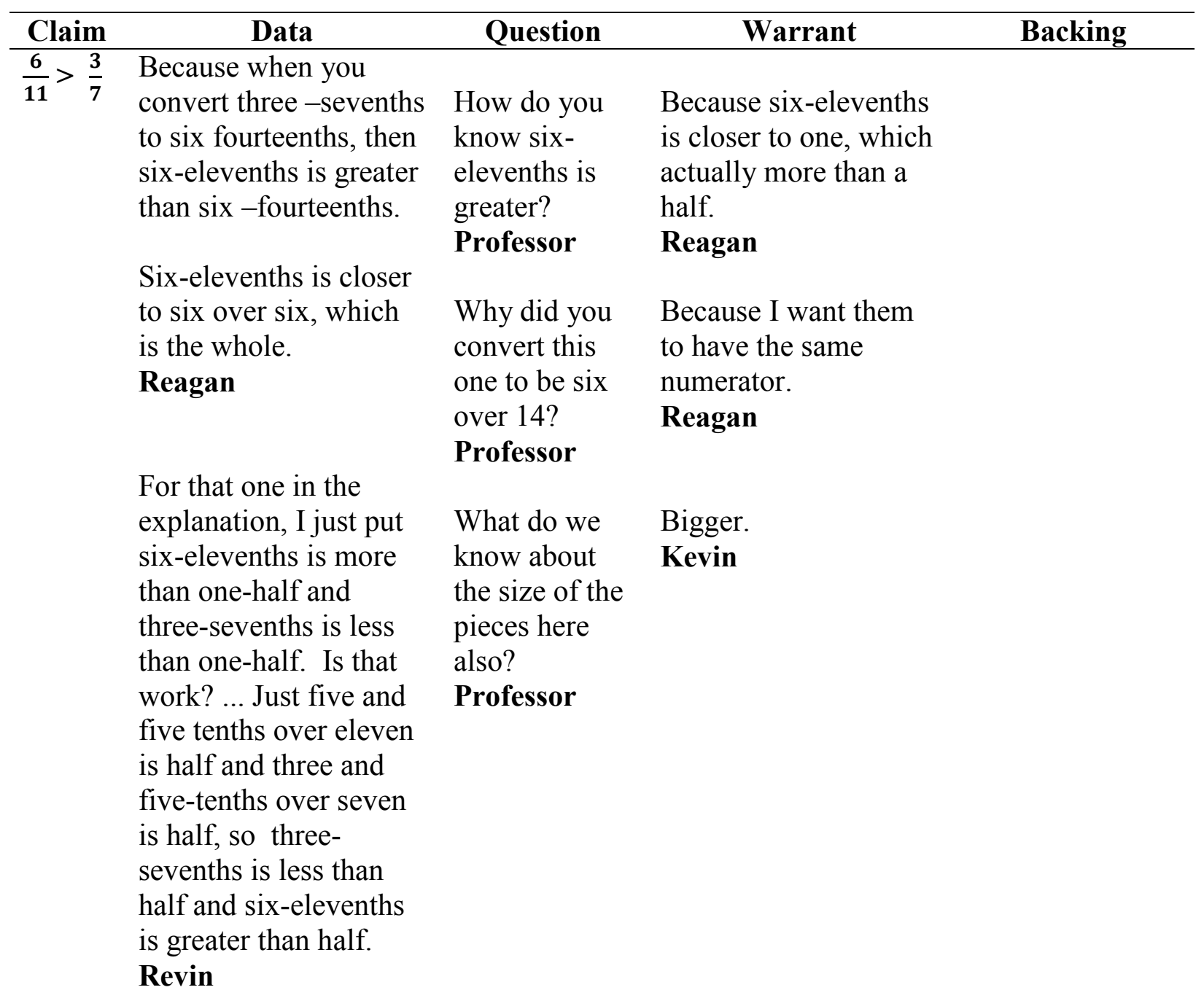


Day 6: Used as data for a new problem - not questioned

\begin{tabular}{|c|c|c|c|c|}
\hline Claim & Data & Question & Warrant & Backing \\
\hline$\frac{25}{99}>\frac{1}{4}$ & $\begin{array}{l}\text { Twenty-four and } \\
\text { three-fourths over } \\
\text { ninety nine, which is } \\
\text { equal to one-fourths } \\
\text { and is less than twenty } \\
\text { five-ninety ninths. } \\
\text { Pulianna }\end{array}$ & & & \\
\hline
\end{tabular}




\section{The larger something is broken into the smaller the pieces become}

Day 6: It came as a backing when the professor prompted it.

Ninety nine split individually is bigger than a hundred—the pieces will be bigger.

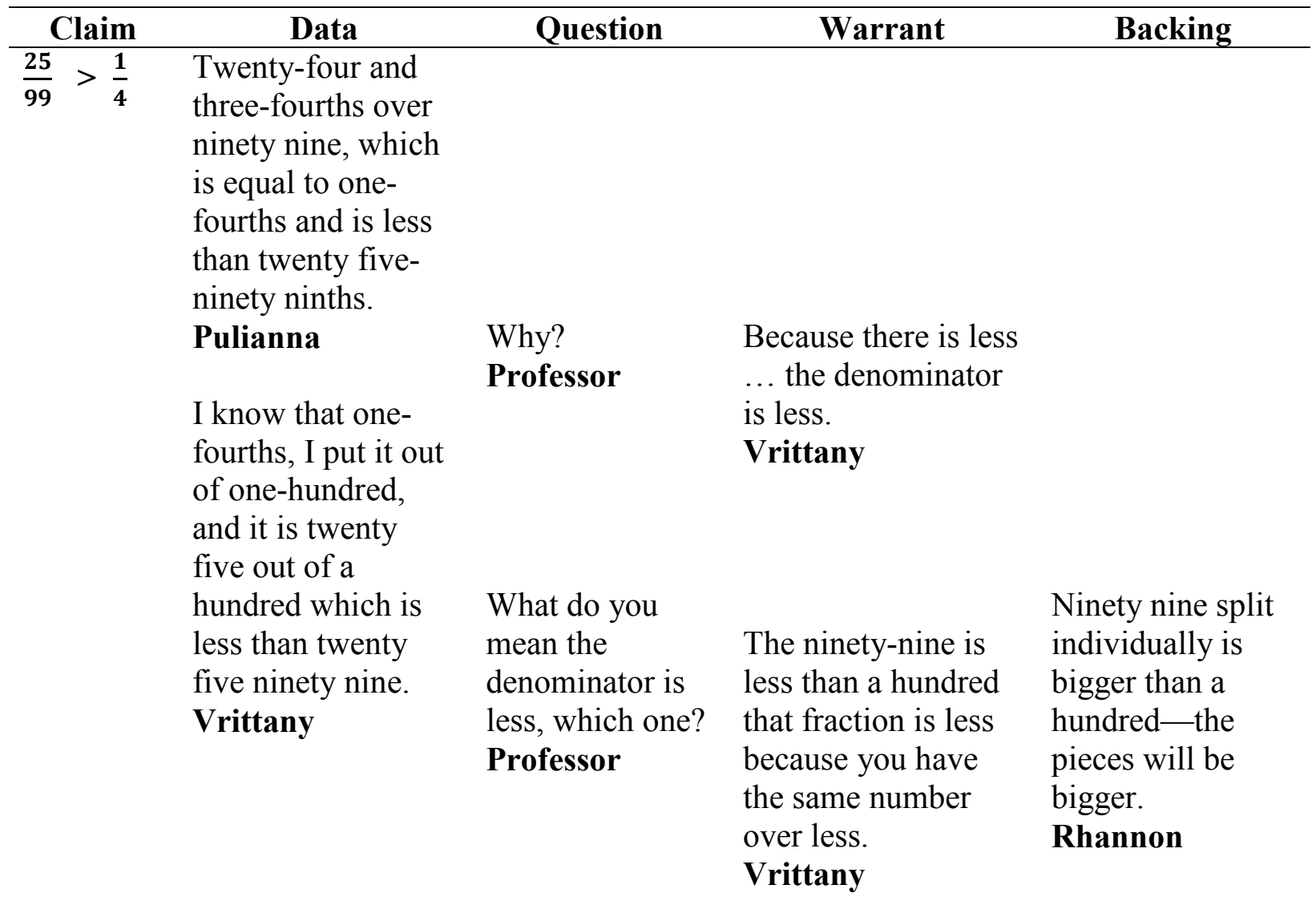


Day 6: Shifts to a Warrant, but prompted by the professor

$\frac{12}{13}>\frac{8}{9}$

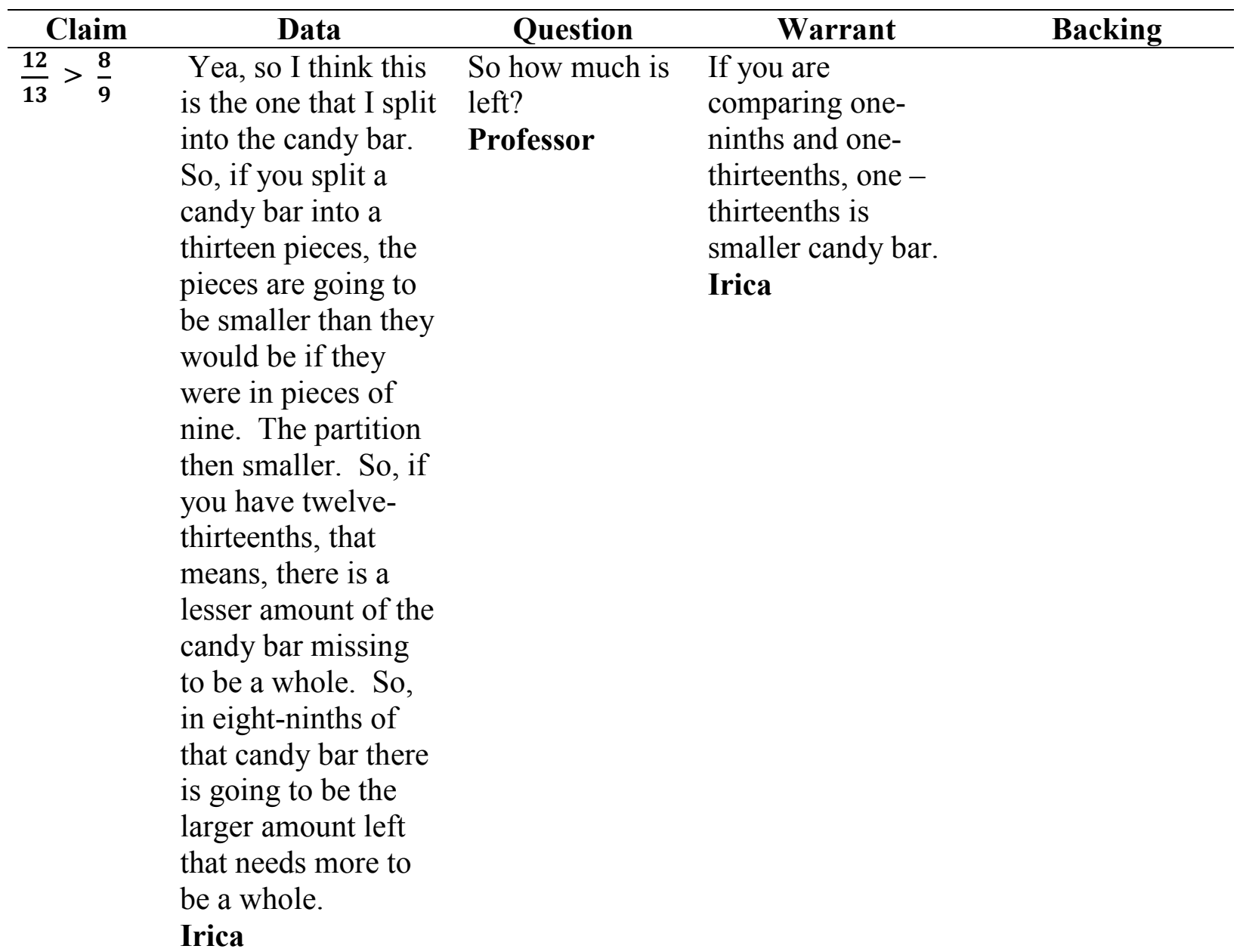


Day 6: The larger something is broken into the smaller the pieces become changes from a backing to a warrant.

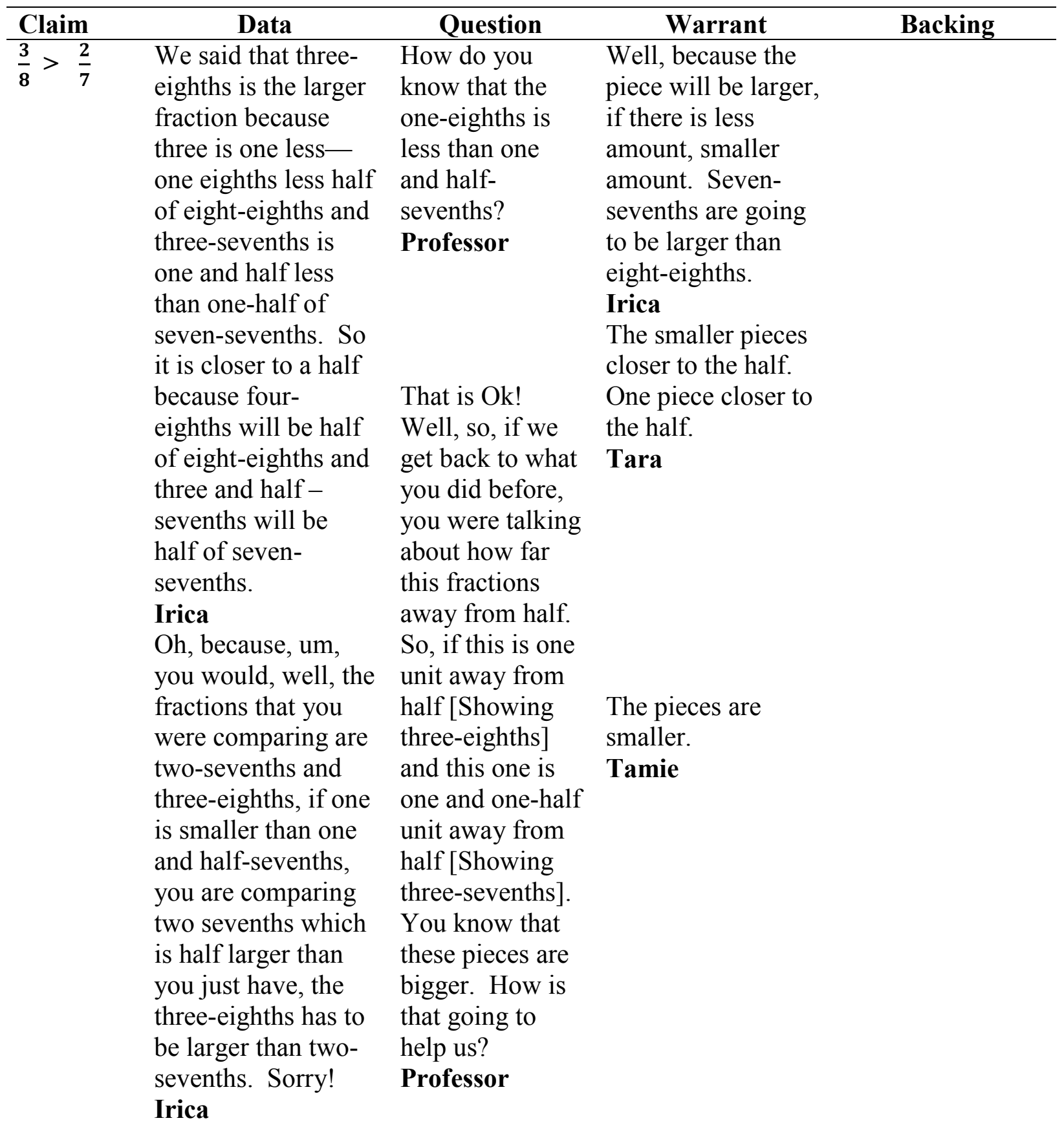




\section{More-bigger piece is coming from a smaller denominator and bigger numerator}

Day 6: Introduced as Data

$\frac{18}{25}>\frac{16}{27}$ Twenty five is a smaller denominator than twenty-seven and will have a bigger

pieces here

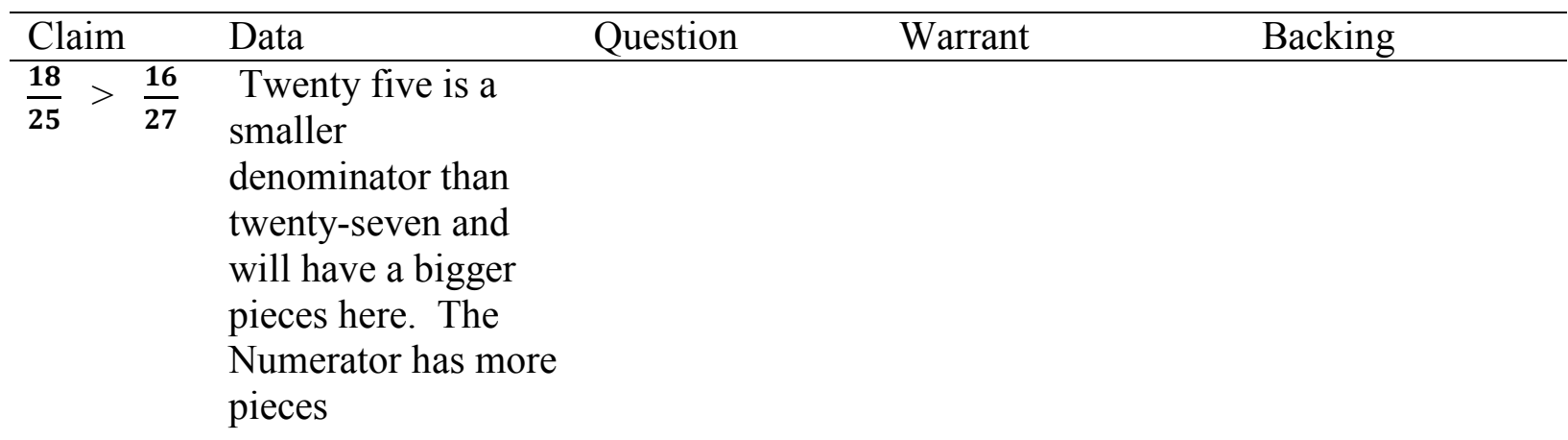

\section{Yosepheine}

Day 6: Shifts from data to warrant but questioned by the instructor as further information was needed

It is bigger pieces. It is going to be more pieces.

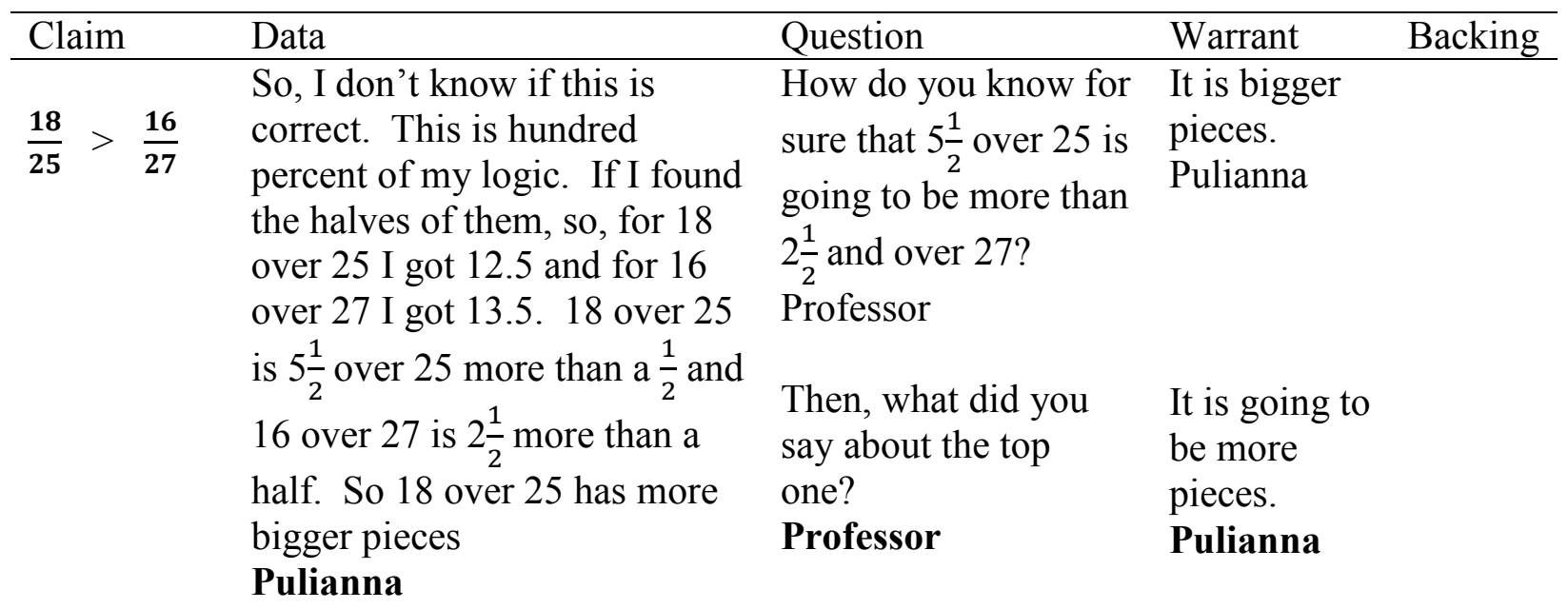


Day 6: Shifts from warrant to data but not questioned

It is bigger pieces. It is going to be more pieces.

\begin{tabular}{|c|c|c|c|c|}
\hline Claim & Data & Question & Warrant & Backing \\
\hline$\frac{3}{8}>\frac{2}{9}$ & $\begin{array}{l}\text { I said three-eighths because smaller } \\
\text { denominator is bigger pieces and } \\
\text { there is also more pieces. } \\
\text { Tanny }\end{array}$ & & & \\
\hline
\end{tabular}

$\frac{\mathbf{8}}{\mathbf{9}}>\frac{\mathbf{7}}{\mathbf{1 0}} \quad \begin{aligned} & \text { Because it is bigger and mort } \\ & \text { pieces, the same reason for } \\ & \text { problem thirteen and fourteen. } \\ & \text { Rhannon }\end{aligned}$

The last one is eight- ninth because

seven -tenths is missing three-

tenths and eight-ninths is missing

one -ninths.

Yosephenie 


\section{The greater the denominator the smaller the piece}

$\frac{7}{11}<\frac{7}{8}-$ Because it is less than you have to cut into pieces.

Day 6: The bigger pieces coming from a smaller denominator and the idea of that the number of pieces into which a fraction is broken is inversely related to the size of the pieces shifted to warrant and the idea that the less you cut something into the bigger the pieces become, was introduced.

How do we know for example that seven-elevenths is smaller than seven-eighths?

\begin{tabular}{|c|c|c|c|c|}
\hline Claim & Data & Question & Warrant & Backing \\
\hline$\frac{7}{11}<\frac{7}{8}$ & $\begin{array}{l}\text { Because the whole of } \\
\text { eleven is greater than } \\
\text { the whole of eight. } \\
\text { So, you have the same } \\
\text { amount of pieces, but } \\
\text { the whole is getting } \\
\text { bigger, so then } \\
\text { technically you have } \\
\text { like, with the seven- } \\
\text { eighths you have } \\
\text { more eighths than you } \\
\text { do with elevenths. } \\
\text { The numerators- } \\
\text { which both are seven. } \\
\text { With the eighths you } \\
\text { have one missing and } \\
\text { with the elevenths } \\
\text { you have three } \\
\text { missing. } \\
\text { Gessica }\end{array}$ & $\begin{array}{l}\text { If I cut } \\
\text { something up } \\
\text { into eighths } \\
\text { and I cut } \\
\text { something up } \\
\text { into } 11 \text { and it } \\
\text { happens from } \\
\text { the same } \\
\text { something, } \\
\text { which one will } \\
\text { have the } \\
\text { bigger pieces? } \\
\text { Professor }\end{array}$ & $\begin{array}{l}\text { The Eighths. } \\
\text { Gessica }\end{array}$ & $\begin{array}{l}\text { Because it is less } \\
\text { than you have to } \\
\text { cut into pieces. } \\
\text { Gessica }\end{array}$ \\
\hline
\end{tabular}

'Table Continues' 
Day 6: The idea of the denominator determining the size of the pieces and the idea of that the number of pieces into which a fraction is broken is inversely related to the size of the pieces which explain that bigger pieces are associated with coming a smaller denominators, was also presented and it came as a backing when the professor prompted it.

Ninety nine split individually is bigger than a hundred - the pieces will be bigger.

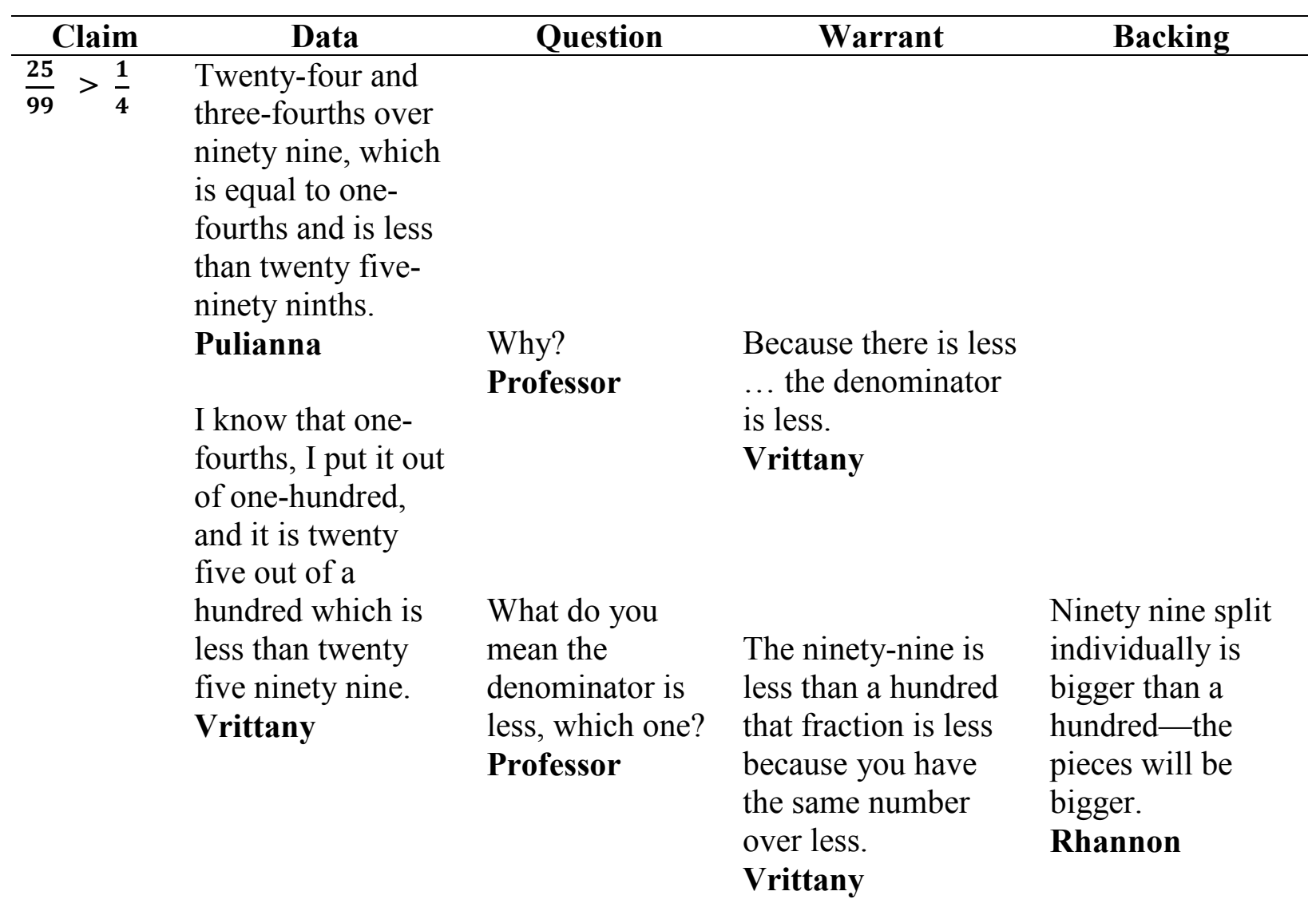


Day 6: The idea that the more something is cut into the larger the pieces are shifted from backing to warrant. The idea of more-bigger pieces coming from a smaller denominator did not need a warrant, and was not questioned. It became taken-as-shared.

The idea of that the number of pieces into which a fraction is broken is inversely related to the size of the pieces was also became taken-as-shared.

$\frac{18}{25}>\frac{16}{27}$

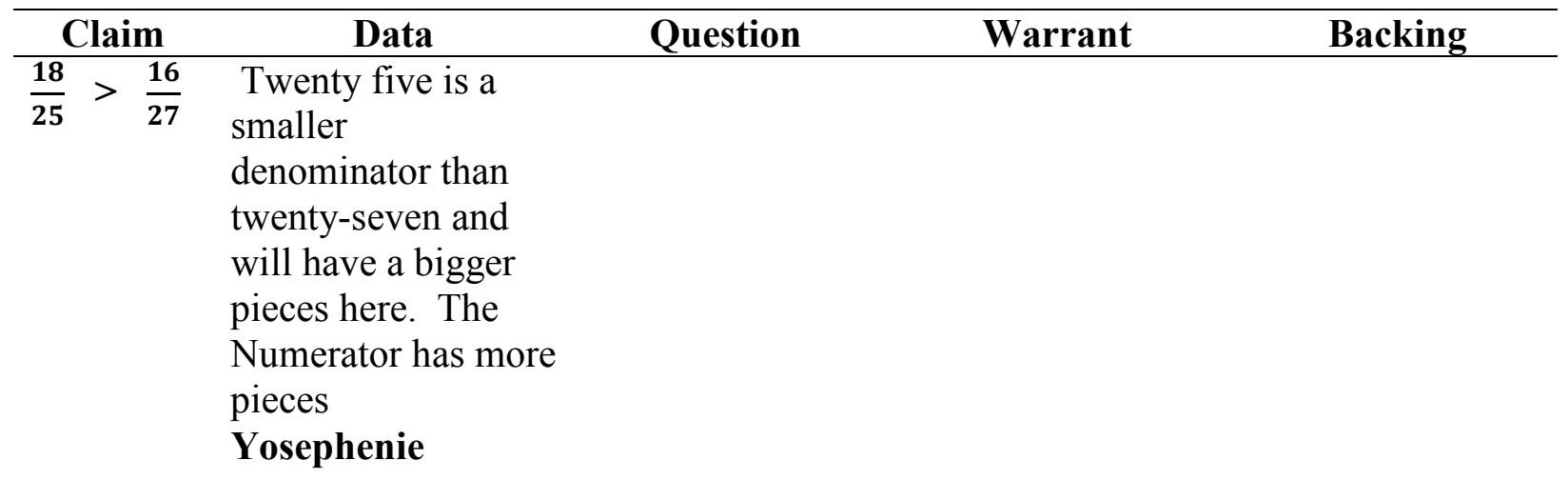


Fraction Addition (The pieces must be the same size (the denominators/whole stays the same)

To add one-half and one-third, I had to make the denominator the same. $\frac{3}{6}+\frac{2}{6}$ equals $\frac{5}{6}$.

Day 1: Early discussions involving fraction addition occurred on a procedural level and the idea of breaking up a denominator into other denominators, which is essentially making equivalent fractions for one-half and one-third in this case, was introduced as a data and not questioned. So, the denominator does not change when combining two or more fractions as the whole remains the same)

Share 5 Candy Bars Equally Among 6 People

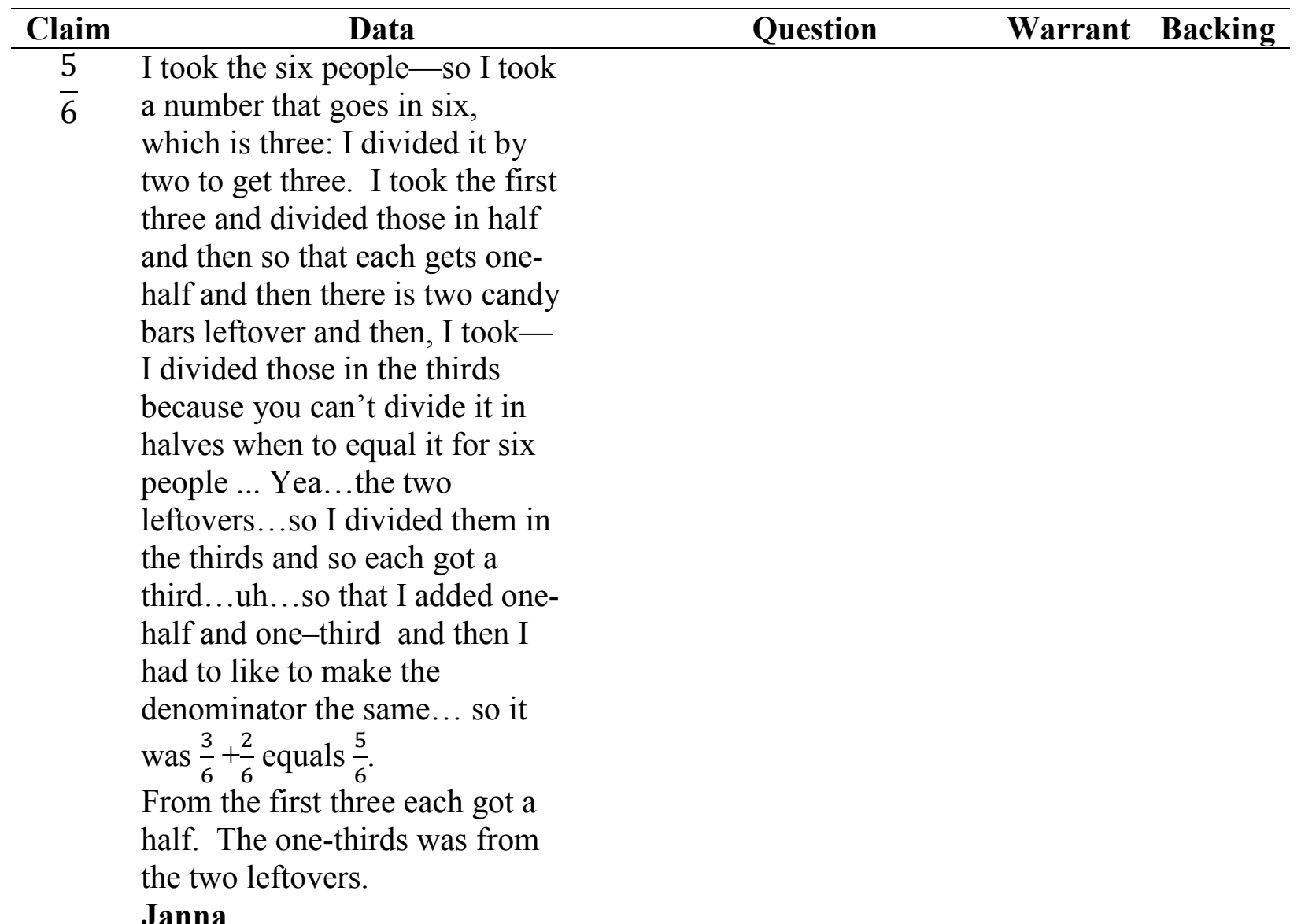


Day 7: The idea of breaking up a denominator into other denominators was introduced in fraction Day 1 and developed during the number-line activity as the PTs were finding a common denominator for two fractions, which involves generating equivalent fractions by subdividing partitions on the number line). The data were questioned by the PTs

Find the point on the number line that is two-thirds of the way from $\frac{3}{4}$ to $1 \frac{1}{3}$.

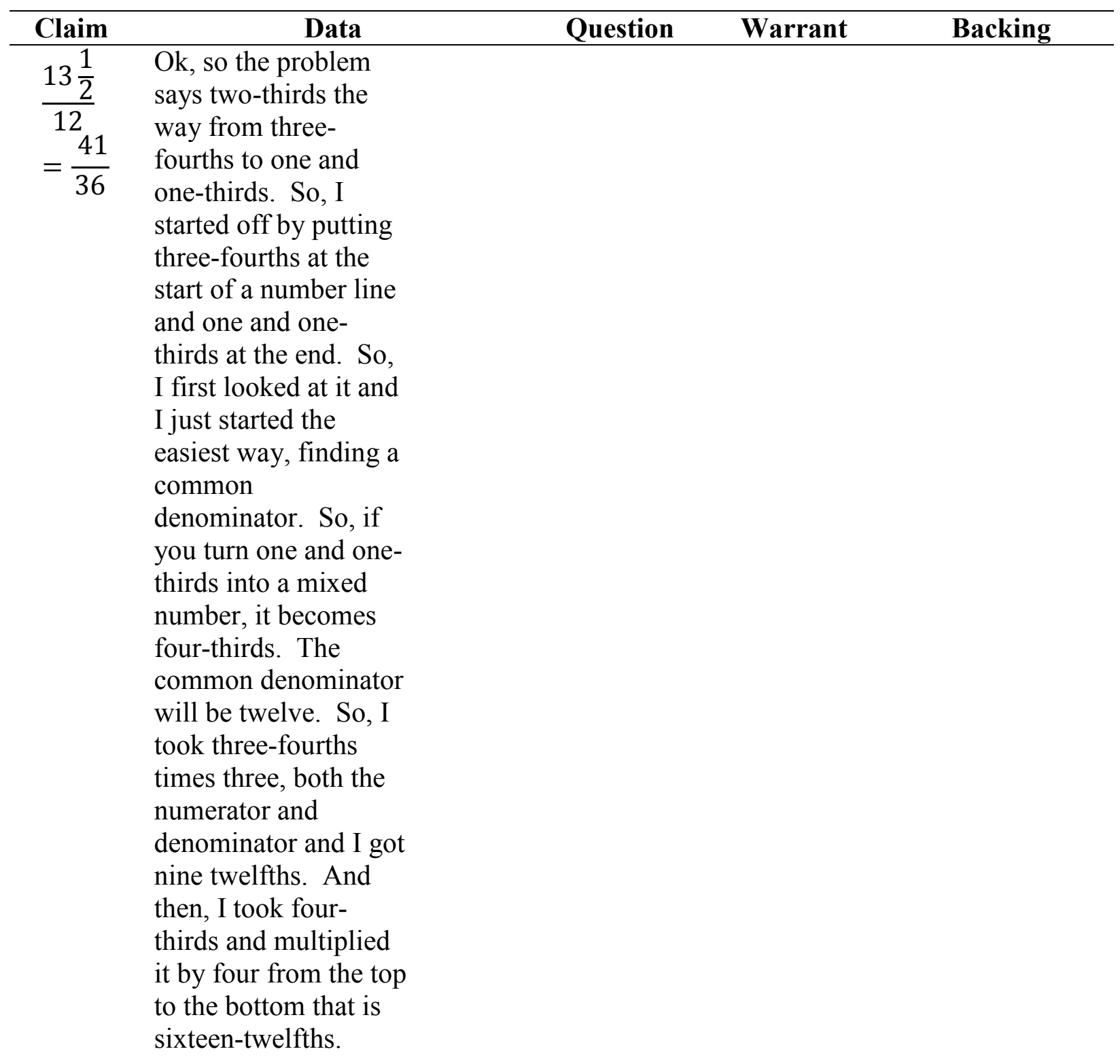




\begin{tabular}{|c|c|c|c|c|}
\hline Claim & Data & Question & Warrant & Backing \\
\hline & $\begin{array}{l}\text { So, I just build in from nine- } \\
\text { twelfths to ten-twelfths, } \\
\text { elven-twelfths, twelve- } \\
\text { twelfths, thirteen-twelfths, } \\
\text { and so on until sixteen- } \\
\text { twelfths. } \\
\text { So, then, I counted, if you } \\
\text { could see like from nine- } \\
\text { twelfths to ten-twelve- } \\
\text { twelfths, elven-twelfths, and } \\
\text { so on. That was seven } \\
\text { spaces. So, I knew that it } \\
\text { goes on into twenty one } \\
\text { spaces. I knew that it says } \\
\text { two-thirds, I know that seven } \\
\text { goes into twenty one three } \\
\text { times. So, it says two-thirds, } \\
\text { it will be two sevens, I kind } \\
\text { of shaded, you guys see right } \\
\text { there? So it is kind of two- } \\
\text { thirds, seven plus seven is } \\
\text { fourteen. Right thirteen and } \\
\text { two-thirds over twelve and } \\
\text { so, I knew that I had to } \\
\text { multiply the top and the } \\
\text { bottom, thirteen and two- } \\
\text { thirds over twelve by three- } \\
\text { over one, I got fourteen and I } \\
\text { got here between thirteen- } \\
\text { twelfths and fourteen- } \\
\text { twelfths. }\end{array}$ & $\begin{array}{l}\text { Why did they } \\
\text { multiply by } \\
\text { three? } \\
\text { Tara }\end{array}$ & $\begin{array}{l}\text { To get rid of } \\
\text { the fraction } \\
\text { on the top, } \\
\text { because the } \\
\text { fraction is } \\
\text { two-thirds. } \\
\text { Rhannon } \\
\text { Like you } \\
\text { have a } \\
\text { fraction over } \\
\text { a fraction... } \\
\text { they just... } \\
\text { they knew } \\
\text { that they need } \\
\text { to cross out } \\
\text { that two- } \\
\text { thirds by } \\
\text { multiplying } \\
\text { by three. } \\
\text { Irica }\end{array}$ & \\
\hline
\end{tabular}




\begin{tabular}{|c|c|c|c|c|}
\hline Claim & Data & Question & Warrant & Backing \\
\hline & $\begin{array}{l}\text { But it is right thirteen } \\
\text { and two-thirds over } \\
\text { twelve and so, I knew } \\
\text { that I had to multiply } \\
\text { the top and the bottom, } \\
\text { thirteen and two-thirds } \\
\text { over twelve by three- } \\
\text { over one, I got thirty } \\
\text { nine plus two to get } \\
\text { forty one for the top } \\
\text { number, and thirty-six } \\
\text { for the bottom. I got } \\
\text { forty- one over thirty } \\
\text { six... Forty-one over } \\
\text { thirty-sixths is like how } \\
\text { you looking at it. See } \\
\text { how we move from } \\
\text { thirteen-twelfths to } \\
\text { fourteen-twelfths, } \\
\text { three spaces and so you } \\
\text { know that two-thirds is } \\
\text { second line in your box } \\
\text { that you color into, that } \\
\text { would be the point, } \\
\text { because it says two- } \\
\text { thirds the way from } \\
\text { three-fourths to one } \\
\text { one-thirds. } \\
\text { Treanna }\end{array}$ & & & \\
\hline & $\begin{array}{l}\text { So there is like seven } \\
\text { sections. Each section } \\
\text { broke it up like nine- } \\
\text { twelfths, ten-twelfths, } \\
\text { and then we broke each } \\
\text { section up into thirds. }\end{array}$ & & & \\
\hline
\end{tabular}




\begin{tabular}{|c|c|c|c|c|}
\hline Claim & Data & Question & Warrant & Backing \\
\hline & $\begin{array}{l}\text { So we did that with all } \\
\text { the sections. Then, we } \\
\text { counted how many like } \\
\text { sections there are. } \\
\text { There are twenty-one } \\
\text { in total. So then, we } \\
\text { knew that seven goes } \\
\text { in twenty-one three } \\
\text { times so it is like three } \\
\text { sevens basically, so we } \\
\text { took two of the sevens } \\
\text { and added them } \\
\text { together to get fourteen } \\
\text { over twenty-one is } \\
\text { equivalent to two- } \\
\text { thirds. } \\
\text { Treanng }\end{array}$ & & & \\
\hline
\end{tabular}

And then, so like our like fraction with that tally mark is thirteen two-thirds over twelve. And multiplied the numerator and denominator by three. Like thirteen twothirds multiplied by three to get thirty-nine and add the two to get forty-one and twelve times by three is thirtysix. I got forty-one over thirty-six.

\section{Irica}


Day 8: The idea that the denominator represents the number of pieces in the whole which was introduced in fraction Day 1 and was developed in fraction Day 7 came up here again.

Particularly, the idea of cutting pieces up to create common denominators using pictures became taken-as-shared idea in the context of adding fractions. The first idea that we encountered previously, which explained that the denominator does not change when combining two or more fractions as the whole remains the same, was taken-as-shared.

Calvin has two-thirds of a bag of candy and Hobbes has three-fourths of the same size bag of candy. Their mother puts the amounts of candy together. How much candy is there?

\begin{tabular}{|c|c|c|c|c|}
\hline Claim & Data & Question & Warrant & Backing \\
\hline $1 \frac{5}{12}$ & $\begin{array}{l}\text { I cut the } \frac{2}{3} \text { into fourths } \\
\text { and the } \frac{3}{4} \text { in thirds to } \\
\text { create } 12 \text { pieces in } \\
\text { each } \\
\text { Hanna }\end{array}$ & & & \\
\hline
\end{tabular}




\section{Fraction multiplication (The whole changes through the problem)}

Charlie Brown takes two-fifths of the pattern blocks that Lucy has and so I think that would mean he takes two-fifths, the whole being five-fifths that is what Lucy has.

Day 4: Introduced as a Data

Charlie Brown takes two-fifths of the pattern blocks that Lucy has and gets a blue Parallelogram, a yellow hexagon, and two green triangles. What pattern blocks might Lucy have had before Charlie took any away?

\begin{tabular}{|c|c|c|c|c|}
\hline Claim & Data & Question & Warrant & Backing \\
\hline $\begin{array}{l}1 \text { hexagon, } 1 \\
\text { parallelogram, } \\
\text { and } 2 \\
\text { triangles. }\end{array}$ & $\begin{array}{l}\text { Charlie Brown takes two- } \\
\text { fifths of the pattern blocks } \\
\text { that Lucy has and so I think } \\
\text { that would mean he takes } \\
\text { two-fifths, the whole being }\end{array}$ & $\begin{array}{l}\text { How the } \\
\text { two } \\
\text { triangles } \\
\text { are a } \\
\text { fifths? }\end{array}$ & $\begin{array}{l}\text { In general, two- } \\
\text { pieces are equal to } \\
\text { one-fifths. } \\
\text { Gessica }\end{array}$ & \\
\hline $\begin{array}{l}10 \text { pieces. } \\
\text { Gessica }\end{array}$ & $\begin{array}{l}\text { five-fifths that is what Lucy } \\
\text { has. So, I drew my } \\
\text { rectangle and I split up into } \\
\text { fifths so each rectangle is } \\
\text { one-fifths from that I } \\
\text { figured out that one -fifths } \\
\text { is two pieces because he } \\
\text { took a total of four pieces } \\
\text { from her -one } \\
\text { parallelogram, one hexagon, } \\
\text { and two green triangles. So, } \\
\text { then I just took them put in } \\
\text { the boxes so one-fifths will } \\
\text { be a hexagon and a } \\
\text { parallelogram, one fifths } \\
\text { will be two triangles, that I } \\
\text { originally took it. }\end{array}$ & Rhannon & & \\
\hline
\end{tabular}




\begin{tabular}{lllll}
\hline Claim & Data & Question & Warrant & Backing \\
\hline
\end{tabular}

So, I had question mark because that would be what we want.

I just did triangles so then we have the one hexagon, the one parallelogram, two triangles from four a total of eight triangles one parallelogram and one hexagon.

\section{Gessica}

She is putting one-

fifths.

\section{Tanny}

She splitting up...there is twofifths... two pieces in one-fifths.

\section{Irica}


$\frac{6}{15}=\frac{2}{5}$. With multiplication just whenever the two boxes ... like the shading overlap. So, that box shows there is six of them are shaded out of fifteen [Indicating the overlapped rectangular area]

Day 9: Shifts from warrant to data but the data were not questioned.

Charlie Brown has three-fifths of a pie. Lucy has two-thirds of the amount that Charlie Brown has. How much pie does Lucy have?

\begin{tabular}{|c|c|c|c|c|}
\hline Claim & Data & Question & Warrant & Backing \\
\hline 6 & I did ... I split it into & & & \\
\hline \multirow[t]{20}{*}{$\overline{15}$} & fifteen boxes and then I & & & \\
\hline & shaded for Charlie ... & & & \\
\hline & This is fifths ... and this & & & \\
\hline & is thirds [Showing how & & & \\
\hline & the rectangular figure is & & & \\
\hline & partitioned]. So I & & & \\
\hline & shaded three-fifths of it & & & \\
\hline & and Lucy has two- & & & \\
\hline & thirds, so Linus' two- & & & \\
\hline & thirds is this way. And & & & \\
\hline & then multiplication just & & & \\
\hline & whenever the two boxes & & & \\
\hline & ... like the shading & & & \\
\hline & overlap. So, that box & & & \\
\hline & shows there is six of & & & \\
\hline & them are shaded out of & & & \\
\hline & fifteen [Indicating the & & & \\
\hline & overlapped rectangular & & & \\
\hline & area] & & & \\
\hline & Rhannon & & & \\
\hline
\end{tabular}


Day 9: With another preservice teacher's strategy, the idea for the whole to change with multiplication was presented as a data again - not questioned and became taken-as shared

\begin{tabular}{|c|c|c|c|c|}
\hline Claim & Data & Question & Warrant & Backing \\
\hline 2 & Charlie Brown has & & & \\
\hline$\overline{5}$ & three-fifths, the picture & & & \\
\hline & shows three-fifths and it & & & \\
\hline & says that Lucy has two- & & & \\
\hline & thirds of what Charlie & & & \\
\hline & Brown has, so which he & & & \\
\hline & just have like two of the & & & \\
\hline & three pieces. I started & & & \\
\hline & that Charlie Brown had & & & \\
\hline & three-fifths and Lucy & & & \\
\hline & has two-thirds of that. & & & \\
\hline & Lucy has two-fifths of & & & \\
\hline & the whole pie. & & & \\
\hline & Pulianna & & & \\
\hline
\end{tabular}




\section{APPENDIX B: EQUAL SHARING CLASS TASK 1}

Name:

For each of the following problems:
A. Draw a picture to solve
B. Explain and justify what you did to solve the problem

1. How much candy would each person receive if 6 people share 5 candy bars equally?

2. How much candy would each person receive if 5 candy bars are shared equally among 3 people? 


\section{APPENDIX C: EQUAL SHARING CLASS TASK 2 PART 1}

A class of students was asked to find how much candy each person receives if 6 people share 5 candy bars equally.

For each response, determine whether or not the solution is correct and why.

Student 1: $\frac{5}{6}$ of the candy bars

Student 2: $\frac{1}{6}$ of a candy bar

Student 3: $\frac{5}{6}$ of 1 candy bar

Student 4: $\frac{5}{30}$ of 5 candy bars

Student 5: $\frac{5}{6}$ of each candy bar 


\section{APPENDIX D: EQUAL SHARING CLASS TASK 2 PART 2}

A class of students was asked to find how much candy each person receives if 5 candy bars are shared equally among 3 people.

For each response, determine whether or not the solution is correct and why.

Student 1: $\frac{5}{3}$ of the candy bars

Student 2: $1 \frac{2}{3}$ of 1 candy bar

Student 3: $\frac{1}{3}$ of 5 candy bars

Student 4: $1 \frac{2}{3}$ of 2 candy bars

Student 5: $\frac{1}{3}$ of each candy bar 


\section{APPENDIX E: IDENTIFYING AND CREATING “CONVENIENT” WHOLE}

\section{TASK 3}

28. Use each of your manipulative sets to represent three-eighths in three different ways.

29. Use pattern blocks to represent nine-fifths in three different ways.

30. Suppose a rectangle is partitioned into five same-sized parts and two of the same-sized parts are shaded.

d. Can you see $\frac{2}{5}$ of something?

e. Can you see $\frac{5}{2}$ of something?

f. Can you see any other fractions represented? How?

g. Now take a circle and partition it into 5 same-sized pieces, and shade 2. Do you see the same fractions you saw before? Why or why not?

32. There are nine circles, four of which are shaded. What fractional part is shaded?

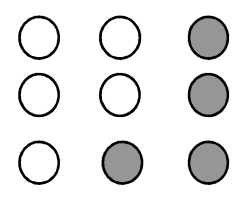




\section{APPENDIX F: CHARLIE BROWN PROBLEM TASK 4}

34. a. Charlie Brown takes two-fifths of the pattern blocks that Lucy has and gets a blue parallelogram, a yellow hexagon, and two green triangles. What pattern blocks might Lucy have had before Charlie took any away?

b. Pigpen has three green triangles and three blue rhombi pattern blocks. This is three-sevenths of what Lucy has. What pattern blocks might Lucy have had?

c. Lucy has four-thirds of the pattern blocks that Linus has. Lucy has five green triangles and a red trapezoid. What pieces could Linus have had?

d. One half of Linus' pattern blocks are the same as one third of Lucy's pattern blocks. Who has fewer total pattern blocks, and what fraction is the lesser amount compared to the larger?

e. Two fifths of Charlie Brown's allowance is the same as $\frac{1}{3}$ of Linus' allowance. Whose allowance is greater, and by how much? 


\section{APPENDIX G: PAYCHECK PROBLEM TASK 5 PART 1}

35. Solve the following problem pictorially.

Emily receives her paycheck for the month. She spends $1 / 6$ of it on food. She then spends $\frac{3}{5}$ of what remains on her house payment. She spends $\frac{1}{3}$ of what is then left for her other bills. Finally she spends $1 / 4$ of the remaining money for entertainment. This activity leaves her with $\$ 150$ that she puts into savings. What was her original take-home pay?

i. What fraction of the amount spent for the house payment is spent on food?

ii. What fraction of the amount spent for food is spent on house payments?

iii. What fraction of the paycheck is other bills? 


\section{APPENDIX H: EQUIVALENT FRACTIONS TASK 5 PART 2}

32. Show in at least two different ways using pictorial representations that the fractions $\frac{3}{4}$ and $\frac{9}{12}$ are equivalent. 


\section{APPENDIX I: FRACTION COMPARISON TASK 6}

1. Write everything you know about the fraction $\frac{7}{8}$.

For each set of fractions below, circle the fraction that is greater (or if the fractions are equivalent, write "=" in between them), and provide a "sense-making" explanation for how you know. You may use pictures if that is helpful to you, but your explanation cannot rely solely on a picture.

- Calculators may not be used.

- Feel free to work on these problems in any order that makes sense to you. If you find yourself struggling with any of the problems, skip them and revisit them later.

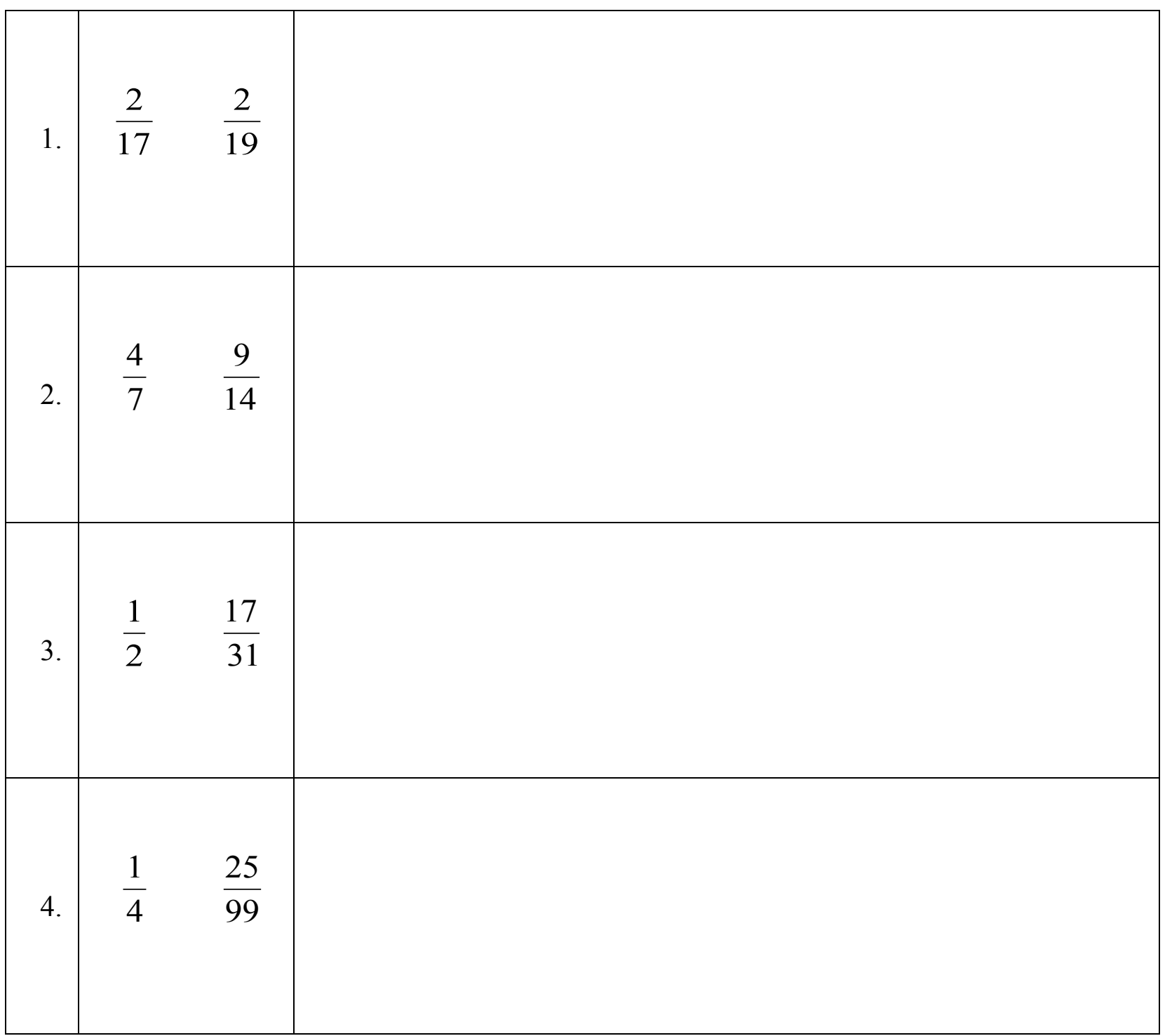




\begin{tabular}{|c|c|c|}
\hline 5. & $\frac{15}{17}$ & $\frac{19}{18}$ \\
\hline 6. & $\frac{24}{7}$ & $\frac{34}{15}$ \\
\hline 7. & $\frac{3}{7}$ & $\frac{6}{11}$ \\
\hline 8. & $\frac{25}{12}$ & $\frac{31}{15}$ \\
\hline 9. & $\frac{11}{20}$ & $\frac{19}{36}$ \\
\hline 10. & $\frac{8}{9}$ & $\frac{12}{13}$ \\
\hline
\end{tabular}




\begin{tabular}{|c|c|c|}
\hline 11. & $\frac{13}{15}$ & $\frac{17}{19}$ \\
\hline 12. & $\frac{2}{7}$ & $\frac{3}{8}$ \\
\hline 13. & $\frac{18}{25}$ & $\frac{16}{27}$ \\
\hline 14. & $\frac{2}{9}$ & $\frac{3}{8}$ \\
\hline 15. & $\frac{7}{10}$ & $\frac{8}{9}$ \\
\hline
\end{tabular}




\section{APPENDIX J: NUMBER LINE TASK 7}

38. Find the point on the number line that is:

a. One third of the way between 1 and $2 \frac{1}{2}$.

b. Half way between $\frac{1}{4}$ and $\frac{7}{8}$.

c. Two-thirds of the way from $\frac{3}{4}$ to $1 \frac{1}{3}$. 


\section{APPENDIX K: FRACTION ADDITION AND SUBTRACTION TASK 8}

41. For each of the following problems:

A. Solve the problem with manipulatives or a picture. Do not use any algorithms for computation! Discuss where the "common denominator" comes from.

B. Write a word problem to match the expression.

i. $\frac{1}{4}+\frac{2}{3}$

ii. $1 \frac{1}{2}-\frac{2}{3}$

43. Solve each problem with a picture and write a number sentence to match the situation.

A. Marty has $\frac{3}{4}$ of a bag of candy and gives Jane half of his candy. How much of a bag of candy does Marty have left?

B. Marty has $\frac{3}{4}$ of a bag of candy and gives Jane half of the bag of candy. How much of a bag of candy does Marty have left?

C. Calvin has two-thirds of a bag of candy and Hobbes has three-fourths of the same size bag of candy. Their mother puts the amounts of candy together. How much candy is there? 


\section{APPENDIX L: FRACTION MULTIPLICATIONS AND DIVISION TASK 9}

49. Solve each problem with a picture and write a number sentence to match the situation.

A. Justin has $\frac{15}{8}$ pounds of hamburger. Each serving of chili requires $\frac{3}{4}$ pound of hamburger. Using the entire hamburger, exactly how many servings of chili can he make?

B. Charlie Brown has three-fifths of a pie. Lucy has two-thirds of the amount that Charlie Brown has. How much pie does Lucy have? 
For each of the following problems:

a. Solve the problem with manipulatives or a picture. Do not use any algorithms for computation!

b. Write a word problem to match the expression.

i. $\quad \frac{1}{2} \times 1 \frac{3}{4}$

1. $1 \frac{3}{4} \div \frac{1}{2}$ 